SANDIA REPORT

AUG $24 \quad 1998$

SAND98-1733

Unlimited Release

Printed August 1998

\title{
Energy Storage Systems Program Report
} for FY97

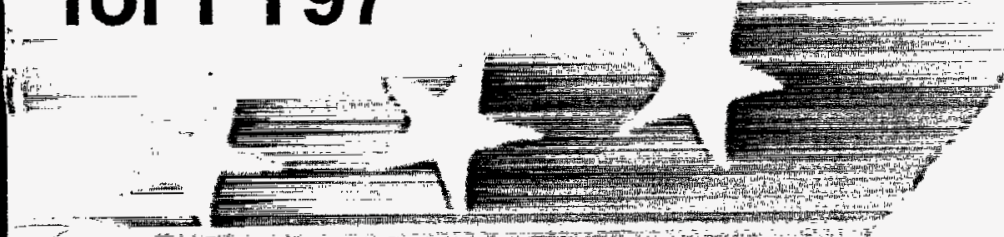

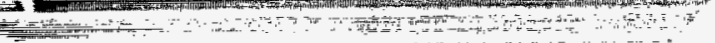

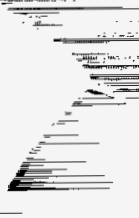

Paul C. Butler

\section{Prepared by}

Sandia National Laboratories

Albuquerque, New Mexico 87185 and Livermore, California 94550

Sandia is a multiprogram laboratory operated by Sandia Corporation,

a Lockheed Martin Company, for the United States Department of

Energy under Contract DE-AC04-94AL85000.

Approved for

Sandia National Laboratories
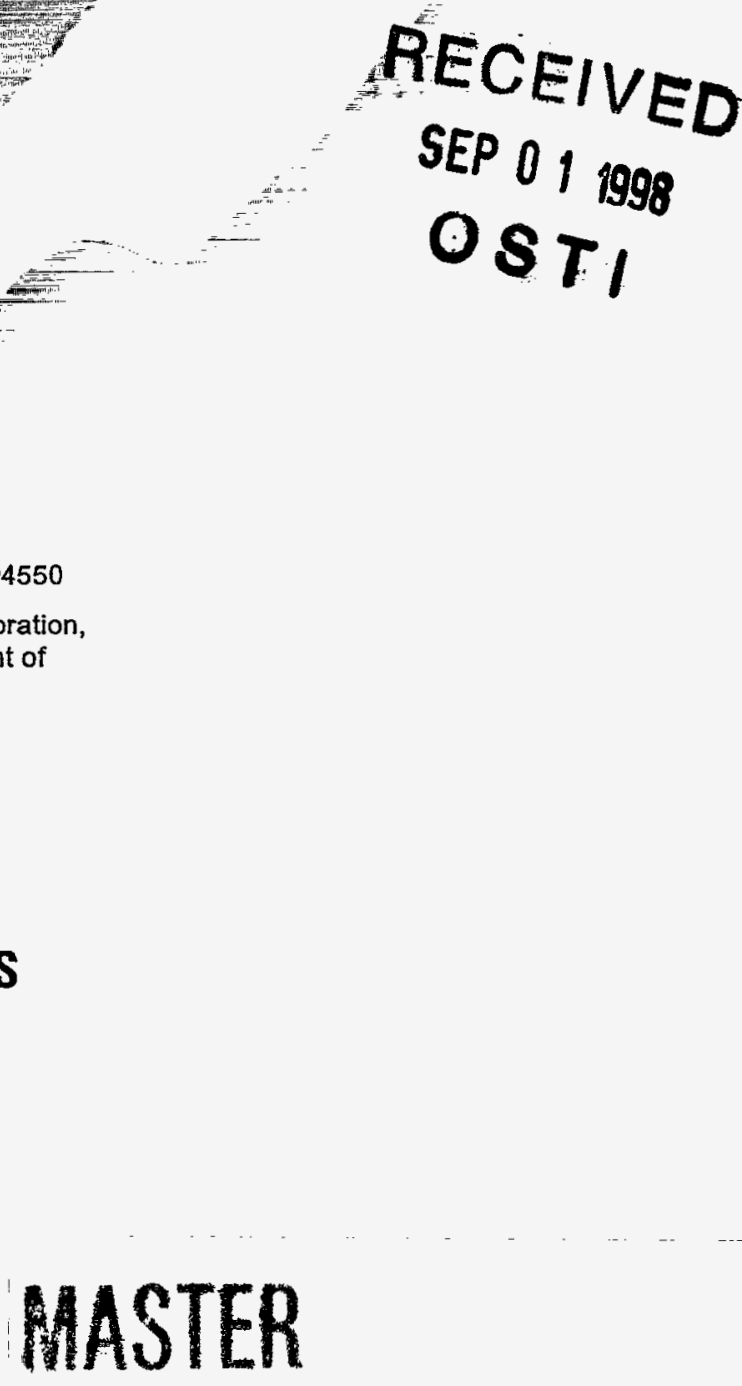
Issued by Sandia National Laboratories, operated for the United States Department of Energy by Sandia Corporation.

NOTICE: This report was prepared as an account of work sponsored by an agency of the United States Government. Neither the United States Government nor any agency thereof, nor any of their employees, nor any of their contractors, subcontractors, or their employees, makes any warranty, express or implied, or assumes any legal liability or responsibility for the accuracy, completeness, or usefulness of any information, apparatus, product, or process disclosed, or represents that its use would not infringe privately owned rights. Reference herein to any specific commercial product, process, or service by trade name, trademark, manufacturer, or otherwise, does not necessarily constitute or imply its endorsement, recommendation, or favoring by the United States Government, any agency thereof, or any of their contractors or subcontractors. The views and opinions expressed herein do not necessarily state or reflect those of the United States Government, any agency thereof, or any of their contractors.

Printed in the United States of America. This report has been reproduced directly from the best available copy.

Available to DOE and DOE contractors from

Office of Scientific and Technical Information

P.O. Box 62

Oak Ridge, TN 37831

Prices available from (615) 576-8401, FTS 626-8401

Available to the public from

National Technical Information Service

U.S. Department of Commerce

5285 Port Royal Rd

Springfield, VA 22161

NTIS price codes

Printed copy: A05

Microfiche copy: A01

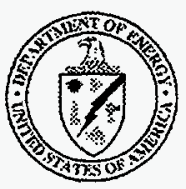


SAND98-1733

Unlimited Release

Printed August 1998

\title{
Energy Storage Systems Program Report for FY97
}

\author{
Paul C. Butler, Manager \\ Energy Storage Systems Department \\ Sandia National Laboratories \\ P.O. Box 5800 \\ Albuquerque, New Mexico 87185-0613
}

\begin{abstract}
Sandia National Laboratories, New Mexico, conducts the Energy Storage Systems Program, which is sponsored by the U.S. Department of Energy's Office of Utility Technologies. The goal of this program is to collaborate with industry in developing cost-effective electric energy storage systems for many high-value stationary applications. Sandia National Laboratories is responsible for the engineering analyses, contracted development, and testing of energy storage components and systems. This report details the technical achievements realized during fiscal year 1997.
\end{abstract}




\section{Acknowledgment}

Sandia National Laboratories would like to acknowledge and thank Dr. Christine E. Platt of the U.S. Department of Energy's Office of Utility Technologies for the support and funding of this work. Our appreciation is also extended to all of the contributing organizations that have been instrumental in the success of many ESS Program activities in FY97. 


\section{DISCLAIMER}

Portions of this document may be illegible electronic image products. Images are produced from the best available original document. 


\section{Contributors}

\section{Sandia National Laboratories:}
A. Akhil, Analysis, Substation Power Quality
E. Binasiewicz, Subsystems Engineering, Evaluation
N. Clark, Subsystems Engineering, Zinc/Bromine
G. Corey, Integration and Implementation
T. Crow, A. Jimenez, G. Rodriquez, Technology Evaluation
J. Freese, Subsystems Engineering, Evaluation
R. Jungst, Subsystems Engineering, Lead-Acid, and System Field Evaluation
D. Rovang, Analysis, Substation Power Quality
T. Unkelhaeuser, Subsystems Engineering, Evaluation

\section{Contractors/Subcontractors:}

M. Anderson, University of Missouri - Rolla

L. Charles, Energetics, Inc.

P. Eidler, ZBB Technologies, Inc.

B. Flemming, AC Battery Corporation

G. Hunt, J. Boehm, GNB Industrial Battery Co.

H. Meyer, Omnion Power Engineering Corporation

R. Sen, Sentech, Inc.

S. Swaminathan, Sentech, Inc.

P. Symons, Electrochemical Engineering Consultants, Inc.

P. Taylor, Energetics, Inc. 
Issued by Sandia National Laboratories, operated for the United States Department of Energy by Sandia Corporation.

NOTICE: This report was prepared as an account of work sponsored by an agency of the United States Government. Neither the United States Government nor any agency thereof, nor any of their employees, nor any of the contractors, subcontractors, or their employees, makes any warranty, express or implied, or assumes any legal liability or responsibility for the accuracy, completeness, or usefulness of any information, apparatus, product, or process disclosed, or represents that its use would not infringe privately owned rights. Reference herein to any specific commercial product, process, or service by trade name, trademark, manufacturer, or otherwise, does not necessarily constitute or imply its endorsement, recommendation, or favoring by the United States Government, any agency thereof, or any of their contractors or subcontractors. The views and opinions expressed herein do not necessarily state or reflect those of the United States Government, any agency thereof, or any of their contractors or subcontractors.

Printed in the United States of America

Available from

National Technical Information Service

U.S. Department of Commerce

5285 Port Royal Road

Springfield, VA 22161

NTIS price codes

Printed copy: A09

Microfiche copy: A01 


\section{Contents}

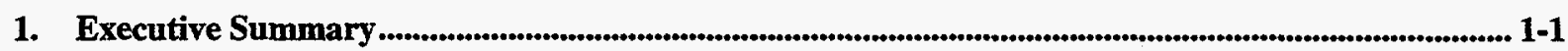

Introduction

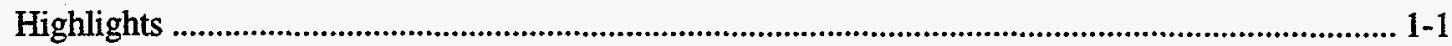

Integration and Implementation................................................................................. 1-2

Component Research and Development and Technology Evaluation ................................... 1-4

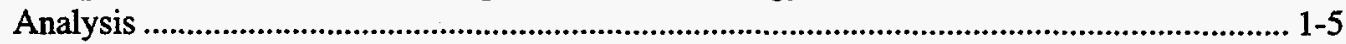

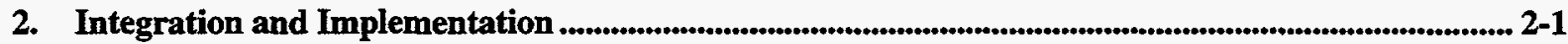

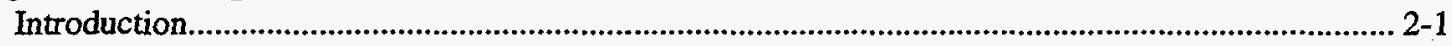

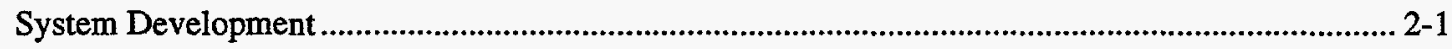

PQ2000 Receives R\&D Magazine's R\&D 100 Award ........................................................ 2-1

Transportable Battery Energy Storage System.................................................................. 2-1

Advanced Battery Energy Storage System.......................................................................... 2-5

Renewable Generation and Storage and Related Projects .............................................................. 2-14

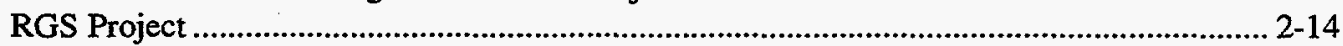

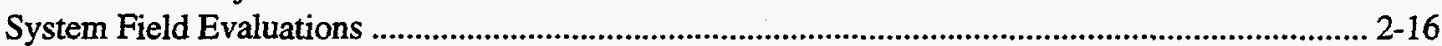

AC Battery PM250 Field Evaluation.......................................................................... 2-16

Field Test of Final GNB VRLA Battery Deliverable ....................................................... 2-17

PV/Hybrid Evaluation Project .......................................................................................... 2-21

Metlakatla Monitoring Project............................................................................................ 2-28

ZBB 100-kWh Zinc/Bromine Battery Test ................................................................ 2-29

Nickel/Metal Hydride Battery Testing at ANL .................................................................... 2-31

3. Component Research and Development and Technology Evaluation...................................................... 3-1

Introduction......................................................................................................................................................... 3-1

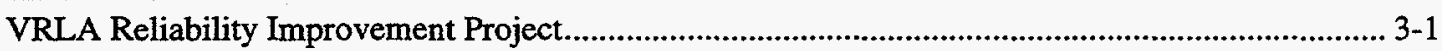

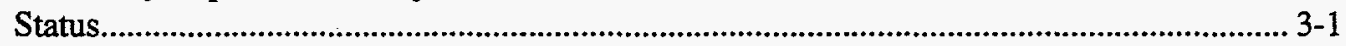

Development, Validation, and Demonstration of Power Quality and Peak-Shaving

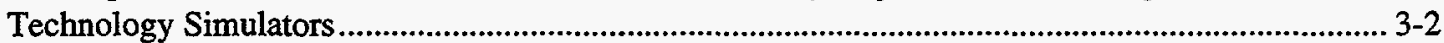

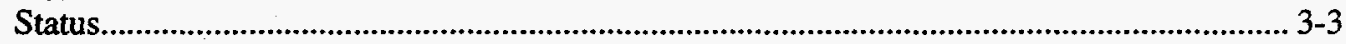

Lead-Acid Battery Evaluation at SNL ................................................................................................ 3-3

VRLA Absorbed Glass Mat Testing ....................................................................................... 3-3

SLI Battery Cycle Testing ..................................................................................................... 3-10

Trojan Battery Prototype-_VRLA Gel Battery Testing .......................................................... 3-15

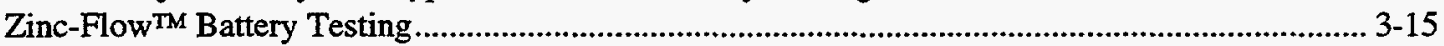

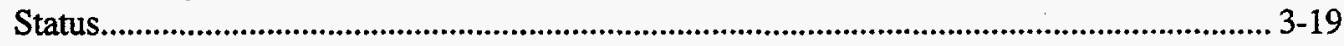

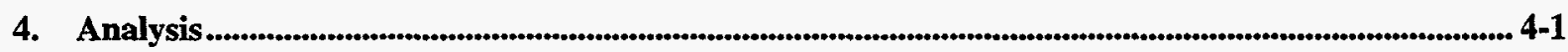

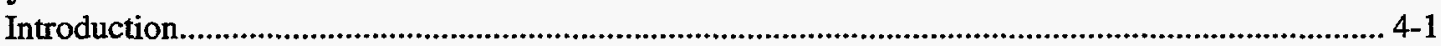

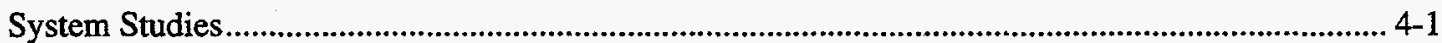

Quantification of Utility Cost Savings from Using Batteries_UMR...................................... 4-1

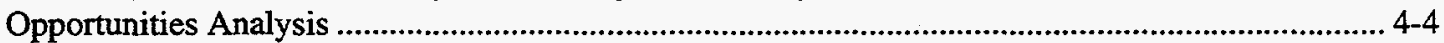

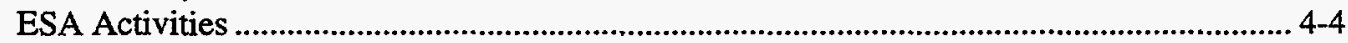

ILZRO RAPS Testing Activities ....................................................................................... 4-5

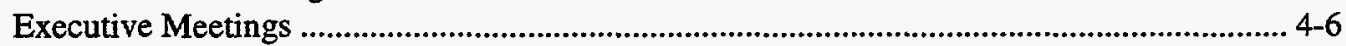

PV Battery and Charge Controller Market and Applications Survey........................................ 4-6

Utility Restructuring Analyses ….................................................................................. 4-7

Technology Assessments............................................................................................................. 4-9

International Energy Agency Annex IX Project Activities .................................................. 4-9

PCS Assessment Project............................................................................................... 4-12

Performance and Economic Analysis of SMES, Flywheels, and CAES Systems Project .... 4-13

Advanced Technologies..................................................................................................... 4-15 


\section{Contents (continued)}

Electricity Consumers Resource Council Meeting. 4-17

Articles in the Electrical World Trade Journal. 4-17

Battery Energy Storage Market Feasibility Study 4-17

Premium Power Applications and Telecommunications

4-17

NIST/ATP for Focused Program in Premium Power 4-17

Appendix A: Presentations and Publications.... A-1 


\section{Figures}

Page

2-1 Final TBESS Trailer Equipment Layout

2-3 Cutaway View of the PQ2000 Container.

The TBESS Being Readied for Over-The-Road Operations Ultimately to be Fielded

at a Utility Test Site

The TBESS Configured for Over-The-Road Transportation.

2-8 Right View Schematic of ZBB 50-kWh Battery Module ............................................................... 2-9

2-9 50-kWh Module Data Collection Profiles ...................................................................................... 2-11

2-10 Cycle Efficiencies for ZBB Battery Serial No. V1-98 …................................................................... 2-12

2-11 Cycle Efficiencies for ZBB Battery Serial No. V1-97 ..................................................................... 2-13

2-12 Preinstallation Flooding in Battery Staging Area …........................................................................ 2-18

2-13 Tray Sitting in a Pool of Water with Water Collecting on Top of Tray ................................................. 2-19

2-14 Corrosion of Battery Trays and Support Structure .............................................................................. 2-20

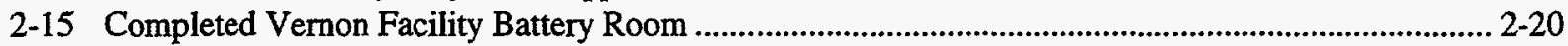

2-16 Largest Peak Shaving Period for the Month of July ................................................................................ 2-25

2-17 Largest Peak Shaving Period for the Month of August ........................................................................... 2-25

2-18 Largest Peak Shaving Period for the Month of September................................................................... 2-26

2-19 APS STAR Hybrid Test Facility ..................................................................................................... 2-27

2-20 The 15-kW PV Array Supplying Power to the APS STAR Hybrid Test Facility ................................. 2-27

2-21 Yuasa-Exide Battery Installed in the APS STAR Hybrid Test Facility ..................................................... 2-28

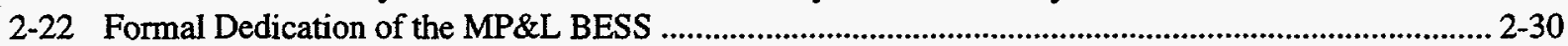

2-23 Comparison of Diesel Fuel Consumption at Metlakatla, Alaska, for FY96 and FY97 ….................... 2-30

2-24 Voltage and Current Profiles for the ZBB 100-kWh Zinc/Bromine Battery During a Baseline Cycle.

2-25 Voltage and Current Profiles for Module 2 of the ZBB 100-kWh Zinc/Bromine Battery

During a Baseline Cycle .................................................................................................................... 2-32

3-1 Amp-Hours Removed (Capacity) and Returned for the ABSOLYTE IIP Battery for FY97 .................. 3-5

3-2 Cell Voltages at EOD for the ABSOLYTE IIP Battery for FY97 ........................................................... 3-5

3-3 Amp-Hours Removed (Capacity) and Returned for the ABSOLYTE II.................................................. 3-8

3-4 Amp-Hours Removed (Capacity) and Returned for the Yuasa-Exide Battery for FY97 ......................... 3-9

3-5 Cell Voltages at EOD for the Yuasa-Exide Battery for FY97 ................................................................. 3-9

3-6 PV Cycles on Yuasa Pafecta NS-100 100-Ah SLI Lead-Acid Battery, SNL. ID No. 730, Cycle 36 .... 3-11

3-7 PV Cycles on Yuasa Pafecta NS-40 40-Ah SLI Lead-Acid Battery, SNL ID No. 728, Cycle 67 ........ 3-12

3-8 PV Cycles on Yuasa Pafecta NS-70 65-Ah SLI Lead-Acid Battery, SNL ID No. 729, Cycle 60 ........ 3-12

3-9 Final Capacity Cycle for Yuasa Pafecta NS-40 40-Ah Lead-Acid SLI Battery, SNL ID No. 728,

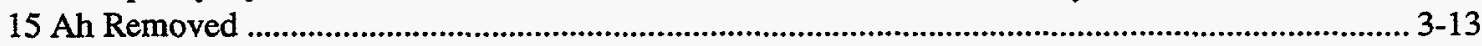

3-10 Final Capacity Cycle for Yuasa Pafecta NS-70 65-Ah Lead-Acid SLI Battery, SNL ID No. 729, 22 Ah Removed ..................................................................................................................... 3-13

3-11 Trojan Capacity and Temperature Plot, SNL ID No. 722............................................................. 3-16

3-12 Trojan Capacity and Temperature Plot, SNL ID No. 723..................................................................... 3-17

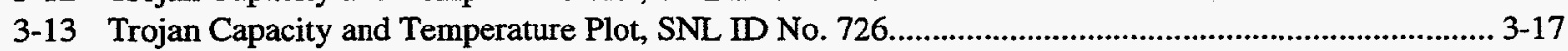

3-14 Trojan Capacity and Temperature Plot, SNL ID No. 727................................................................. 3-18

3-15 Top View Schematic of 9-kWh Zinc-Flow ${ }^{\mathrm{TM}}$ Battery ..................................................................... 3-19

3-16 Front View Schematic of 9-kWh Zinc-Flow ${ }^{\mathrm{TM}}$ Battery ................................................................... 3-20

3-17 Perspective View Schematic of 9-kWh Zinc-Flow TM Battery ................................................................. 3-20

3-18 Six 9-kWh Zinc-Flow ${ }^{\mathrm{TM}}$ Batteries from Powercell's Production Line .................................................. 3-21 


\section{Figures (continued)}

4-1 BESS Used for Spinning Reserve Only by KCPL (1997) (Simulation Method:

Monte Carlo, 12 iterations)

4-2 BESS Used for Load Leveling Only by KCPL (1995) (Simulation Method:

Monte Carlo, 12 iterations)

4-3 BESS Used for Load Leveling Including Spinning Reserve by KCPL (1996)

(Simulation Method: Monte Carlo, 12 iterations). 


\section{Tables}

Page

2-1 400-kWh Battery Specifications

$2-10$

2-2 Performance of Recent Battery Separator Samples..

$2-12$

2-3 Bromine Diffusion of Cycled and Uncycled ZBB Battery Separators.

2-13

$2-4$

July Discharge Data on Vernon BESS Operations

$2-22$

$2-5$

August Discharge Data on Vernon BESS Operations

$2-23$

September Discharge Data on Vernon BESS Operations.

$2-24$

ABSOLYTE IIP Test Regimes ........................................................................................................... 3-4

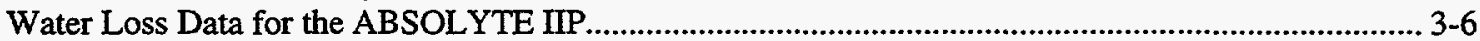

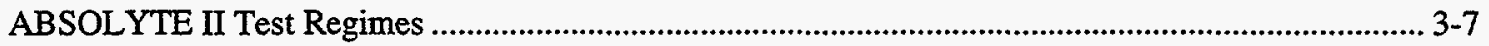

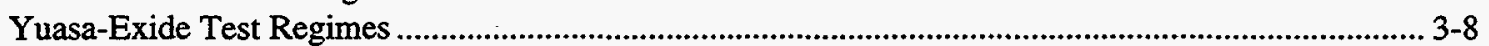

Customer-Determined Duty Cycle Based on Array Output, Battery Sizing, and Load Demand.......... 3-10

Summary Status of Yuasa Pafecta SLI Lead-Acid Battery Cycle Activities......................................... 3-11

3-7 Initial Capacity Cycles Run on Yuasa Pafecta Lead-Acid SLI Batteries to Verify Performance Prior to PV Cycling.

3-8 FY97 Watering Data for Yuasa Pafecta Lead-Acid SLI Batteries ........................................................ 3-14

3-9 Trojan Gel VRLA Batteries Undergoing Testing at SNL................................................................... 3-15

3-10 Trojan VRLA Test Regime .............................................................................................................. 3-16

3-11 Status of the Four Trojan Batteries at the End of FY97........................................................................... 3-18

4-1 1996 vs. 1997 Annual Energy Outlook Comparison ............................................................................... 4-9

4-2 Storage Media, Power Conversion Devices, Peripheral Devices, and Related Technologies............... 4-13

4-3 SMES, Flywheel, and CAES Project Thrusts, Activities, and Status at the End of FY97 ................... 4-14 
Intentionally Left Blank

$v i$

CONTENTS 


\section{Acronyms and Abbreviations}

ABESS Advanced Battery Energy Storage System

ACU adaptive control unit

AEG Applied Energy Group

AES Advanced Energy Storage

AGM absorbed glass mat

ALABC Advanced Lead-Acid Battery Consortium

ANL Argonne National Laboratory

APS Arizona Public Service Company

ARPA Advanced Research Projects Agency

ATP Advanced Technology Program

BESS battery energy storage system

BMI Basic Measuring Instrument

CAES compressed-air energy storage

CAT Customer Acceptance Test

ComEd Commonwealth Edison

DAS data acquisition system

DOC U.S. Department of Commerce

DoD U.S. Department of Defense

DOD depth of discharge

DOE U.S. Department of Energy

ECES Energy Conservation through Energy Storage

EESAT Electrical Energy Storage Applications \& Technology

EFOR Effective Forced Outage Rate

EIA Energy Information Agency

EOD end of discharge

EPRI Electric Power Research Institute

ESA Energy Storage Association

ESD electronic sensor device

ESS Energy Storage Systems

EV electric vehicle

FAT Factory Acceptance Test

FES flywheel energy storage

FY fiscal year

GE General Electric

GNB GNB Technologies, Inc.

GTO gate turn-off thyristor

IEA International Energy Agency

IEEE Institute of Electrical and Electronics Engineers 


\section{Acronyms and Abbreviations (continued)}

$\begin{array}{ll}\text { IES } & \text { International Energy Systems } \\ \text { IIZRO } & \text { International Lead Zinc Research Organization } \\ \text { IUG } & \text { Industry Users Group } \\ \text { KCPL } & \text { Kansas City Power and Light Co. } \\ \text { LANL } & \text { Los Alamos National Laboratory } \\ \text { LVD } & \text { low-voltage disconnect } \\ \text { MGTF } & \text { Modular Generation Test Facility } \\ \text { MOU } & \text { memorandum of understanding } \\ \text { MP\&L } & \text { Metlakatla Power and Light } \\ \text { NCPV } & \text { National Center for Photovoltaics } \\ \text { NEMI } & \text { National Electronics Manufacturing Initiative } \\ \text { NEMS } & \text { National Energy Modeling System } \\ \text { NIST } & \text { National Institute of Standards and Technology } \\ \text { NRECA } & \text { National Rural Electric Cooperative Association } \\ \text { NREL } & \text { National Renewable Energy Laboratory } \\ \text { NWTC } & \text { National Wind Technology Center } \\ \text { O\&M } & \text { operations and maintenance } \\ \text { ORNL } & \text { Oak Ridge National Laboratory } \\ \text { OUT } & \text { Office of Utility Technologies } \\ \text { PCS } & \text { power conversion system } \\ \text { PG\&E } & \text { Pacific Gas \& Electric } \\ \text { PLC } & \text { programmable logic controller } \\ \text { PNM } & \text { Public Service Company of New Mexico } \\ \text { PSEL } & \text { PV System Evaluation Laboratory } \\ \text { PV } & \text { photovoltaic } \\ \text { R\&D } & \text { research and development } \\ \text { RAPS } & \text { Remote Area Power Supplies } \\ \text { RFP } & \text { request for proposal } \\ \text { RFQ } & \text { request for quotation } \\ \text { RGS } & \text { Renewable Generation and Storage } \\ \text { SEIA } & \text { Solar Energy Industry Association } \\ \text { SLI } & \text { starting, lighting, and ignition } \\ \text { SMES } & \text { superconducting magnetic energy storage } \\ \text { SNL } & \text { Sandia National Laboratories } \\ \text { SOC } & \text { state of charge } \\ \text { statement of work } \\ \text { Solar Test and Research } \\ \text { Southwest Technology Development Institute }\end{array}$




\title{
Acronyms and Abbreviations (continued)
}

\author{
T\&D transmission and distribution \\ TBESS Transportable Battery Energy Storage System \\ UES utility energy storage \\ UK United Kingdom \\ UMR University of Missouri-Rolla \\ UPS uninterruptible power supply \\ U.S. United States \\ USABC United States Advanced Battery Consortium \\ VRLA valve-regulated lead-acid \\ ZBB ZBB Technologies, Inc.
}


Intentionally Left Blank 


\section{Executive Summary}

\section{Introduction}

The U.S. electric utility industry is undergoing revolutionary change as a result of impending deregulation and competition, limitations on installing new conventional generation and transmission and distribution (T\&D) equipment, and greatly reduced resources for research and development (R\&D). The United States Department of Energy (DOE), through the Energy Storage Systems (ESS) Program activities at Sandia National Laboratories (SNL), continues to work cooperatively with the electricity supply industry and the manufacturing sector to develop energy storage systems that will play a vital role during and after this transition period. In doing so, the ESS Program is furthering the goals of the DOE by developing technology that can be used by industry to (1) strengthen the nation's energy security in terms of electricity supply, (2) reduce the environmental impact of electricity generation and $T \& D$, and (3) increase the global economic competitiveness of U.S. industry with more reliable, higher quality, and cheaper electricity.

Forecasts of energy prices through 2015 that are given in the Energy Information Agency (EIA) 1997 Annual Energy Outlook are lower than those given in the 1996 Annual Energy Outlook. In absolute terms, all sectors of the economy are forecast to use more energy, but energy use per dollar of gross domestic product will decline. Consumption of all forms of energy is expected to grow, except for nuclear, which will see a decline paralleling nuclear plant closings through 2015.

The ESS Program is conducting focused R\&D, leveraged by U.S. industry, to make possible the widespread use of energy storage systems for renewable generation and other electric system applications. Its goal is the development of new energy storage systems with superior performance and higher energy densities at competitive prices. The program includes a portfolio of storage technologies such as advanced batteries, flywheels, and superconducting magnetic energy storage (SMES).

The ESS Program balances the R\&D of promising new technologies and equipment with focused analytical and educational tasks. The primary emphasis of ESS hardware development projects in fiscal year (FY) 1997 was on the development of the Transportable Battery Energy Storage System (TBESS) and on the continuation of utility field experiments such as the storage project at the GNB Technologies, Inc. (GNB) Lead Recycling Center in Vernon, California, and that for the Metlakatla Indian Community. Program initiatives in FY97 included the Advanced Battery System Development and Testing project and the substation power quality project. Planning continued on the Renewable Generation and Storage (RGS) Project, which is envisioned as possibly including the design, fabrication, or operation at a host utility site of a modular, integrated RGS system capable of control by a utility. The program plan also included a broad spectrum of analytical activities such as determining the value of storage to renewables and characterizing advanced storage technologies. Finally, an Industry Review Group was formed to provide program guidance and peer review in order to achieve tighter integration of the program with utility and industry stakeholder needs.

The ESS Program is organized into three interrelated elements:

- Integration and Implementation

- System Development

- System Field Evaluations

- Component R\&D and Technology Evaluation

- Analysis

- System Studies

- Opportunities Analysis

- Technology Assessments

In keeping with ESS Program goals of maintaining its information base on energy-related technologies and initiatives, ESS staff often attend meetings and pursues collaborations that may not be specifically associated with a program project but could potentially yield valuable information and relationships. These peripheral activities are detailed at the end of each section within this document.

\section{Highlights}

During FY97, the Annual Operating Plan for the ESS Program was implemented. The major hardware project for FY97, the development and testing of the TBESS, met its schedule to deliver a significant prototype unit by late summer 1997. Substantial new projects for the Substation Power Quality Storage System and the Advanced Battery Energy Storage System (ABESS) 
remain on target to deliver major hardware prototypes in the coming years. Preliminary data acquisition began for a study aimed at quantifying the state of the art of flywheel and SMES technologies. ESS Program representatives attended several national and international meetings that encompassed a range of energy storage technology issues including energy storage for Remote Area Power Supplies (RAPS) and telecommunications applications. Initiatives related to storage with renewable generation were in progress, including the completion of the market assessment of batteries for photovoltaic (PV) systems. The program continued to build its global relationships through Annex IX work on electric energy storage with the International Energy Agency (IEA), RAPS initiatives with the International Lead Zinc Research Organization (ILZRO), and contact with other international organizations that are pursuing similar goals. Finally, continued active involvement in the ESS Program by industry groups such as the Energy Storage Association (ESA) helped focus the ESS Program on relevant, critically important $R \& D$ projects that will benefit the nation.

\section{Integration and Implementation}

\section{System Development}

\section{PQ2000 Receives R\&D Magazine's R\&D 100 Award}

On September 25, 1997, the PQ2000 development team lead by AC Battery and SNL received a 1997 R\&D 100 Award from R\&D Magazine at a banquet at the Chicago Museum of Science and Industry. Capable of delivering $2 \mathrm{MW}$ of power for up to 10 seconds, the $\mathrm{PQ} 2000$ is expected to meet a market demand for high quality, reliable power for industrial and utility applications. These prestigious awards have been referred to as the Nobel Prizes of applied research.

\section{Transportable Battery Energy \\ Storage System (TBESS)}

During the fourth quarter of FY97, factory testing of the TBESS was completed. The TBESS was transferred to a Virginia Power maintenance facility for final shake-down testing and customer acceptance. Following a 3-month testing period at the maintenance site, the TBESS will be transported and installed at a Virginia Power Customer site for an initial demonstration period of approximately 6 months. The TBESS is expected to be installed and demonstrated in up to three additional industrial sites in Virginia for a total demonstration period of 2 years.

\section{Advanced Battery Energy Storage System (ABESS)}

The principal FY97 activity of the ABESS project was the initiation of a development contract. The contracting process, which began in 1996, included (1) formulation of a statement of work (SOW) and evaluation criteria, (2) release of a request for quotation (RFQ) to all qualified domestic suppliers, (3) evaluation of the proposals and contractor selection, (4) contract placement, and (5) initiation of the SOW.

In the third and fourth quarters of FY97, a contract was placed with ZBB Technologies, Inc. (ZBB) and work began on the demonstration of a $400-\mathrm{kWh}$ ABESS. In the fourth quarter, the design was completed and testing of the control systems began and is continuing. In July, a major demonstration of the ZBB $100-\mathrm{kWh}$ zinc/bromine battery was successfully completed.

\section{Renewable Generation and Storage and Related Projects}

On September 30, 1997, a meeting was held in conjunction with the Institute of Electrical and Electronics Engineers (IEEE) PV Specialists Conference to gather industry feedback on the needs for integrated storage in PV energy systems. The ESS Program, in coordination with the DOE PV Program, sponsored the meeting to describe the ESS Program to the PV community and introduce the RGS project concept of a factory-integrated, turnkey, modular PV energy system that includes storage. The feedback from this group was to be analyzed and combined with feedback from a storage industry group meeting to be held in first quarter of FY98. An approach to implementing the RGS project will then be determined.

On August 5-6, 1997, SNL staff from the ESS Program attended the Photovoltaic Reliability workshop in Las Cruces, New Mexico. Discussions during this workshop determined that unreliable inverters, ground faults, leakage, battery container materials, and the lack of communication and experience in the PV-battery system design process were issues in the field. To address these issues, additional collaboration between SNL ESS staff and the National Center for Photovoltaics (NCPV) and the DOE Wind Program will be pursued.

On May 22, 1997, a member of SNL's ESS Program staff conducted a battery seminar and workshop for more than 45 National Renewable Energy Laboratory (NREL) staff members at the National Wind Technology Center near Denver, Colorado. Seminar topics covered included battery fundamentals, battery system 
management, failure mechanisms, issues to be addressed when specifying and integrating particular battery technologies for remote or minimal maintenance systems, and lessons learned from large batteries used in utility applications. NREL has indicated that it could use assistance in determining the type of battery technology that will function best under a wind/hybrid operating environment. An increase in interactions of the NREL and SNL staff in energy storage was endorsed by the workshop participants.

\section{System Field Evaluations}

\section{AC Battery PM250 Field Evaluation}

Final refurbishment activities were completed early in the first quarter of FY97, and final testing was accomplished for the fully operational system. A Factory Acceptance Test (FAT) was conducted at the AC Battery facilities in East Troy, Wisconsin. Following completion of the FAT and baseline capacity testing, two major problems were noted that involved over-temperatures in one module and synchronization faults in a second module. In early January 1997, all problems noted during the FAT were resolved, but operations conducted during the debug phase yielded information that many batteries were marginally acceptable. Consequently, if testing of the PM250 was to proceed at specified power levels, it was necessary to replace the complement of Advanced Energy Storage (AES) 2010 batteries with Delco 2000 units. Evaluating the replacement, however, depended on the application that was to be identified for continuation of the PM250 test program. R\&D testing was stopped. The PM250 will continue to be stored at the AC Battery facilities until an application is identified for the unit.

\section{Field Test of Final GNB VRLA Battery Deliverable}

SNL has cost-shared with GNB, a major manufacturer of valve-regulated lead-acid (VRLA) battery products, development of improved lead-acid batteries for energy storage systems. A field test at Vernon, California, using its ABSOLYTE IIP cell is just completing a second year of operation. The field test results have been positive. The 3.5-MWh battery, into which the ESS Program development deliverable was incorporated and which makes up about $10 \%$ of the battery cells, has proven capable of taking over the entire battery-recycling-center plant load. This system is helping the Vernon battery recycling center avoid air emission violations in the event of a power interruption from the local electric utility. During the first part of FY97, both battery strings at Vernon underwent an extensive cleaning and inspection, which was effective in solving a recur- ring problem with ground faults. The ground faults were due to electrolyte leakage and corrosion caused by extremely wet conditions during the original assembly of the battery. Testing of the battery in the secondary mode of peak shaving continued during the fourth quarter. Long-term continuous operation of the system is required to determine the economic benefit provided by peak shaving.

\section{PV/Hybrid Evaluation Project}

The joint Arizona Public Service (APS) and Renewable Hybrid Project moved closer to test initiation this year. This project is the first implementation of an integrated 30-KVA diesel, battery, and PV system supplying a load, which is the APS Solar Test and Research (STAR) Center. The project was proposed to APS by the ESS Program to test a hybrid controller under field conditions and will generate valuable operational data for APS, allowing it to assess the commercial viability of a packaged hybrid system for off-grid applications. The key participants are: SNL; APS; the battery supplier, Yuasa-Exide; the power conversion system (PCS) supplier, Trace Engineering; and the Southwest Technology Development Institute (STWDI), a Department of New Mexico State University, which will develop the data acquisition system (DAS).

\section{Metlakatla Monitoring Project}

The formal dedication of the 1.0-MW, 1.4-MWh energy storage system recently installed in southeast Alaska with the technical support of the ESS Program took place on August 7, 1997. The state-of-the-art system utilizes improved battery technology developed through a cooperative program between GNB and the ESS Program. It is located on the Annette Island Indian Reserve and serves the Metlakatla Power and Light (MP\&L) utility network. The battery system was purchased by the utility with a loan from the Rural Utility Service and will pay for itself within about three years. The storage system is charged from hydroelectric generators on the island and allows the utility to greatly reduce the use of a 3.3-MW diesel generator in serving large load spikes caused by a local lumber mill.

At the dedication, Alaska Senator Ted Stevens attended and was very interested in the potential benefits that similar storage systems could offer other Alaskan villages and requested copies of the proceedings and other materials from a technical seminar on energy storage held during the previous two days. The ESS program was one of the sponsors for the Electric Utility Battery Energy Storage Seminar, held in Ketchikan, Alaska, on August 5-6, 1997. This two-day seminar 
presented the ESS program work, battery energy storage system (BESS) technology and case studies, and BESS cost/benefit issues to utility industry representatives and others regarding opportunities in Alaska.

\section{ZBB 100-kWh Zinc/Bromine Battery Test}

Testing on a 100-kWh, prototype zinc/bromine system was completed in the third quarter of FY97. This milestone represents the culmination of a multiyear Zinc/Bromine Development Project by ZBB and SNL. The development of the zinc/bromine technology was cost-shared by the DOE and ZBB. The primary goal of the battery testing was to determine the suitability of the zinc/bromine battery as a peak-shaving device. Summary test results can be found in Chapter 2, with the complete test results to be published in a final report in FY98.

\section{Component Research and Development and Technology Evaluation}

\section{VRLA Reliability Improvement Project}

VRLA battery reliability has been questioned recently, particularly by users of standby power systems. Because SNL believes that this battery technology offers significant advantages for utility and renewable energy applications, a VRLA reliability improvement project was formulated. Discussions with VRLA battery manufacturers and others continued in FY97 regarding the types of information that need to be obtained to adequately demonstrate battery reliability and the most productive way to collect this information.

During the fourth quarter, a draft SOW was developed for a collaborative project with ILZRO to survey VRLA reliability issues in the field. During the second quarter, SNL received a white paper from ILZRO that discusses VRLA battery performance issues. Establishing the best charge control system appeared to be one area that might provide a substantial benefit. SNL examined the information in the white paper to identify other areas where collaborative work with ILZRO could be pursued. A meeting with ILZRO personnel was held to continue discussions on collaboration. Goals were outlined and a SOW prepared for an initial joint effort on VRLA reliability.

This project has been planned as a three-phase study. Phase 1 is to be a survey of the industry to objectively assess the status of the VRLA technology. Phase 2 investigates the critical issues identified in Phase 1 and suggests improvements. Phase 3 will attempt to match VRLA technologies to specific applications. A contract was placed with IIZRO during the fourth quarter, and ILZRO is evaluating proposals from subcontractors on carrying out the Phase 1 part of the study.

\section{Development, Validation, and Demonstration of Power Quality and Peak-Shaving Technology Simulators}

The ESS Program has initiated a collaborative project with the National Rural Electric Cooperative Association (NRECA) to develop, validate, and demonstrate simulators of power quality and peak-shaving systems. The simulators will provide technical and economic data about peak shaving and power quality improvement at electric power suppliers. More importantly, the project introduces a technology assessment tool that is more exact and no more expensive than a traditional feasibility study.

Work began on the ESS Program portion of the project, which supports the development and validation of the energy storage system simulators that will mimic the operation of two BESSs: one that Oglethorpe Power Corporation operates for power quality and one that Crescent Electric Membership Coop operates for peak shaving. A conceptual design change allowed both systems to use the same hardware and topology, with the exception of a differentiated programmable chip. Installation of the simulators at the Crescent and Oglethorpe sites is planned for FY98.

\section{Lead-Acid Battery Evaluation at SNL}

\section{VRLA Absorbed Glass Mat (AGM) Testing}

Testing of deliverables from the GNB VRLA battery development contract continued at SNL in FY97. Two 18-V batteries, an ABSOLYTE II and an ABSOLYTE IIP, have undergone long-term cycle life tests, and over 350 cycles have been accumulated on each. Battery maintenance issues and capacity losses observed to this point were discussed in a meeting with GNB to determine whether any abnormal changes were occurring. GNB also described its most recent cell design, the ABSOLYTE XI. This was developed in collaboration with Nippon Telephone and Telegraph in response to its request for a high-capacity sealed cell that would reduce the need for external paralleling of connections. This effort benefited from information obtained during the ESS development program.

In addition, a VRLA battery from Yuasa-Exide was tested to characterize the technology. Test results from 
these three units, the ABSOLYTE II, ABSOLYTE IIP, and the VRLA battery from Yuasa-Exide, are in Chapter 3. All three batteries, will remain on test until the units have lost $20 \%$ of their rated capacity. The data generated in these tests will also be used in the VRLA Reliability Improvement task.

\section{SLI and Trojan Battery Testing}

SNL continues to perform in-house battery evaluation tasks on both lead-acid, starting, lighting, and ignition (SLI) batteries for Community Power Corporation and VRLA gel batteries for Trojan Battery Corporation. The SLI batteries are destined for use in offshore domestic PV applications. In general, SLI batteries have not performed well in the cycling environment. Consequently, there is high interest in demonstrating whether, with proper care and management, they could support a cycling application. During FY97, 1,000 daily shallow PV cycles were completed on the SLI batteries. Results indicate that the 100-Ah model is the likely candidate for PV installation because of its better performance and reduced maintenance.

Testing on four 12-V VRLA Trojan gel batteries, which are designed for deep-cycling applications primarily in the renewable energy arena, continued throughout FY97. Batteries are cycled using the 25-A charge/discharge Battery Council International testing program and are discharged daily to $20 \%$ state of charge (SOC) and then charged to full SOC. The objectives of testing at SNL are to (1) confirm the electrical performance ratings, (2) evaluate the batteries' ability to meet customer requirements, and (3) determine the service life of the batteries. Testing began in the first quarter of FY97, but in the second quarter the test facility experienced temperature fluctuations that affected the test data for measured capacities. In the third quarter, the batteries were moved to a different facility and testing resumed.

By the end of FY97, two of the Trojan batteries had reached their defined end of life and were no longer being tested. One battery had experienced a cell failure and was no longer being tested and one battery was still under test.

\section{Zinc-Flow ${ }^{\mathrm{TM}}$ Battery Testing}

In FY97, the ESS Program initiated a contract with Powercell Corporation to conduct testing on Powercell's Zinc-Flow ${ }^{\mathrm{TM}}$ battery. The objective of this project is to characterize the performance of a 9-kWh Zinc-Flow ${ }^{\mathrm{TM}}$ battery. The project comprises of three tasks: the pro- duction of a data summary report, the delivery of the Zinc-Flow ${ }^{\mathrm{TM}}$ battery for testing, and the creation of a draft test plan. The battery has been designed and fabricated and was awaiting a suitable controller for testing. A draft test plan was written that excludes characterization testing and will allow testing to begin with a different controller.

\section{Analysis}

\section{System Studies}

\section{Quantification of Utility Cost Savings from Using Batteries-University of Missouri-Rolla}

The University of Missouri-Rolla (UMR) is continuing to use the DYNASTORE computer program to calculate utility-generation, operating-cost savings that can be realized with battery energy storage. A reanalysis of the calculations for a grid-connected utility system at Kansas City Power and Light Co. (KCPL) was carried out in FY97 to provide data for a combined report comparing results for island and grid-connected utility systems. Work has concentrated on determining the changes in KCPL operating costs/savings due to inadvertent outages in generation. This was done by making many computer runs using the Monte Carlo iteration method of DYNASTORE to model the randomness of the outages. An analysis of BESS O\&M costs is also being carried out to determine their effect on operating cost savings. A draft report comparing the island and grid-connected system is expected to be delivered in the first part of FY98.

\section{Substation Power Quality Project}

SNL has been working with Public Service Company of New Mexico (PNM) and Los Alamos National Laboratory (LANL) to address power quality problems at the utility level, i.e., those that would occur at the 12to $15-\mathrm{kV}$ level. During FY97, each of the project participants reassessed his or her role and objective as the project progressed beyond evaluating the technical and economic feasibility of the concept to the design, development, and implementation of a prototype system. Project participants successfully developed a power quality design concept that would be capable of providing undisturbed and uninterrupted voltage at a utility substation bus. Participants entered into negotiations on the final terms for the agreement under which this work will be conducted. 


\section{Opportunities Analysis}

\section{ESA Activities}

Early in FY97, the ESA held its first official meeting after incorporating as a trade association. At this meeting, the ESA broadened its charter to include nonbattery forms of electrical energy storage. Many of the presentations at this meeting related to analysis and development projects sponsored or performed by the DOE ESS Program, which has had a sustaining role in the ESA since its original formation as the Utility Battery Group over 6 years ago. This meeting also emphasized the completion of the PQ2000, a 2-MW/10-sec power quality system developed and tested by the ESS Program in collaboration with industry and now being commercially installed for utility and industrial applications.

During April 26-30, 1997, ESS Program personnel participated in the SOLTECH meeting in Washington, D.C. Three specific sessions were held in which energy storage was either discussed or highlighted. All meetings were well attended, and storage issues consistently generated much interest and discussion. A key issue was a need for additional performance and life data for storage components and systems. Many new contacts were made with the PV industry, which will allow for improved interactions between the storage and renewables industries.

Also in April, the ESA held its spring meeting, which took place in Washington, D.C., April 30-May 1, 1997. The spring meeting followed the SOLTECH ' 97 Conference and helped to enrich the collaboration between the solar and energy storage industries. This meeting focused on partnering renewable generation with energy storage.

The DOE also sponsored an Industry Users Group (IUG) meeting. The objective of this meeting was to provide the DOE with feedback, direction, and suggestions with regard to potential users of energy storage. The IUG will be a standing group that assists the DOE in an advisory capacity.

\section{ILZRO RAPS Testing Activities}

The ESS Program initiated a collaboration with ILZRO on RAPS in the first quarter of FY97. On April 1, 1997, DOE ESS staff met with ILZRO to continue dialogue for defining this collaboration. It was agreed that standard RAPS duty cycles were needed for laboratory testing. Concern was raised over Third World national regulations. A workshop will be held in the first quarter of FY98 to address these issues.

\section{Executive Meetings}

In FY95, the ESS Program established an outreach team to assess industry needs and to assist the program in broadening its scope from BESS to a portfolio of energy storage technologies. The team met with executives from more than 15 organizations, who represented a cross section of independent power producers, investor-owned utilities, electric cooperatives, and equipment manufacturers. The meetings led to greater DOE awareness of the perceptions and needs of U.S. industry, promoted U.S. industry awareness of the ESS Program activities, and stimulated participation in the ESS Program by industrial organizations that were not previously involved. The final report, titled Report on the Energy Storage Systems Program Executive Meetings Project, was published and distributed early in FY97.

\section{PV/Battery and Charge Controller Market and Applications Survey}

The purpose of this study was to determine the market size for PV systems that use battery storage to improve their efficiency and availability. The study was conducted using a survey designed and implemented under a contract with Arizona State University. The study sought to determine what types of and how many batteries are currently used in the stand-alone PV market. The survey also polled system integrators on their methods of specifying batteries and charge controllers for the systems they design. The final report was published by SNL in early FY97 and is available from SNL upon request.

\section{Utility Restructuring Analyses}

An ESS Program representative attended the Keystone Energy Board meeting in Keystone, Colorado, February 27-March 1, 1997. The main topic was utility restructuring. The conclusion of the conference was that restructuring is inevitable, but many complex and critical issues need to be addressed before restructuring can efficiently and effectively proceed and deliver benefits to the public.

The ESS Program sent a representative to the National Energy Modeling System (NEMS)/Annual Energy Outlook Conference that took place in Crystal City, Virginia, on March 17, 1997. The emphasis was not on modeling but on energy issues in general, with the impact of deregulation being the primary topic. Although the use of the NEMS tool was highlighted in various debates, deregulation-related issues remained the central theme. 
ESS Program staff visited Oak Ridge National Laboratory (ORNL) to review the preliminary analysis that has begun on utility $T \& D$ in deregulated markets. There is interest in studying spot market electricity prices and in reviewing how renewables and storage could interact. Coordination issues were reviewed, and it was agreed that exchanging technical reports and maintaining open communication are essential to the process.

\section{Technology Assessments}

\section{International Energy Agency Annex IX Project Activities}

Phase 1 of the Annex IX work program was essentially completed in FY97. The principal output developed during this phase were two models for the quantification of storage systems' financial and environmental benefits. ESS Program staff attended, via teleconference, the IEA's Energy Conservation Through Energy Storage (ECES) Modeling Requirements Experts' Meeting, held in Arnhem, The Netherlands, on September 29,1997 . This meeting was the second of two modeling meetings held in FY97. At this meeting, the various applications of storage systems were discussed in detail, with close attention being paid to the range of potential secondary applications vs. a corresponding range of primary applications. A short demonstration of the prototypical model functionality was provided.

\section{PCS Assessment Project}

The ESS Program initiated a PCS study at SNL in FY97. An agreement was reached on April 21, 1997, to conduct a study and produce a final report that does the following:

- Characterizes the design architecture and cost of the various types of PCSs (based on gate turnoff thyristor or integrated gate bipolar transistor, four-quadrant, self-commutated, line-commutated, etc.) needed for utility and renewable utility applications;

- Identifies state-of-the-art PCS electrical interfaces to batteries, flywheels, SMES, and supercapacitors;

- Identifies standards relevant to PCS use in the utility industry; and

- Synthesizes the results to develop recommendations for an R\&D plan for components and subsystems.

The ideal PCS would be able to interface any and all of the four major storage technologies (batteries, fly- wheels, SMES, and supercapacitors) with the utility grid (grid-tied operation) or renewable (nongrid-tied operation) power sources. The study will require about a year to complete.

\section{Performance and Economic Analysis of SMES, Flywheels, and CAES Systems Project}

In keeping with the ESS Program goal of characterizing and identifying the requirements for advanced energy storage components (flywheels, SMES, etc.), the ESS Program initiated an analysis project at Energetics, Inc. The four major thrusts of the analysis are: Collect Information, Analyze Information, Identify Actions, and Report Results. In a review of the project at SNL during the fourth quarter of FY97, Energetics reported that the literature review for Flywheels and SMES was complete and an industry survey instrument was in final review. Interviews with industry experts began in early September. The first review of the technology primers for SMES, flywheels, cryogenics, and power electronics was completed, and a first draft of the compressed-air energy storage (CAES) primer was finished. An initial review of the spreadsheet analysis tool was completed; data entry of literature-provided technology characteristics was underway, with additional development dependent on the results of the industry survey. The study will be completed early in 1998.

\section{Electricity Consumers Resource Council Meeting}

On March 14, 1997, ESS Program staff met with a staff representative from the Electricity Consumers Resource Council (Elcon) in Washington, D.C. Elcon, an association of 28 large industrial consumers of electricity, is strongly in favor of utility deregulation and retail competition and expects that unbundling will reduce electricity costs and improve power quality. There will be significant opportunities in the deregulated utility industry for use of storage in such applications as power quality and peak shaving, according to the Elcon representative. In order to communicate ESS Program activities and issues, the Elcon representative will send a letter to all members describing the program and summarizing storage opportunities for industrial applications.

\section{Articles in the Electrical World Trade Journal}

Utilities, manufacturers, and electrical end users are being made aware of the technical and economic advances that energy storage systems have made in recent years through the authoring efforts of the ESS Program and one if its industry partners, Energetics, Inc. The outreach initiative is an effort to update this audi- 
ence about these advances and to encourage them to consider energy storage as a way to address either operation or strategic issues. This effort is also a means of reaching a wider audience than would otherwise be possible. The ESS Program has coauthored several articles about energy storage installations and electric utility industry developments in recent issues of McGrawHill's utility trade journal, Electrical World.

\section{Battery Energy Storage Market Feasibility Study}

The Battery Energy Storage Market Feasibility Study was published in July 1997. An expanded report was published in September 1997. The study was conducted by Frost \& Sullivan and was designed specifically to quantify the expected utility energy storage (UES) markets for utility applications. Based on extensive surveys conducted, the report concluded that many industry experts viewed battery energy storage as an important enabling technology to facilitate the use of renewable energy, to address power quality improvement, and to resolve asset utilization issues.

\section{Premium Power Applications and Telecommunications}

On July 10, 1997, the DOE ESS Program Manager and SNL staff made program-related presentations to the Lucent Technologies Premium Power Design Team. The Lucent team, which is meeting about every 3 months, is investigating technologies that provide high quality power at the point of use. At the request of Lucent and the ESS Program Manager, SNL ESS staff will continue active participation in these meetings.

\section{NIST/ATP Workshop for Focused Program in Premium Power}

At a National Institute of Standards and Technology (NIST) planning workshop on August 12 and 13, 1997, ESS staff discussed a Focused Program proposal for the Advanced Technology Program (ATP). The topic of the workshop was "Premium Power," i.e., a low-disturbance, high-reliability power source. The need for premium power results from the changing infrastructure needs of U.S. industry, which has been estimated to suffer over $\$ 26 \mathrm{~B}$ in annual losses due to power interruption. Lucent, one of the driving forces in the workshop, envisions a convergence of technologies in telephony, electronics/information systems, aerospace, and deregulated/distributed power, leading to a revolution in communication technology. SNL had a strong presence at the workshop, which reflects its industrial ties through NEMI and its DOE programs such as the ESS Program and PV R\&D. 


\section{Integration and Implementation}

\section{Introduction}

Under the Integration and Implementation element, a strategy is being pursued to reduce the inefficient oneof-a-kind system engineering historically required when a UES system is designed and built. A modular battery system approach has been adopted as the preferred method of achieving system flexibility and the lowest possible cost. The major subsystem components (battery, PCS, and controls) are designed as separate modules. This allows integration to take place either at the factory or at the utility site. From a cost perspective, this modular approach permits more efficient engineering, design, and manufacturing processes to be used. Finally, the large quantity of on-site labor required to assemble and to start up the system at the user site is minimized.

\section{System Development}

\section{PQ2000 Receives R\&D Magazine's R\&D 100 Award}

On September 25, 1997, the PQ2000 development team lead by AC Battery and SNL received a 1997 R\&D 100 Award from R\&D Magazine at a banquet at the Chicago Museum of Science and Industry. The award was received by the team in recognition of successful teaming of government and industry in a heavily cost-shared project in which the DOE provided $20 \%$ of the total cost of the development effort. Under a DOE Cooperative Agreement, the first prototype $\mathrm{PQ} 2000$ was designed and fabricated by AC Battery with technical oversight by SNL and the Albuquerque offices of the DOE. The prototype was tested at PG\&E's MGTF in San Ramon, California. Capable of delivering $2 \mathrm{MW}$ of power for up to 10 seconds, the $\mathrm{PQ} 2000$ is expected to meet a market demand for high quality, reliable power for industrial and utility applications. The first commercial system was purchased by Oglethorpe Power Corporation under a tailored collaboration arrangement with EPRI. It was installed in the Slash Pine Electric Cooperative grid in Homerville, Georgia, to provide quality power to a lithograph plant.

\section{Transportable Battery Energy Storage System}

The goal of the TBESS project is to further the development of prototype battery systems built with commercially available and advanced components and to evaluate these systems in typical utility operating environments. The project covers the design, fabrication, siting, installation, testing, and reporting on these systems. The systems are designed such that they can be moved to a new location (on the same or on a different utility grid), installed, and tested. They are being developed for use by one or more utilities over a multiyear period to obtain field data at more than one site to prove reliability, functionality, and cost-effectiveness. The entire project was expected to span a 2-yr period and a significant cost-share (about 50\%) was required.

\section{TBESS Development}

This project is part of a cooperative activity known as the Transportable Battery System Program, which is an initiative of the DOE and EPRI. The SOW was coordinated with EPRI, and a related project with EPRI has been conducted by EPRI. A request for proposal was issued by SNL in late FY95, and final contractor selection was made in the second quarter of FY96. The contract was placed on August 5, 1996, with AC Battery. The TBESS project kickoff meeting was held on September 25, 1996.

The TBESS design recommended in the AC Battery proposal was modified to improve system control and response functionality, which resulted in a slight cost increase. The project was divided into two phases. Phase I consisted of the initial design, fabrication, and factory testing of the TBESS. This included design and fabrication of a control system that provides standard input/output channels and appropriate control actions for all required protective relaying equipment at the individual host utility sites. Phase II consisted of the transportation and setup of the TBESS at a minimum of two host utility test sites. The contractor was to ship, install, start up, and field test the TBESS at the first site and then prepare, transport, and field test the TBESS at the second site. The host utility for Phase II was to be identified by AC Battery before Phase I began.

The SOW for the contract describes several desirable characteristics for the TBESS. First, it was important that the TBESS design and the host utility test plans 
fulfill the overall intent of the project as closely as possible. For example, emphasis on power quality improvement at the host utility test sites was an area that would signify a good match. The design was to be flexible and incorporate additional power or energy capacity above that required by the mandatory specifications, or provide enhancements that increase modularity, enable the system to be used for several different applications, and/or have long-term market applications. The system design included the potential for upgrades and cost reduction. Finally, the system was to be designed for the greatest possible transportability while keeping the charge time, footprint, and life-cycle costs to a minimum.

\section{Status}

Design work was initiated and continued throughout FY97, and long-lead items were ordered early by AC Battery. Included in the initial acquisition plan was the decision to have the trailer built from the ground up rather than modifying an existing three-axle, doubledrop, low-boy trailer. Because of the importance of the interconnecting conduit between the subsystems installed on the trailer, it was determined that existing trailer designs were inadequate for modification. The trailer was delivered to AC Battery in late February 1997. Final layout of the TBESS, showing the trailer and the PQ2000, is shown in Figure 2-1.
The TBESS is composed of the PQ2000 battery, the electronic sensor device (ESD), the transformer, and the double-drop low-boy trailer.

A decision was made to consolidate all system controls and decision logic in the PQ2000 electronics rather than have them split between the ESD controls and the $\mathrm{PQ} 2000$ controls. This decision was due to problems identified early in the $P Q 2000$ test program at the PG\&E MGTF. These problems were partially caused by the coordination required by the separation of the sensing systems and the decision and control logic. Consolidating the controls under one primary controller eliminated complex communication requirements that proved troublesome during initial testing. The concept of control consolidation was tried and proven during the assembly and factory testing of the second PG\&E PQ2000. The container, the transformer, and the ESD were mounted on the trailer in mid-March 1997. Interconnection cabling began in early April. Figure 2-2 shows the trailer-mounted components in place. The TBESS container was designed by AC Battery Corporation to be operated in a power quality mode at a power level of $2 \mathrm{MW}$ for $15 \mathrm{sec}$. A cutaway view of the $\mathrm{PQ} 2000$ container is shown in Figure 2-3. The PQ2000 consists of 48 Delco $115012-\mathrm{V}$ batteries in series ( 384 batteries).
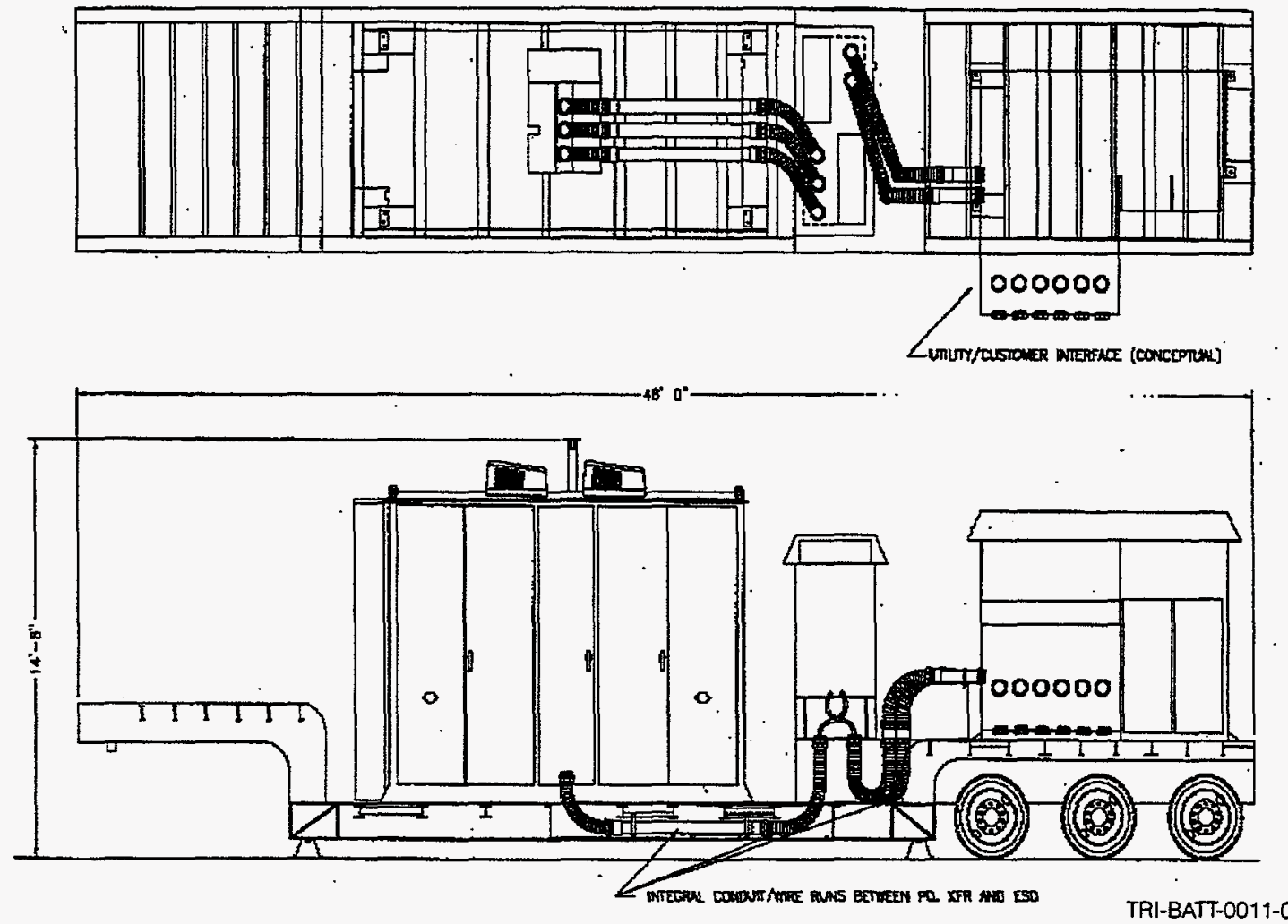

Figure 2-1. Final TBESS Trailer Equipment Layout. 
$0-Z 100-\perp \forall Q-18 \perp$

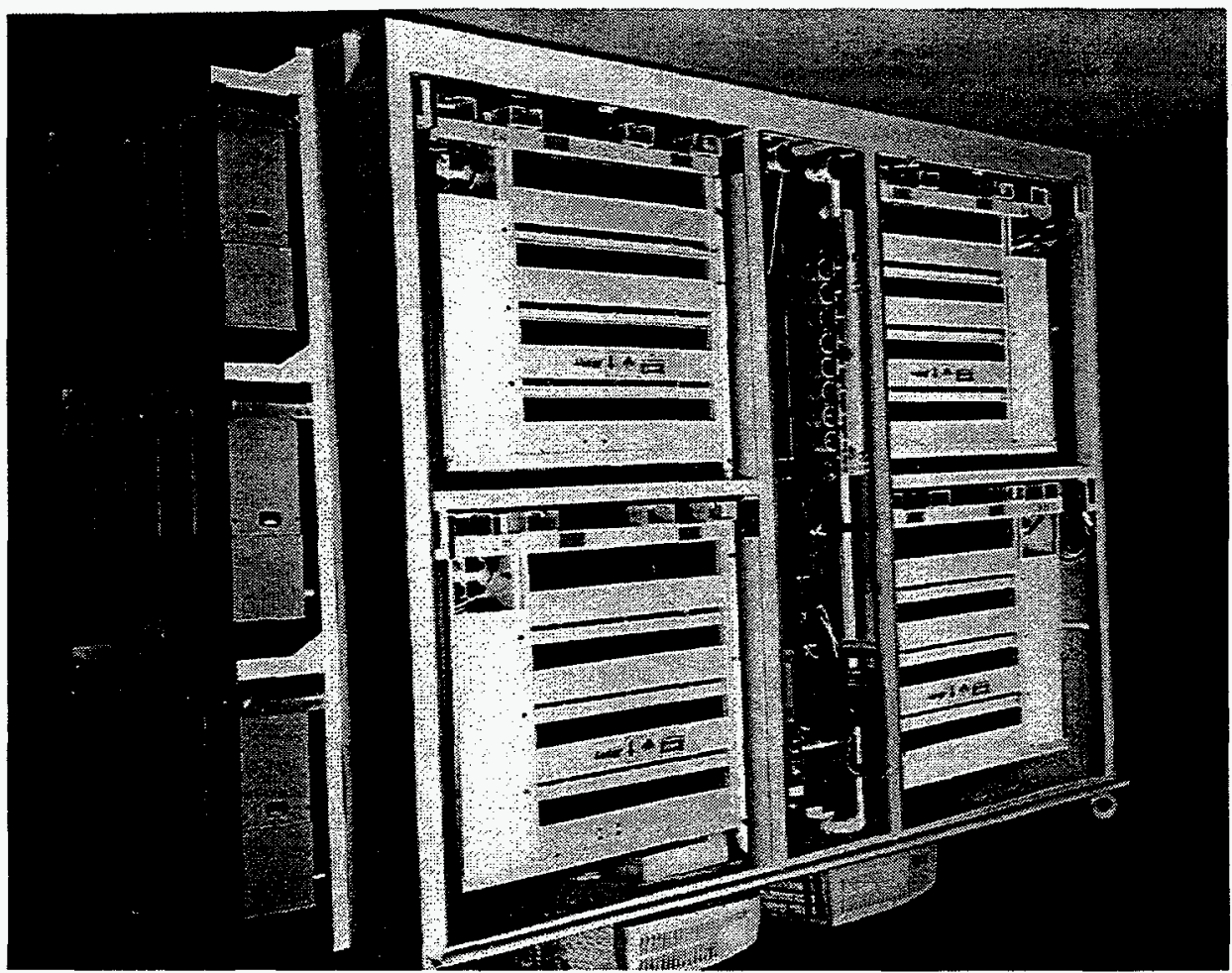

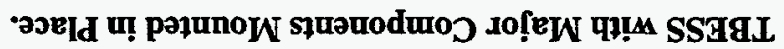

$0-0200-1178-181$

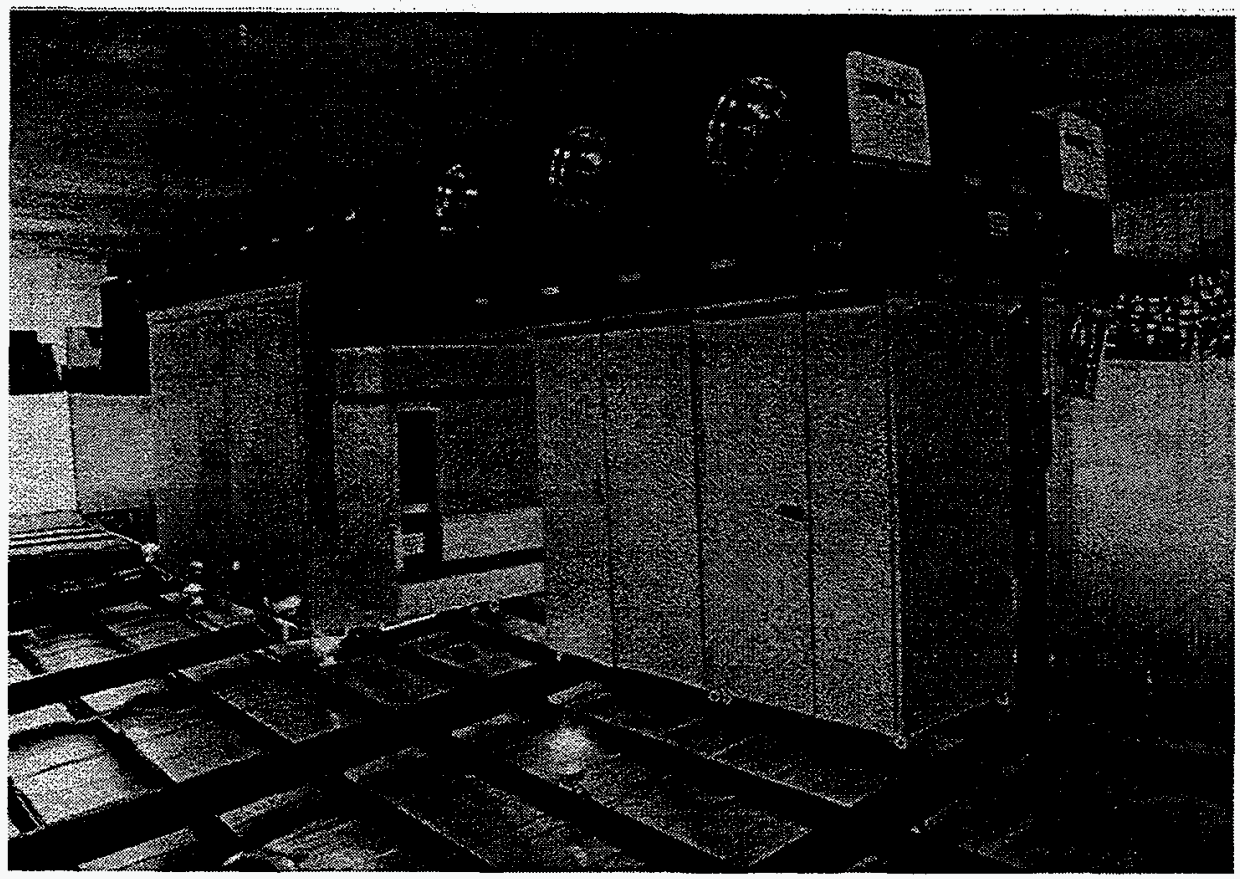


Negotiations between AC Battery Corporation of East Troy, Wisconsin, and Virginia Power of Richmond, Virginia, on Virginia Power joining the TBESS test team as its utility partner continued through April 1997. On May 9,1997, a contractual agreement to participate in the siting and testing of the TBESS was signed by AC Battery and Virginia Power. The terms of the final agreement stated that the TBESS was to be transported to the Virginia Power Iron Bridge facility where it was to be operated for 6 to 9 mo in field testing and system characterization in preparation for relocation to a Virginia Power customer facility. The TBESS was scheduled to be transported and operated at up to three commercial/industrial sites in the utility's customer area to demonstrate the benefits of premium power to these facilities. In addition, the tests were designed to demonstrate the feasibility of a mobile, power quality BESS.

Several other key events occurred in the third quarter of FY97. The draft O\&M manual for the TBESS was received. Also, a program review meeting was held at $\mathrm{AC}$ Battery. Cabling was progressing well and the project was on schedule.

Final assembly of the TBESS was completed in early July and the unit entered the factory test phase, which proved to be routine and uneventful. A program review attended by AC Battery Corporation and SNL personnel was held at AC Battery in mid-July. Following a walk-around inspection of the TBESS unit, a low power demonstration of TBESS was conducted to terminate the meeting. A FAT was completed with SNL and Virginia Power participating. During the following six weeks, the TBESS was thoroughly tested and characterized at the AC Battery facilities. Figure 2-4 shows TBESS being readied for over-the-road transport operations with its final destination being Virginia Power utility.

During the last week of August, the TBESS was moved from the AC Battery factory to Omnion where facilities exist to test the unit at full power. Figure 2-5 shows the final configuration of the TBESS for over-theroad transportation. While en route from AC Battery to Omnion, the unit was driven several miles on interstate highways in the Milwaukee area to test the trailer in transport operations. There were no problems during this exercise.

In early September, the TBESS Customer Acceptance Test (CAT) was conducted by Virginia Power and AC Battery Corporation at the Omnion Power Engineering facilities where the capability exists to operate the TBESS at the 2-MW power point for up to $15 \mathrm{sec}$. SNL

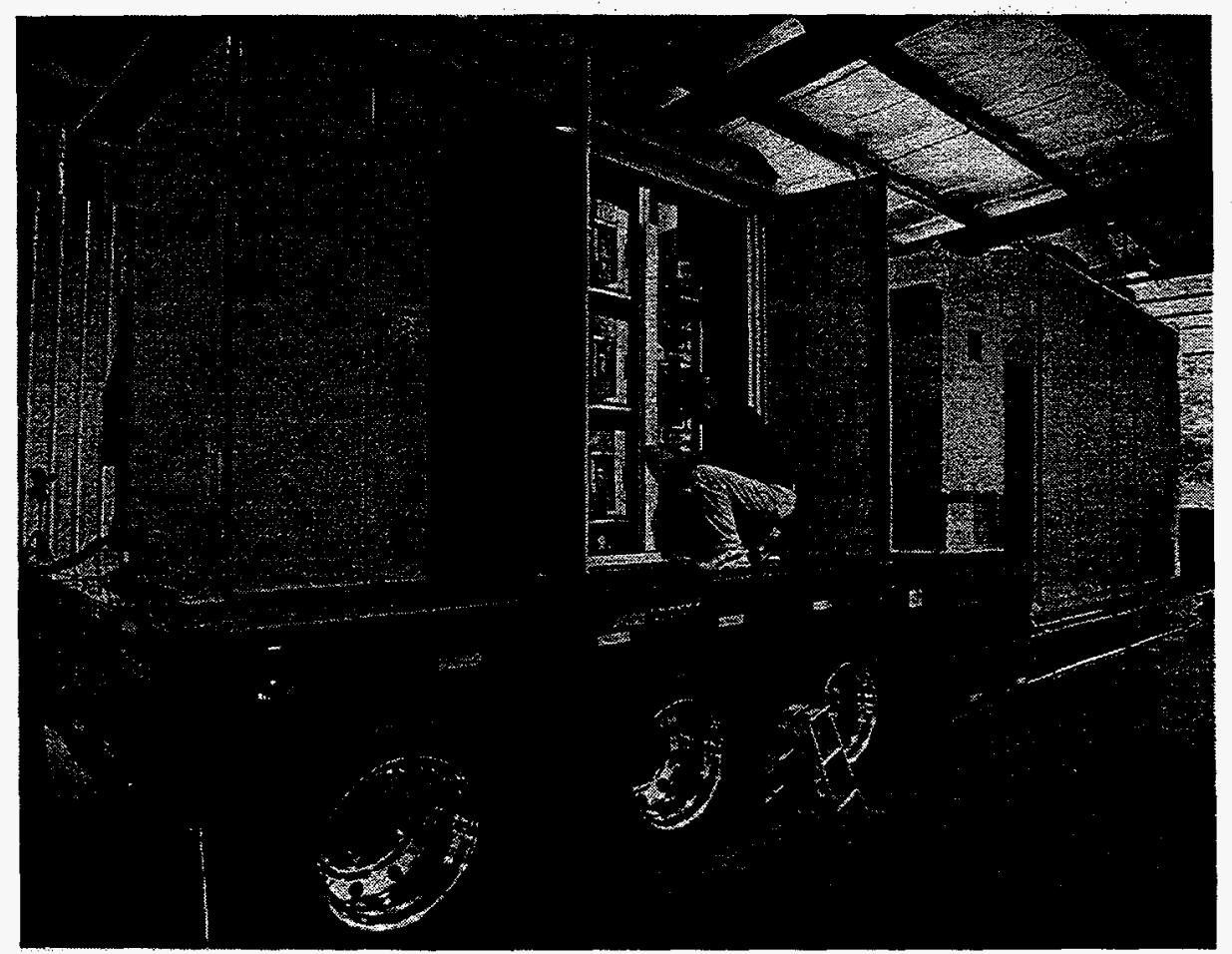

TRI-BATT-0046-0

Figure 2-4. The TBESS Being Readied for Over-The-Road Operations Ultimately to be Fielded at a Utility Test Site. 


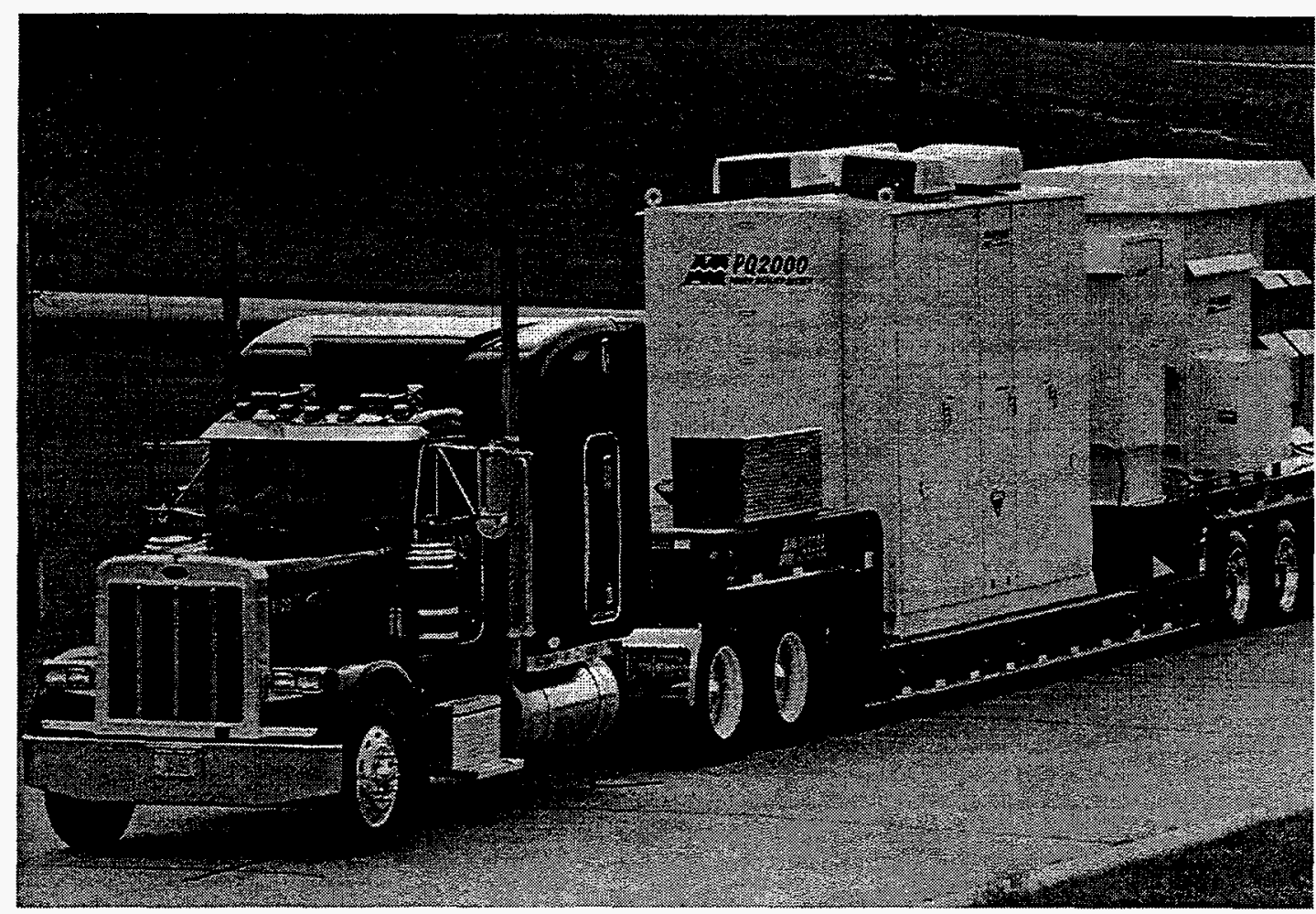

TRI-BATT-0021-0

Figure 2-5. The TBESS Configured for Over-The-Road Transportation.

and DOE personnel also participated in the CAT. Minor modifications were identified and requested by Virginia Power, primarily in the remote notification procedures, which were completed prior to shipping the unit to Virginia, scheduled for early October FY98.

During the wrap-up discussion following the completion of the CAT, Virginia Power requested that AC Battery provide a new reconnect strategy. The new strategy would be used following an interruption that exceeded the 15-sec limit of the TBESS unit. This would mean that the reconnect to the utility would occur outside of the standard operational specifications. The discussion that followed this request identified the fact that the reconnection strategy proposed by Virginia Power was the original reconnect procedure that was in effect when the first prototype PQ2000 was delivered to PG\&E for field testing in FY96. Serious problems were encountered when using this strategy including the burnout of three-phase motors, which were online when the reconnection occurred and the phases were out of specification. The SNL representative made it clear that Virginia Power would be solely responsible for all costs associated with the reconnect modification. SNL recommended that AC Battery not proceed with the requested modification. In response to the discussion on the merit of the requested reconnect strategy modifica- tion, Virginia Power acknowledged SNL's position and will reevaluate the request prior to instructing AC Battery to proceed. Resolution of this issue is expected in early FY98.

\section{Advanced Battery Energy Storage System}

The Preliminary Opportunities Analysis performed during FY94-95 showed that advanced batteries have a clear and important role in energy storage systems. The lead-acid technologies have the potential to satisfy most UES applications. However, their primary deficiency is with those applications that place importance on footprint and portability and where higher energy capacity is required (duration $>1 \mathrm{hr}$ ). Advanced technologies are needed for applications including T\&D utility deferral, renewables, and customer/transit system peak reduction. Advanced batteries may fill this need.

During the 1980 s and early 1990 s, the DOE-sponsored development of the UES sodium/sulfur and zinc/ bromine technologies permitted their conceptual feasibility to be validated and set the stage for focused subsystem development. Development of other candidate advanced batteries with desirable characteristics of 
higher energy/power ratios and relatively low footprint has been proceeding concurrently with both private and public funding. The focus of these latter efforts is typically on portable consumer or electric vehicle applications. Nevertheless, some compatibility between the capabilities of these other advanced batteries and UES requirements may exist. Increasing energy demands on utilities and the establishment of a meaningful role for advanced batteries in UES applications combined with their progressing development status warrants a new and dedicated effort to ensure that viable advanced battery systems will be available by the turn of the century.

The principal FY97 activity concerning ABESS was the initiation of a development contract. Because the identification of customers for this technology is the critical element to the final production-engineering phase of development, the focus and end product of this task will be a field demonstration at a utility or customer site. This prototype, integrated system (battery, PCS, controls) will perform one or several UES applications. As such, active participation of an advanced battery developer, a utility customer, and a PCS manufacturer is required. In addition, targeted applications must be consistent with the needs identified in the Opportunities Analysis that cannot be optimally satisfied with leadacid technology. Lead-acid battery technologies were precluded from consideration.

The SOW involves the following tasks:

- ABESS specifications and field-test plan preparation

- Engineering design definition

- ABESS fabrication

- Acceptance testing

- Documentation and training for field testing

- Preparation for testing

- Field test

- Decommissioning

The contracting process, which began in 1996, included (1) formulation of the SOW and evaluation criteria, (2) release of a RFQ to all qualified domestic suppliers, (3) evaluation of the proposals and contractor selection, (4) contract placement, and (5) initiation of the SOW. In the first quarter of FY97, several proposals were evaluated. Two potential contractors were strongly considered. One contractor was selected for a series of fixed-priced contracts to complete the SOW. The contract was placed and work commenced in last half of the year.
ZBB participated in one of the largest turnkey, advanced battery demonstrations in the U.S. This major demonstration, a 100-kWh zinc/bromine battery system, was partially funded by the DOE/ESS Program and was completed July 1997 at the ZBB test facility. Following the completion of the $100-\mathrm{kWh}$ battery tests, the SOW described above was initiated for the development and testing of a $400-\mathrm{kWh}$ ABESS. Field testing a prototype, integrated energy storage system should enable ZBB to validate the technology and refine the quality and reliability to the satisfaction of the electric utilities.

The objectives of the ABESS project are to design, fabricate, evaluate, and optimize a zinc/bromine battery system suitable for electric utilities. The soundness of the battery technology was demonstrated and new larger cell stacks, designed for an electric utility battery, were developed during previous contracts between $\mathrm{ZBB}$ and SNL. The end product of the present contract is to demonstrate a $400-\mathrm{kWh}$ system at a utility installation. Based on the results of this testing and utility interest, larger systems may be tested in the future.

The zinc/bromine battery is an emerging technology that has many attributes that make it attractive for utility storage applications. The main advantage of the zinc/bromine battery system is the good gravimetric density, which results in a modular transportable battery system with a sufficient capacity to be placed anywhere on the utility grid. The battery is made almost entirely from plastic (high-density polyethylene), which makes it cost competitive with lead-acid batteries without the hazardous manufacturing and recycling concerns. Also the battery operates efficiently over a wide temperature range, functions under intermittent charge/discharge conditions, and experiences complete discharge hundreds of times without damage.

\section{Status}

In the fourth quarter of FY97, ZBB began to develop a 400-kWh transportable zinc/bromine system. The initial phase of the project consists of the following tasks:

1. Applications Analysis/Preliminary Field Test

2. Complete Preliminary System Specifications

3. PCS Specifications Development

4. Design/Assemble/Test Improved Modules 


\section{Battery Design}

The zinc/bromine battery differs from conventional lead/acid batteries because the electrolyte is circulated and stored external to the battery stack. The battery system consists of battery stacks, electrolyte storage reservoirs, and an electrolyte circulation system.

Flowing electrolyte is necessary to ensure uniform zinc plating on the anode, to separate the reactive bromine from the electroplated zinc in the battery stack, and to improve the thermal management of the system.

A bipolar electrode design is used and results in a good specific energy for the battery. During charge, zinc is electroplated on the anode, and bromine is evolved at the cathode. A complexing agent in the electrolyte is used to reduce the reactivity and vapor pressure of the elemental bromine by forming a polybromide complex with bromine. This minimizes the selfdischarge of the battery and significantly improves the safety of the system. The complexed bromine is removed from the stacks with the flowing electrolyte and is stored in an external reservoir. On discharge, the complexed bromine is returned to the battery stacks, zinc is oxidized to zinc ions, and bromine is reduced to bromide ions. The electrochemical reactions are given as follows:

$$
\begin{array}{ll}
\text { Overall: } & \mathrm{ZnBr}_{2} \leftrightarrow \mathrm{Zn}+\mathrm{Br}_{2} \\
\text { Anode: } & \mathrm{Zn}^{2+}+2 \mathrm{e}-\leftrightarrow \mathrm{Zn} \\
\text { Cathode: } & 2 \mathrm{Br}^{-} \leftrightarrow \mathrm{Br}_{2}+2 \mathrm{e}^{-} \\
\text {Bromine Complex: } & \mathrm{QBr}^{-}+\mathrm{nBr}_{2} \leftrightarrow \mathrm{Q}\left(\mathrm{Br}_{2}\right) \mathrm{nBr}^{-}, \\
\text {where } \mathrm{QBr}^{-}=\text {Complexing Agent }
\end{array}
$$

The zinc/bromine battery stack contains nearly $100 \%$ plastic materials. Only a thin metal screen imbedded in the terminal electrodes is necessary to collect the electrical current in the $x$ - $y$ plane of the electrode. Plastic electrodes contain carbon for electrical conductivity and glass to minimize warpage. Separators are microporous silica filled with polyethylene. Each electrode separator is welded into a polyethylene frame that contains channels and diverters to distribute the flowing electrolyte uniformly across the face of the electrodes and separators.

Alternating electrode and separator flow frames are then vibration-welded together between glass-filled polyethylene endblocks to form a sealed battery stack. A patented endblock design was developed to maintain dimensional stability of the battery stack under pressure. The electrolyte normally flows through the battery stack under a pressure 6-8 psi, and tests have demonstrated that the burst strength of the stack is about three times that operating pressure.

The 400-kWh ABESS design is expected to be similar to the $100-\mathrm{kWh}$ stand-alone system tested previously at ZBB. It will consist of a $400-\mathrm{kWh}$ standalone system housed in a portable (approximately $8^{\prime} \times 18^{\prime} \times 20^{\prime}$ ) hazardous-materials chemical storage vault. It will contain eight battery modules, each rated at $50 \mathrm{kWh}$ for a 2 -hr discharge. Each module will consist of three 60 -cell, $2500-\mathrm{cm}^{2}$ battery stacks connected in parallel, a pair of electrolyte storage reservoirs, and an electrolyte circulation system. The system will be designed to sustain a 300-A discharge at an average of $424 \mathrm{~V}$ for $2 \mathrm{hr}$. The vault will accommodate a spill containment sump in addition to those containment provisions for each individual module.

The modules use an epoxy-coated steel frame to support their weight, with rotational molded reservoirs inserted into the structure of the frame and the three battery stacks located between the reservoirs. The reservoirs contain two 6-in. openings, fitted with caps, for filling and emptying the electrolyte. The floats, heat exchanger lines, thermocouples, and connection line between reservoirs are all located on the caps of the reservoirs. Schematics of the $50-\mathrm{kWh}$ battery module are shown in Figure 2-6 through 2-8. The plumbing and electrical lines have been left out in order to simplify the drawings.

Each reservoir accommodates a recessed sump area where the pumps are located. The anolyte reservoir will use one pump, while two pumps will be used to circulate the catholyte aqueous and complexed bromine phases. Brushless DC motors will run centrifugal pumps that are mounted in the recessed area in the reservoir. The inlets to the pumps are located below the liquid level in the reservoirs, eliminating the need to prime the pumps. Bulkhead fittings with quick disconnect fittings are used to attach the pump heads to the reservoirs. This enables rapid changing of pump heads and/or motors. The majority of the plumbing is polypropylene, which is located inside the reservoir to minimize leakage from the system. The number of exposed fittings has been minimized to improve safety.

The plumbing from the reservoirs to the stacks will be reinforced viton, which has been selected because of its flexibility and chemical resistance. The viton tubing is connected to the batteries and the reservoirs with barbed fittings and clamps.

Liquid-level sensors are located at the top of each reservoir. The analog sensors are accurate to $0.25 \mathrm{in}$. and supply data to the battery controller. The data are 


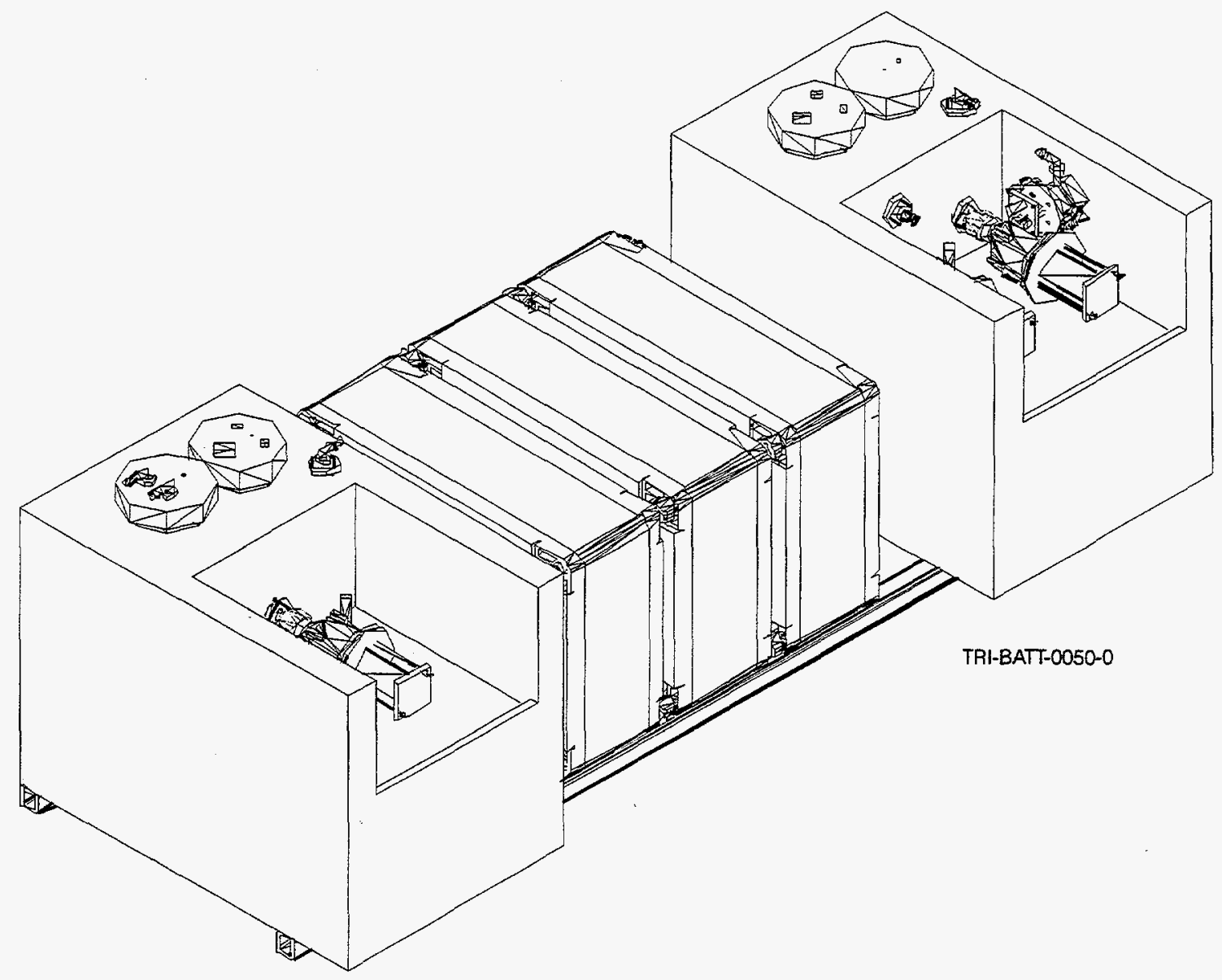

Figure 2-6. Left View Schematic of ZBB 50-kWh Battery Module (module $=98$ " length $\times 38$ " width $\times 34$ " height).

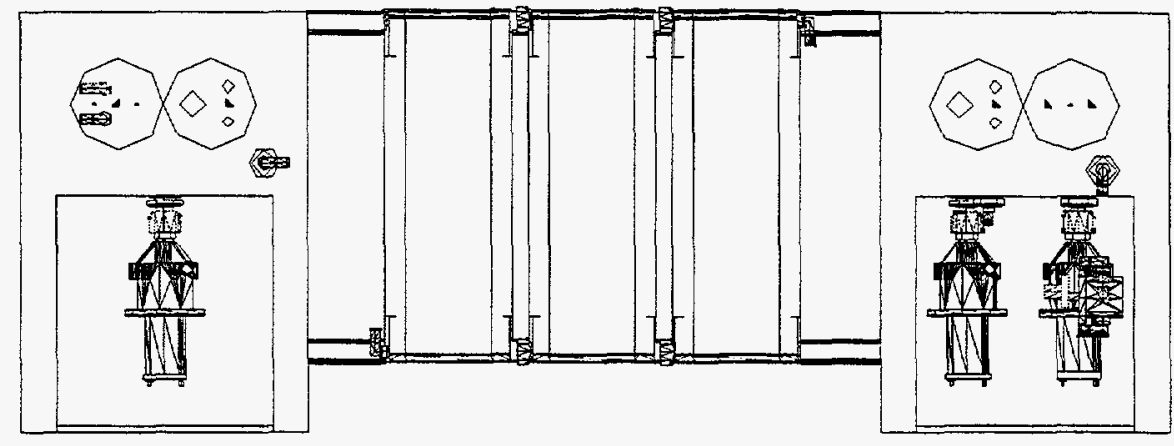

TRI-BATT-0051-0

Figure 2-7. Top View Schematic of ZBB 50-kWh Battery Module (module $=98$ " length $\times 38$ " width $\times 34$ " height). 


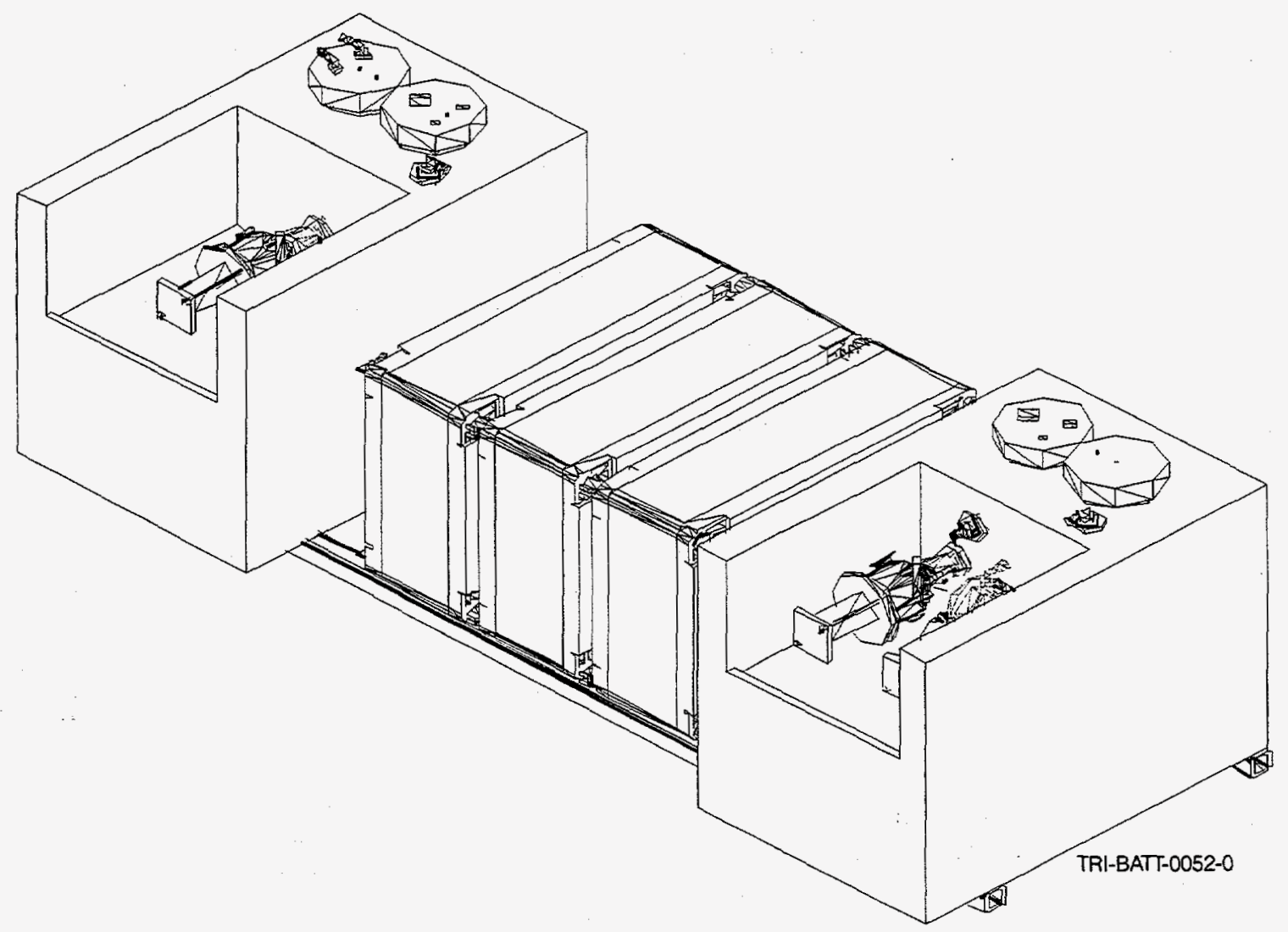

Figure 2-8. Right View Schematic of ZBB 50-kWh Battery Module (module $=98$ " length $\times 38$ " width $\times$ 34" height).

used to maintain constant electrolyte levels in each reservoir by adjusting pump speeds. Leak-sensing wires will be located in the module spill tray and in each reservoir sump area.

Forklift provisions will be made for transporting the modules. Each module will have an open-circuit voltage of $109 \mathrm{~V}$. The $400-\mathrm{kWh}$ battery system specifications are given in Table 2-1.

An internal load management system will be integrated into the battery by running all of the auxiliary equipment such as the heater, scrubber, etc., off of a 60-A circuit. Therefore, if the scrubber needs to be activated, the heater will automatically be disconnected from the circuit to maintain the 60-A load.

\section{Control Systems}

A separate programmable logic controller (PLC) will monitor and control each module. Each PLC will have $2 \mathrm{~Kb}$ of user memory and will be capable of data acquisition through a full duplex RS232C serial port. The PLCs will monitor the module voltage, stack current, pump motor currents, and electrolyte levels in the module reservoirs. The PLCs will compare the measured parameters to preset limits to determine if the battery modules are performing properly. If the measured parameters fall outside the measured norm, they will adjust variables, such as pump speed, to compensate. If the measured parameters cannot be modified, they will generate either a fault or a shutdown condition and proceed to turn off the system.

An additional PLC (system controller) will coordinate the overall operation and safety of the system. The system controller will monitor system parameters such as electrolyte temperatures, bromine and hydrogen concentrations inside the building, building temperature, ambient temperature, peripheral current, and seismic activity. If a potentially hazardous condition to the system and its surroundings are sensed by the monitoring system, the controller will completely shut down the system. Conditions that would result in a complete 
Table 2-1. 400-kWh Battery Specifications

\begin{tabular}{lcc}
\hline & Typical & Maximum \\
\hline Charge Voltage & $480 \mathrm{~V}$ & $504 \mathrm{~V}$ \\
Charge Current & $300 \mathrm{~A}$ & $450 \mathrm{~A}$ \\
Open-Circuit Voltage & $436 \mathrm{~V}$ & \\
DIscharge Current & $300 \mathrm{~A}$ & $600 \mathrm{~A}$ \\
Low-Voltage Cutoff & $240 \mathrm{~V}$ & \\
Strip-Current Cutoff & $0.5 \mathrm{~A}$ &
\end{tabular}

shutdown of the system include an electrolyte or coolant leak, high levels of bromine or hydrogen, and elevated enclosure temperature.

Software will monitor the performance of the system. The PLCs send the monitored data over RS232C serial lines to a designated personal computer. This data collected by the monitoring PLCs will be displayed on the computer screen. The information includes such parameters as module and system voltage and currents, electrolyte levels, and reservoir temperatures. This information is saved on the hard disk to be recalled at a later date and to be presented in either tabular or graphical format.

The communication and control protocol was written and demonstrated on the $100-\mathrm{kWh}$-deliverable battery system. The system software needed to operate the 400-kWh ABESS will be distributed on floppy disks that can be installed on any personal computer that meets the performance requirements necessary for the control of the system.

The initial phase of the project involves demonstrating the control of a $50-\mathrm{kWh}$ battery module. The first $50-\mathrm{kWh}$ battery module has been assembled and is being tested. In the fourth quarter, only demonstration of the control system was performed. Battery stacks that were found to have poor-quality separators and endblocks are being tested. The pump speeds that are necessary to obtain optimum battery performance are being investigated. This testing will continue after new battery stacks are inserted into the system.

In the fourth quarter, data were collected on various pump-drive configurations. Initial performance of the motors and drives will be examined by performing a two-factor designed experiment for each combination of pump heads, motors, and controllers. For each motor/ drive configuration, two factors will be varied. Adjusted values for the catholyte motor will range from a high of $1750 \mathrm{rpm}$ to a low of $1500 \mathrm{rpm}$. The second-phase motor speed will range from $1500 \mathrm{rpm}$ to $1000 \mathrm{rpm}$. The responses observed during these tests will include:

- Pressure

- Efficiencies

- Motor Currents

- Controller Currents

From these tests, information will be used to determine which combination of motors, pumps, and controllers is the most efficient. Also, the effect of motor speed on battery performance can be examined.

The software interface of the $50-\mathrm{kWh}$ module has been developed, and data acquisition on the module has been initiated. The voltage readings are accurate on the higher end to $0.1 \mathrm{~V} \pm 0.5 \mathrm{~V}$. The temperature readings are within two degrees at the extremes, but improving the reliability of the current sensors is being investigated. The use of set value resistors, in place of the potentiometer, and adjustment of the sensor values in the software are being examined. An example of voltage and currents profiles for a 50-kWh module using the data collection software is given in Figure 2-9. The variation of the currents during discharge is due to the variable quality of the individual stacks. Work continues to define the various signal interactions from the PCS and the interaction of the control signals. Also under investigation is finding a way to delay start-up of one of the electrolyte pumps so that the peak draw on the system is minimal upon start-up. 


\section{Other Components}

In the fourth quarter, components, such as floats and cabling, were ordered. The motor controller was not yet selected, so the acquisition of the transformer was pending. The motor controllers were scheduled for examination in early FY98.

ESS program staff are examining PCS specifications and data sheets from PCS system providers for the 400-kWh system. A new PCS will, most likely, need to be a stock configuration or it will exceed the budget.

During the initial operation of the 50-kWh module, it was noted that the platform portion of the reservoirs, on which the pumps and motors rest, deflected approximately $1 \mathrm{in}$. due to the internal pressure of the fluid. The manufacturer was notified of this problem, and to reduce this deffection the reservoirs will be made with a thicker wall, and a rib pattern will be installed to a portion of the mold to add strength. These mold modifications were expected to be complete in early FY98.

In addition to the problems associated with the reservoirs, warpage of the endblocks for the battery stacks was observed. Extensive modifications have been made on the endblock base mold to minimize deflection and reduce shrinkage in the part. Additionally, modifica- tions were also made to decrease component cycle time and mold installation time. Several cooling fixtures will also be made to reduce the stress in the endblock base. These modifications are expected to be completed early in FY98. Minor changes have also been made in the flow frame in an effort to reduce cycle time, reduce scrap, and improve component quality.

A program has been initiated to develop and improve separator materials for zinc/bromine batteries. Efforts are being made to develop materials that perform well in the battery. The material that was previously used is no longer being manufactured, so an alternative material is being sought.

One separator material had worked fairly well in the batteries. One battery, Serial No. V1-87, which was tested by ZBB, completed over 500 cycles. Also, a ZBB battery presently on test, Serial No. V1-98, has completed 118 cycles and is still performing at $88.0 \%$ coulombic efficiency, $84.7 \%$ voltaic efficiency, and $74.5 \%$ energy efficiency. A plot of cycle efficiencies for ZBB battery Serial No. V1-98 is given in Figure 2-10.

A number of uncycled separator samples, manufactured by one vendor, gave very low diffusion results but did not perform particularly well in a battery. The efficiencies for each battery are given in Table 2-2. It can

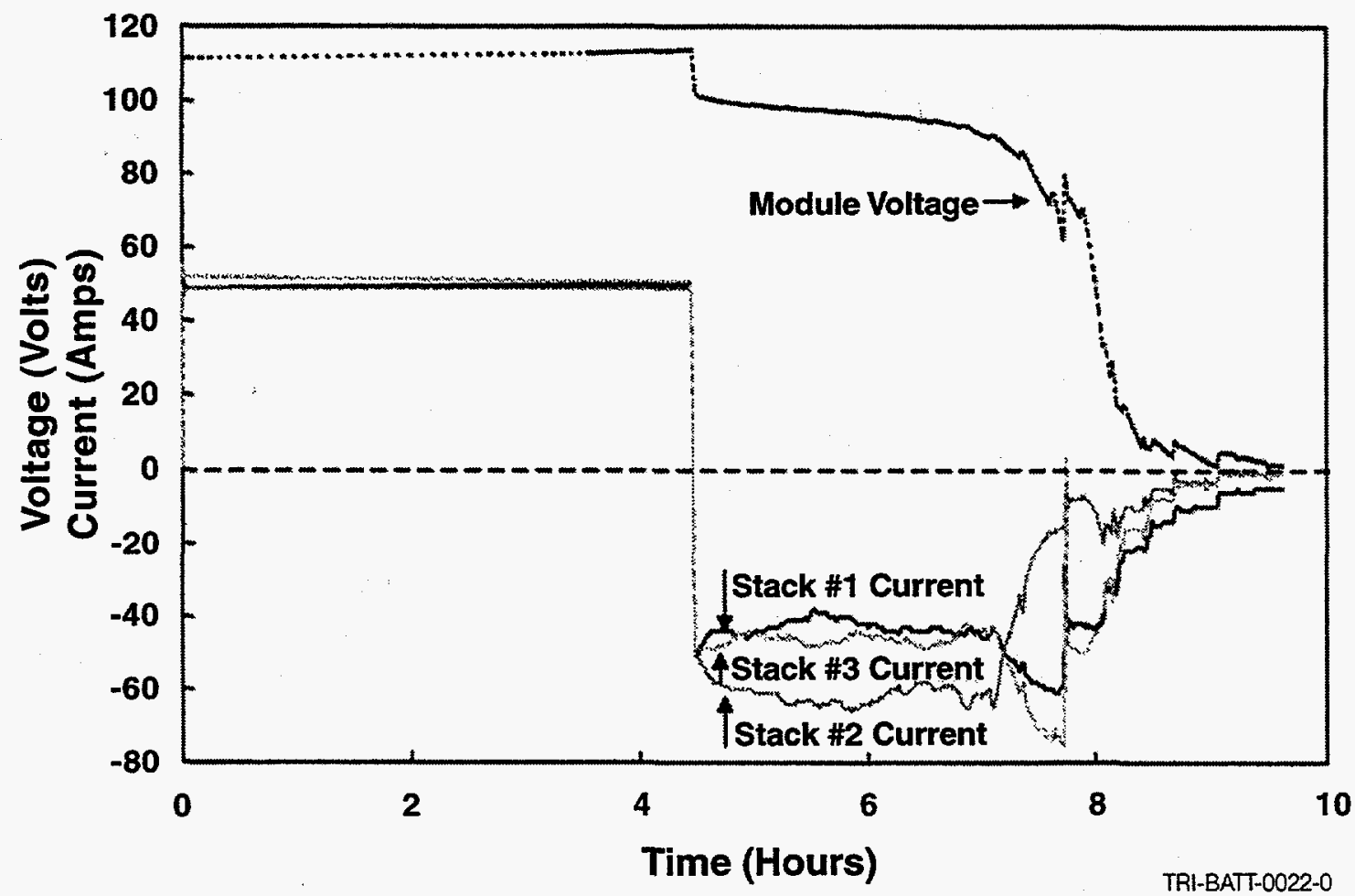

Figure 2-9. 50-kWh Module Data Collection Profiles. 


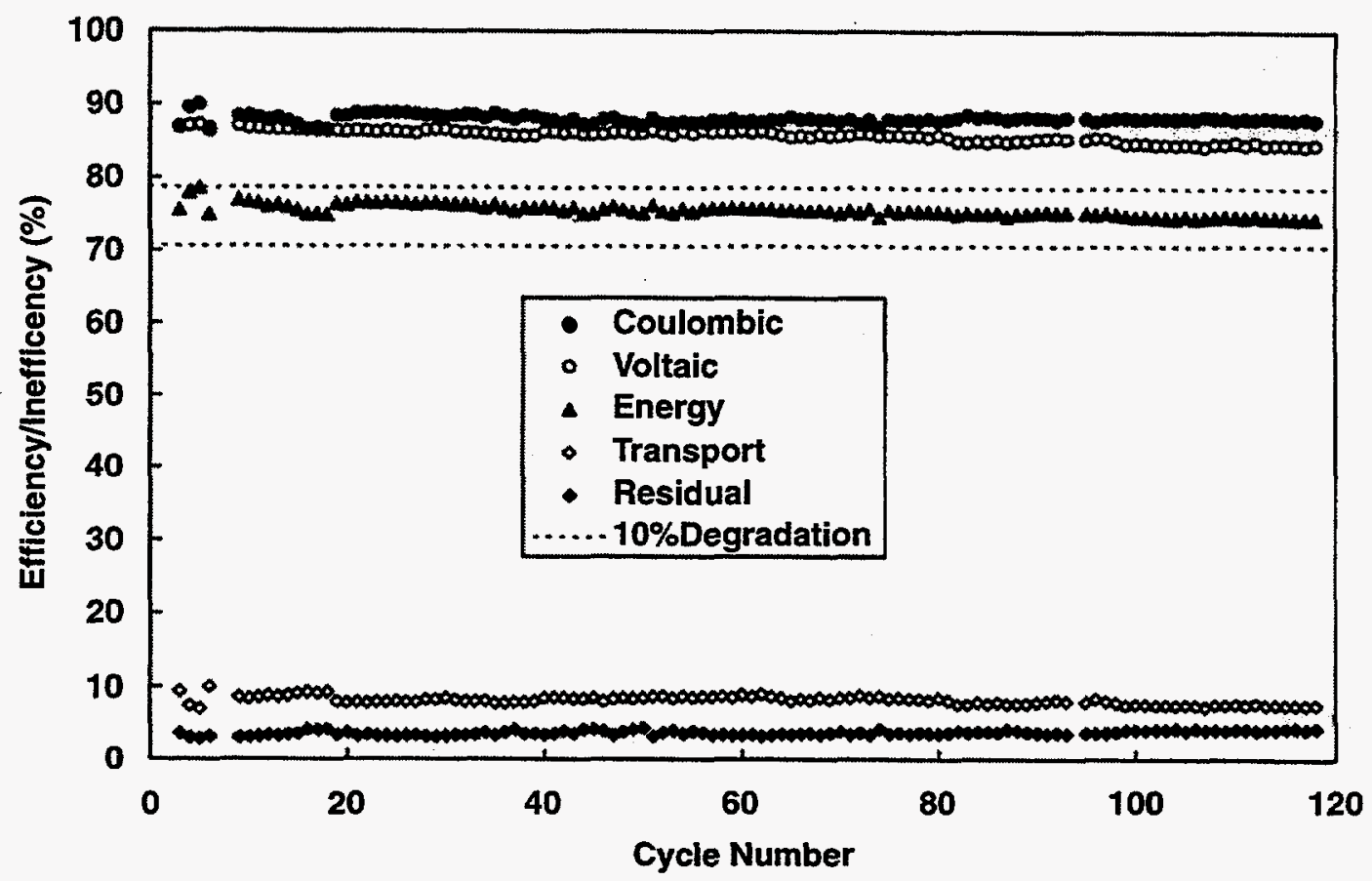

TRI-BATT-0023-0

Figure 2-10. Cycle Efficiencies for ZBB Battery Serial No. V1-98.

Table 2-2. Performance of Recent Battery Separator Samples

\begin{tabular}{lccccc}
\hline $\begin{array}{c}\text { Battery } \\
\text { Serial No. }\end{array}$ & $\begin{array}{c}\text { Separator } \\
\text { Sample }\end{array}$ & $\begin{array}{c}\text { Uncycled } \\
\text { Normalized } \\
\text { Bromine } \\
\text { Diffusion* }\end{array}$ & $\begin{array}{c}\text { Number of } \\
\text { Cycles }\end{array}$ & $\begin{array}{c}\text { Energy } \\
\text { Efficiency } \\
\text { (Peak) }\end{array}$ & $\begin{array}{c}\text { Energy } \\
\text { Efficiency } \\
\text { (Last Cycle) }\end{array}$ \\
\hline V1-92 & 0620 & 0.68 & 76 & $72.4 \%$ & $66.6 \%$ \\
V1-93 & 0621 & 0.30 & 137 & $77.2 \%$ & $64.9 \%$ \\
V1-94 & 0622 & 0.28 & 8 & $70.7 \%$ & $70.7 \%$ \\
V1-95 & 0620 & 0.68 & 1 & $72.2 \%$ & $72.7 \%$ \\
V1-96 & 0621 & 0.30 & 37 & $71.3 \%$ & $67.8 \%$ \\
V1-97 & 0622 & 0.28 & 118 & $76.5 \%$ & $61.6 \%$ \\
V1-99 & $\mathrm{A}$ & 0.45 & 36 & $71.1 \%$ & $67.5 \%$ \\
V1-100 & $\mathrm{B}$ & 0.24 & 14 & $71.8 \%$ & $70.2 \%$
\end{tabular}

*Bromine diffusion results were normalized for diffusion rate and thickness to a standard. 
be seen that some of the materials performed well initially, but performance dropped off rapidly as the cycling progressed. The cycle performance of one of these batteries, Serial No. V1-97, can be seen in Figure 2-11. This battery demonstrated a decline in performance over time, which can be attributed to a significant increase in transport inefficiency. Reasons for the rapid decline in performance are being investigated. The goal of the work in this area is to develop a battery separator that performs well but does not demonstrate a rapid decline in performance.

ZBB battery Serial No. V1-97 was cut apart, and a piece of the separator material was compared to the vir- gin material, Serial No. 0622, for bromine diffusion. The results of these diffusion tests are shown in Table 2-3. The bromine diffusion values were normalized to a standard for diffusion rate and thickness. The results in Table 2-3 indicate that the cycled battery separator has a much higher rate of bromine diffusion than the virgin material (different sample other than that shown in Table 2-2). The large increase in bromine diffusion rate for the cycled 0622 battery separator corresponds to an increase in transport inefficiency from $8.3 \%$ initially to $22.4 \%$ after 118 cycles for battery V1-97.

An in-depth analysis of the standard material, which is no longer being manufactured, and the type-M

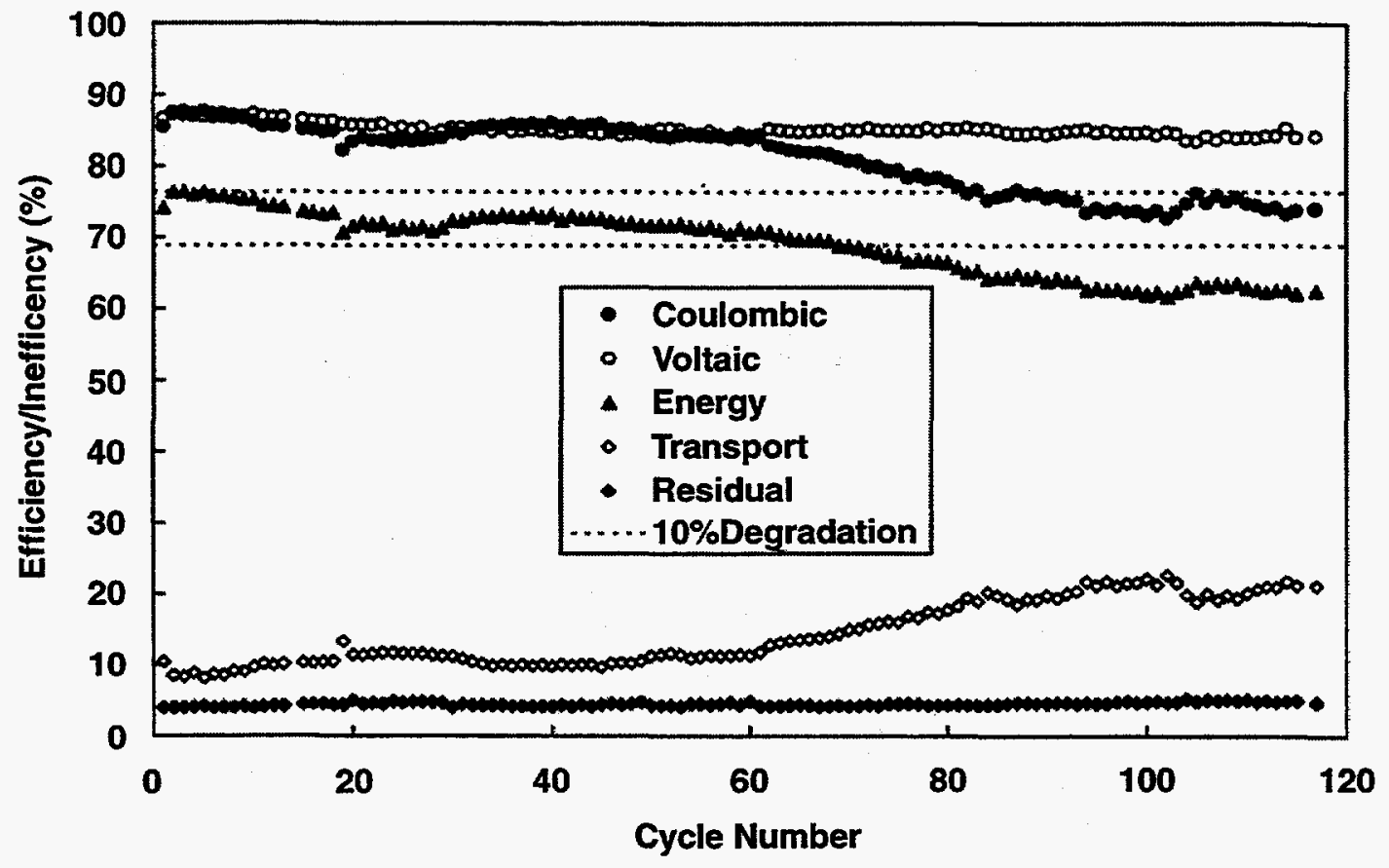

Figure 2-11. Cycle Efficiencies for ZBB Battery Serial No. V1-97.

Table 2-3. Bromine Diffusion of Cycled and Uncycled ZBB Battery Separators

\begin{tabular}{lc}
\hline \multicolumn{1}{c}{ Separator Sample } & Normalized Diffusion \\
\hline 0622 (uncycled) & 0.74 \\
0622 from Serial No. V1-97 (118 cycles) & 2.02
\end{tabular}


separator is currently in progress. Attempts are being made to determine the reason that these two materials perform better than others do. Separator $M$ is considered to be a possible material for the $400-\mathrm{kWh}$ battery, but a vendor for separator material still needs to be qualified.

\section{Renewable Generation and Storage and Related Projects}

\section{RGS Project}

A new initiative for FY97 and beyond is the RGS Project. This project is envisioned as encompassing the investigation of modular, integrated RGS systems capable of control by utilities and other electricity suppliers. The RGS project includes wind and PV generation options.

An integrated RGS system will provide a new option for the utilization of renewable generation. At present, renewable systems have typically been siteintegrated, that is, components have been specified and purchased by a designer or an architecture and engineering firm and then assembled at the final site. System integration using this approach may not always result in the lowest cost or most reliable system. In the case of several recent utility battery demonstrations, site integration has caused significant start-up problems because of control interface mismatches, low battery SOC resulting from prolonged storage without a charge, and power electronics failures. There are several examples of renewable systems that have been site-integrated that have had similar experiences.

In addition, utilities have traditionally not given a high capacity credit to renewable systems. This is because of the intermittent nature of most renewable generation and the inherent inability to dispatch such energy by the utility. An integrated, modular renewable system with storage can address many of these issues and thereby greatly increase the environmental and economic benefits of renewable technologies. An RGS system may cost-effectively increase the stability of power from intermittent and fluctuating renewable resources and provide energy upon demand when the utility needs it the most, regardless of the availability of the renewable resource at that time.

The RGS project is anticipated to be a multiyear effort competitively placed with an industry team that consists of a systems integrator, component manufacturers, and at least one host for testing. The RGS project will be cost-shared by the industry team at about the $50 \%$ level.

In FY97, a conceptual plan for the RGS project was developed. The full support of all relevant DOE organizations and stakeholders was pursued.

Projects related to the RGS initiative include furthering cooperative relationships with renewable (PV and wind) programs at SNL and NREL. These programs utilize batteries in many of their laboratory and field experiments and have expressed interest in having technical contact with the ESS Program. One ESS staff member is partially supported by the SNL PV Program and contributes to several PV projects involving batteries. A seminar was held at NREL's National Wind Technology Center (NWTC) on batteries. All of these interactions are leading to increased collaboration on renewable technologies and storage among the national laboratories and will reduce duplication of effort and result in improved RGS systems.

It was the mutual intention of the ESS Program and PV group to expand this collaboration effort in FY 97 by jointly sponsoring a testing and analysis effort for large batteries that are used in off-grid PV systems. This project consisted of the joint development of a program to define requirements and collect and analyze data from large batteries that are currently in use with large PV arrays in the U.S. The data will be collected and analyzed to verify the proper management of batteries used in these systems and will be stored in a database. As this database grows, it will become the primary experience reference source for large batteries used in PV applications.

\section{Status}

\section{RGS Project Status}

On September 30, 1997, a meeting was held in conjunction with the IEEE PV Specialists Conference to gather industry feedback on the needs for storage in PV energy systems. The ESS Program, in coordination with the DOE PV Program, sponsored the meeting to describe the ESS Program to the PV community and introduce the RGS project concept of a factory-integrated, turnkey, modular PV energy system that includes storage.

The meeting attracted over 25 attendees, including representatives from PV system integrators, a battery manufacturer, national laboratories, research and trade associations, and the DoD and DOE. A key point made by industry was that education of the PV and battery communities was critical to successful system integra- 
tion. Some of the information needed includes performance data, charging information, and operating and maintenance instructions. Some attendees suggested more research be done on the storage components (e.g., batteries, flywheels). There was consensus that any system development project undertaken must be market driven.

Many diverse opinions were expressed as to whether a RGS development project should be performed by DOE. One suggestion was for multiple awards to be made to industry to field its best integrated PV and storage systems and characterize the performance, with the best system after $1 \mathrm{yr}$ receiving an award for more R\&D. Such an approach would address several issues, including remote data acquisition and monitoring capabilities, accumulating reliability data for mean time to failure estimates, and providing the industry with objective performance testing. It was agreed that any RGS project will be fully coordinated with ongoing PV Program activities in PVMat, PV Bonus, and Team-Up. The feedback from this group was to be analyzed and combined with feedback from a storage industry group meeting to be held in first quarter of FY98. An approach to implementing the RGS project will then be determined.

In January 1997, ESS Program staff visited NREL to exchange information on battery technology issues for the RGS project. More than 10 NREL staff members attended and discussed a variety of battery technology problems and questions. Areas of mutual interest involved battery characterization testing, standardized test procedures, the need for models of battery performance and life, and sharing of data and project results. Both groups committed to follow up with specific task ideas, a visit to SNL, and increased data and project communications.

In February 1997, Sentech staff attended the IEEE Power Engineering Society meeting. The IEEE has four main committees, one of which is the Energy Development and Power Generation Committee. One of the subcommittees within this committee is the Energy Development Subcommittee. The Storage and Indirect Renewable Technologies group is one of several working groups within the subcommittee and includes a representative from the DOE ESS Program. The working group met as part of the IEEE winter meeting in New York City on February 3-5, 1997. The general sessions had presentations from Federal Energy Regulatory Commission, the North American Electric Reliability Council, system designers, power marketers trading electricity futures and options, and experts on smart metering and electricity pricing. The Storage and Indirect Renewable Technologies working group met with approximately 12 of the members present. Discussions ranged from the ruling of New England regulators on the need for each utility to invest money in renewable generation, to the drafting of a standard for connecting fuel cells to the electric grid. The Chair and members of the working group were interested in establishing a relationship with the ESS Program and the ESA.

On May 22, 1997, a member of SNL's ESS Program staff conducted a battery seminar and workshop for more than 45 NREL staff members at the NWTC. NREL staff attending included representatives from the three major NREL program areas that specify and use battery energy storage in their systems: Transportation, Wind, and PVs. Seminar topics covered included battery fundamentals, battery system management, failure mechanisms, issues to be addressed when specifying and integrating particular battery technologies for remote or minimal maintenance systems, and lessons learned from large batteries used in utility applications.

During the workshop, members from each of the NREL groups and the SNL PV group made presentations on current projects in battery testing and evaluation and reviewed energy storage problems that need to be resolved to increase reliability in fielded renewable systems. The seminar participants suggested that SNL ESS staff increase their participation and assistance in both the testing and evaluation of batteries currently fielded or under consideration by NREL renewable groups. The increase in interactions of the NREL and SNL staff in energy storage was endorsed by the workshop participants.

PV project participants are currently defining an area where the ESS Program can provide the greatest input to PV storage needs and battery system management. Initial concepts include the verification of VRLA gel testing results by operating VRLA gel batteries for more than 80 cycles between $40 \%$ and $80 \%$ SOC and then fully charging, capacity testing, and equalizing them before resuming intermediate SOC cycling. If VRLA gel batteries can indeed operate in this mode, the result would be major changes in the way batteries are implemented in PV and wind/hybrid systems. This test is being strongly considered for use in the joint PV storage project.

On August 5-6, 1997, SNL staff from the ESS Program attended the Photovoltaic Reliability workshop in Las Cruces, New Mexico. Presentations were made on system, component and storage subsystem sizing, performance, and reliability. In spite of record PV module production, systems in the field are still considered to be alpha or beta units, and consequently system reliability is not at expected levels. Inconsistent system rating pro- 
cedures among system suppliers are also resulting in lower than anticipated performance. A number of standards initiatives are addressing this issue. The PV modules were judged, in general, to be the most reliable part of the system. Inverters were believed to be rather unreliable, and intense discussion considered the relative performance of the various inverter suppliers. Battery storage issues were considered, with ground faults, leakage, and battery container materials issues being significant concerns. A major issue, raised by a battery manufacturer, was the lack of communication and experience in the PV-battery system design process. To address these issues, additional collaboration between SNL ESS staff and the NCPV and the DOE Wind Program will be pursued. Furthermore, the value of factory-integrated RGS systems as proposed by the ESS Program appear to have the potential to greatly improve PV power system performance and reliability.

\section{System Field Evaluations}

Evaluation of hardware that incorporates prototype designs is being performed in this part of the program. This activity involves the detailed characterization of performance, maintenance requirements, and reliability (service life) of integrated systems at relevant sites. Once the usefulness of these designs is demonstrated, private industry will take responsibility for completing the final commercial product phase of engineering development.

\section{AC Battery PM250 Field Evaluation}

The AC Battery PM250 was assembled and factory tested in 1993 under a contract with Omnion Power Engineering Corporation of East Troy, Wisconsin. In October 1993, the PM250 began field testing at the PG\&E MGTF in San Ramon, California. After approximately 100 deep-cycle discharges, field testing ended. The unit remained idle at the MGTF until late 1995 when it was returned to AC Battery Corporation for retrofit of the battery complement and correction of problems identified in field testing. Following completion of the retrofit and factory checkout in FY97, additional field testing of the PM250 unit will be conducted in an operational environment that is currently being identified.

\section{Status}

Final refurbishment activities were completed early in October 1996, and final factory testing was accom- plished for the fully operational system. Some minor unrelated hardware problems that were traced to assembly procedures were discovered and corrected in several modules. Delays in full-power testing were experienced as the AC Battery Corporation assembly plant electric service was updated to allow the PM250 to charge and discharge at the rated capacities required for future PM250 production and testing. Following completion of the upgrade by the local utility, the PM250 was tested at full power and taken through its paces for long-term cycling applications.

In mid-November 1996, a meeting of the PM250 Test Team was called and the status of the test pad at the PG\&E MGTF was thoroughly discussed. The pad was being occupied by the PG\&E $P Q 2000$ prototype while the prototype underwent field testing. Scheduled removal of the $\mathrm{PQ} 2000$ from the pad was postponed to early 1997. A consensus was reached that the PM250 should begin cycle operations, as defined for the MGTF test program, as soon as the FAT was completed and the PM250 declared ready for cycle testing. AC Battery agreed to begin cycle testing at its facility while waiting for instructions for shipment to the MGTF. The test team also agreed that the purpose of the test was to evaluate system operations and not the batteries, as the batteries are not the specified production battery for future PM250 systems.

In late November 1996, the FAT was conducted at the AC Battery facilities in East Troy, Wisconsin. The purpose of the FAT was to test the AC Battery PM250 prototype in preparation for resumption of cycle testing. The test consisted of verifying that all safety functions were operating properly and establishing a baseline capacity prior to shipping. Following completion of the FAT and baseline capacity testing, two major problems were noted that involved over-temperatures in one module and synchronization faults in a second module. Cycle testing was to begin at the AC Battery facilities immediately after the problems were corrected.

In early January 1997, all problems noted during the FAT were resolved. The system only marginally met capacity specifications, as several batteries were in failure in two modules. Operations conducted during the debug phase following the FAT yielded information that showed that many batteries were marginally acceptable. Consequently, if testing of the PM250 was to proceed at specified power levels, it was necessary to replace the complement of AES 2010 batteries with Delco 2000 units. Proceeding with the replacement, however, depended on the application that was to be identified for continuation of the PM250 test program. $R \& D$ testing was stopped. 
With the cancellation of all R\&D testing and the shutdown of the PG\&E MGTF, a new application for the PM250 was sought. AC Battery identified two projects that could utilize the PM250.

The first application was identified in Chicago on the ComEd grid. A peak-shaving requirement for $50 \mathrm{~kW}$ for a 2 -hr peak was proposed by ComEd to support a sharp daily peak at a local foundry. AC Battery and SNL staff briefed the ComEd R\&D group in midFebruary 1997, describing the functionality of the PM250 and discussing the level of cost share needed. ComEd committed to complete its evaluation of a BESS for peak shaving at the foundry. The PM250 is capable of supporting the peak-shaving requirement at the foundry; however, a test program of 12 to 24 mo would have been adequate to prove the benefit of the BESS for peak-shaving applications.

In early April 1997, ComEd withdrew its support for the project, stating that there was no economic benefit to be realized in the peak-shaving demonstration application. The decision was based on the estimated cost of approximately $\$ 60,000$ for site preparation, transportation of the PM250 to Chicago, and installation of the PM250 at the site. The PM250 would have been on loan to ComEd for the duration of the 2-yr demonstration project and savings for the peak-shaving application were estimated at only about $\$ 15,000 / y r$. Thus, with a 2-yr demonstration, costs outweighed the savings.

The second possible application was a voltage/frequency controller needed to stiffen a wind hybrid system installed at a DoD communications facility on Ascension Island in the South Atlantic. The PM250 would eliminate the need for an on-line diesel genset to stabilize power generated from four wind turbine systems recently installed on the island. Initial analysis indicated that it would require two PM250 units to support the loads in a voltage/frequency regulation mode. The diesel gensets are used to stiffen the local grid when variations in the wind resource (which drives the wind turbine generators) cause voltage/frequency regulation problems. AC Battery is actively involved in the analysis of the problem and is attempting to ascertain whether the PM250 can solve it.

In mid-July, AC Battery Corporation was contacted by Interface, Inc. with a proposal to integrate the PM250 with a $100-\mathrm{kW}$ PV array at Interface's Bently Mills plant at the City of Industry in the Los Angeles area. Interface is interested in a green solution for a peakshaving application and the PM250 and PV source meet requirements. AC Battery requested that Applied Energy Group, Inc. (AEG), of Hauppauge, New York, assume responsibilities for coordinating the effort. The project is planned to be heavily cost-shared, with SNL providing the PM250 for a 5-yr operational period. At the end of the 5-yr period, AEG would be responsible for disposing of the PM250. Overall cost of the project is estimated at $\$ 1.1 \mathrm{M}$. Negotiations continued throughout the fourth quarter of FY97.

The PM250 will continue to be stored at the AC Battery facilities. If appropriate, SNL will initiate a contract with AEG to upgrade the PM250 modules with Delphi absorbed glass mat (AGM) VRLA batteries prior to moving the unit to the Bently Mills site. The retrofit will increase the PM250 container rating to $250 \mathrm{~kW}$, $300 \mathrm{kWh}$ at the 8 -hr rate.

\section{Field Test of Final GNB VRLA Battery Deliverable}

As the final deliverable from its VRLA battery development contract, GNB furnished a battery that is capable of providing approximately $250 \mathrm{~kW} / 500 \mathrm{kWh}$ for a field test. The site selected for this test was the GNB lead recycling center in Vernon, California, and a new contract was placed with GNB at the beginning of FY96 to carry out the field testing. GNB has installed a battery system at the recycling center to support critical plant loads during utility power outages so that violations of air emission standards are very unlikely. The total system is capable of providing $3.5 \mathrm{MW}$ of power to the plant for $1 \mathrm{hr}$ and a peak power of $5 \mathrm{MW}$ for $10 \mathrm{sec}$. The battery consists of two parallel strings of GNB ABSOLYTE IIP type 100A99 VRLA cells. Each string contains 378 modules (three cells per module) operating at a nominal $756 \mathrm{~V} \mathrm{DC}$. Battery energy is converted to plant $A C$ voltage via three $G E$ power conversion units, each rated at $1.25 \mathrm{MW}$. The battery is also available for periodic block loading to reduce plant peak loads and utility demand charges. Operation of this system will provide an opportunity to evaluate the performance of a large VRLA battery while it is being used in an actual field application. Approximately $10 \%$ of the battery cells at Vernon were supplied by the ESS Program.

A remote communications link has been established between the Vernon site and GNB's engineering laboratories in Lombard, Illinois. This communications link makes it possible to monitor from a remote terminal all status screens of the control system, including battery status and SOC, plant power requirements, status of the power equipment, whether peak shaving is active or inactive, and alarm conditions. The data presented by the battery monitor screens include battery voltage, battery current, battery temperature, and ambient temperature. It is possible to manipulate BESS parameters so as 
to activate peak shaving, initiate an equalization charge, or perform a discharge test; this can be done remotely or locally.

\section{Status}

In early FY97, the BESS was operated at partial capability due to several occurrences that prevented the system from being on line for continuous peak shaving operation, although backup power was available for a majority of this time. These occurrences included a system trip because of a ground fault occurrence and an outage that arose from damage to some of the inverter circuit boards from work done at the local substation. Because of these incidents, the battery could not perform as planned the power reliability and peak-shaving functions that had been started in previous months. In order to determine the economic benefit from the peakshaving function, the BESS must be operated consistently throughout the electric utility's billing cycle. Any interruption in peak shaving operations of the battery causes billing to revert to the normal peak-power demand basis of calculation, which is then applied over the entire billing cycle. In spite of the incidents preventing continuous operation during early FY97, the BESS was available to support the Vernon recycling facility during power interruptions. Several minor power out- ages were recorded, but none of them lasted long enough to cause a deep discharge of the battery.

An equalization of both battery strings was performed early in FY97, and during the equalization, several ground fault alarms were noted in both strings. After the equalization charge was completed, the system was placed in standby mode, and local GNB service personnel were assigned to locate and correct the ground faults. This was a difficult task because the ground faults appeared to move around the string as connections were broken while trying to isolate the faults. Finally, a decision was made to disassemble and clean at least one entire battery string, pressure-test each cell, and remove any questionable cells from the circuit.

One factor believed to have contributed to corrosion of the BESS hardware was the extremely wet conditions at the Vernon site during installation of the battery. While the BESS building was nearing completion, cells, in their accompanying trays, were stored on the dock area pavement just outside the BESS building. To minimize exposure to the elements, all cell pallets were covered with plastic tarps. However, relentless rain and slow drainage flooded the dock area and immersed all cell pallets in up to 6 in. of water. Several pallets were also exposed to moisture because of high winds. Figure 2-12 shows preinstallation flooding in the battery stag-

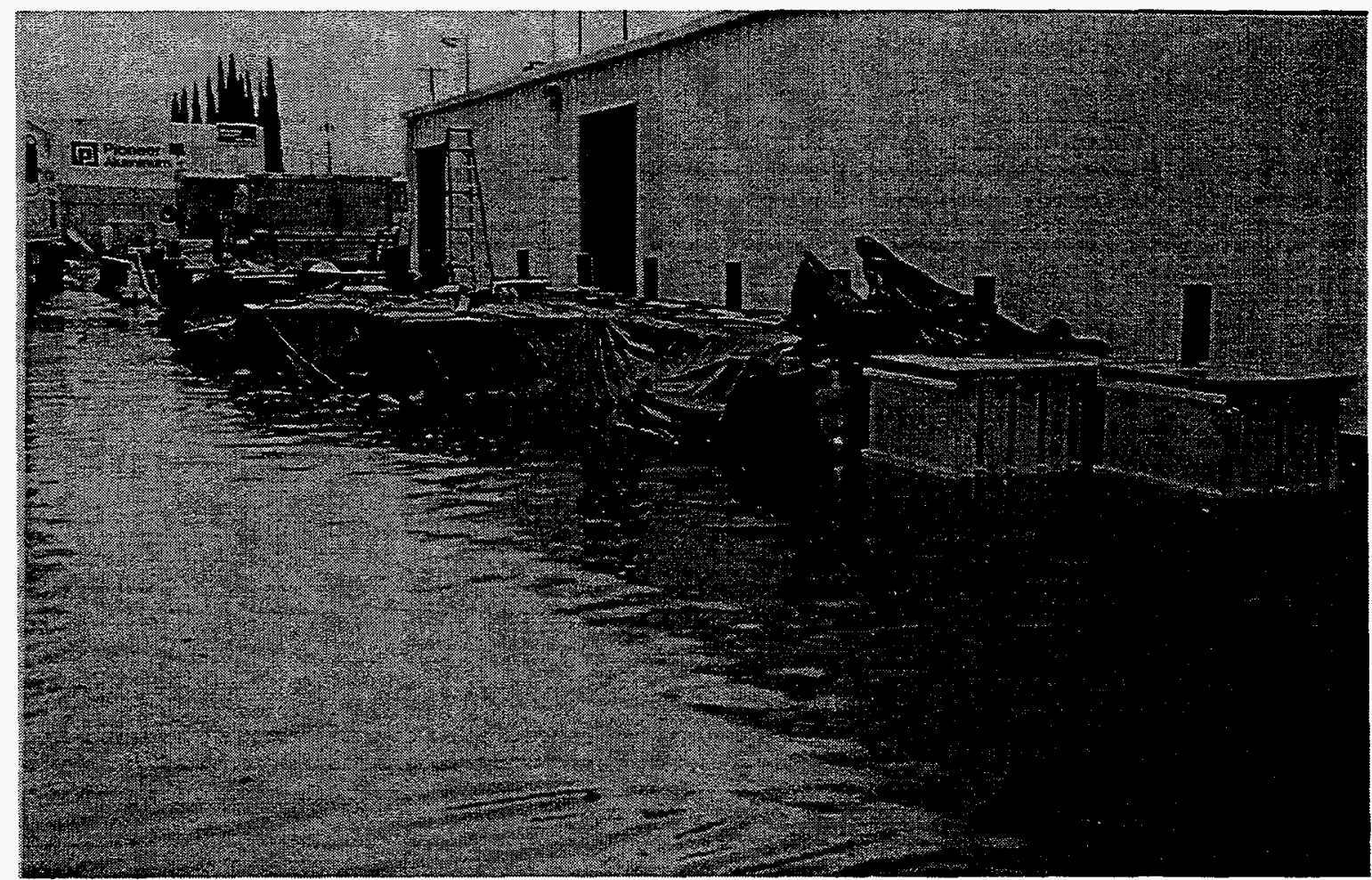

TRI-BATT-0053-0

Figure 2-12. Preinstallation Flooding in Battery Staging Area. 
ing area. Water puddling on top of and underneath one of the battery trays can be seen in Figure 2-13.

The BESS underwent extensive restoration during the second quarter and part of the third. String No. 2 did not exhibit the excessive leaking and corrosion/rusting that String No. 1 did; a decision was made to leave String No. 1 off line and place emphasis on getting String No. 2 on line as soon as possible. Only a handful of cells (eight) were replaced on String No. 2, and corrosion/rust spots were less frequent. Work on String No. 2 was completed by the end of January 1997 . It was then placed back on line and provided half of the rated backup power capabilities.

String No. 1 was highly problematic. Cells overfilled with electrolyte during manufacturing (causing significant amounts of electrolyte to expel during recharge) and flooding of the BESS hut after installation (causing additional corrosion/rust to the lower portion of each battery string as shown in Figure 2-14) resulted in extensive man-hours being required to bring the string to a reliable state of operation. Over 70 cells were replaced in String No. 1, as were eight metal trays. Corrosion/rust spots were common, and the ground fault detection wiring was examined closely for defective connections.
The questionable cells removed from the Vernon BESS were returned to the GNB manufacturing facilities in Fort Smith, Arkansas, for analysis. A plan was also established to locate several spare cells at the Vernon site and to maintain them at a fully charged condition by continuous float charging. This would expedite the removal and replacement of defective cells and avoid the shutdown of a battery string for an extended period of time.

By mid-May 1997, 12 cells of the same type used in the BESS (ABSOLYTE IIP, 100A99 cells) were installed next to the BESS battery to act as a bank of new fully charged cells, in the event that BESS cells needed replacing. Both strings were back on line and in "BESS-Ready" mode by the end of May 1997. In addition, the underlying floor of the entire battery area was cleaned and repainted, repairing any damage caused by electrolyte leakage and corrosion/rust spots.

The BESS was monitored closely throughout June to determine the success of the restoration. No ground fault alarms occurred and the BESS appeared ready for resumption of peak-shaving operation, which was scheduled for July 1, 1997. Figure 2-15 shows the completed battery room.

In the fourth quarter of FY97, ESS Program staff met with GNB engineering personnel to review test data

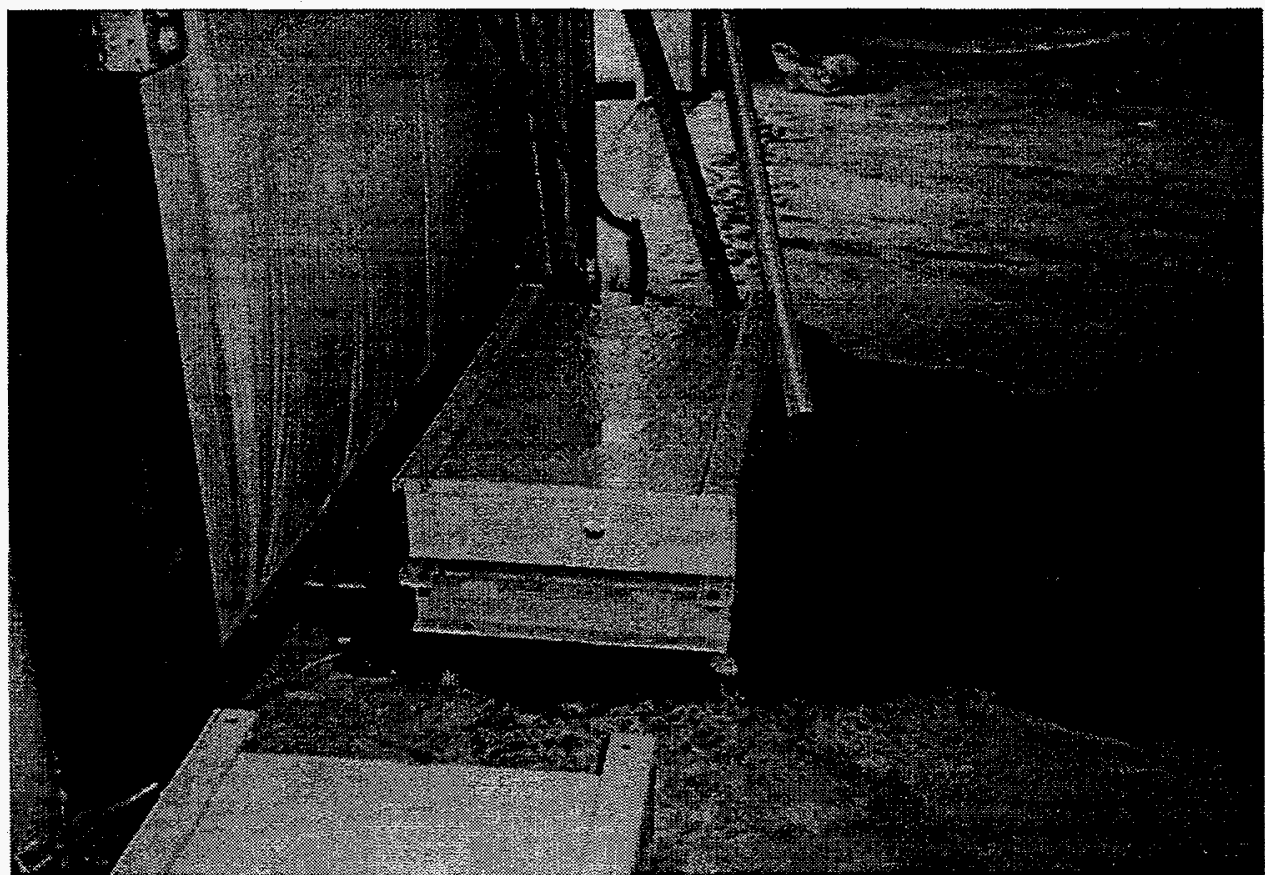

TRI-BATT-0054-0

Figure 2-13. Tray Sitting in a Pool of Water with Water Collecting on Top of Tray. 


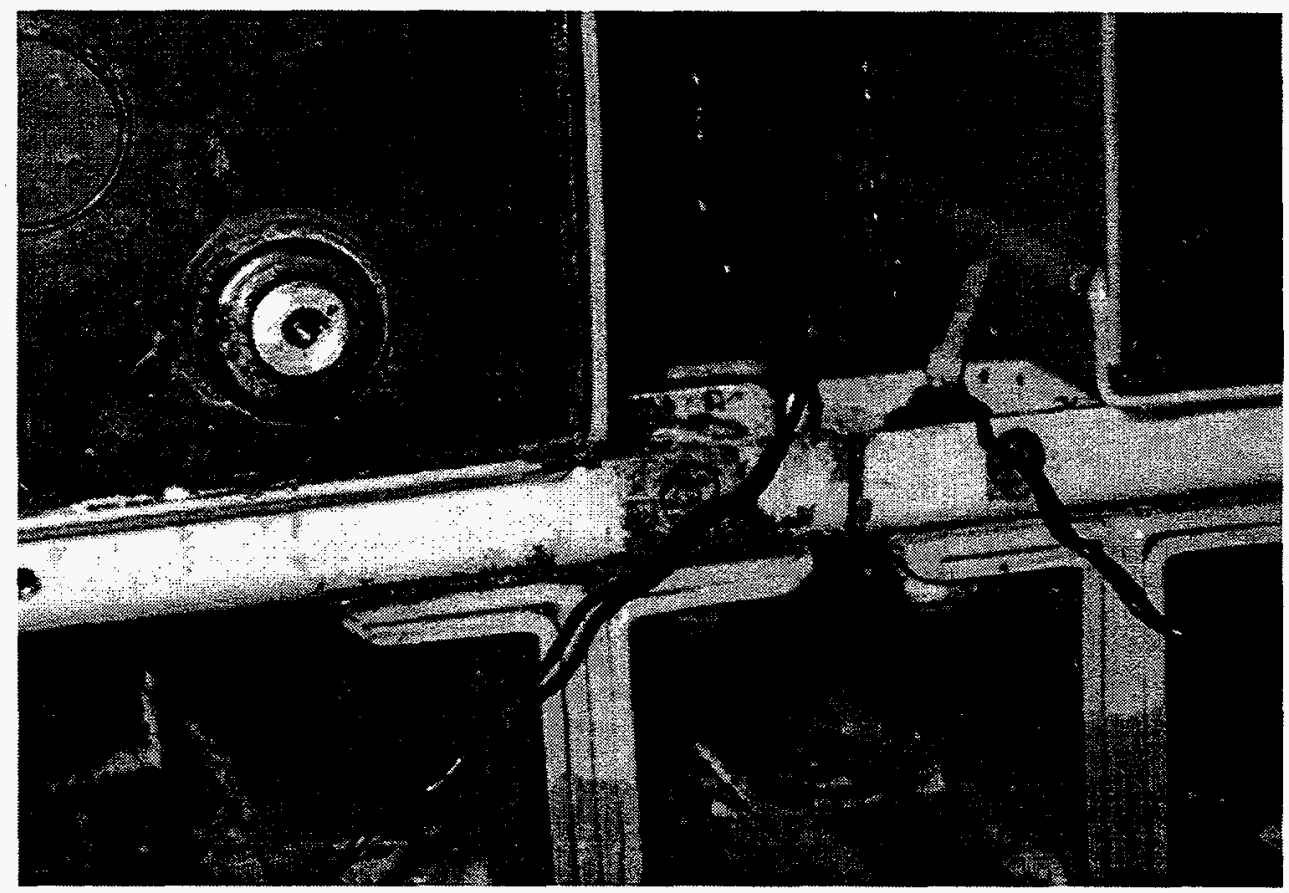

TRI-BATT-0055-0

Figure 2-14. Corrosion of Battery Trays and Support Structure.

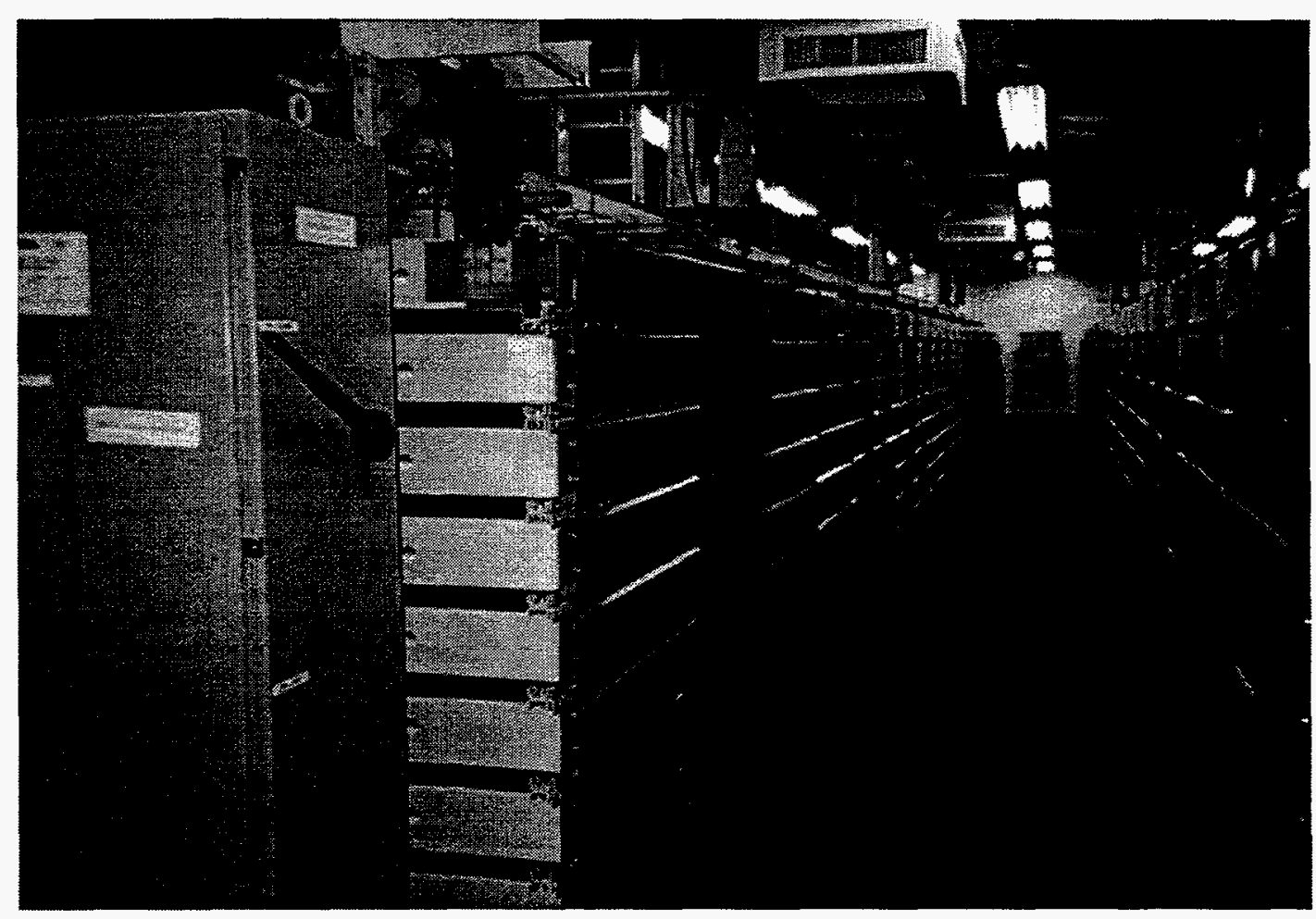

TRI-BATT-0017-0

Figure 2-15. Completed Vernon Facility Battery Room. 
on GNB products, discuss battery reliability initiatives, and review new product developments by GNB. Strategies for collecting battery performance data during the load peak-shaving mode of operation were also discussed.

Since July 1997, active peak shaving was initiated on the BESS in order to determine an approximate peak shaving level (or trigger level) at which the BESS provides maximum peak shaving output and cost savings while not becoming the primary power source. During peak shaving periods, the BESS is able to deplete up to 50 percent battery capacity while the remaining 50 percent is dedicated specifically to UPS backup power.

In the beginning months of peak shaving, JulyAugust 1997, the trigger level (expressed in $\mathrm{kW}$ ) was set at a relatively high $3400 \mathrm{~kW}$. This permitted GNB engineers to observe peak shaving events, yet barely exercise the battery. In addition, plant $\mathrm{kW}$ demand was observed in order to determine a trigger level at which the BESS would provide maximum cost savings. For the following months, the intent was to lower the trigger level until the BESS SOC would fall to $60-70 \%$ during the 8 -hr peak shaving period.

A daily analysis of the operation of the Vernon BESS has been obtained since July 1, 1997 (see Tables 2-4 through 2-6). The 3,400-kW trigger level resulted in relatively few hits on the battery, as expected, since average plant demand was less than $3,100 \mathrm{~kW}$, even on weekdays. In September, the number of battery hits increased due to a slight increase in plant demand and reduction in trigger level to $3,300 \mathrm{~kW}$. The amount of energy removed from the daily peak-shaving period was still very small, however, and the lowest SOC was just over $90 \%$, an average. It should be noted that about a $7-8 \%$ loss of charge occurs during a peak shaving period from maintaining the battery in the ready mode. Figures 2-16 through 2-18 show a comparison of the average and peak plant demand to the trigger level for the first three months of the operation.

\section{PV/Hybrid Evaluation Project}

The initial evaluation of the first PV/battery hybrid controller at the SNL PV System Evaluation Laboratory (PSEL) was completed in FY95. The project plan called for the installation of the prototype control unit in an industry facility in combination with a PV array and a diesel generator. A multiyear operational test plan was successfully negotiated with APS to perform a complete system field test of the controller at APS's STAR Center in Tempe, Arizona. An memorandum of understanding (MOU) and loan agreement were finalized in FY97, and the controller will be tested at APS for a period of two to three years.

\section{Status}

Early in the first quarter, a draft MOU was written by SNL and delivered to APS for its consideration and approval. An agreement to test the hybrid controller was signed and returned to SNL in December 1996. Coordination of the MOU with the DOE continued throughout the second quarter. Approval was completed in the third quarter.

In early December 1996, SNL facilitated a meeting between APS and Yuasa-Exide to discuss the availability of a Yuasa-Exide battery that would support the STAR Center hybrid test program. Yuasa-Exide is in the process of developing a VRLA tubular gel battery that it believes will provide superior performance in the renewable environment, especially in hybrid systems operations. APS was very interested in including state-of-theart battery technology in the STAR Center hybrid test program and solicited a proposal from Yuasa-Exide.

In the second quarter of FY97, APS accepted a proposal from Yuasa-Exide to provide a state-of-the-art, heavily cost-shared, VRLA tubular gel battery for the APS STAR Hybrid Test Facility. The proposed battery would provide approximately $200 \mathrm{kWh}$ of energy to support an anticipated peak load of $30 \mathrm{~kW}$ for the STAR facility. The battery was expected to support a typical average load of $10-15 \mathrm{~kW}$, which would result in approximately 14 to $20 \mathrm{hr}$ of battery storage. Power would also be provided by a $15-\mathrm{kW}$ PV array and a $30-\mathrm{kW}$ generator. Yuasa-Exide was extremely interested in how this battery would perform in this widely varying load hybrid environment. APS accepted the proposal, and delivery took place in June 1997.

As final testing at SNL of the first hybrid controller was nearing completion, a very serious flaw was discovered in the original controller design that could ultimately compromise its functionality at the APS STAR Center. The flaw had to do with the inability of the controller to automatically curtail battery charging operations as load fluctuations forced the controller to deliver power beyond the continuous operational capacity of the genset $(30 \mathrm{~kW})$. Consequently, if a power excursion forced a frequency shift outside the range of the system, the genset would attempt to meet the excessive load and ultimately drop off line. The controller developer was asked for a quote on the cost of modifying the original controller to accommodate the management of battery charging to eliminate the possibility of overload during charging operations when heavy equipment such as heating, venting, and cooling systems are activated. 
Table 2-4. July Discharge Data on Vernon BESS Operations

\begin{tabular}{|c|c|c|c|c|}
\hline \multicolumn{5}{|c|}{$\begin{array}{l}\text { July } 1997 \\
3,400-k W \text { Trigger Level }\end{array}$} \\
\hline Date & $\begin{array}{l}\text { Day of the } \\
\text { Week }\end{array}$ & $\begin{array}{l}\text { No. of Hits During } \\
\text { Required } \\
\text { Demand Period }\end{array}$ & $\begin{array}{c}\text { Average kW } \\
\text { During Required } \\
\text { Demand Period }\end{array}$ & $\begin{array}{l}\text { Largest Peak } \\
\text { During Peak } \\
\text { Shaving Period }\end{array}$ \\
\hline $7 / 1 / 97$ & $T$ & 0 & 2864 & 3374 \\
\hline $7 / 2 / 97$ & $w$ & 2 & 2915 & 3417 \\
\hline $7 / 3 / 97$ & $R$ & 0 & 1815 & 2196 \\
\hline $7 / 4 / 97$ & $F$ & 0 & 1401 & 1498 \\
\hline $7 / 5 / 97$ & $\mathrm{Sa}$ & 0 & 1288 & 1795 \\
\hline $7 / 6 / 97$ & Su & 0 & 1416 & 2594 \\
\hline $7 / 7 / 97$ & $M$ & 0 & 2219 & 2697 \\
\hline $7 / 8 / 97$ & $T$ & 1 & 2872 & 3433 \\
\hline $7 / 9 / 97$ & $w$ & 0 & 2758 & 3266 \\
\hline $7 / 10 / 97$ & $R$ & 0 & 2620 & 2711 \\
\hline $7 / 11 / 97$ & $F$ & 0 & 2810 & 3040 \\
\hline $7 / 12 / 97$ & Sa & 0 & 2948 & 3280 \\
\hline $7 / 13 / 97$ & Su & 0 & 2926 & 3126 \\
\hline $7 / 14 / 97$ & $M$ & 239 & 3300 & 3767 \\
\hline $7 / 15 / 97$ & $T$ & 321 & 3325 & 3766 \\
\hline $7 / 16 / 97$ & $w$ & 237 & 3291 & 3702 \\
\hline $7 / 17 / 97$ & $R$ & 292 & 3312 & 3690 \\
\hline $7 / 18 / 97$ & $F$ & 289 & 3319 & 3816 \\
\hline $7 / 19 / 97$ & $\mathrm{Sa}$ & 46 & 3148 & 3451 \\
\hline $7 / 20 / 97$ & $\mathrm{Su}$ & 0 & 3118 & 3377 \\
\hline $7 / 21 / 97$ & $M$ & 124 & 3244 & 3620 \\
\hline 7/22/97 & $T$ & 83 & 3230 & 3641 \\
\hline 7/23/97 & $w$ & 115 & 3257 & 3655 \\
\hline $7 / 24 / 97$ & $\mathbf{R}$ & 217 & 3262 & 3699 \\
\hline $7 / 25 / 97$ & $F$ & 191 & 3246 & 3685 \\
\hline $7 / 26 / 97$ & Sa & 0 & 3161 & 3368 \\
\hline $7 / 27 / 97$ & su & 0 & 3122 & 3291 \\
\hline $7 / 28 / 97$ & $M$ & 290 & 3323 & 3757 \\
\hline $7 / 29 / 97$ & $T$ & 264 & 3296 & 3711 \\
\hline $7 / 30 / 97$ & $w$ & 202 & 3265 & 3711 \\
\hline $7 / 31 / 97$ & R & 0 & 2992 & 3310 \\
\hline \multicolumn{5}{|c|}{ (Note: Data acquired from BESS has 10-sec sample rates on discharge and 3-min on recharge.) } \\
\hline \multicolumn{3}{|c|}{ Largest of the month: } & \multicolumn{2}{|c|}{3816} \\
\hline \multicolumn{2}{|c|}{ Average for entire month: } & 94 & 2873 & 3272 \\
\hline \multicolumn{2}{|c|}{ Average for weekdays only: } & 125 & 2954 & 3355 \\
\hline
\end{tabular}


Table 2-5. August Discharge Data on Vernon BESS Operations

\begin{tabular}{|c|c|c|c|c|}
\hline \multicolumn{5}{|c|}{$\begin{array}{l}\text { August } 1997 \\
3,400-k W \text { Trigger Level }\end{array}$} \\
\hline Date & $\begin{array}{l}\text { Day of the } \\
\text { Week }\end{array}$ & $\begin{array}{c}\text { No. of Hits } \\
\text { During Required } \\
\text { Demand Period }\end{array}$ & $\begin{array}{c}\text { Average kW } \\
\text { During Required } \\
\text { Demand Period }\end{array}$ & $\begin{array}{l}\text { Largest Peak } \\
\text { During Peak } \\
\text { Shaving Period }\end{array}$ \\
\hline $8 / / 1 / 97$ & $\bar{F}$ & 215 & 3236 & 3705 \\
\hline $8 / 2 / 97$ & Sa & 0 & 3034 & 3286 \\
\hline $8 / 3 / 97$ & Su & 0 & 3084 & 3245 \\
\hline $8 / 4 / 97$ & $\mathbf{M}$ & 1 & 56 & 3430 \\
\hline $8 / 5 / 97$ & $T$ & 0 & 25 & 3177 \\
\hline $8 / 6 / 97$ & $w$ & 1 & 2955 & 3410 \\
\hline $8 / 7 / 97$ & $\mathbf{R}$ & 68 & 3145 & 3615 \\
\hline $8 / 8 / 97$ & $F$ & 66 & 3158 & 3631 \\
\hline $8 / 9 / 97$ & $\mathrm{Sa}$ & 0 & 2911 & 3217 \\
\hline $8 / 10 / 97$ & $\mathrm{Su}$ & 0 & 2918 & 3217 \\
\hline $8 / 11 / 97$ & $\mathbf{M}$ & 178 & 3231 & 3654 \\
\hline $8 / 12 / 97$ & $T$ & 56 & 3183 & 3623 \\
\hline $8 / 13 / 97$ & $w$ & 15 & 3002 & 3582 \\
\hline $8 / 14 / 97$ & $R$ & 0 & 2966 & 3203 \\
\hline $8 / 15 / 97$ & $F$ & 0 & 3010 & 3212 \\
\hline $8 / 16 / 97$ & $\mathrm{Sa}$ & 0 & 2915 & 3064 \\
\hline $8 / 17 / 97$ & $\mathrm{Su}$ & 0 & 3062 & 3233 \\
\hline $8 / 18 / 97$ & $\mathbf{M}$ & 0 & 3085 & 3279 \\
\hline $8 / 19 / 97$ & $\mathbf{T}$ & 185 & 3250 & 3686 \\
\hline $8 / 20 / 97$ & $w$ & 105 & 3208 & 3663 \\
\hline $8 / 21 / 97$ & $R$ & 134 & 3225 & 3709 \\
\hline $8 / 22 / 97$ & $\mathbf{F}$ & 29 & 3159 & 3549 \\
\hline $8 / 23 / 97$ & $\mathrm{Sa}$ & 0 & 3032 & 3285 \\
\hline $8 / 24 / 97$ & $\mathrm{Su}$ & 0 & 2956 & 3265 \\
\hline $8 / 25 / 97$ & $M$ & 0 & 3062 & 3239 \\
\hline $8 / 26 / 97$ & $T$ & 167 & 3250 & 3749 \\
\hline $8 / 27 / 97$ & $w$ & 205 & 3223 & 3705 \\
\hline $8 / 28 / 97$ & $\mathbf{R}$ & 60 & 3150 & 3682 \\
\hline $8 / 29 / 97$ & $F$ & 86 & 3198 & 3632 \\
\hline $8 / 30 / 97$ & $\mathrm{Sa}$ & 0 & 2976 & 3267 \\
\hline $8 / 31 / 97$ & Su & 0 & 2922 & 3233 \\
\hline \multicolumn{5}{|c|}{ (Note: Data acquired from BESS has 10-sec sample rates on discharge and 3-min on recharge.) } \\
\hline \multicolumn{2}{|c|}{ Largest of the month: } & \multicolumn{3}{|c|}{$\mathbf{3 7 4 9}$} \\
\hline \multicolumn{2}{|c|}{ Average for entire month: } & 51 & 2890 & 3434 \\
\hline \multicolumn{2}{|c|}{ Average for weekdays only: } & 75 & 2847 & 3530 \\
\hline
\end{tabular}


Table 2-6. September Discharge Data on Vernon BESS Operations

September 1997

3,300-kW Trigger Level

\begin{tabular}{|c|c|c|c|c|c|}
\hline Date & $\begin{array}{l}\text { Day of the } \\
\text { Week }\end{array}$ & $\begin{array}{c}\text { No. of Hits } \\
\text { During Required } \\
\text { Demand Period }\end{array}$ & $\begin{array}{c}\text { Average kW } \\
\text { During Required } \\
\text { Demand Period }\end{array}$ & $\begin{array}{l}\text { Largest Peak } \\
\text { During Peak } \\
\text { Shaving Period }\end{array}$ & $\begin{array}{l}\text { Lowest SOC } \\
\text { During Peak } \\
\text { Shaving Period }\end{array}$ \\
\hline $9 / / 1 / 97$ & $M$ & 0 & 2975 & 3126 & $92 \%$ \\
\hline $9 / 2 / 97$ & $T$ & 40 & 3006 & 3566 & $92 \%$ \\
\hline $9 / 3 / 97$ & $w$ & 104 & 3088 & 3536 & $92 \%$ \\
\hline $9 / 4 / 97$ & $R$ & 167 & 3151 & 3596 & $95 \%$ \\
\hline $9 / 5 / 97$ & $\mathrm{~F}$ & 964 & 3279 & 3906 & $99 \%$ \\
\hline $9 / 6 / 97$ & $\mathrm{Sa}$ & 34 & 3038 & 3559 & $99 \%$ \\
\hline $9 / 7 / 97$ & Su & 0 & 3010 & 3194 & $99 \%$ \\
\hline $9 / 8 / 97$ & $M$ & 313 & 3191 & 3603 & $91 \%$ \\
\hline 9/9/97 & $T$ & 420 & 3252 & 3646 & $90 \%$ \\
\hline $9 / 10 / 97$ & $w$ & 313 & 3172 & 3607 & $91 \%$ \\
\hline $9 / 11 / 97$ & $\mathbf{R}$ & 389 & 3230 & 3604 & $90 \%$ \\
\hline 9/12/97 & $F$ & 281 & 3202 & 3686 & $92 \%$ \\
\hline 9/13/97 & Sa & 0 & 3013 & 3263 & $93 \%$ \\
\hline 9/14/97 & $\mathrm{Su}$ & 0 & 2967 & 3167 & $92 \%$ \\
\hline 9/15/97 & $M$ & 369 & 3215 & 3658 & $92 \%$ \\
\hline $9 / 16 / 97$ & $T$ & 249 & 3181 & 3554 & $92 \%$ \\
\hline $9 / 17 / 97$ & $w$ & 227 & 3171 & 3585 & $92 \%$ \\
\hline 9/18/97 & $R$ & 22 & 3065 & 3486 & $92 \%$ \\
\hline 9/19/97 & $F$ & 46 & 3065 & 3463 & $92 \%$ \\
\hline $9 / 20 / 97$ & $\mathrm{Sa}$ & 0 & 2629 & 2774 & $92 \%$ \\
\hline 9/21/97 & $\mathrm{Su}$ & 0 & 2941 & 3083 & $92 \%$ \\
\hline 9/22/97 & $M$ & 93 & 3098 & 3595 & $92 \%$ \\
\hline 9/23/97 & $T$ & 131 & 3089 & 3521 & $92 \%$ \\
\hline 9/24/97 & $w$ & 359 & 3226 & 3627 & $91 \%$ \\
\hline $9 / 25 / 97$ & $R$ & 223 & 3182 & 3558 & $92 \%$ \\
\hline $9 / 26 / 97$ & $F$ & 550 & 3281 & 3642 & $89 \%$ \\
\hline 9/27/97 & $\mathrm{Sa}$ & 0 & 3022 & 3208 & $93 \%$ \\
\hline $9 / 28 / 97$ & Su & 7 & 3124 & 3346 & $93 \%$ \\
\hline 9/29/97 & $M$ & 492 & 3260 & 3672 & $90 \%$ \\
\hline $9 / 30 / 97$ & $T$ & 412 & 3215 & 3609 & $92 \%$ \\
\hline
\end{tabular}

(Note: Data acquired from BESS has 10-sec sample rates on discharge and 3-min on recharge.)

Largest of the month:

3906

Average for entire month

207

3111

3481

$92.5 \%$

Average for weekdays only:

252

3158

3567

$91.4 \%$ 

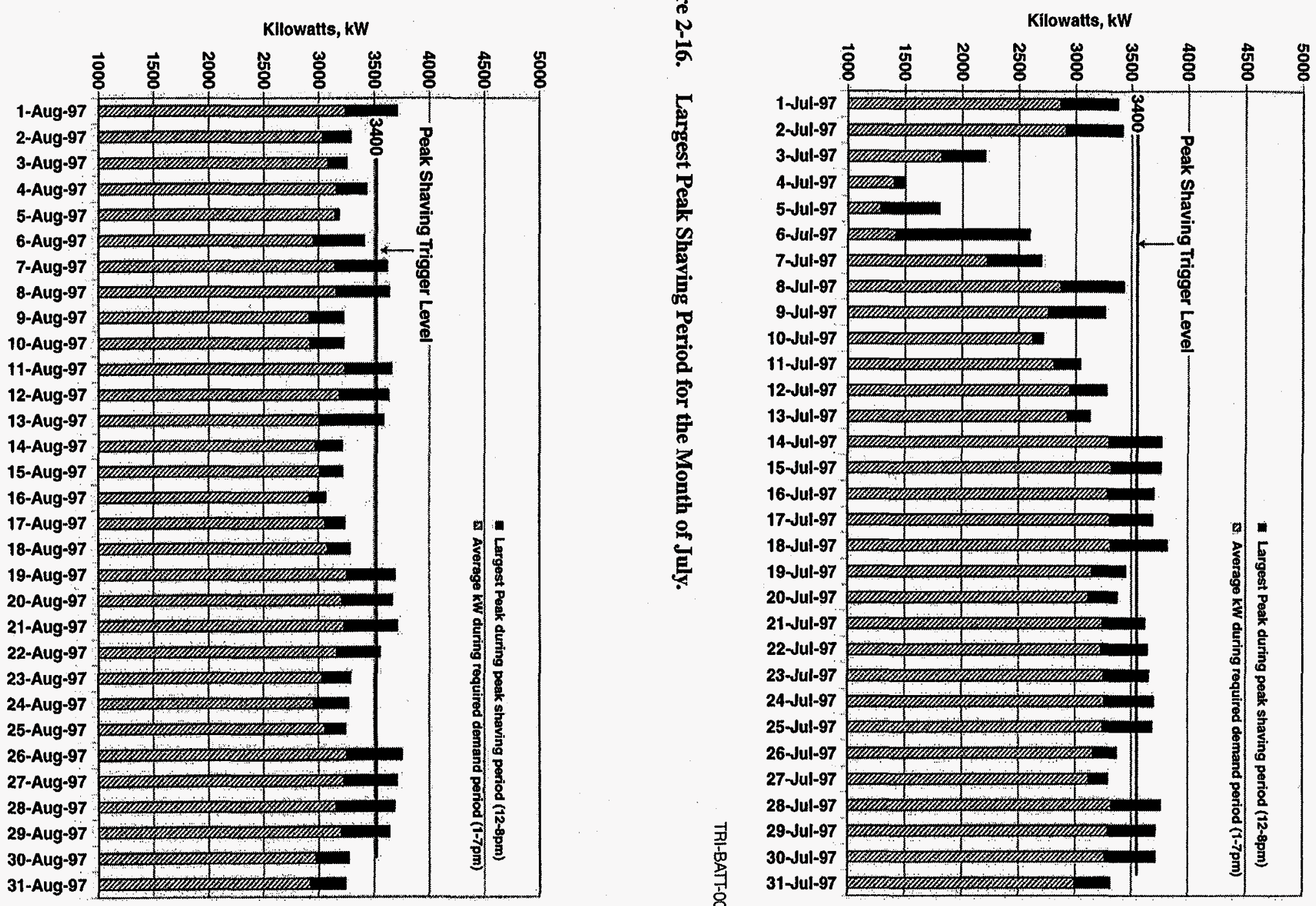


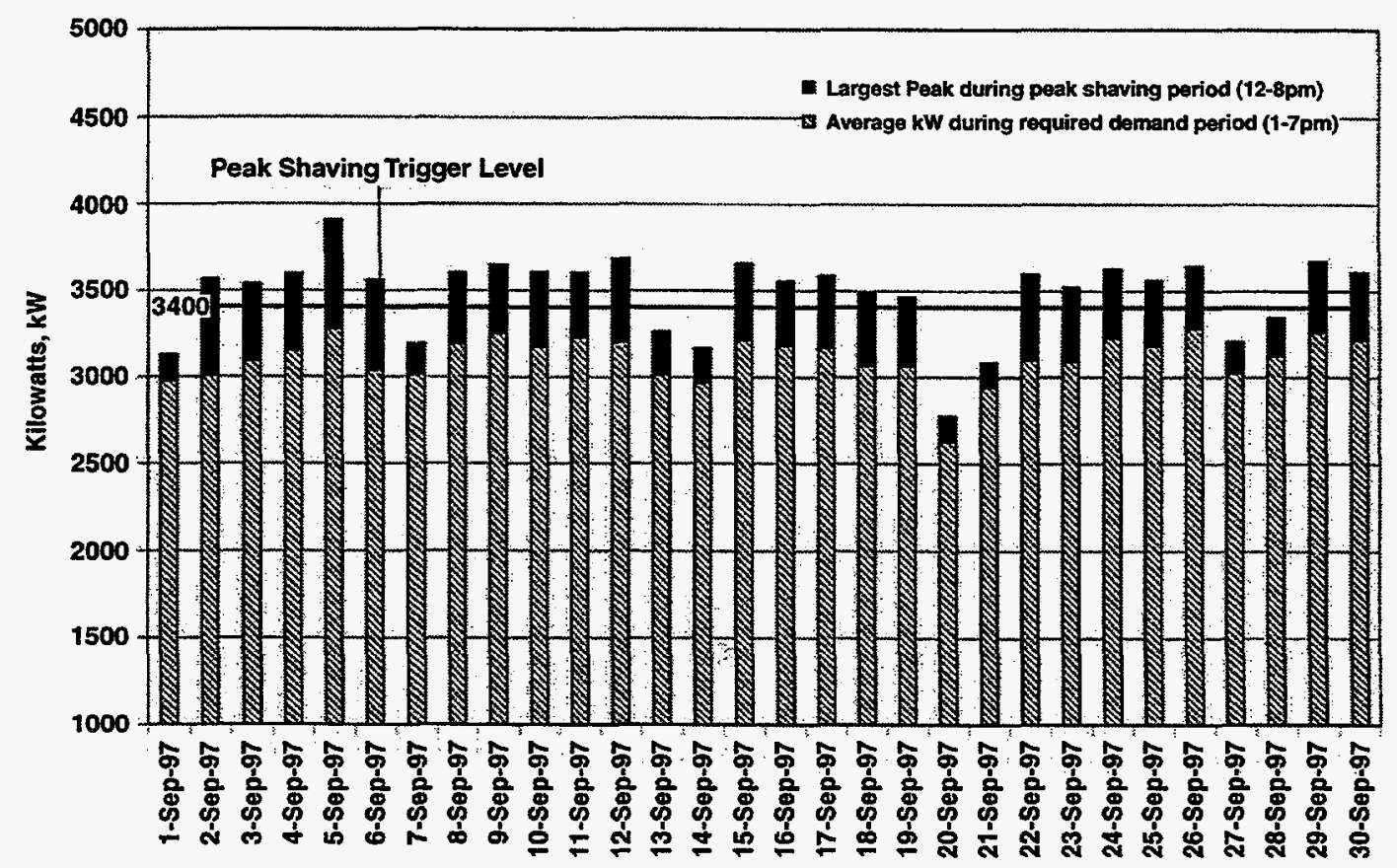

Figure 2-18. Largest Peak Shaving Period for the Month of September.

TRI-BATT-0058-0

Based on the cost and schedule proposed by the developer for the modifications, a decision was made to abandon the first controller in favor of a new state-ofthe-art hybrid system controller and PCS in final development by Trace Technologies of Livermore, California. The 30-kW inverter and controller design is based on a mature design that has been operational in AC-DC-AC wind generation systems for several years. APS was notified of the decision to use a different controller and of the impact on the schedule this would have: Delivery of a controller to the STAR Center was delayed significantly.

A contract was placed with Trace Technologies to fabricate and deliver a $30-\mathrm{kW}$ PCS and hybrid system controller based on its $300-\mathrm{kW}$ wind turbine system design. Specifications were generated to fit the requirements of a stand-alone, off-grid power system and hybrid controller that will automatically regulate and manage the operation of the battery charger under a fluctuating load environment. The new Trace controller is expected to solve all problems identified during the system integration process.

As this project provided a unique opportunity to learn how a variable-load, off-grid hybrid functions in an operational facility, SNL also agreed to provide a comprehensive DAS to collect data specific to the opera- tion of the off-grid system. The DAS will be designed and installed by SWTDI, with delivery scheduled to coincide with delivery of the Trace Controller.

Figure 2-19 is a photograph of the APS STAR Hybrid Test Facility located in Tempe, Arizona. The battery room entrance is shown on the near wall. The genset is located at the far end of the building. The controller and switching equipment will be installed in the room at the other end of the building. The 15-kW PV array (shown in Figure 2-20) is situated behind the STAR facility. The complete facility was expected to be fully operational early in FY98.

The Yuasa-Exide Dynacell DT-11 VRLA tubular gel batteries were delivered and installed in June. Figure 2-21 shows the battery installed in the battery room of the APS STAR facility. The battery is configured as two parallel 120 -cell strings to provide the $240-\mathrm{V}$ input to the Trace Technologies $30-\mathrm{kW}$ inverter. Because of the anticipated delay in the delivery of the Trace controller, the batteries were supported by an on-site battery charger provided by APS. Yuasa-Exide provided details on the best way to manage the batteries while the system was idle and waiting for the inverter.

In early July, the APS STAR Hybrid Test Facility Team met at the STAR Center. The team from the par- 


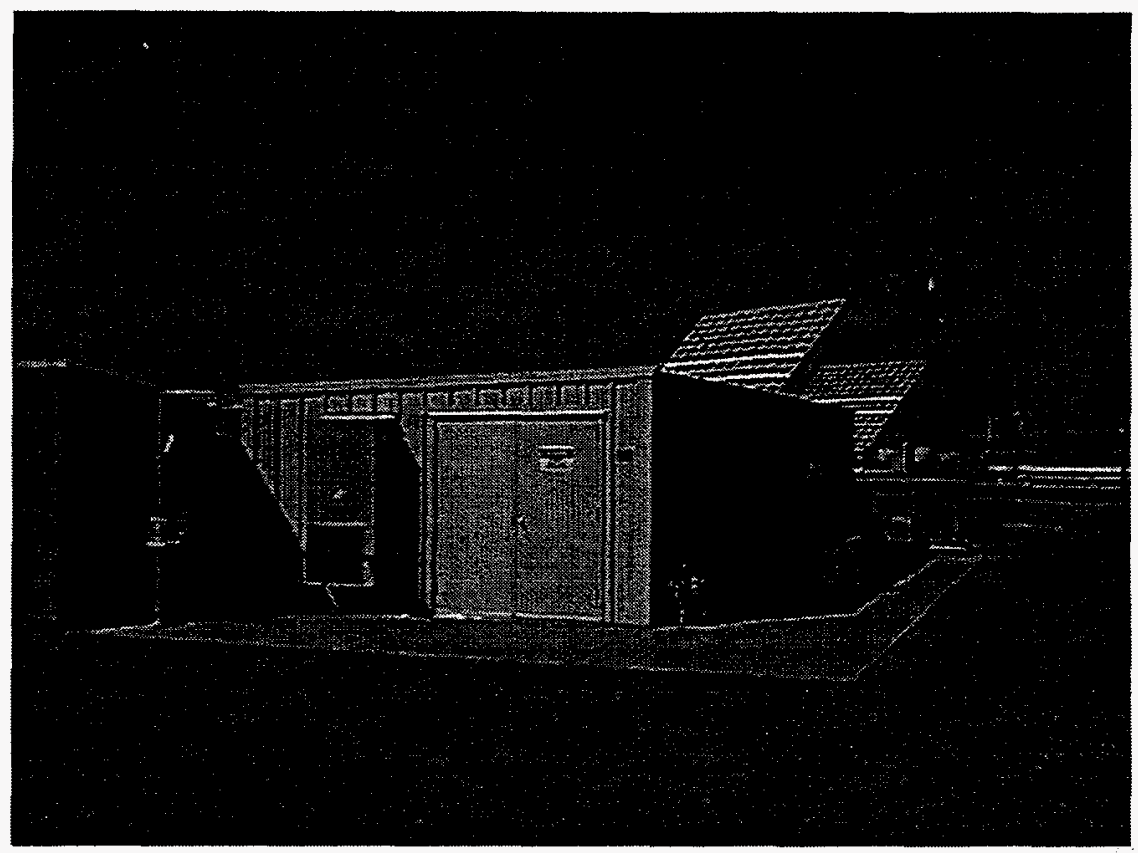

TRI-BATT-0004-0

Figure 2-19. APS STAR Hybrid Test Facility.

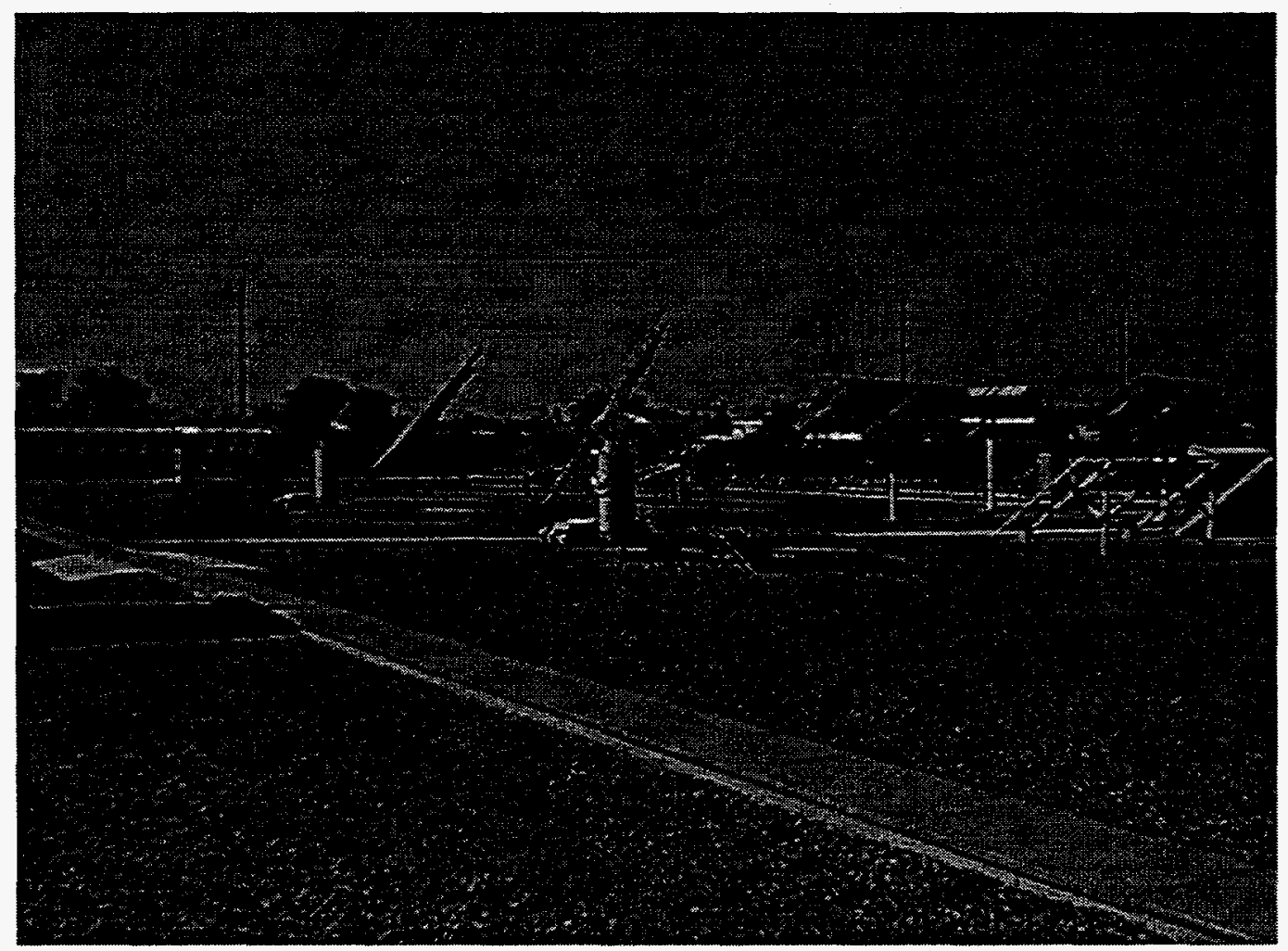

TRI-BATT-0045-0

Figure 2-20. The 15-kW PV Array Supplying Power to the APS STAR Hybrid Test Facility. 


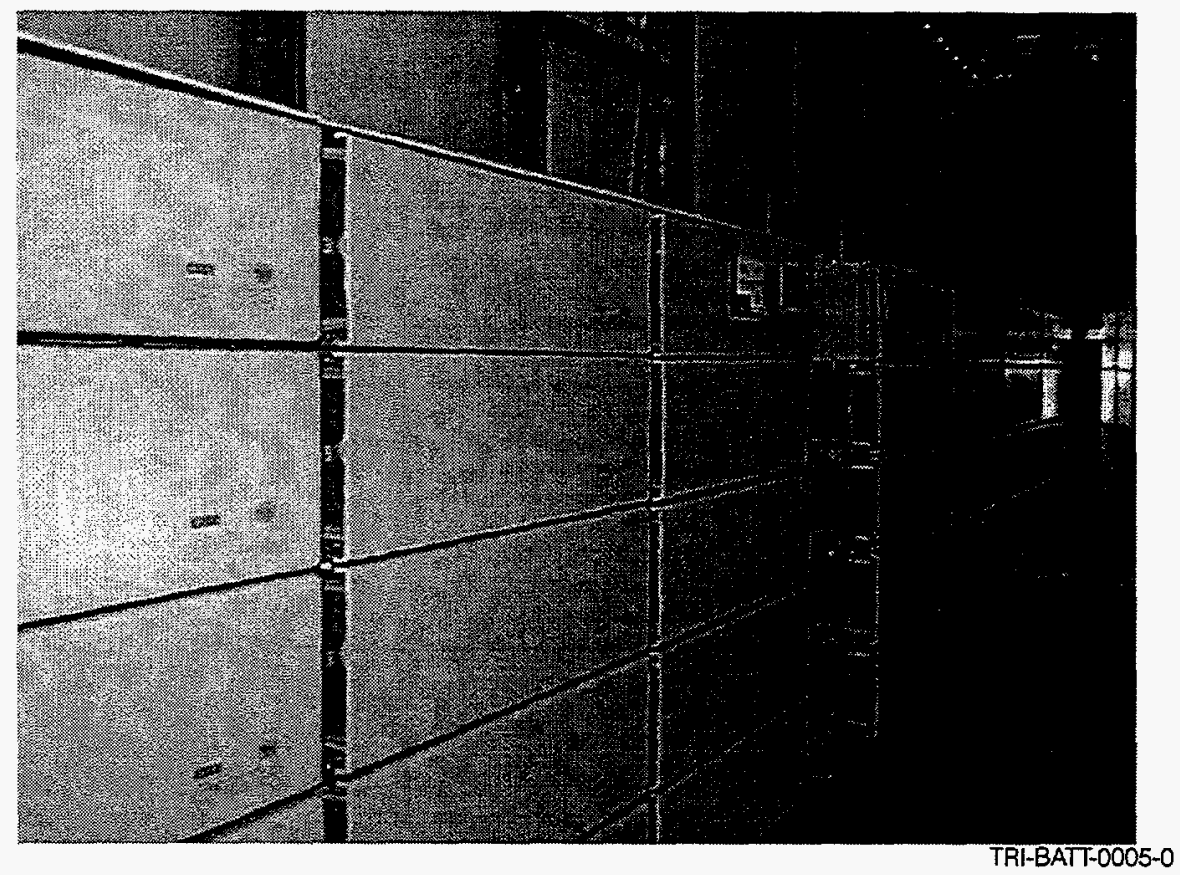

Figure 2-21. Yuasa-Exide Battery Installed in the APS STAR Hybrid Test Facility.

ticipating companies was in attendance to discuss the progress of the preparations for integrating the Trace inverter with the currently installed Yuasa-Exide battery and the genset; participants included APS (system integrators), Trace Technologies (inverters), Yuasa-Exide (batteries), SWTDI (data acquisition), and SNL (engineers for system, battery, and integration issues). Completion of the hybrid test facility was anticipated well in advance of the receipt of the Trace inverter.

A project coordination meeting was held later in August in which the functionality of each subsystem was discussed.

Factory acceptance of the Trace inverter was scheduled for early FY98. After factory acceptance, the inverter will be shipped to the PSEL at SNL for characterization and shakedown testing. After completion of characterization testing, the inverter will be shipped to the APS STAR Center for operational testing.

\section{Metlakatla Monitoring Project}

A 1.2-MW/1.2-MWh battery system, designed and built under a partnership of GNB and GE, was installed in Metlakatla, Alaska, in 1996. The BESS is designed to compensate for the severe voltage and frequency excursions caused by the operation of large motors at the local lumber mill in the remote village. Several years ago, MP\&L installed a fast-response diesel genset to stabilize the system. The diesel operated continuously and augmented existing hydrogeneration units that were too slow to respond to the rapid fluctuations caused by the lumber mill machinery. However, operation of the diesel in this mode incurred fuel and maintenance expenditures of over $\$ 400,000 / y$ r. With input from the ESS Program, MP\&L recognized battery energy storage as a potential alternative to the diesel and contracted with the GNB/GE team to supply a turnkey battery system.

The basic building block for this battery system design evolved out of a GNB/GE agreement to develop and market turnkey BESSs in the 1- to 5-MW range. The first implementation of this design was the 3.5MW/1-hr battery system commissioned at the GNB lead recycling smelter in Vernon, California. The battery system in Alaska replicates the Vernon design at half the scale and has built-in capabilities to add extra storage to accommodate future load growth.

The storage system consists of a string of $378 \mathrm{GNB}$ ABSOLYTE IIP series-connected 2-V VRLA cells. The battery has a nominal rating of $756 \mathrm{VDC}$ and is operated at around $80 \%$ SOC to enable it to accept energy during voltage spikes. It consists of a PCS, an automatic generation control system, and the batteries, which are housed in a 40-by-70-ft steel battery building that sits on a 
cement pad at the $12.47-\mathrm{kV}$ substation for MP\&L's diesel generator.

The ESS Program contributed to the project by initially identifying the Metlakatla application and providing the community with an independent assessment of battery storage capabilities. In addition, the ESS Program funded the installation of a first-of-a-kind remote monitoring capability that displays the battery system status on personal computers equipped with a modem via commercial phone lines. The ESS Program also shared the cost of providing an on-site technician for a 3-mo period to train the MP\&L staff in the day-to-day operation and management of the battery system.

\section{Status}

The MP\&L installation was completed in December 1996. On February 3, 1997, the diesel was shut down, and the battery system started operation in coordination with the hydrogeneration units; it met all of the power requirements of the island community while damping the lumber mill fluctuations.

According to MP\&L's general manager, the battery system is exceeding expectations. He described how the battery discharged for $45 \mathrm{~min}$ when a $1-\mathrm{MW}$ load was rejected and tripped one of the hydrogeneration units. Even when the Annette Hemlock Mill and the Tsimshian Lumber Mill, owned by Metlakatla Forest Products, were running simultaneously, the only time the diesel operated was to recharge the battery. MP\&L saved $\$ 39,100$ in diesel-fuel costs in one month. If MP\&L can defer diesel shipments, overall cash flow for the facility will improve, and the savings will be passed on to the consumer.

To address possible growth, MP\&L has considered taking a proposal before the tribal council to connect Metlakatla to the Ketchikan-Southeast-Intertie on the mainland. The additional power and system stability would come with a demand charge and rate ratchet clause if MP\&L purchases power from the mainland. However, the connection could be a source of revenue if MP\&L provides power during the Ketchikan summer peak season.

While interconnection to a larger grid could improve system stability, several issues create uncertainty about the future for Metlakatla, MP\&L, and the BESS. The cost of interconnection, estimated at approximately $\$ 6 \mathrm{M}$, could be prohibitive. Also, new federal legislation could make interconnection unnecessary. In March 1997, Congress passed a law that prohibits logging in the Tongass National Forest after December 31,1999 . Since the mills on Metlakatla get all of their lumber from the Tongass, the disruption of the lumber industry will radically affect employment in the community, as well as its electricity needs and, potentially, MP\&L's use of the BESS.

MP\&L held a formal dedication of the battery system in August 1997. The dedication followed a battery energy storage workshop that MP\&L, GNB, and the ESS Program cosponsored in Ketchikan and Metlakatla. This two-day seminar presented the ESS program work, BESS technology and case studies, and BESS cost/benefit issues to utility industry representatives and others regarding opportunities in Alaska. The seminar was attended by seven utility managers and planners, and staff of the Alaska State Division of Energy. Attendees also toured the Metlakatla, Chester and Purple Lakes, and Centennial Diesel facilities. At the dedication, Alaska Senator Ted Stevens (seen in Figure 2-22) was very interested in the potential benefits that similar storage systems could offer other Alaskan villages and requested copies of the proceedings and other materials from the seminar.

Diesel fuel consumption for FY96 and FY97 is shown in Figure 2-23.

\section{ZBB 100-kWh Zinc/Bromine Battery Test}

The ESS Program began supporting programs to develop advanced battery systems such as zinc/bromine in the 1980s. The zinc/bromine battery development project, which resulted in a stand-alone $100-\mathrm{kWh}$ system, was the product of a multiyear, in-kind, cost-shared contract with ZBB and SNL. Testing of the prototype system was finished in the second quarter of FY97. Complete test results will be published in a final report in FY98.

The potential advantages of the zinc/bromine technology include high specific energy $(70-80 \mathrm{Wh} / \mathrm{kg})$, rapid charge (two to four hours), deep-discharge capability (100\%) and a built-in thermal management system. Inexpensive raw materials and mass production manufacturing techniques have resulted in a battery that is potentially low in cost $(\$ 150 / \mathrm{kWh})$ and has a stack replacement cost of $\$ 50 / \mathrm{kWh}$. Initially, the zinc/bromine battery project emphasized component development and improved manufacturing techniques, but the emphasis has since shifted to battery system integration and field evaluation.

The objectives of Phase I of the project were to design, fabricate, and evaluate a zinc/bromine battery system suitable for electric utilities. In Phase I, the 


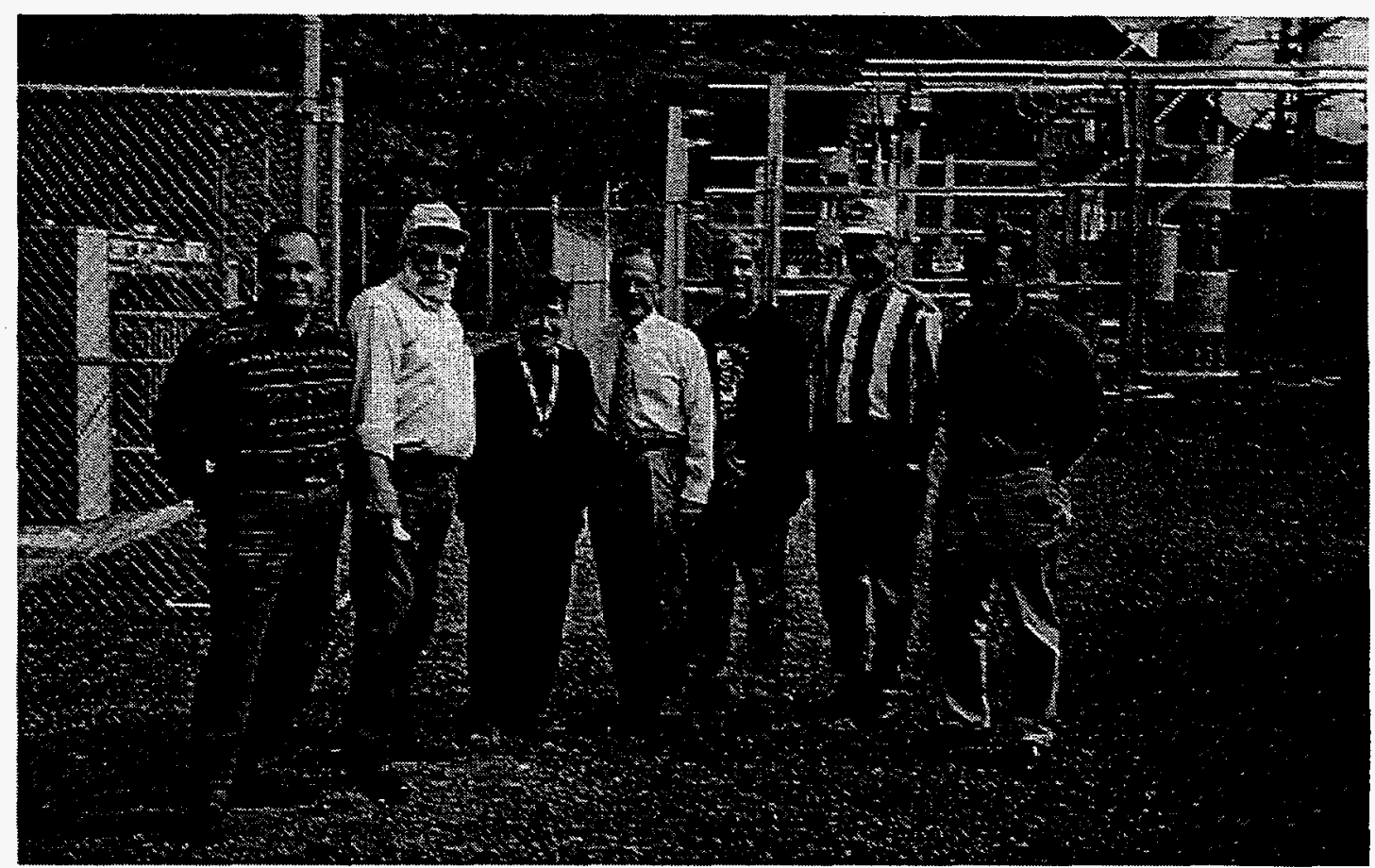

TRI-BATT-0044-0

Figure 2-22. Formal Dedication of the MP\&L BESS (from left to right: George Hunt, GNB Technologies; Dutch Achenbach, MP\&L General Manager; Linda Clement, Metlakatla Acting Mayor; Alaska Sen. Ted Stevens; Abbas Akhil, SNL; Joe Slocik, Construction Project Manager; and Percy Frisby, Director, Alaska Division of Energy).

\section{Monthly Fuel Consumption}

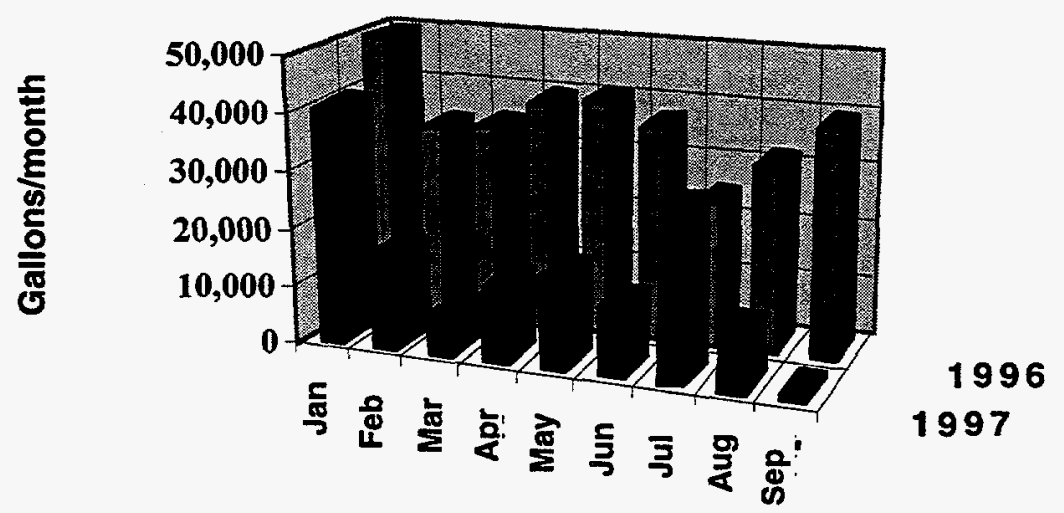

TRI-BATT-0028-0

Figure 2-23. Comparison of Diesel Fuel Consumption at Metlakatla, Alaska, for FY96 and FY97. 
soundness of the technology was demonstrated by its meeting a number of criteria, including the following:

- Leak-free battery stacks

- Steady long-term operation by achievement of over 100 cycles with a less than $10 \%$ drop in energy efficiency and with an overall efficiency of approximately $75 \%$

- Six consecutive no-strip cycles

- A battery that costs $\$ 150 / \mathrm{kWh}$ or less

- A safer battery, through resolution of safety issues associated with the battery

In Phase II, a design for a larger electric utility battery stack was developed while the core technology research continued. A $2500-\mathrm{cm}^{2}$ design was selected to reduce the number of stacks required to achieve the higher storage capacity in utility systems; system manufacturing costs were also reduced by reducing the number of stacks. The system is an integration of three main components: the zinc/bromine battery, the PCS, and the necessary control equipment. The primary aim of the battery testing conducted under the development project was to determine the suitability of the zinc/bromine battery as a peak shaving device. Other testing of the battery, under different criteria, would require a modification of the PCS unit or the PCS control circuitry. A component-type approach was chosen to provide flexibility. With the component approach, the inverter and application can be independent of the design of the zincl bromine battery.

\section{Status}

Before the battery tests were run, the safety features of the battery were checked to ensure that all the automatic fault and shutdown procedures were working properly. Battery testing included nominal benchmark discharges (baseline cycles), power factor control and power quality testing, block load characterizations, load-following characterizations, multiple-dual-peak tests, and auxiliary load monitoring and characterization. For each test, information was compiled on the battery alone using the battery control software, and information on the overall system was accumulated using a BMI 3060 Power Profiler. Information gathered during each test included energy capacity ( $k W h$ ), DC-DC efficiency, DC-AC efficiency (discharge), $A C-D C$ efficiency (charge), AC-AC efficiency, harmonics, frequency, and power factor.

The nominal benchmark discharge test, a standard baseline cycle, was performed occasionally on the
$100-\mathrm{kWh}$ zinc/bromine system to obtain a characterization of the full discharge performance of the battery and to establish a benchmark performance upon which subsequent tests will be based. The system was charged at $100 \mathrm{~A}$ for $4.5 \mathrm{hr}$, then discharged at $100 \mathrm{~A}$ until the system voltage went below $180 \mathrm{~V}$ or the voltage of an individual module reached $30 \mathrm{~V}$.

Specific areas of interest for characterizing the benchmark performance included:

- AC-kWh capacity

- PCS efficiency at nominal output

- Harmonics at nominal output

- DC voltage profile on stacks

- End-of-discharge (EOD) behavior (low-DCvoltage-induced shutdown)

Voltage and current profiles for the $100-\mathrm{kWh}$ battery and for the individual modules were obtained for each cycle. An example of the voltage and current profiles for the battery and for an individual module during a baseline cycle are given in. Figures 2-24 and 2-25, respectively. The harmonics for the overall system, including the PCS, were obtained using a Basic Measuring Instrument (BMI) 3060 Power Profiler.

\section{Nickel/Metal Hydride Battery Testing at ANL}

On April 10, 1997, staff from the ESS Program attended a review of the USABC-sponsored nickel/ metal hydride battery testing project at ANL. The goal of this project is to test batteries that have failed in EV tests and characterize their performance in stationary applications such as spinning reserve, load following, frequency regulation, and UPSs, and in industrial vehicles. A complex test plan was developed by ANL staff with significant input by ESS testing experts. Testing is in progress at ANL on eight nickel/metal hydride modules that had previously failed standard USABC EV battery tests. About half of the test plan has been completed so far, and tests are accumulating cycle data rapidly. While most of the modules are performing acceptably and will probably achieve their test objectives, one module failed prior to its goal and another is nearly at the failure point, having just barely achieved its goal. Unfortunately, the intensive effort required by the test plan and considerable unanticipated activities attempting to recover the two weak modules are causing a cost overrun for the project. In addition, no cost estimates have been made yet to quantify the price of failed 


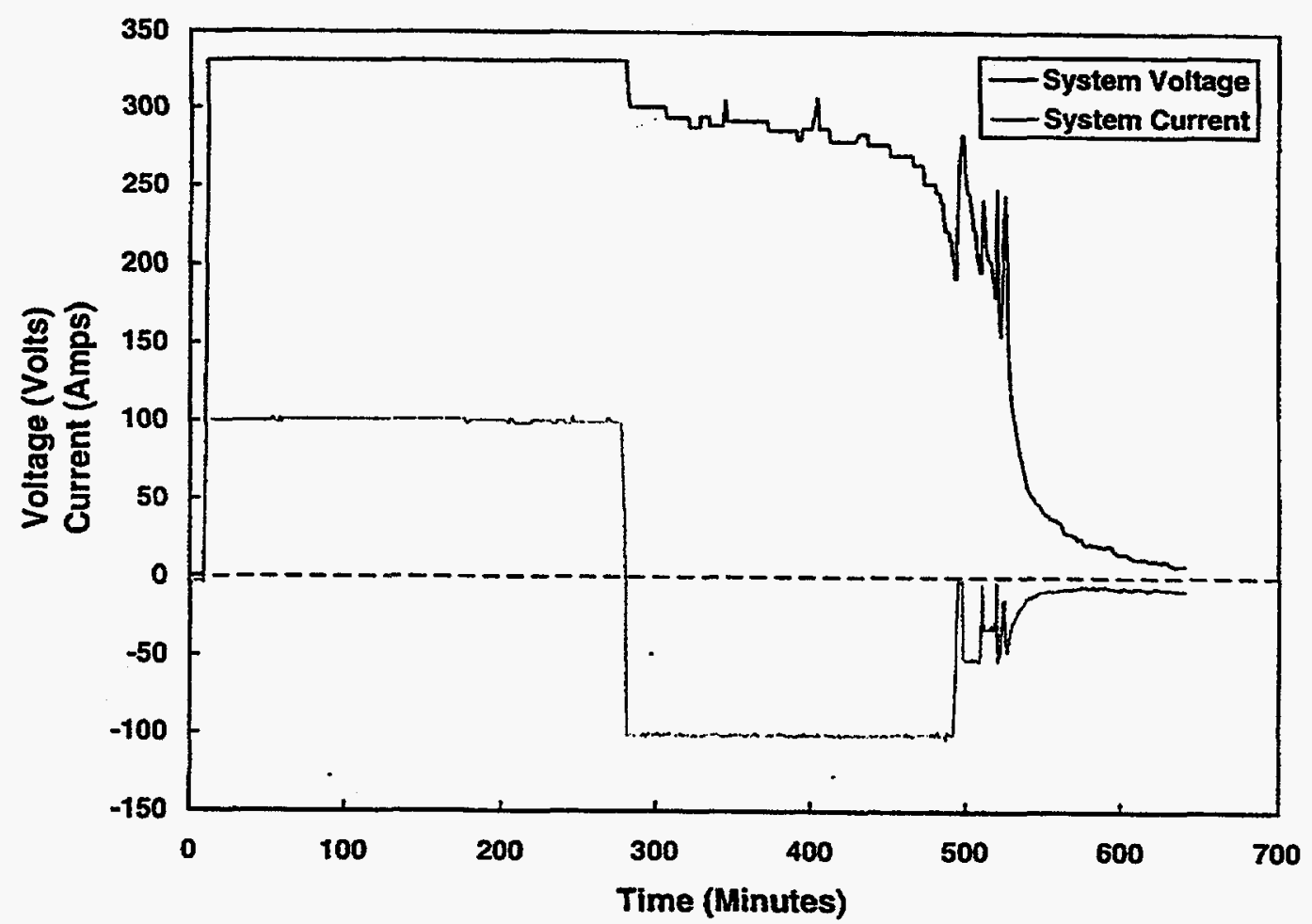

TRI-BATT-0048-0

Figure 2-24. Voltage and Current Profiles for the ZBB 100-kWh Zinc/Bromine Battery During a Baseline Cycle.

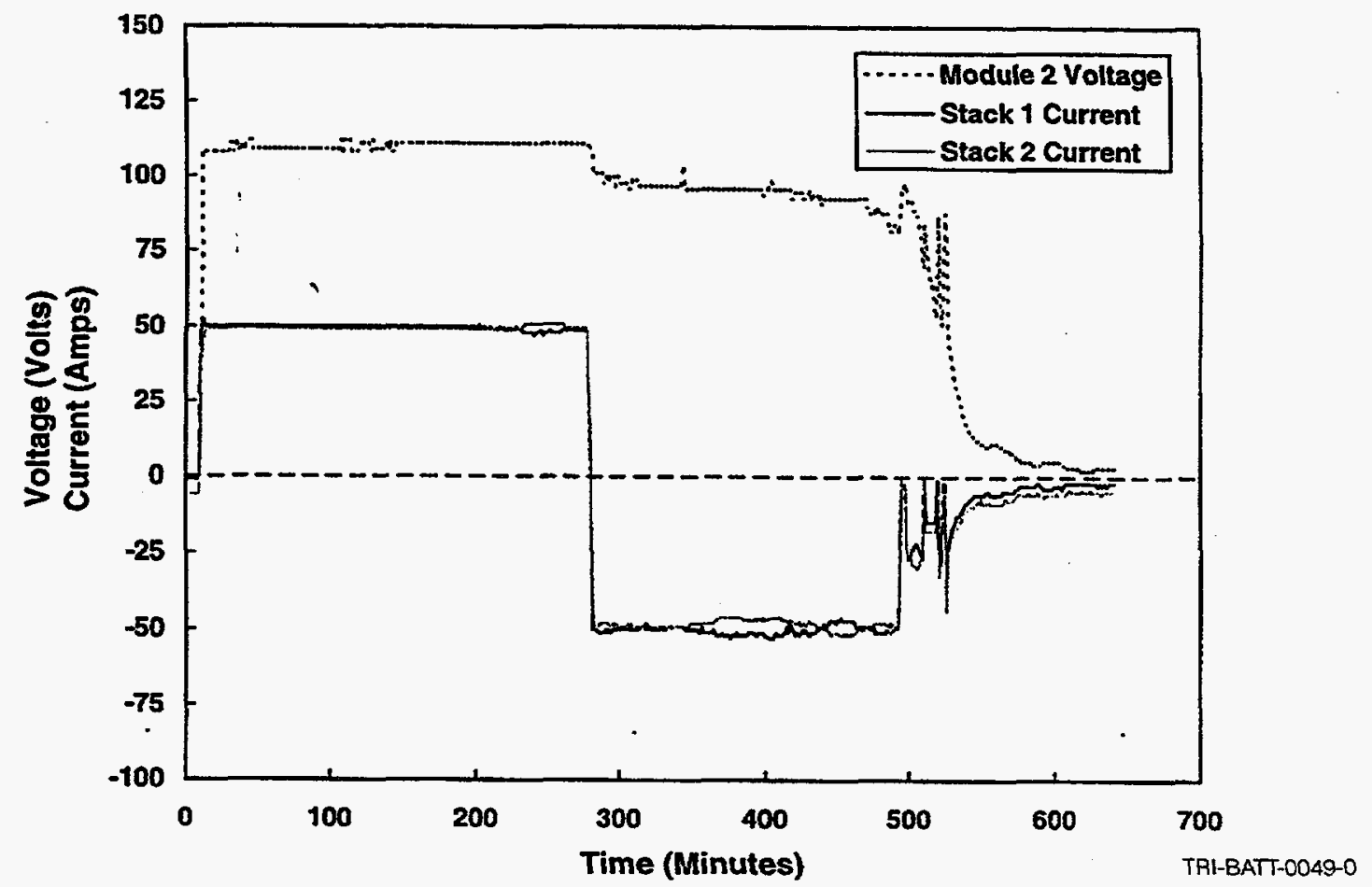

Figure 2-25. Voltage and Current Profiles for Module 2 of the ZBB 100-kWh Zinc/Bromine Battery During a Baseline Cycle. 
EV modules for the stationary and industrial vehicle applications. However, the project is accumulating extensive data on used batteries, data that is of consider- able interest to the battery and application analysis communities. The progress of this project will be followed in the future as appropriate. 
Intentionally Left Blank 


\section{Component Research and Development and Technology Evaluation}

\section{Introduction}

Work in the Component Research and Development element focuses on improving the subsystems that make up energy storage systems: Improvements are developed and evaluated in the primary components of the energy storage system, including the storage device (e.g., battery) and the electrical equipment (power conversion and control). The ESS Program is developing storage components that cost less, have higher performance, and are better integrated with other parts of the system than those currently available.

SNL also continues to pursue the VRLA battery reliability initiative, which is attempting to address reliability issues in cooperation with industry. SNL believes a critical component of this activity is continued laboratory testing. Controlled laboratory tests are the best method of determining capacity degradation rates and provide mechanisms that allow for an understanding of the relevant cause-and-effect relationships.

As part of its technical mission in support of the ESS Program, SNL performs in-house applied research and battery evaluation tasks. These tasks utilize specialized and unique facilities and capabilities established during many years of program activities in all battery technologies. Current tasks include the evaluation of flooded lead-acid, VRLA Gel, SLI, and advanced batteries. These independent, objective tests using computercontrolled testers capable of simulating application-specific test regimes provide critical data for the assessment of the status and probable success of these technologies.

\section{VRLA Reliability Improvement Project}

VRLA batteries have been commercially available for more than 10 years and have been enthusiastically embraced by users of UPSs because of anticipated reductions in maintenance costs and the smaller footprint available with this technology. As field experience has accumulated, it is becoming more widely appreciated that VRLA batteries are more sensitive to their operating conditions than flooded lead-acid batteries. This is particularly true under conditions such as elevated temperatures or overcharging, which can result in battery dry-out in starved-electrolyte designs, thereby shortening battery life compared with that to which users are accustomed. Although the majority of recent VRLA failures may be attributed to abusive environments or improper float-charging conditions, there is a lack of confidence among some users that all of the possible life-limiting conditions for VRLA batteries have been identified. The information on recent failures has made potential utility battery customers, including users of standby power systems, more reluctant to adopt battery energy storage technology, particularly if VRLA designs are being proposed.

Because SNL believes that VRLA battery technology offers real advantages in utility and renewable energy applications, a VRLA reliability improvement project was formulated. The primary objective of the project is to determine VRLA cycle and calendar life under typical utility battery operating conditions and use modes.

\section{Status}

During the first quarter of FY97, representatives from Yuasa-Exide, Inc., visited SNL, and the subject of VRLA battery reliability was again discussed. As in previous meetings, Yuasa-Exide voiced more interest in having testing done on their products for stationary energy storage applications than in a more general investigation of VRLA battery reliability. Efforts to define a program that can garner broader support from the battery industry continued.

During the second quarter of FY97, a white paper was received from Dr. Patrick Moseley of ILZRO that discussed VRLA battery performance issues and how these batteries might be optimized for stationary applications. Establishing the best charge control system appeared to be one area that might provide a substantial benefit. SNL examined the information in the white paper to identify areas where additional collaborative work with ILZRO could be pursued.

Also during the fourth quarter of FY97, a meeting was held with ILZRO to discuss areas of collaboration including VRLA reliability assessment. As a result of the consensus that reliability was an important issue to address and that no current method exists to rapidly characterize VRLA battery life, an SOW was prepared for a jointly funded study. 
Because of the scarcity of laboratory test data and the complex nature of the aging process, life data for VRLA batteries are being obtained from field use information. Within the last three years, as batteries in the field have begun to reach five to seven years of life, some problems caused by unanticipated capacity losses have been reported. In some instances, the information from field returns indicates premature capacity loss, while in other cases reversible capacity losses are indicated. The level of monitoring and field maintenance applied to VRLA battery systems has increased significantly as users have attempted to verify proper capacity and readiness for operation. The need for such monitoring and maintenance has obviously diluted the original advantages of the VRLA products. A desirable goal for the industry would be to verify that VRLA technology has the same performance and life as flooded lead-acid technology (possibly up to 20 years of life).

A three-phase project was defined to clarify and suggest a method of resolving these life issues. Phase 1 involves a survey of the industry, in cooperation with VRLA manufacturers and users, to determine objectively and accurately the status of the technology. Phase 2 investigates the critical issues identified in Phase 1 and suggests improvements to the charging methods or other aspects of the technology. Because it is expected that charging protocols will be one of the most critical areas identified for optimum operation, Phase 2 includes a charging study that focuses on those issues. Phase 3 then attempts to correlate and match the various types of VRLA technologies to the numerous applications now using lead-acid batteries. This will assist users and battery suppliers in selecting a design for an intended application, so that the battery will be appropriately specified.

The purpose of the initial contract will be to perform Phase 1. The cooperation of the battery manufacturers and users is necessary to evaluate field return information. An accurate and objective evaluation of the performance characteristics of batteries and identification of the frequency and severity of problems with batteries in the field is essential to this study. Information on environments, charging methods and equipment, and discharge use modes is also needed to understand battery performance properly. These data should lead to identification of the source of any problems and a recommended course of action for research and development to resolve remaining issues.

The Phase 1 study comprises three tasks:

Task 1: Identify all VRLA manufacturers and characterize their share of the market by design type and application. Invite each to participate in the study and to involve representative users of the products.

Task 2: Develop a detailed list of data needed to characterize the VRLA technology and problems identified by the users. Recover field monitoring data on the systems wherever possible. Organize a database to receive the information.

Task 3: Collect the data, analyze for trend information, and summarize the results in a final report.

A purchase order to fund the Phase 1 study was placed with ILZRO during the fourth quarter, and then IIZRO issued a request for quote on a subcontracted study. Two proposals were received, and these were still being reviewed at the end of the quarter.

\section{Development, Validation, and Demonstration of Power Quality and Peak-Shaving Technology Simulators}

The ESS Program has initiated a collaborative project with NRECA to develop, validate, and demonstrate simulators of power quality and peak-shaving systems. The project provides technical and economic data about peak shaving and power quality improvement at electric membership cooperatives. More important, the project introduces a technology assessment tool that is more exact and no more expensive than a traditional feasibility study.

The ESS portion of the project supports the development and validation of energy storage simulators that will mimic the operation of two BESSs: one that Oglethorpe Power Corporation operates for power quality improvement and one that Crescent Electric Membership Coop operates for peak shaving. Work has begun on the ESS portion of the project.

The NRECA portion of the project will support field demonstrations of the energy storage simulators and the development, validation, and field demonstration of a diesel generator simulator. NRECA validation and demonstration activities will be hosted at sites within Oglethorpe's and Crescent's service territories. Work on the NRECA portion of the project began in late August 1997. 
The project team of Energetics, Inc., and Orion Energy Corporation is developing the simulators, conducting the simulations, and analyzing the output of the simulators. For the validations, analysis consists of comparing the simulator behavior with the real energy storage systems. For the demonstrations, analysis will determine the financial feasibility of the utility hardware being mimicked. Work began on the ESS portion of the project in June 1997. Work on the NRECA portion of the project began in late August 1997.

\section{Status}

Progress on the collaborative project between the ESS Program and NRECA produced design specifications for a device to simulate the operation of a batterybased integrated system to reduce customer demand peaks. Work on the peak-shaving simulator led to major conceptual modifications that were included in the design specifications for a device to simulate a batterybased integrated system to improve power quality. The most significant modification to the initial design concept for the power quality simulator is the elimination of an external power quality monitor. This change allowed both systems to share hardware and topology, with the exception of a differentiated programmable chip.

Orion Energy Corporation expects to complete construction and testing of the peak-shaving simulator and to install the simulators at the Crescent and Oglethorpe sites in the first quarter of FY98. Orion Energy and Energetics will operate the simulators for 3 to $6 \mathrm{mo}$ to validate them against the actual peak-shaving and power quality systems that they mimic. Installation of the simulators for demonstrations was scheduled for spring 1998, during which time the financial feasibility of using the utility hardware being mimicked will be analyzed.

\section{Lead-Acid Battery Evaluation at SNL}

\section{VRLA Absorbed Glass Mat Testing}

SNL has been testing the performance of VRLA batteries both to address the requirements of deliverables from the GNB battery development program and to determine the suitability of various manufacturers' products for energy storage applications. Utility and telecommunications users of VRLA-based systems have experienced field failures and reliability problems. Con- trolled laboratory tests are the best method of evaluating battery performance and determining capacity degradation rates and mechanisms. While field tests and controlled laboratory tests would both reveal similar information, with field tests there are almost always too many uncontrolled variables to allow a complete understanding of the relevant cause-and-effect relationships.

Testing of contract deliverables from the GNB VRLA development contract continued at SNL in FY97. Two 18-V batteries, an ABSOLYTE II and an ABSOLYTE IIP, have undergone extensive testing. Battery maintenance issues and capacity losses observed to this point were discussed with GNB to determine whether any abnormal changes were occurring. GNB also described its most recent cell design, the ABSOLYTE XI. This was developed in FY97 in collaboration with Nippon Telephone and Telegraph in response to its request for a high-capacity sealed cell that would reduce the need for external paralleling of connections. Both 2000- and 3000-Ah cell designs are being built and use some of the same materials (e.g., grid alloy) as previous ABSOLYTE designs. Other features (seals, plate growth allowance) have been redesigned, and this effort benefited from information obtained during the ESS development program. The XI cell is anticipated to provide improved reliability, higher energy density, and better power capability in large stationary battery applications.

In addition, a VRLA battery from Yuasa-Exide was tested to characterize the technology. The following subsections detail test results from the two ABSOLYTE units and the VRLA battery from Yuasa-Exide. All three batteries will remain on test until the units have lost $20 \%$ of their rated capacity. The data generated in these tests will also be used in the VRLA Reliability Improvement task.

\section{ABSOLYTE IIP Testing}

\section{Status}

The ABSOLYTE IIP is a 9-cell, 18-V, VRLA battery rated at $1200 \mathrm{Ah}$ at a $\mathrm{C} / 8$ discharge rate. Testing of the ABSOLYTE IIP deliverable from the GNB battery development project began in September 1994. The battery capacity was initially determined at several different discharge rates and then the unit was tested to evaluate its suitability for a defined frequency-regulation/ spinning-reserve UES cycle. These tests were completed in June 1996, and the battery was placed on a lifecycle testing regime beginning with Cycle 171 on August 7, 1996. Some adjustments to the charge profiles were made to improve compatibility between the 
tester and battery and to improve charge acceptance of the battery. For details of these test results, see the ESS Program FY96 Annual Progress Report. The life-cycle testing will continue until the battery reaches $960 \mathrm{Ah}$, $80 \%$ of rated capacity. Capacity at the end of FY97 was $1100 \mathrm{Ah}$.

During the first quarter of FY97, life-cycle testing continued using a C/8 (150-A) discharge, followed by the ABSOLYTE IIP F-charge regime defined in Table 3-1. Amp-hours charge and discharge are shown for all quarters of FY97 in Figure 3-1. Capacity, which had been steadily declining in FY96, continued to decline, and a boost charge was performed at Cycle 211, which raised the capacity slightly. Capacity continued to decline through the first quarter, decreasing from approximately $1190 \mathrm{Ah}$ to $1130 \mathrm{Ah}$.

Cells 3 and 5 EOD voltages were low throughout the first quarter, as is shown in Figure 3-2. The EOD voltage of Cell 5 was improved somewhat by the boost charge at Cycle 211 but not enough to bring it to the average of the other cells. A decision was made to continue life-cycle testing.

Life-cycle testing of the ABSOLYTE IIP battery continued during the second quarter of FY97. Tester malfunctions and electrolyte level adjustments limited the number of cycles during this period to 18 , bringing the total number to 283. At Cycle 266, the beginning of the second quarter, each cell was removed from the battery, weighed, and replaced. The weights shown in Table 3-2 are compared to the original weights. The average weight loss was about $1 \mathrm{~kg}$. A C/8 equalization charge to $125 \%$ was done at Cycle 267 and life cycling resumed. As in the previous quarter, the life cycles consisted of a $\mathrm{C} / 8$ discharge at $150 \mathrm{~A}$ to a cutoff voltage of $15.75 \mathrm{~V}$ (an average of $1.75 \mathrm{~V} /$ cell) and the ABSOLYTE IIP F-charge regime shown in Table 3-1. Tester malfunctions produced incomplete data and uncertain charging from Cycle 268 through Cycle 274.

At Cycle $270,300 \mathrm{ml}$ of deionized water was added to each cell. An equalization charge to $1,720 \mathrm{Ah}$ was performed at Cycle 275, and life cycles resumed with varying $\mathrm{C} / 8$ capacities of $1160 \mathrm{Ah}$ to $1200 \mathrm{Ah}$ measured. At the end of Cycle 281, 400 to $900 \mathrm{ml}$ of deionized water was added to each cell to bring the weight back up to its original value (see Table 3-2). Cells 1, 4, and 6 vented on Cycle 282, and the test was halted. All cells were examined for electrolyte level and found to be satisfactory. An equalization charge was performed during Cycle 283 to $1,580 \mathrm{Ah}$ and testing was resumed at the end of the second quarter. EOD cell voltages varied

\section{Table 3-1. ABSOLYTE IIP Test Regimes}

\begin{tabular}{|c|c|}
\hline F-Charge & G-Charge \\
\hline Discharge at $150 \mathrm{~A}$ to cutoff of $15.75 \mathrm{~V}$ & Discharge at $150 \mathrm{~A}$ to cutoff of $15.75 \mathrm{~V}$ \\
\hline 5-min rest & 5-min rest \\
\hline $\begin{array}{l}\text { Constant-voltage charge at } 21.6 \mathrm{~V} \text { with a } 300-\mathrm{A} \text { current } \\
\text { limit, tapering to } 24 \mathrm{~A} \text { or to amp-hours returned equal to } \\
\text { amp-hours removed }\end{array}$ & $\begin{array}{l}\text { Constant-voltage charge at } 19.2 \mathrm{~V} \text { with a } 300-\mathrm{A} \text { current } \\
\text { limit, tapering to } 24 \mathrm{~A} \text { or to amp-hours returned equal to } \\
\text { amp-hours removed }\end{array}$ \\
\hline Wait until battery cools below $40^{\circ} \mathrm{C}$ & Wait until battery cools below $40^{\circ} \mathrm{C}$ \\
\hline $\begin{array}{l}\text { Constant-voltage charge at } 21.6 \mathrm{~V} \text { with a } 300-\mathrm{A} \text { current } \\
\text { limit, tapering to } 24 \mathrm{~A} \text { or to } 7 \% \text { overcharge }\end{array}$ & $\begin{array}{l}\text { Constant-voltage charge at } 19.2 \mathrm{~V} \text { with a } 300-\mathrm{A} \text { current } \\
\text { limit, tapering to } 24 \mathrm{~A} \text { or to } 7 \% \text { overcharge }\end{array}$ \\
\hline 5-min rest & 5-min rest \\
\hline Charge at $24 \mathrm{~A}$ to $7 \%$ overcharge, or to $23.85 \mathrm{~V}$ & Charge at $24 \mathrm{~A}$ to $7 \%$ overcharge, or to $21.2 \mathrm{~V}$ \\
\hline Wait until battery cools below $27^{\circ} \mathrm{C}$ & Wait until battery cools below $27^{\circ} \mathrm{C}$ \\
\hline
\end{tabular}




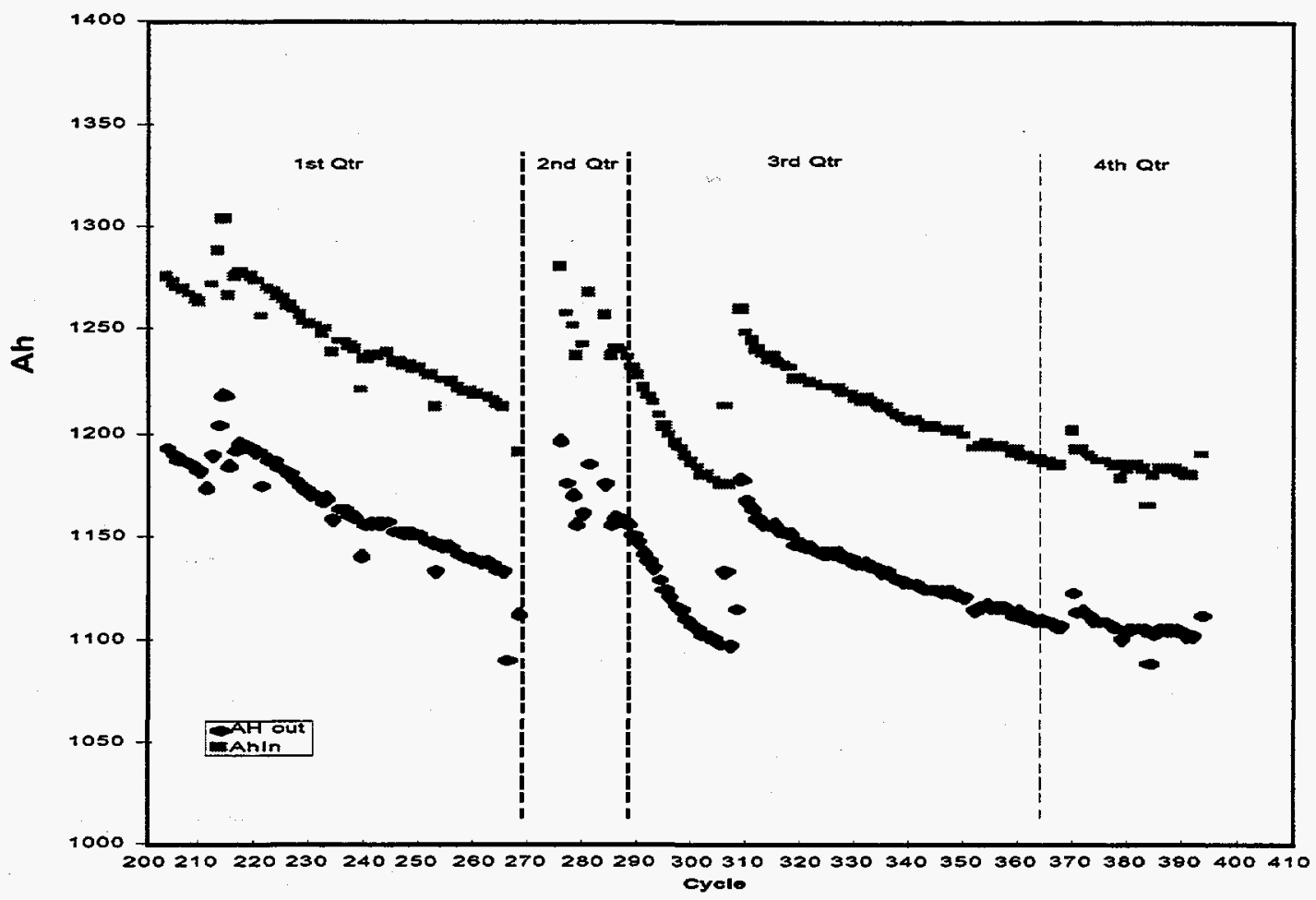

TRI-BATT-0029-0

Figure 3-1. Amp-Hours Removed (Capacity) and Returned for the ABSOLYTE IIP Battery for FY97.

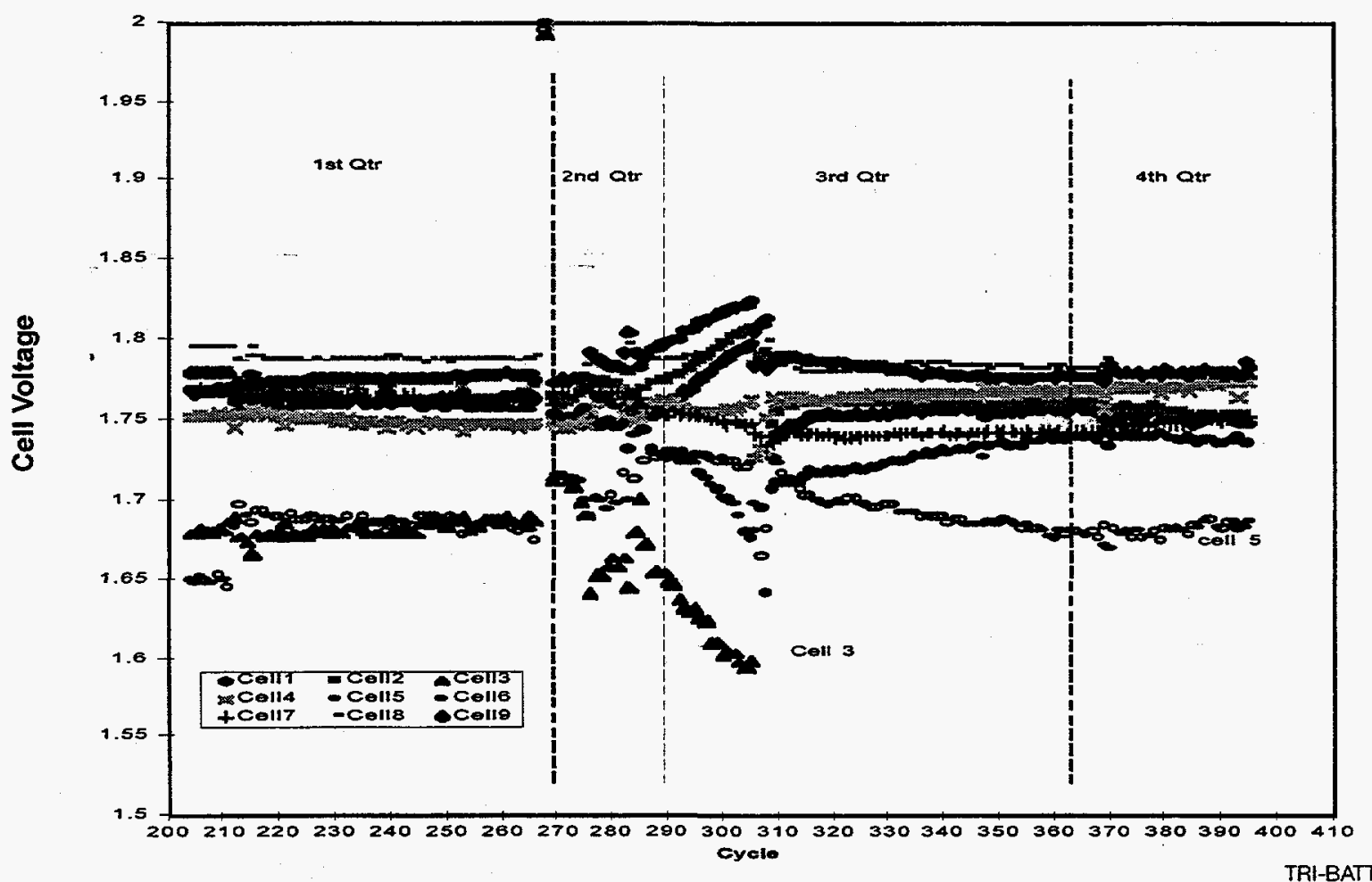

TRI-BATT-0030-0

Figure 3-2. Cell Voltages at EOD for the ABSOLYTE IIP Battery for FY97. 
Table 3-2. Water Loss Data for the ABSOLYTE IIP

\begin{tabular}{|c|c|c|c|c|c|c|c|c|c|}
\hline $\begin{array}{l}\text { SNL } \\
614 \\
\text { Cells }\end{array}$ & $\begin{array}{c}\text { Weight } \\
\text { as of } \\
\text { Dec. 16, } \\
1994 \\
(\mathbf{k g})\end{array}$ & $\begin{array}{c}\text { Weight } \\
\text { as of } \\
\text { Jan. 16, } \\
1997 \\
\text { (kg) }\end{array}$ & $\begin{array}{l}\text { Weight } \\
\text { Loss } \\
\text { after Two } \\
\text { Years } \\
\text { (kg) }\end{array}$ & $\begin{array}{c}\text { Water } \\
\text { Added } \\
\text { Jan. 29, } \\
1997 \\
(\mathrm{ml})\end{array}$ & $\begin{array}{c}\text { Water } \\
\text { Added } \\
\text { Mar. 6, } \\
1997(\mathrm{ml})\end{array}$ & $\begin{array}{c}\text { Calculated } \\
\text { Weight with } \\
\text { Water Added } \\
\text { (kg) }\end{array}$ & $\begin{array}{c}\text { Weight } \\
\text { on Mar. } \\
\text { 11, 1997 } \\
\text { (kg) }\end{array}$ & $\begin{array}{l}\text { Weight } \\
\text { Lost Due } \\
\text { to Vent- } \\
\text { ing (kg) }\end{array}$ & $\begin{array}{l}\text { Liquid } \\
\text { Equiva- } \\
\text { lent (mi) }\end{array}$ \\
\hline 1 & 73.70 & 72.62 & -1.08 & 300 & 630 & 73.55 & 73.42 & 0.13 & 130 \\
\hline 2 & 73.11 & 71.74 & -1.37 & 300 & 900 & 72.94 & 72.93 & 0.01 & 10 \\
\hline 3 & 72.76 & 71.86 & -0.90 & 300 & 630 & 72.79 & 72.66 & 0.13 & 130 \\
\hline 4 & 72.91 & 71.89 & -1.02 & 300 & 630 & 72.82 & 72.58 & 0.24 & 240 \\
\hline 5 & $72.51^{\prime}$ & 71.74 & -0.77 & 300 & 400 & 72.44 & 72.30 & 0.14 & 140 \\
\hline 6 & 74.56 & 73.67 & -0.89 & 300 & 630 & 74.60 & 74.42 & 0.18 & 180 \\
\hline 7 & 74.31 & 73.25 & -1.06 & 300 & 630 & 74.18 & 73.93 & 0.25 & 250 \\
\hline 8 & 74.11 & 73.05 & -1.06 & 300 & 630 & 73.98 & 73.82 & 0.16 & 160 \\
\hline 9 & 73.60 & 72.55 & -1.05 & 300 & 630 & 73.48 & 73.32 & 0.16 & 160 \\
\hline Total & 661.57 & 652.37 & -9.20 & 2700 & 5710 & 587.23 & 585.96 & 1.27 & 1270 \\
\hline
\end{tabular}

during this period, with Cell 5 slightly improved and Cell 3 degrading to $1.65 \mathrm{~V}$.

Life-cycle testing of the ABSOLYTE IIP battery in the third quarter continued with $\mathrm{C} / 8$ discharges to $15.75 \mathrm{~V}$ followed by the ABSOLYTE IIP F-charge regime for Cycles 284 to 305 . EOD voltages of Cells 1 , 2,8 , and 9 increased during this period, while Cells 3 and 6 decreased in EOD voltage. By Cycle 306, Cell 3 EOD voltage had declined to $1.58 \mathrm{~V}$, and Cell 3 was bypassed for the remainder of the life-cycle tests. Testing resumed using the ABSOLYTE IIP G-charge regime (shown in Table 3-2), which is the F-charge regime adjusted for the lower total battery voltage.

An equalization charge to $2400 \mathrm{Ah}$ was performed on Cycle 308 in an attempt to reduce the variation in EOD cell voltages. The immediate result was to reduce the unusually high voltages of Cells $1,2,8$, and 9 and to boost capacity from approximately $1100 \mathrm{Ah}$ to approximately $1175 \mathrm{Ah}$. Testing continued using C/8 discharges to $14.0 \mathrm{~V}$, followed by the G-charge regime. Capacity continued to decline after the boost charge, reaching $1115 \mathrm{Ah}$ by Cycle 356 at the end of the third quarter of FY97. EOD voltage of Cell 6 improved steadily after the boost charge, while the EOD voltage of Cell 5 degraded to $1.68 \mathrm{~V}$.
Testing continued in the fourth quarter of FY97 with the same charge and discharge life-cycle profiles, with all EOD cell voltages remaining essentially unchanged and moderate decline in the capacity from $1115 \mathrm{Ah}$ at Cycle 356 to $1100 \mathrm{Ah}$ at Cycle 395. A boost charge was done at Cycle 369 to $2100 \mathrm{Ah}$, with essentially no effect. A tester malfunction halted testing on September 18, 1997, at Cycle 395.

\section{ABSOLYTE II Testing}

Testing of the ABSOLYTE II battery resumed in FY97. The ABSOLYTE II is similar to the ABSOLYTE IIP but has a rated capacity of $1040 \mathrm{Ah}$ at a C/8 discharge rate, although measured capacity at the beginning of testing was approximately $1300 \mathrm{Ah}$ at a 150 -A discharge rate. Various tests were done in FY96 to compare the performance of the ABSOLYTE II and ABSOLYTE IIP batteries (see ESS Program Progress Report FY96 Annual, Figures 4-3 through 4-5). Because of tester problems, the ABSOLYTE II remained on open circuit from April 5, 1996, until the resumption of testing on November 5,1996 . Life-cycle testing continued to December 16,1996, when testing was suspended for 6 weeks. Life-cycle testing resumed on January 31, 1997, and continued to March 11, 1997, 
when a tester malfunction halted testing. The battery remained on open circuit for the remainder of FY97.

During the first quarter, charge and discharge activities followed the ABSOLYTE II E-charge regime (shown in Table 3-3), with capacity gradually increasing. Amp-hours removed and returned during testing in the first and second quarters of FY97 are shown in Figure 3-3.

Testing continued into the second quarter, with charge cycles occasionally interrupted by battery high temperature alarms. To avoid the high temperatures, a change was made at Cycle 118 to put the ABSOLYTE II on the F-charge regime (Table 3-3), which includes a cool-down period to $<40^{\circ} \mathrm{C}$ after Charge 1 and two separate 24-A charge periods. The charge times proved to be unacceptably long, and at Cycle 140 the ABSOLYTE II was put on the G-charge regime (Table 3-3), in which the second 24-A charge was eliminated. One cycle was done with the G-charge, and the testing was halted because of a tester malfunction. At this time, March 11, 1997 , the battery capacity had declined slightly to $1160 \mathrm{Ah}$.

\section{Yuasa-Exide Testing}

Life-cycle testing of the Yuasa-Exide battery began in July 1995. The battery contains 11 Dynacell DD cells. Because of a lack of data channels, 9-cell voltages were monitored. The battery has a rated capacity of 110 Ah at an 8-hr rate to $10.25 \mathrm{~V}(1.75 \mathrm{~V}$ per cell $)$.

Testing continued in FY97 from Cycle 101, initially using the Yuasa-Exide F-charge regime shown in Table 3-4. Amp-hours removed and returned during cycles in FY97 are shown in Figure 3-4. Voltages for Cells 1 to 9 are shown in Figure 3-5 for the same cycles. While battery capacity remained relatively constant during the first quarter, Cell $1 \mathrm{EOD}$ voltage steadily declined while Cell 5 EOD voltage, which was initially low, steadily increased. A boost charge was performed at Cycle 153 to equalize cell voltages. The procedure brought Cell 1 up to the average of other cells, but Cell 6 dropped sharply in EOD voltage. Battery capacity was increased slightly by the boost charge. The battery was on open circuit from December 18, 1996, to January 13, 1997 , because of the holiday shutdown and tester recalibration.

Table 3-3. ABSOLYTE II Test Regimes

\begin{tabular}{|c|c|c|}
\hline E-Charge & F-Charge & G-Charge \\
\hline $\begin{array}{l}\text { Discharge at } 150 \mathrm{~A} \text { to cutoff of } \\
15.75 \mathrm{~V}\end{array}$ & $\begin{array}{l}\text { Discharge at } 150 \mathrm{~A} \text { to cutoff of } \\
15.75 \mathrm{~V}\end{array}$ & $\begin{array}{l}\text { Discharge at } 150 \mathrm{~A} \text { to cutoff of } \\
15.75 \mathrm{~V}\end{array}$ \\
\hline 5-min rest & 5-min rest & 5-min rest \\
\hline $\begin{array}{l}\text { Charge at } 21.6 \mathrm{~V} \text { with a } 300-\mathrm{A} \\
\text { current limit, tapering to } 24 \mathrm{~A} \text { or } \\
\text { to } 7 \% \text { overcharge }\end{array}$ & $\begin{array}{l}\text { Charge at } 21.6 \mathrm{~V} \text { with a } 300-\mathrm{A} \\
\text { current limit, tapering to } 24 \mathrm{~A} \text { or } \\
\text { to amp-hours returned equal to } \\
\text { amp-hours removed }\end{array}$ & $\begin{array}{l}\text { Charge at } 21.6 \mathrm{~V} \text { with a } 300-\mathrm{A} \\
\text { current limit, tapering to } 24 \mathrm{~A} \text { or } \\
\text { to amp-hours returned equal to } \\
\text { amp-hours removed }\end{array}$ \\
\hline 3-min rest & $\begin{array}{l}\text { Wait until battery cools below } \\
40^{\circ} \mathrm{C}\end{array}$ & $\begin{array}{l}\text { Wait until battery cools below } \\
40^{\circ} \mathrm{C}\end{array}$ \\
\hline $\begin{array}{l}\text { Charge at } 24 \mathrm{~A} \text { to } 7 \% \text { overcharge } \\
\text { or to } 23.85 \mathrm{~V}\end{array}$ & $\begin{array}{l}\text { Charge at } 24 \mathrm{~A} \text { to } 7 \% \text { overcharge } \\
\text { or to } 21.6 \mathrm{~V}\end{array}$ & $\begin{array}{l}\text { Charge at } 24 \text { A to } 7 \% \text { overcharge } \\
\text { or to } 23.85 \mathrm{~V}\end{array}$ \\
\hline \multirow[t]{3}{*}{$\begin{array}{l}\text { Wait until battery cools below } \\
27^{\circ} \mathrm{C}\end{array}$} & 3-min rest & $\begin{array}{l}\text { Wait until battery cools below } \\
27^{\circ} \mathrm{C}\end{array}$ \\
\hline & $\begin{array}{l}\text { Charge at } 24 \mathrm{~A} \text { to } 7 \% \text { overcharge } \\
\text { or to } 23.85 \mathrm{~V}\end{array}$ & \\
\hline & 5-min rest & \\
\hline
\end{tabular}




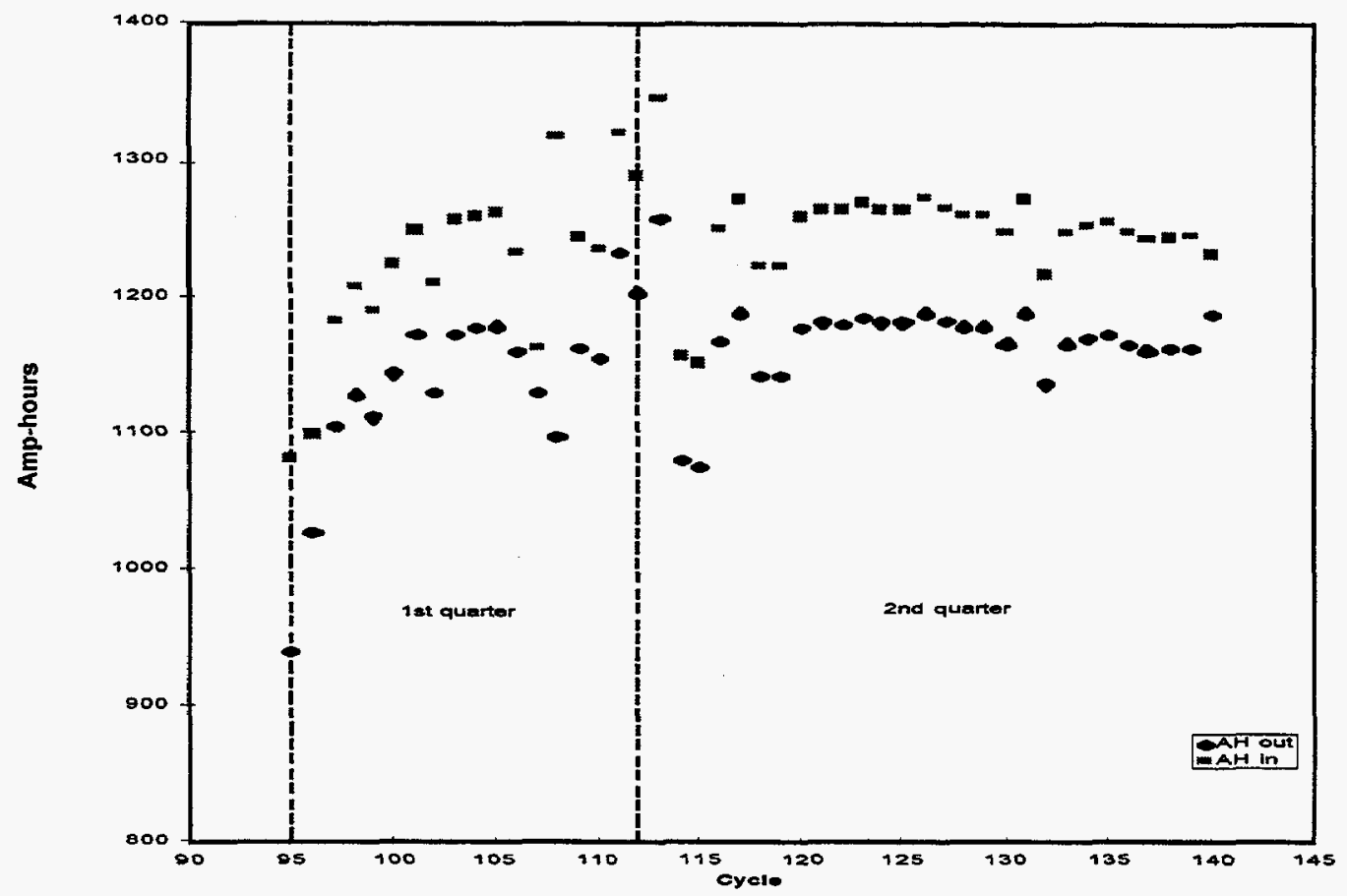

Figure 3-3. Amp-Hours Removed (Capacity) and Returned for the ABSOLYTE II.

Table 3-4. Yuasa-Exide Test Regimes

\begin{tabular}{|c|c|c|}
\hline F-Charge & G-Charge & H-Charge \\
\hline Discharge at $13.5 \mathrm{~A}$ to $19.25 \mathrm{~V}$ & Discharge at $13.5 \mathrm{~A}$ to $19.25 \mathrm{~V}$ & Discharge at $13.5 \mathrm{~A}$ to $19.25 \mathrm{~V}$ \\
\hline 5-min rest & 5-min rest & 5-min rest \\
\hline $\begin{array}{l}\text { Charge at } 44 \mathrm{~A} \text { to } 25.85 \mathrm{~V} \text {, or cut- } \\
\text { off at } 5 \% \text { overcharge }\end{array}$ & $\begin{array}{l}\text { Charge at } 44 \mathrm{~A} \text { to } 25.85 \mathrm{~V} \text {, or cut- } \\
\text { off at } 5 \% \text { overcharge or current } \\
\text { drop to } 0.1 \mathrm{~A}\end{array}$ & $\begin{array}{l}\text { Charge at } 44 \mathrm{~A} \text { to } 23.5 \mathrm{~V} \text {, or cut- } \\
\text { off at } 5 \% \text { overcharge or current } \\
\text { drop to } 0.1 \mathrm{~A}\end{array}$ \\
\hline 5-min rest & 5-min rest & 5-min rest \\
\hline $\begin{array}{l}\text { Charge at } 3 \mathrm{~A} \text { for } 8 \mathrm{hr} \text {, or to a cut- } \\
\text { off of } 26.9 \mathrm{~V}\end{array}$ & $\begin{array}{l}\text { Charge at } 3 \mathrm{~A} \text { for } 8 \mathrm{hr} \text {, or to a cut- } \\
\text { off of } 26.9 \mathrm{~V}\end{array}$ & $\begin{array}{l}\text { Charge at } 3 \mathrm{~A} \text { for } 8 \mathrm{hr} \text {, or to a cut- } \\
\text { off of } 24.5 \mathrm{~V}\end{array}$ \\
\hline 5-min rest & 5-min rest & 5-min rest \\
\hline $\begin{array}{l}\text { Wait until battery cools below } \\
29^{\circ} \mathrm{C}\end{array}$ & $\begin{array}{l}\text { Wait until battery cools below } \\
29^{\circ} \mathrm{C}\end{array}$ & $\begin{array}{l}\text { Wait until battery cools below } \\
29^{\circ} \mathrm{C}\end{array}$ \\
\hline
\end{tabular}




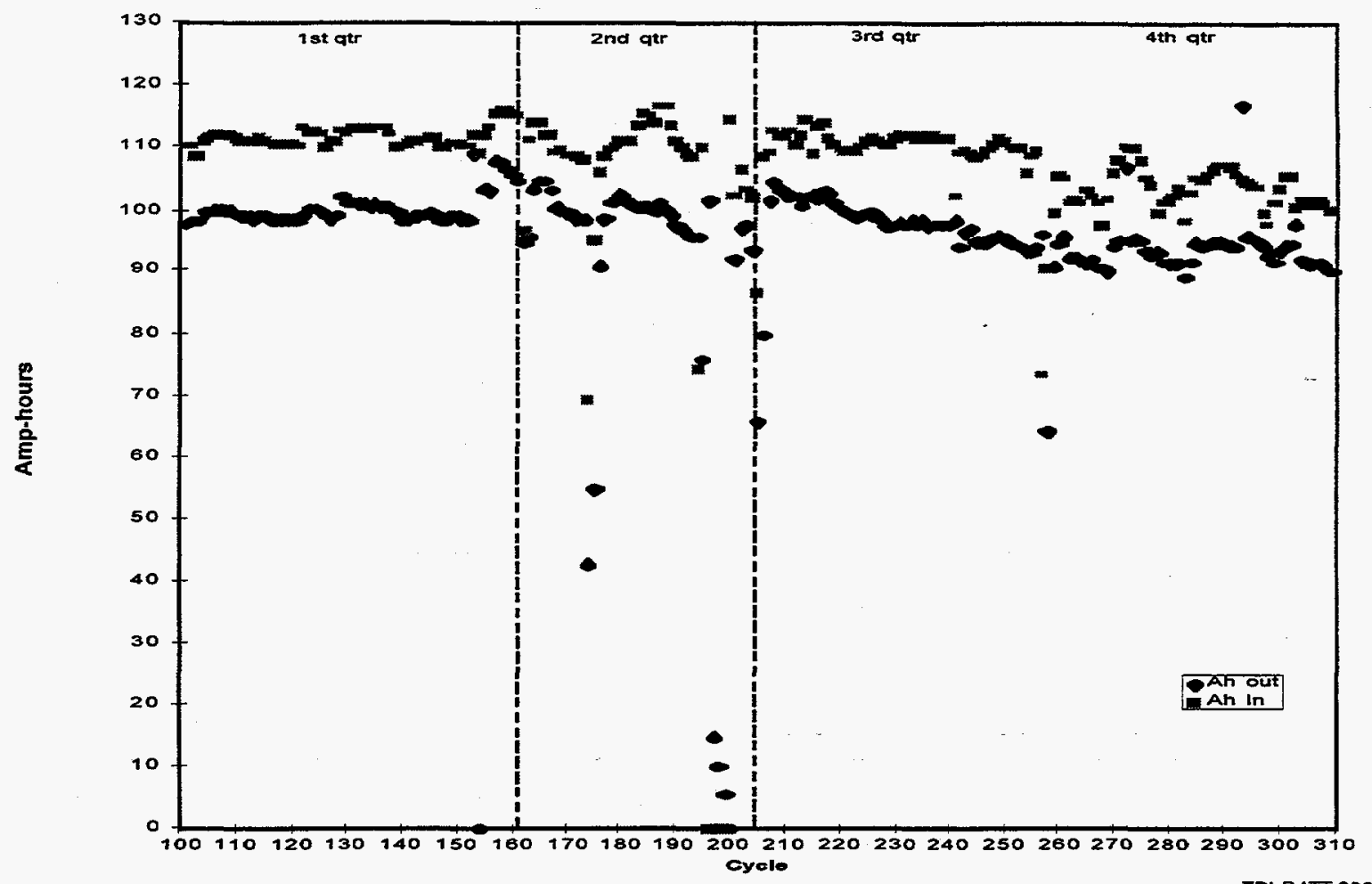

TRI-BATT-0032-0

Figure 3-4. Amp-Hours Removed (Capacity) and Returned for the Yuasa-Exide Battery for FY97.

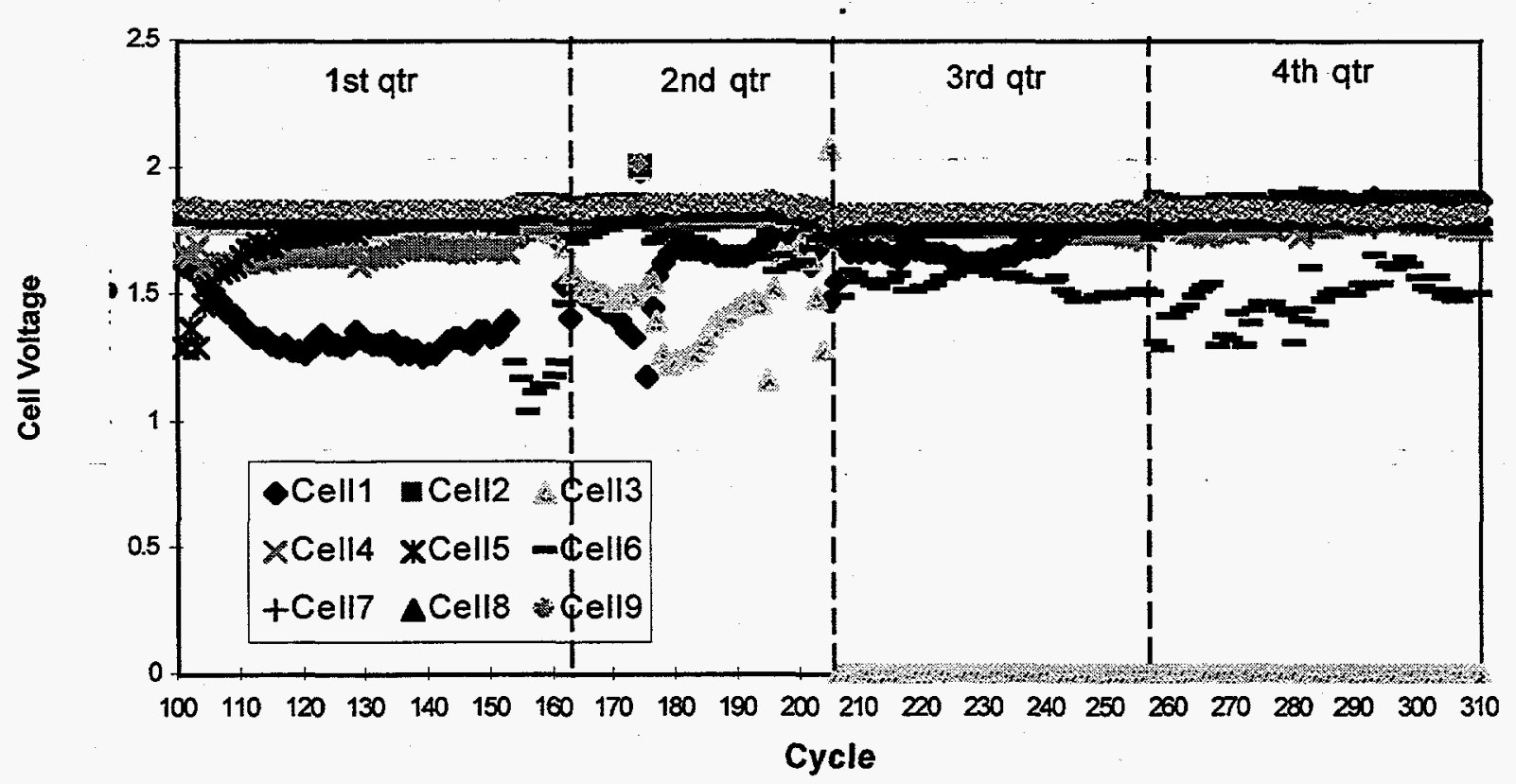

Figure 3-5. Cell Voltages at EOD for the Yuasa-Exide Battery for FY97. 
Testing continued in the second quarter of FY97 with the Yuasa-Exide F-charge regime. Cells 1 and 3 began the new testing period with low EOD voltages, and continued to decline, with a corresponding decline in battery capacity. A boost charge at Cycle 173 improved battery capacity and EOD voltage of Cell 1, but Cell 3 EOD voltage declined further. At Cycle 194, the charge parameters were changed to the Yuasa-Exide G-charge regime (see Table 3-4). Erratic tester operation caused data loss between Cycles 195 and 204.

A decision was made at the beginning of the third quarter (at Cycle 205) to bypass Cell 3, and the charge parameters were changed to the Yuasa-Exide $\mathrm{H}$-charge regime (Table 3-4) to accommodate the lower battery voltage. Battery capacity and EOD Cell 6 voltage continued to decline during the third quarter.

Testing continued through the fourth quarter, with EOD voltage of Cell 6 continuing to be erratic and declining. Battery capacity reached $90 \mathrm{Ah}$ by the end of the fourth quarter, with $88 \mathrm{Ah}$, or $80 \%$ of rated capacity, being end-of-rated life. A decision will be made in the first quarter of FY98 on further testing of this battery.

\section{SLI Battery Cycle Testing}

Late in FY96, Community Power Corporation approached ESS Program staff with a proposal to test an SLI battery destined for use in an offshore domestic PV application; their system is to be used in Indonesia, for a government-sponsored electrification project. A locally manufactured SLI battery, a Yuasa Pafecta type, must be used because there are restrictions on importing batteries to Indonesia and no deep-cycling batteries are manufactured there. Prior experience has shown that SLI batteries do not perform well in a cycling environment.
Consequently, high interest was generated at the prospect of seeing if an SLI battery, with proper care and management, could support a cycling application. All of the batteries were tested at a C/20 discharge rate, and the regime consisted of life-cycling the batteries under a PV test plan that uses electronic power supplies and loads that simulate PV stand-alone components. The duty cycle was determined by the customer (Table 3-5) and is based on array output, battery sizing, and load demand. The battery is slated for use as a residential stand-alone PV/battery system for home lighting, radio, and television. Each system works the same way but differs in array and battery size and will be tailored to meet different system load demands. Strong constraints were placed on rates, PV panel sizing, battery depth of discharge (DOD), and low-voltage disconnect (LVD) levels. Several batteries were placed on test in the ESS Program laboratories. The test target for the batteries was to complete 1,000 daily cycles of $10 \%$ DOD with periodic excursions to the LVD. Energy available for charging the batteries was limited to what could be provided by a $250-\mathrm{W}$ panel on a typical solar day. Partial funding for the project was provided by a small business grant.

\section{Status}

A summary status of all the Yuasa Pafecta SLI leadacid battery cycles completed in FY97 is presented in Table 3-6. The only Yuasa Pafecta SLI lead-acid battery still on test is the 100-Ah battery (SNL ID No. 730). The 100-Ah unit continued testing, returning expected, consistent numbers of subcycles. Representative PV cycles for all of the SLI batteries that were on test are shown in Figures 3-6 through Figure 3-8. Figure 3-6 represents fourth quarter PV cycle data for the 100-Ah unit. In addition to continuous cycling, the battery is

Table 3-5. Customer-Determined Duty Cycle Based on Array Output, Battery Sizing, and Load Demand

\begin{tabular}{cccccccc}
\hline $\begin{array}{c}\text { SNL } \\
\text { ID No. }\end{array}$ & $\begin{array}{c}\text { Battery Rated } \\
\text { Capacity } \\
\text { (Ah @ C/8) }\end{array}$ & $\begin{array}{c}\text { Array } \\
\text { Charge } \\
\text { (A) }\end{array}$ & $\begin{array}{c}\text { Nominal } \\
\text { Array } \\
\text { Output (W) }\end{array}$ & $\begin{array}{c}\text { Daily Array } \\
\text { Recharge } \\
\text { (Ah) }\end{array}$ & $\begin{array}{c}\text { Load } \\
\text { Discharge } \\
\text { (A) }\end{array}$ & $\begin{array}{c}\text { Daily Load } \\
\text { Discharge } \\
\text { (Ah) }\end{array}$ & $\begin{array}{c}\text { Nominal } \\
\text { Load } \\
\text { (W) }\end{array}$ \\
\hline 728 & 40 & 2.34 & 40 & 8.7 & 2.85 & 9.7 & 34 \\
729 & 65 & 3.55 & 60 & 13.4 & 4.42 & 14.9 & 53 \\
730 & 100 & 4.73 & 80 & 17.6 & 5.54 & 19.6 & 67
\end{tabular}


Table 3-6. Summary Status of Yuasa Pafecta SLI Lead-Acid Battery Cycle Activities

\begin{tabular}{ccccccc}
\hline $\begin{array}{c}\text { SNL } \\
\text { ID No. }\end{array}$ & $\begin{array}{c}\text { Rated } \\
\text { Capacity (Ah) }\end{array}$ & $\begin{array}{c}\text { Date } \\
\text { Started }\end{array}$ & $\begin{array}{c}\text { No. of } \\
\text { Cycles }\end{array}$ & $\begin{array}{c}\text { No. of PV } \\
\text { Subcycles }\end{array}$ & $\begin{array}{c}\text { Test } \\
\text { Status }\end{array}$ & $\begin{array}{c}\text { Date } \\
\text { Removed }\end{array}$ \\
\hline 728 & 40 & $10 / 2 / 96$ & 127 & 458 & Off test & $6 / 16 / 97$ \\
729 & 65 & $10 / 2 / 96$ & 125 & 443 & Off test & $6 / 16 / 97$ \\
730 & 100 & $10 / 2 / 96$ & 84 & 881 & Cycling & N/A
\end{tabular}

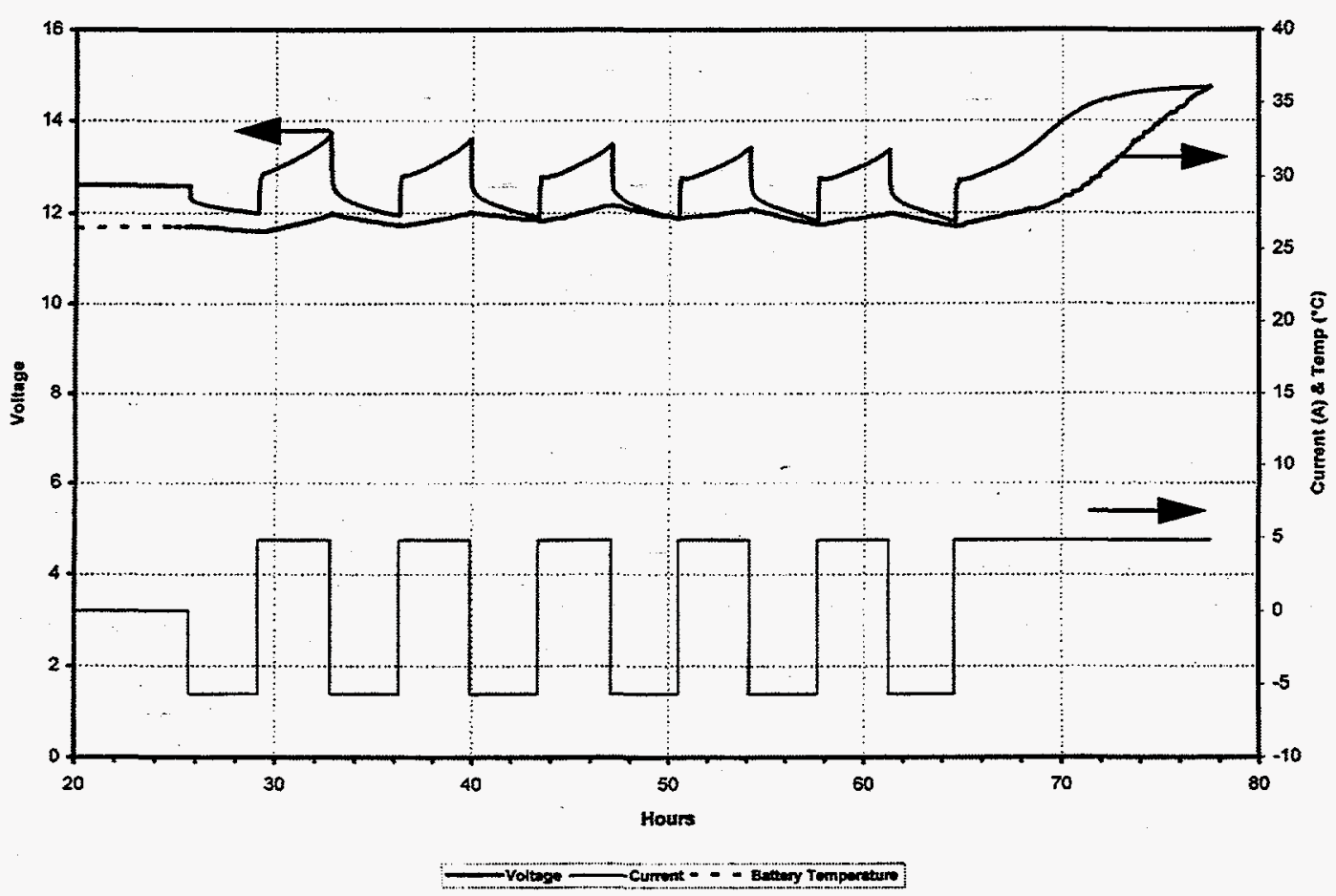

TRI-BATT-0038-0

Figure 3-6. PV Cycles on Yuasa Pafecta NS-100 100-Ah SLI Lead-Acid Battery, SNL ID No. 730, Cycle 36.

jarred and rocked daily to allow bubbles to escape. Also, the 100-Ah model was vigorously bubbled from time to time to alleviate acid stratification. Specific gravity checks prior to and immediately after the bubbling confirmed the successful, albeit temporary, elimination of stratification. Current test results indicate that the 100-Ah model is the likely candidate for PV installation because of its better performance and reduced maintenance.
The 40- and 65-Ah batteries that were on test (SNL ID No. 728 and No. 729) began to steadily decline in performance in the middle of the year and were taken off test in June of FY97. A final capacity verification cycle was run on each battery at this time (Figures 3-9 and 3-10), and it revealed capacities well below the endof-life criteria ( $<50 \%$ rated capacity). 


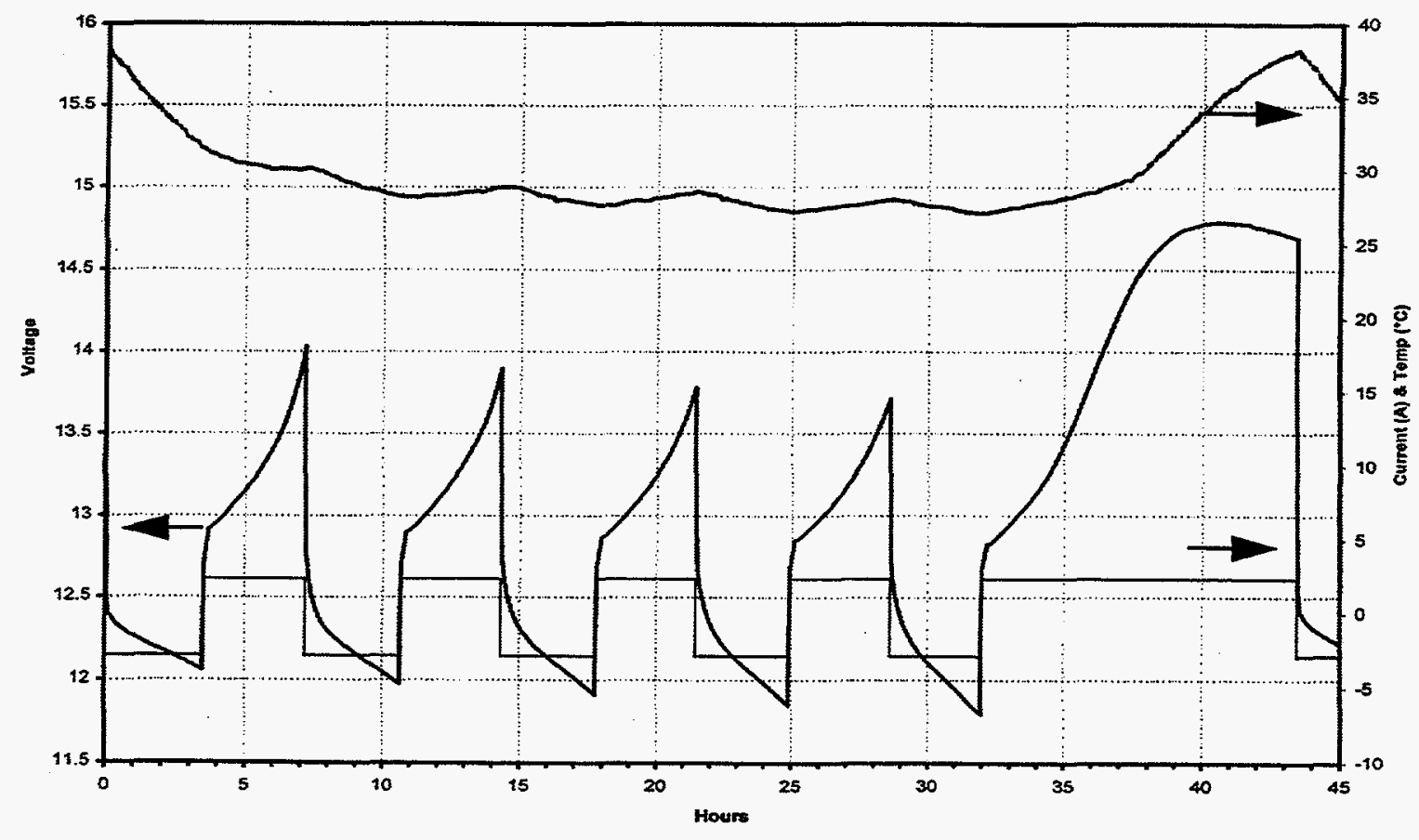

TRI-BATT-0039-0

Figure 3-7. PV Cycles on Yuasa Pafecta NS-40 40-Ah SLI Lead-Acid Battery, SNL ID No. 728, Cycle 67.

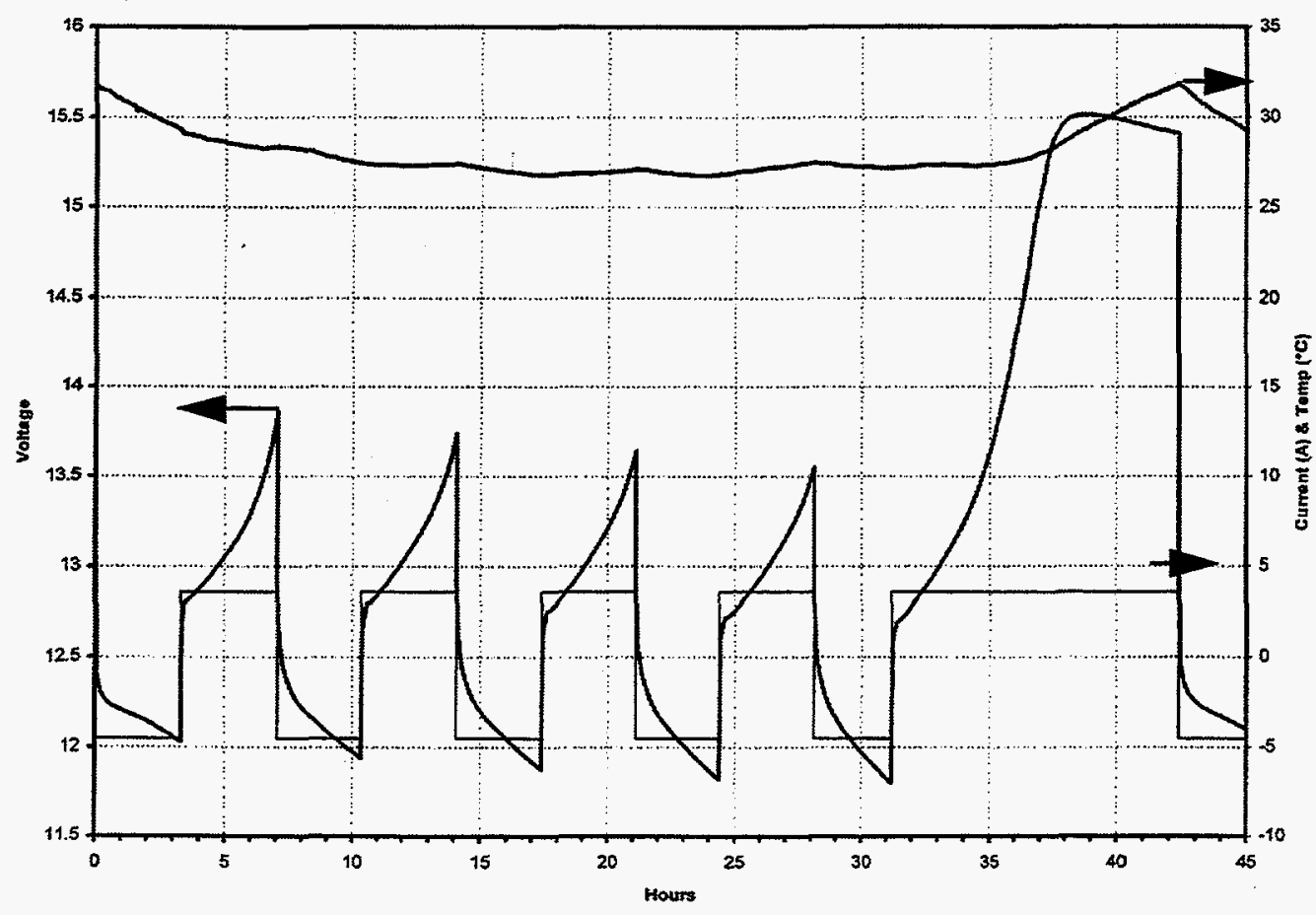

TRI-BATT-0040-0

Figure 3-8. PV Cycles on Yuasa Pafecta NS-70 65-Ah SLI Lead-Acid Battery, SNL ID No. 729, Cycle 60. 


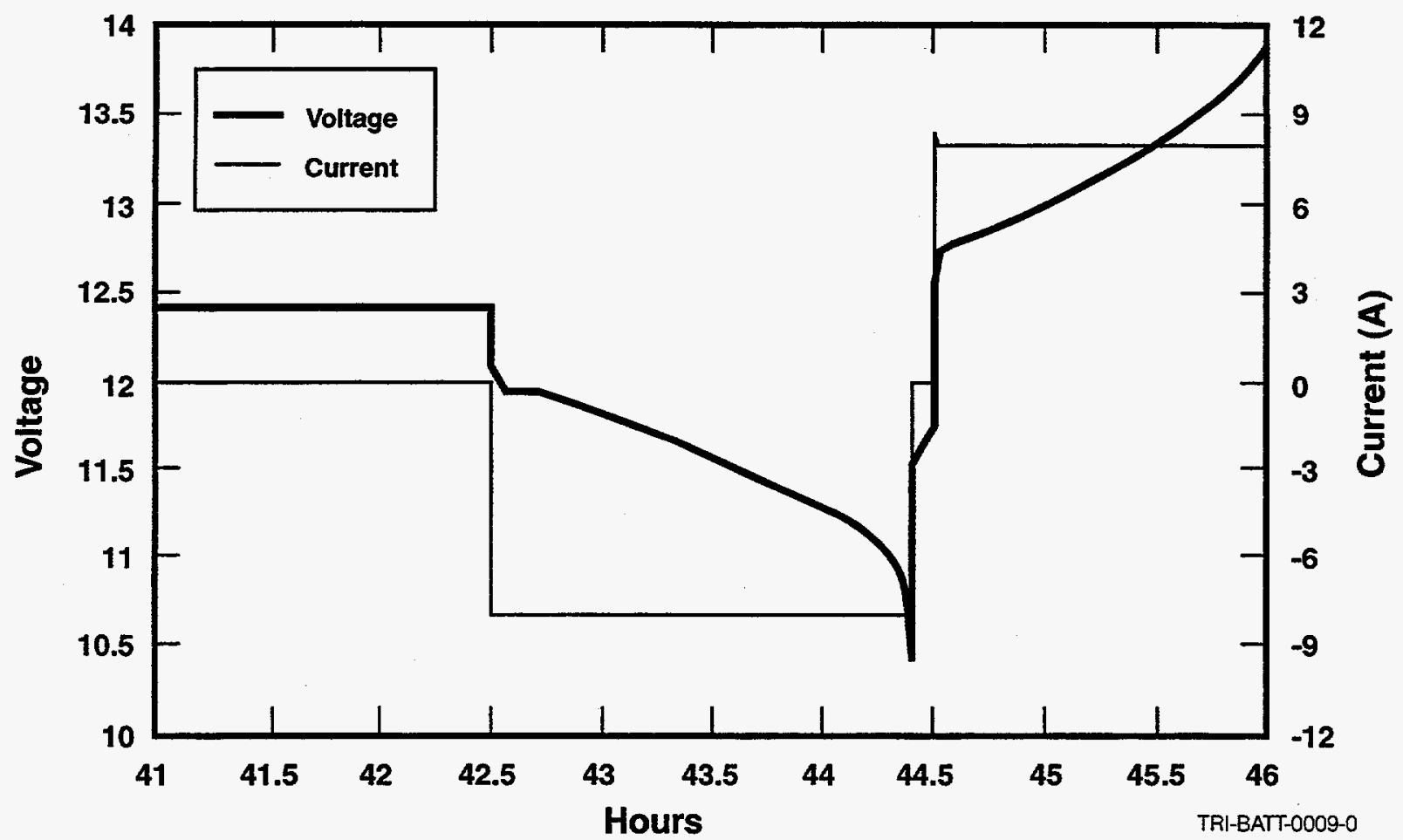

Figure 3-9. Final Capacity Cycle for Yuasa Pafecta NS-40 40-Ah Lead-Acid SLI Battery, SNL ID No. 728, 15 Ah Removed.

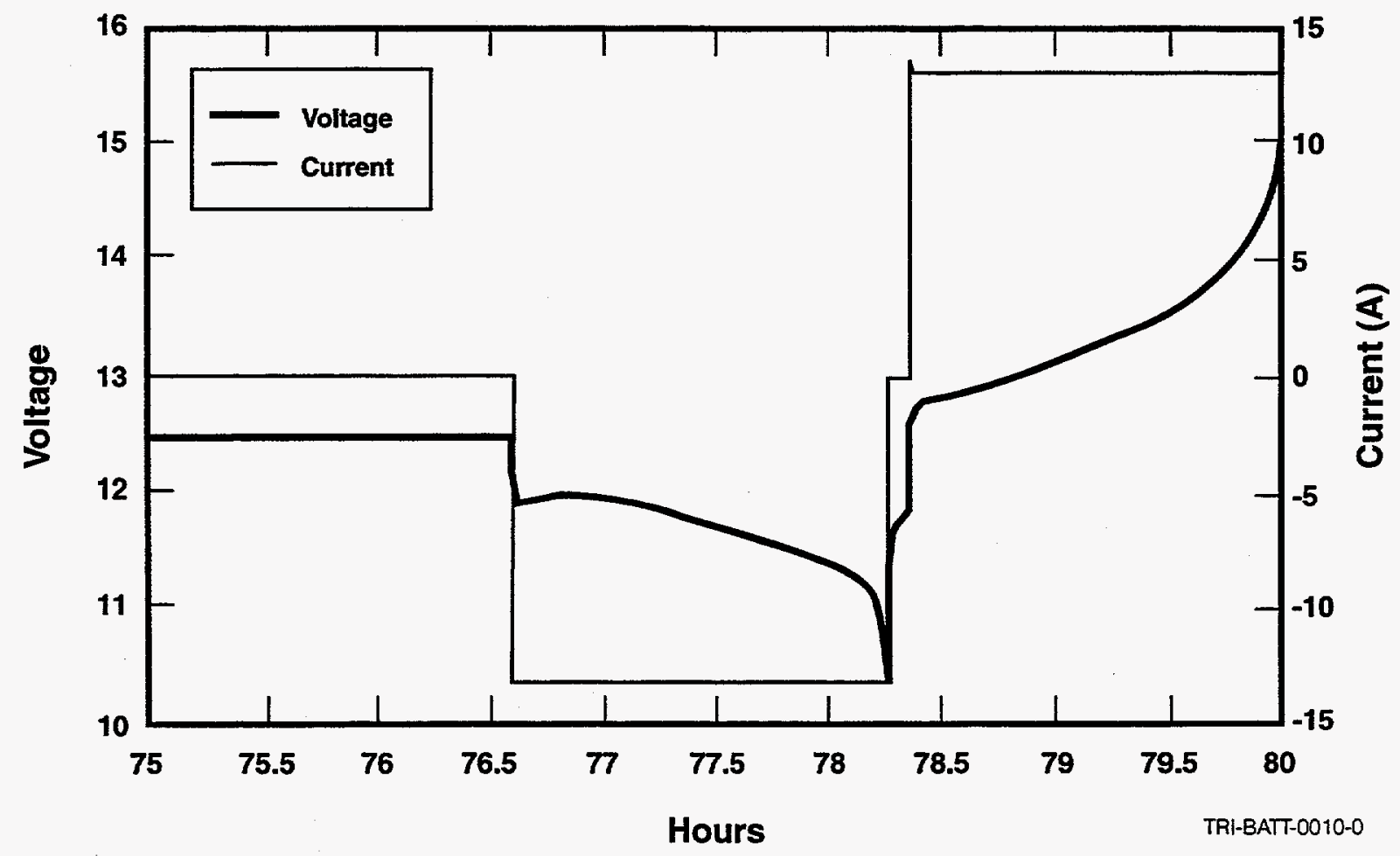

Figure 3-10. Final Capacity Cycle for Yuasa Pafecta NS-70 65-Ah Lead-Acid SLI Battery, SNL ID No. 729, 22 Ah Removed. 
The capacity cycles shown in Table 3-7 were conducted to verify battery performance prior to PV cycling. Although the testing has been repetitive with few changes, the batteries required a fair amount of maintenance, primarily watering (Table 3-8).

Testing has been relatively stable, with little change in battery performance or testing conditions. The following should be noted:

- Battery testing is done in a controlled laboratory with standard environmental conditions. No attempt is being made to simulate the actual environment (tropical/equatorial) that the batteries will operate in, where temperature, humidity, poor maintenance, and varying solar insulation could affect battery performance.
- During the year, all batteries required deionized water; in particular, adding deionized water will continue as a preventive maintenance routine whenever necessary.

- Due to its larger mass and corresponding capacity, the 100-Ah unit provides the highest number of PV cycles and stays cooler.

- The testing regime of the batteries allowed little time on open circuit. Stand periods caused by varying temperatures, humidity, etc. could impact battery performance.

- The testing did not include the PV controller. This device will be critical in the field for maintaining battery discipline.

Table 3-7. Initial Capacity Cycles Run on Yuasa Pafecta Lead-Acid SLI Batteries to Verify Performance Prior to PV Cycling

\begin{tabular}{cccccccc}
\hline $\begin{array}{c}\text { SNL } \\
\text { ID No. }\end{array}$ & $\begin{array}{c}\text { Rated } \\
\text { Capacity } \\
\text { (Ah @ C/8) }\end{array}$ & $\begin{array}{c}\text { Discharge } \\
\text { Rate }\end{array}$ & $\begin{array}{c}\text { EOD } \\
\text { Voltage (V) }\end{array}$ & $\begin{array}{c}\text { Ah } \\
\text { Removed }\end{array}$ & $\begin{array}{c}\text { EOC } \\
\text { Voltage (V) }\end{array}$ & $\begin{array}{c}\text { EOC } \\
\text { Current } \\
\text { (A) }\end{array}$ & $\begin{array}{c}\text { Ah } \\
\text { Returned }\end{array}$ \\
\hline 728 & 40 & $\mathrm{C} / 5$ & 10.44 & 31.22 & 16.28 & 8.132 & 39.11 \\
729 & 65 & $\mathrm{C} / 5$ & 10.34 & 51.55 & 16.63 & 12.370 & 62.85 \\
730 & 100 & $\mathrm{C} / 5$ & 10.88 & 83.75 & 16.47 & 20.489 & 98.52 \\
\hline
\end{tabular}

Table 3-8. FY97 Watering Data for Yuasa Pafecta Lead-Acid SLI Batteries

\begin{tabular}{ccccc}
\hline $\begin{array}{c}\text { SNL } \\
\text { ID No. }\end{array}$ & $\begin{array}{c}\text { Rated } \\
\text { Capacity } \\
\text { (Ah @ C/8) }\end{array}$ & $\begin{array}{c}\text { Battery } \\
\text { Weight (kg) }\end{array}$ & $\begin{array}{c}\text { Total } \\
\text { Water } \\
\text { Added (I) }\end{array}$ & $\begin{array}{c}\text { Water Added } \\
\text { as \% of Battery } \\
\text { Weight (\%) }\end{array}$ \\
\hline 728 & 40 & 11.51 & 1.554 & 13.5 \\
729 & 65 & 17.17 & 2.735 & 15.9 \\
730 & 100 & 27.5 & 4.265 & 15.6
\end{tabular}


PV life cycling on the 100-Ah battery will continue until it is no longer capable of discharging $50 \%$ of rated capacity.

\section{Trojan Battery Prototype—VRLA Gel Battery Testing}

SNL is performing life-cycle testing on four of Trojan Battery Corporation's sealed, gelled, VRLA batteries. The batteries are maintenance-free, deep-cycle, and designed for a 3- to 8-hr duty cycle, with recharging to be performed on any charger with a gel or sealed setting. The batteries have been evaluated in Trojan's laboratories under a number of test conditions and are now being distributed in the field for further evaluation, including the testing currently being performed at SNL. The batteries are discharged daily to $20 \%$ SOC and then charged to full SOC. Equalization is scheduled for every 50 cycles. The test is designed to verify performance, determine cycle life, and identify failure modes.

The objectives of the testing at SNL are to (1) confirm the electrical performance ratings, (2) evaluate the batteries' ability to meet Trojan customer requirements, and (3) determine the service life of the batteries. These batteries were received by SNL on September 17, 1996.

The batteries that are undergoing life-cycle testing are described in Table 3-9. The preconditioning procedure consisted of charging at a constant voltage of $15.0 \mathrm{~V}$ for $24 \mathrm{hr}$.

The Battery Council International life-cycle procedure is shown in Table 3-10.

\section{Status}

The battery tests were started on October 10, 1996. The tests were continued until December 18, 1996, at which time the testers were shut down for annual maintenance and calibration. The tests were resumed at the start of the second quarter of FY97 and continued through the fourth quarter of FY97.

The attached graphs show the capacity of the batteries for each cycle as well as the external battery case temperatures at the end of the cycle (Figures 3-11 through 3-14). During the second quarter of FY97, the test facility experienced temperature fluctuations during battery cycling, and consequently the measured capacity did vary with temperature as shown in the figures. The batteries were moved to a different facility for the remaining cycles starting in the third quarter of FY97.

During the fourth quarter of FY97, SNL ID No. 722 and No. 723 reached their defined end of life of $50 \%$ of initial capacity. SNL ID No. 726 was removed from test in April 1997, because of a cell failure after it was moved to a different test facility for temperature stabilization. The testing of SNL ID No. 727 was to be continued into the first quarter of FY98 because its capacity was still above the defined end of life of $50 \%$ of initial capacity. Table 3-11 shows the status of the four Trojan batteries at the end of FY97.

\section{Zinc-Flow ${ }^{\mathrm{TM}}$ Battery Testing}

In the third quarter of FY97, the ESS Program initiated a contract with Powercell Corporation to conduct testing on Powercell's Zinc-Flow ${ }^{\text {TM }}$ battery. The objec-

Table 3-9. Trojan Gel VRLA Batteries Undergoing Testing at SNL

\begin{tabular}{lcccc}
\hline SNL Battery ID & 722 & 723 & 726 & 727 \\
\hline Battery Type & $2410 \mathrm{GEL}$ & $2410 \mathrm{GEL}$ & $30 \mathrm{H} 14 \mathrm{GEL}$ & $30 \mathrm{H} 14 \mathrm{GEL}$ \\
Serial No. & 1364 & 1365 & 1383 & 1384 \\
Initial Weight $(\mathrm{kg})$ & 21.37 & 21.27 & 28.75 & 28.86 \\
Voltage & 12 & 12 & 12 & 12 \\
Initial Capacity (Ah, C/3) & 34 & 35 & 58 & 60
\end{tabular}




\section{Table 3-10. Trojan VRLA Test Regime}

\footnotetext{
Discharge at 25 A constant-current discharge to $10.5 \mathrm{~V}$, record Ah removed

30-min rest

Charge at constant current of $20 \mathrm{~A}$ until the voltage rises to $14.40 \mathrm{~V}$, then hold the voltage constant and allow the current to taper. Terminate recharge at $15 \%$ overcharge or after a total recharge time of $12 \mathrm{hr}$, whichever comes first

2-hr rest
}

Repeat above for 50 cycles, then perform one boost cycle of constant-current charge for $20 \mathrm{hr}$ at $1.0 \mathrm{~A}$ and $1.4 \mathrm{~A}$ for battery types 24 and $30 \mathrm{H}$, respectively

Repeat above until battery reaches failure, which is defined $<50 \%$ of rated (initial) capacity for two successive cycles

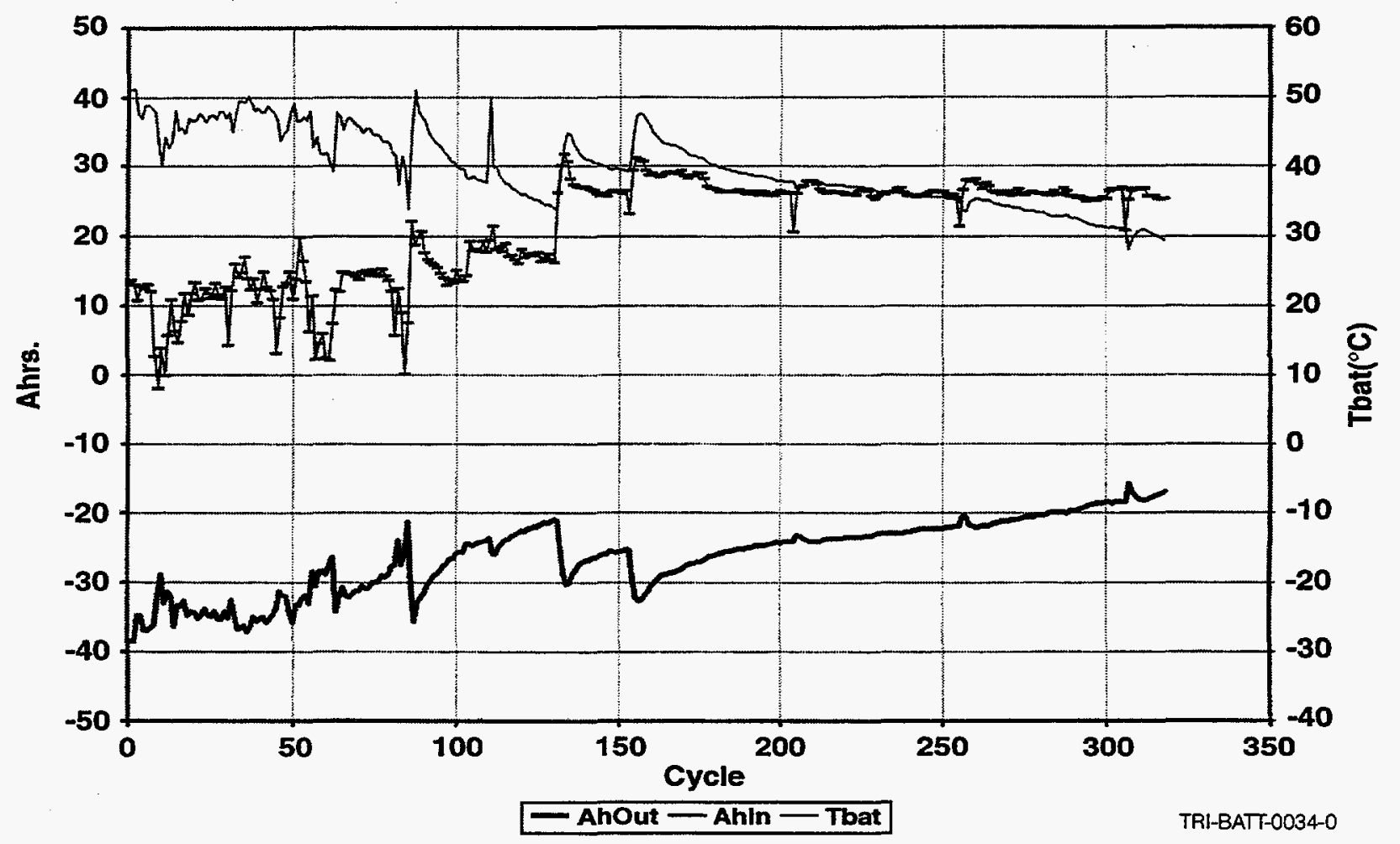

Figure 3-11. Trojan Capacity and Temperature Plot, SNL ID No. 722. 


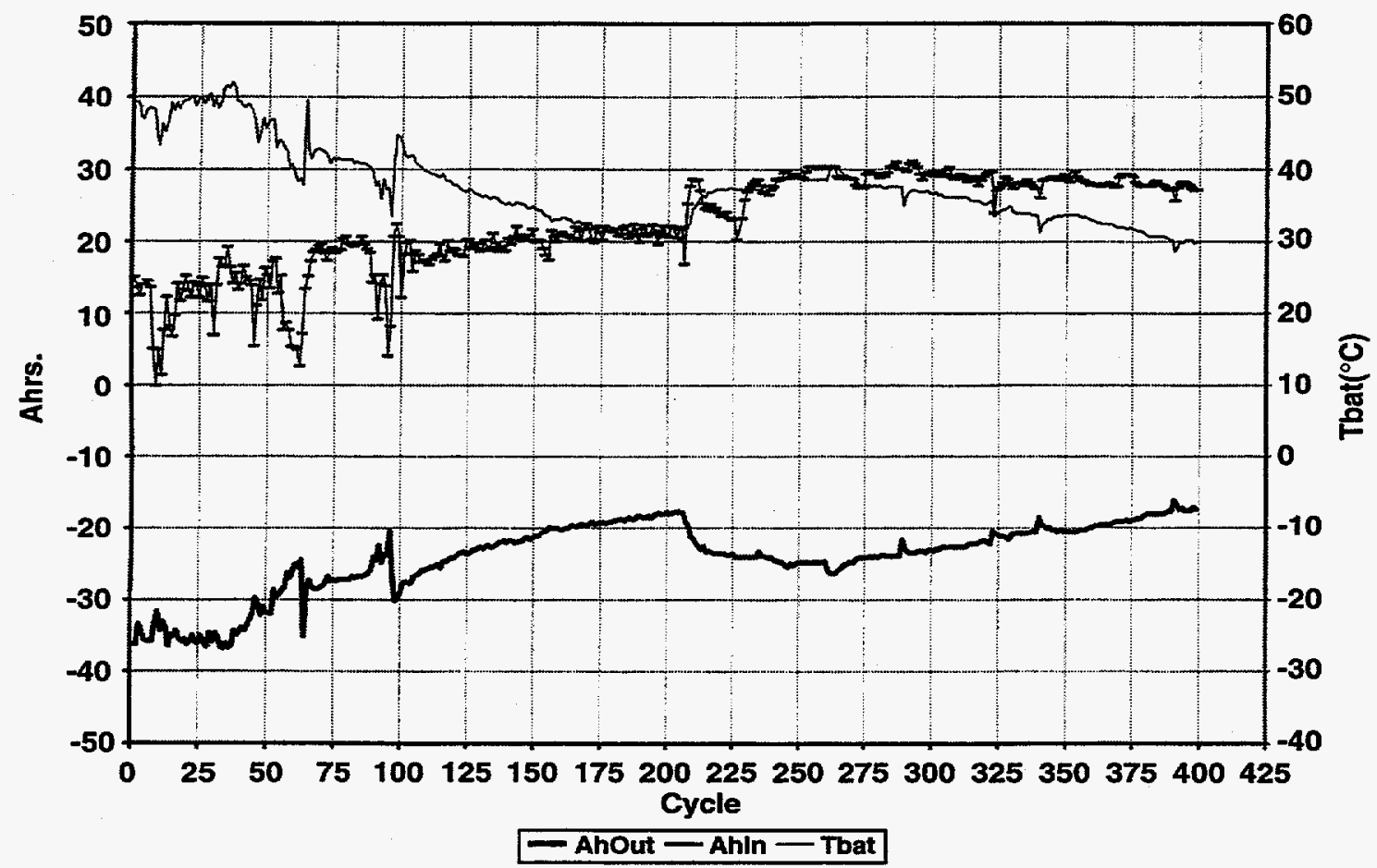

Figure 3-12. Trojan Capacity and Temperature Plot, SNL ID No. 723.

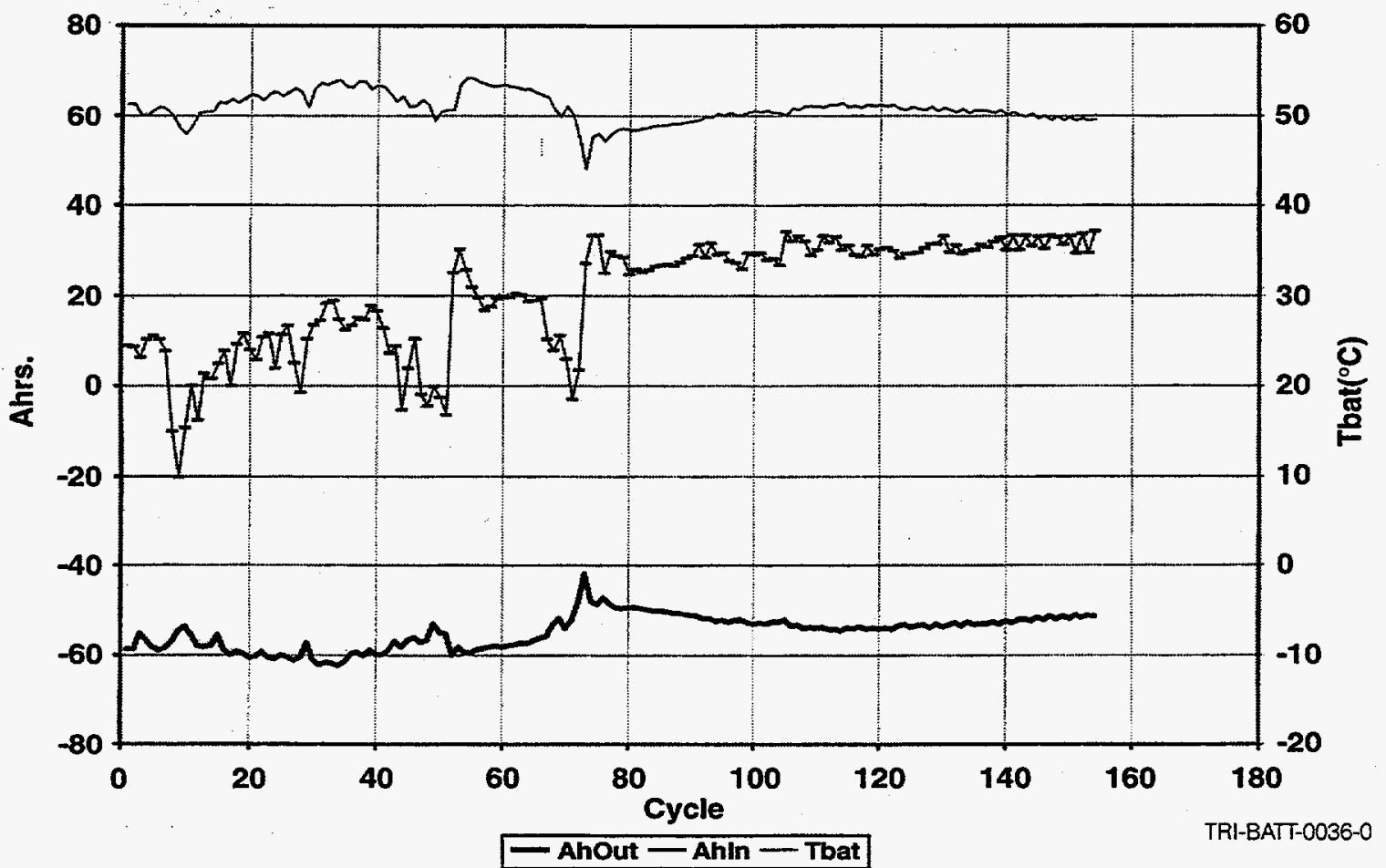

Figure 3-13. Trojan Capacity and Temperature Plot, SNL ID No. 726. 


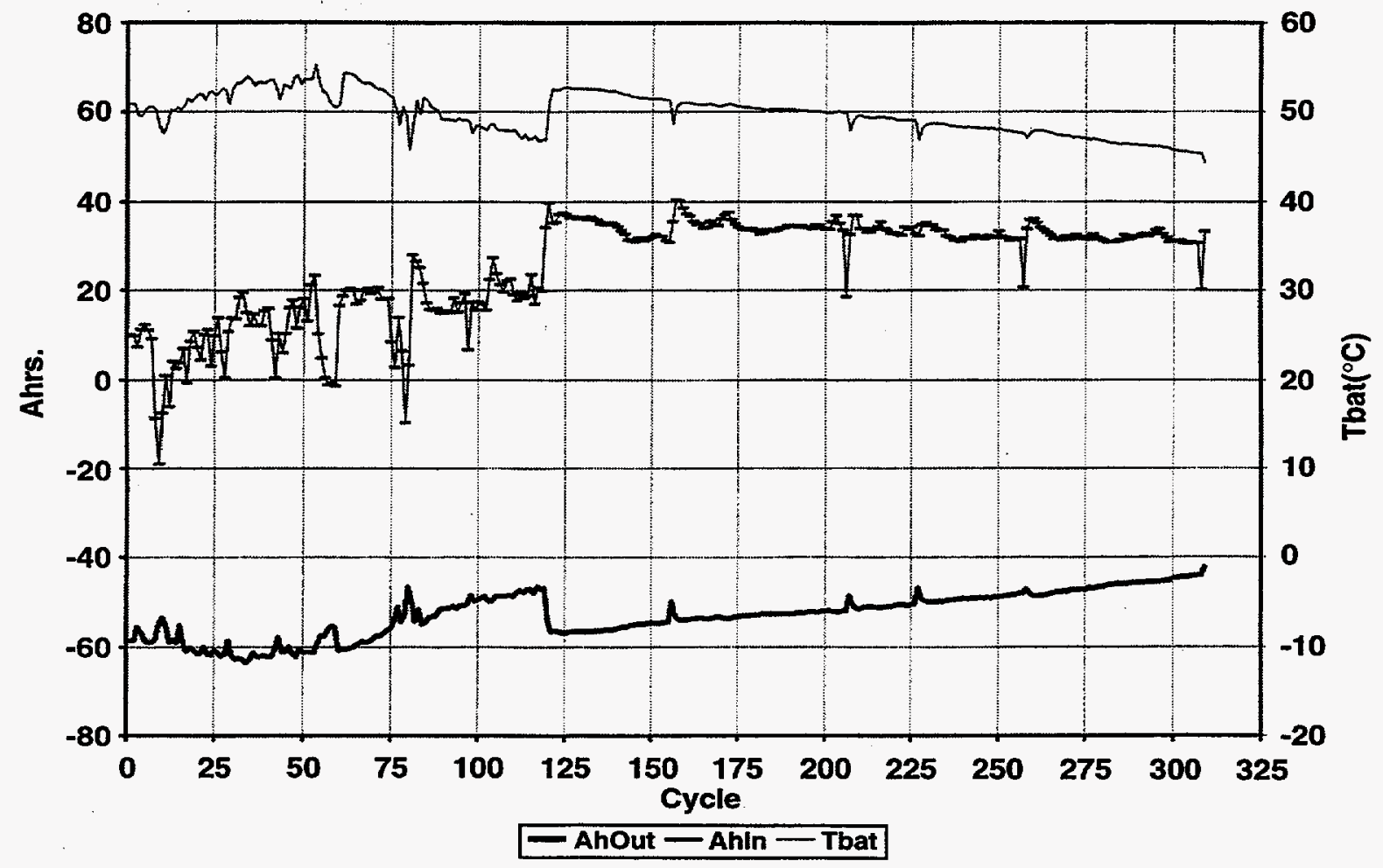

TRI-BATT-0037-0

Figure 3-14. Trojan Capacity and Temperature Plot, SNL ID No. 727.

Table 3-11. Status of the Four Trojan Batteries at the End of FY97

\begin{tabular}{lcccc}
\hline SNL ID No. & 722 & 723 & 726 & 727 \\
\hline Final Capacity (Ah) & 16.9 & 17.2 & cell failure & on test \\
No. of Battery Council & 318 & 399 & 155 & 309 \\
International Life Cycles & & & & \\
Date of Defined End of Life & $9 / 8 / 97$ & $9 / 13 / 97$ & cell failure & on test \\
Months Under Test & 11.0 & 11.2 & 6.0 & 12.8
\end{tabular}

tive of this project is to characterize the performance of a 9-kWh Zinc-Flow ${ }^{\mathrm{TM}}$ battery. The operation of the battery is expected to establish the dynamic and long-term performance capabilities of the technology and its suitability as a robust and reliable electrical storage device for applications within the electric supply industry.
The project is divided into the following tasks:

Task 1: Prepare a data summary report. Information for the data summary report will be gathered and prepared for analysis. This report was a collation of the representative historical data on laboratory and demonstration testing of Zinc-Flow ${ }^{\mathrm{TM}}$ batteries to establish the performance capabilities of the technology. 
Task 2: Deliver the Zinc-Flow ${ }^{\mathrm{TM}}$ battery. A 64-cell battery will be assembled, integrated with a controller, and delivered to SNL.

Task 3: Create a draft test plan. A suitable plan for testing at SNL will be compiled for the ZincFlow ${ }^{\mathrm{TM}}$ battery. While it is intended to focus on life-cycle testing, additional input will be sought to round out the test plan to encompass the widest possible array of applications.

\section{Status}

The 9-kWh Zinc-Flow ${ }^{\mathrm{TM}}$ battery has been designed and fabricated and is awaiting a suitable controller for performing the testing. As commercial controller design is not available, an old controller is being examined for possible service.

The new draft test plan focuses completely on cycle testing. Characterization testing has been removed from the test plan because this will allow testing to be carried out with an old controller and enable testing to begin as soon as possible. Schematics of the $9-\mathrm{kWh}$ battery module are shown in Figures 3-15 through 3-17. Figure 3-18 shows six 9-kWh Zinc-FlowTM batteries from Powercell's production line.

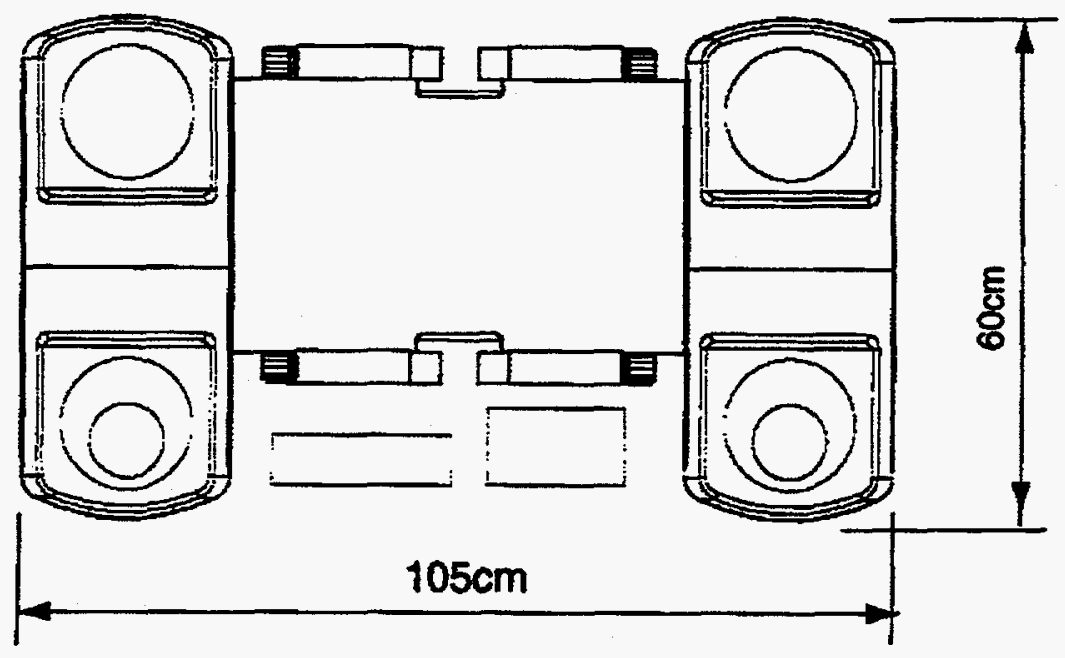

TRI-BATT-0041-0

Figure 3-15. Top View Schematic of 9-kWh Zinc-Flow ${ }^{\mathrm{TM}}$ Battery. 


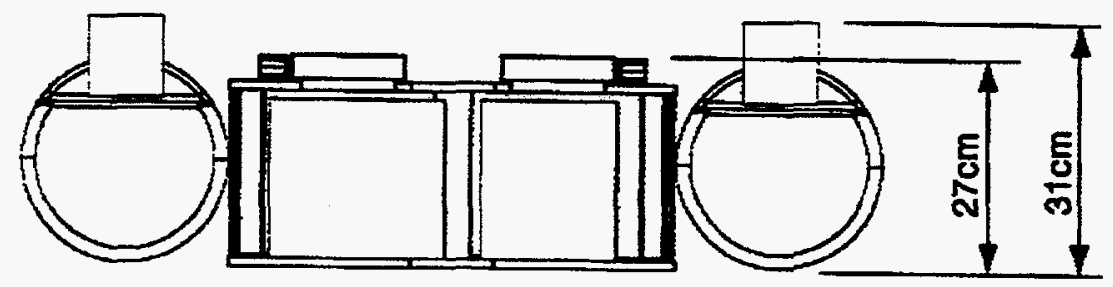

TRI-BATT-0042-0

Figure 3-16. Front View Schematic of 9-kWh Zinc-Flow TM Battery.

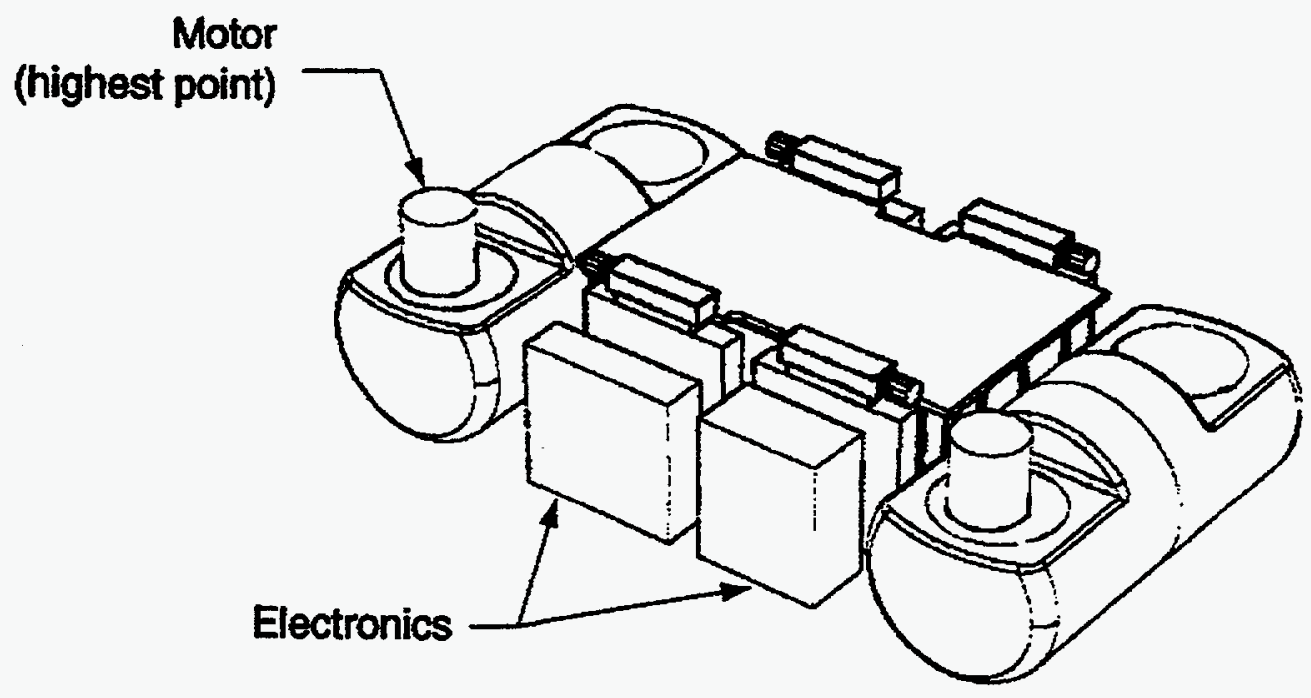

Total Weight, including electrolyt $\theta=111 \mathrm{~kg}$

TRI-BATT-0043-0

Figure 3-17. Perspective View Schematic of 9-kWh Zinc-Flow ${ }^{\mathrm{TM}}$ Battery. 


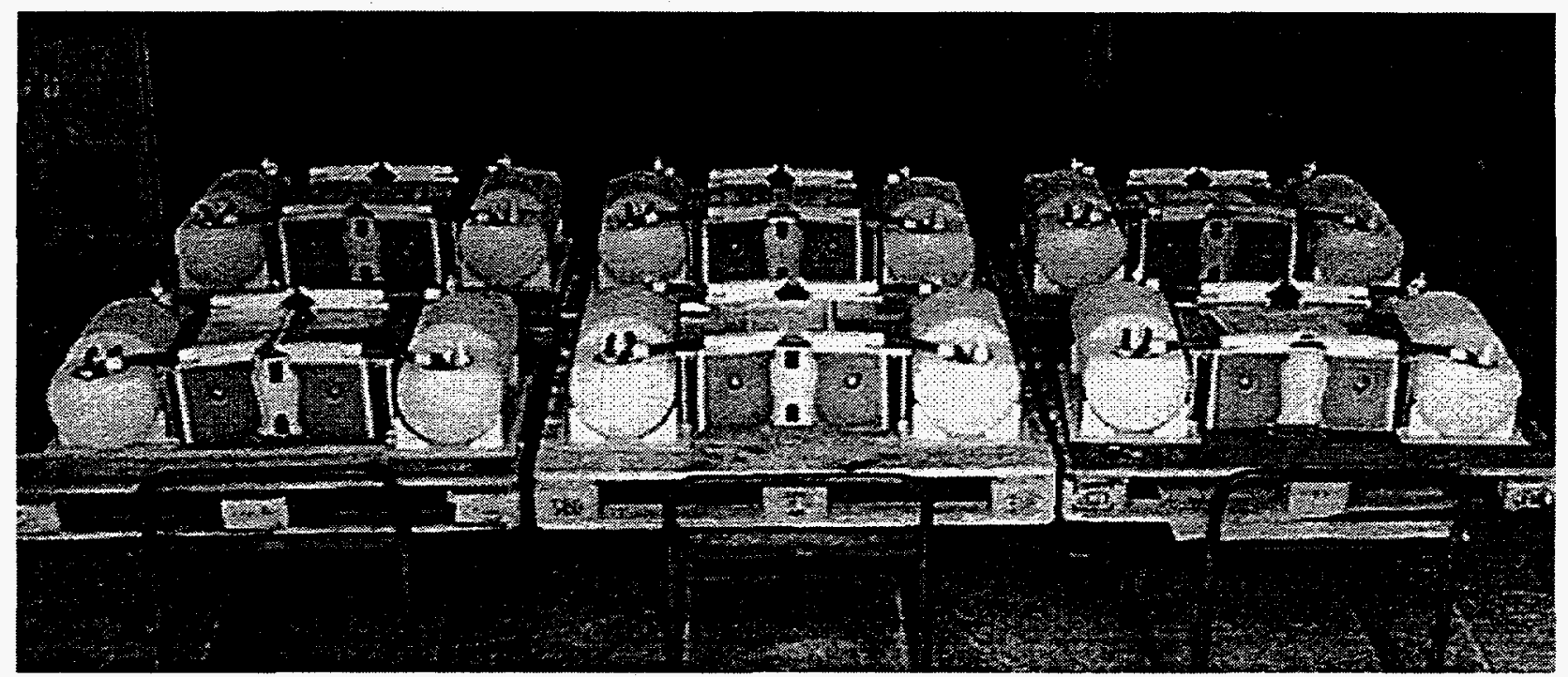

TRI-BATT-0047-0

Figure 3-18. Six 9-kWh Zinc-Flow ${ }^{\mathrm{TM}}$ Batteries from Powercell's Production Line. 
Intentionally Left Blank 


\section{Analysis}

\section{Introduction}

The analytical tasks performed in FY97 derived from studies conducted in past years. The set of studies for FY97 was designed to establish a tighter link between battery storage and renewables through analysis that would determine the value of storage when used to support renewable generation sources such as wind and PV.

\section{System Studies}

\section{Quantification of Utility Cost Savings from Using Batteries-UMR}

This task was initiated during FY94 through the placement of a contract with UMR to use EPRI's DYNASTORE computer program to perform calculations of utility operating costs with and without BES. Operating cost savings are one important component of the battery system cost/benefit picture, along with the system capital cost and other projected utility benefits. In this initial study, UMR calculated generating costs for a medium-sized utility system that was not interconnected with other utilities. The results of this work showed that significant production cost savings could be obtained by using a battery system for spinning reserve.

In FY95, a new contract was placed with UMR for a follow-on study to perform a similar operating cost analysis for a grid-connected utility system. KCPL, which was selected as the subject for this new study, is a typical Midwestern electric utility with many interconnections and a mix of generating plants. As with the previous study, the approach was to run a unit commitment program on energy storage units along with generating units and calculate operating costs with and without energy storage, so that savings could be quantified. This study was completed at the end of the third quarter of FY96, and the greatest production cost savings were projected for the frequency regulation application.

Another contract was placed with UMR for FY97 to continue work in this area. The specific tasks to be addressed were as follows:

- Reanalyze data from the grid-connected utility system study to take into account factors not addressed in the first case, such as battery operating and maintenance costs, and to clarify the reasons for certain trends observed in the previous results. Possible factors to be investigated included the effects of load growth; the handling of scheduled outages for maintenance vs. scheduled outages due to equipment failures, weather, etc.; and DYNASTORE options that can now be applied.

- Produce a combined report that documents the results of the reanalysis and compares the effect of battery energy storage on operating costs for the island and grid-connected utility systems.

- Determine the feasibility of using DYNASTORE to model the integration of a renewable energy generator with conventional utility generation sources. If this is possible, then investigate the benefits of energy storage on operating costs for this configuration.

- Search for another utility configuration that is different from the two already investigated and could be the subject of a future DYNASTORE study.

\section{Status}

The contract for this study was placed midway through the first quarter of FY97. The preliminary approach for this new contract period was to rerun many of the cases studied in the prior contract using the Monte Carlo mode (12 iterations). This mode takes into account the forced outages that occur randomly at the effective forced outage rate.

Use of a BESS for load leveling and spinning reserve was reexamined using a more realistic outage scenario. There are two kinds of outages: (1) manual outages - those scheduled for maintenance/overhaul of generators, etc., and (2) inadvertent forced outagesthose resulting from equipment failures or other "limit violations," which cause equipment to go out of service in a random, unscheduled manner. These outages will last as long as it takes to replace the unit or bring another one on line. To date, UMR's approach has been to assume that BESSs would be used to cover both kinds of outages. This may not be realistic in that replacement equipment could and would be placed on line during a scheduled outage. For example, if a generator were 
scheduled to be down for maintenance, then replacement power would also be scheduled from another generating unit or purchased externally. Spinning reserve would not be depended on to cover the outage in this case. For this reason, UMR is proceeding with its reanalysis of battery energy storage, taking into account mainly forced outages and, to a lesser extent, scheduled outages if spinning reserve is available.

Work in the last half of FY97 concentrated on calculating KCPL operating costs/savings for various battery energy storage applications while including inadvertent outages in generation.

Study cases for BESSs of 1-, 4-, and 8-hr duration and capacities of $40,100,200$, and $300 \mathrm{MW}$ were being rerun using the Monte Carlo mode (12 iterations) to properly model the forced outages. To avoid the impact of plants having maintenance/refueling schedules longer than $1 \mathrm{yr}$, the number of years for the study scenario was increased. This also provides an additional check for data errors.

Input data supplied by KCPL has been used again to calculate savings afforded by battery energy storage. Detailed maintenance schedules were provided by KCPL for each generating unit to beyond the year 2015 . These data were entered into a DYNASTORE file. Alternatively, scheduled maintenance outages can be set up on annual (or multiyear) cycles. For inadvertent (forced unscheduled) outages, statistics including the Effective Forced Outage Rate (EFOR) are entered into a DYNASTORE file, along with maintenance files for each unit. For this study, inadvertent outages along with maintenance cycles made up from the detailed KCPL maintenance schedules were used. The results were contrasted with those of the first study that used the maintenance schedules and ignored the inadvertent outages. Outage time resulting from scheduled maintenance was much greater than inadvertent outage time.

This study includes the years 1995, 1996, and 1997. The resulting savings curves are monotonically increasing, as expected. Concerns existed about the variations in curves between 1995 and 1996 in the previous study, which covered only those two years. Reruns for 1995 and 1996 plus additional runs for 1997 suggest that the differences resulted from variations in annual load profiles and the 18-mo refueling schedule of the Wolf Creek nuclear plant.

The reason for the seemingly erratic behavior of some of the curves is that the savings calculation is the difference between operating costs without BESS and operating costs with BESS. Both are large numbers, more than 650 times the calculated savings. Because of truncation and roundoff errors these numbers may not be very accurate. Curves showing savings greater than 1 percent of operating costs are reasonably smooth.

For spinning reserve only, savings increased rapidly with BESS megawatt capacity up to the spinningreserve requirement of $6 \%$ (approximately $180 \mathrm{MW}$ ). Increases in megawatt capacity above $200 \mathrm{MW}$ produced very little further savings increase. Also note that a 1-hr battery has sufficient time duration (energy) to satisfy the spinning reserve requirement. Extending the BESS energy capacity to 4-hr or 8-hr duration does not increase BESS usage for spinning reserve, and therefore all of the curves are coincident (see Figure 4-1).

For load leveling only, savings increase monotonically with BESS megawatt capacity and megawatt-hour energy (see Figure 4-2). In this case, the savings are much less for a 1-hr battery than for an 8-hr battery; the 8-hr BESS can serve much more of the peak load energy-wise. (In the KCPL load profiles, most of the peaks have a duration of more than one hour). Consequently, a 1-hr battery may never be assigned to level those peaks. Also, the savings go up to as much as $\$ 4,000$ for the years $1995-1997$, indicating that all BESS megawatt and megawatt-hour capacity is being assigned, though the annual load profiles are different. This suggests that more capacity (MW and MWh) could produce even greater savings.

Load leveling with spinning reserve is implemented by allocating BESS resources to load leveling first, then to spinning reserve for any remaining BESS capacity that cannot be allocated to load leveling. The curves are monotonically increasing for all years and BESS capacities in megawatts and megawatt-hours (see Figure 4-3). For capacities below $200 \mathrm{MW}$, the curves are fairly close together, indicating small increases in savings as the BESS energy duration increases from 1 to 4 to $8 \mathrm{hr}$. This would suggest that most of the BESS capacity is being allocated to spinning reserve. For megawatt capacities greater than $200 \mathrm{MW}$, the curves increase more divergently, indicating that more of the capacity is allocated to load leveling.

For each of these modes of BESS application (spinning reserve, load leveling, and load leveling with spinning reserve), a comparison of savings with and without inadvertent outages is being calculated. The preliminary results applications including load leveling will be presented here; a more comprehensive comparison for all of the applications will be completed early in FY98 and included in the final report. In the case of load leveling only and load leveling with spinning reserve, Monte Carlo simulations generally showed greater savings than those using the deterministic method for all three years studied. 


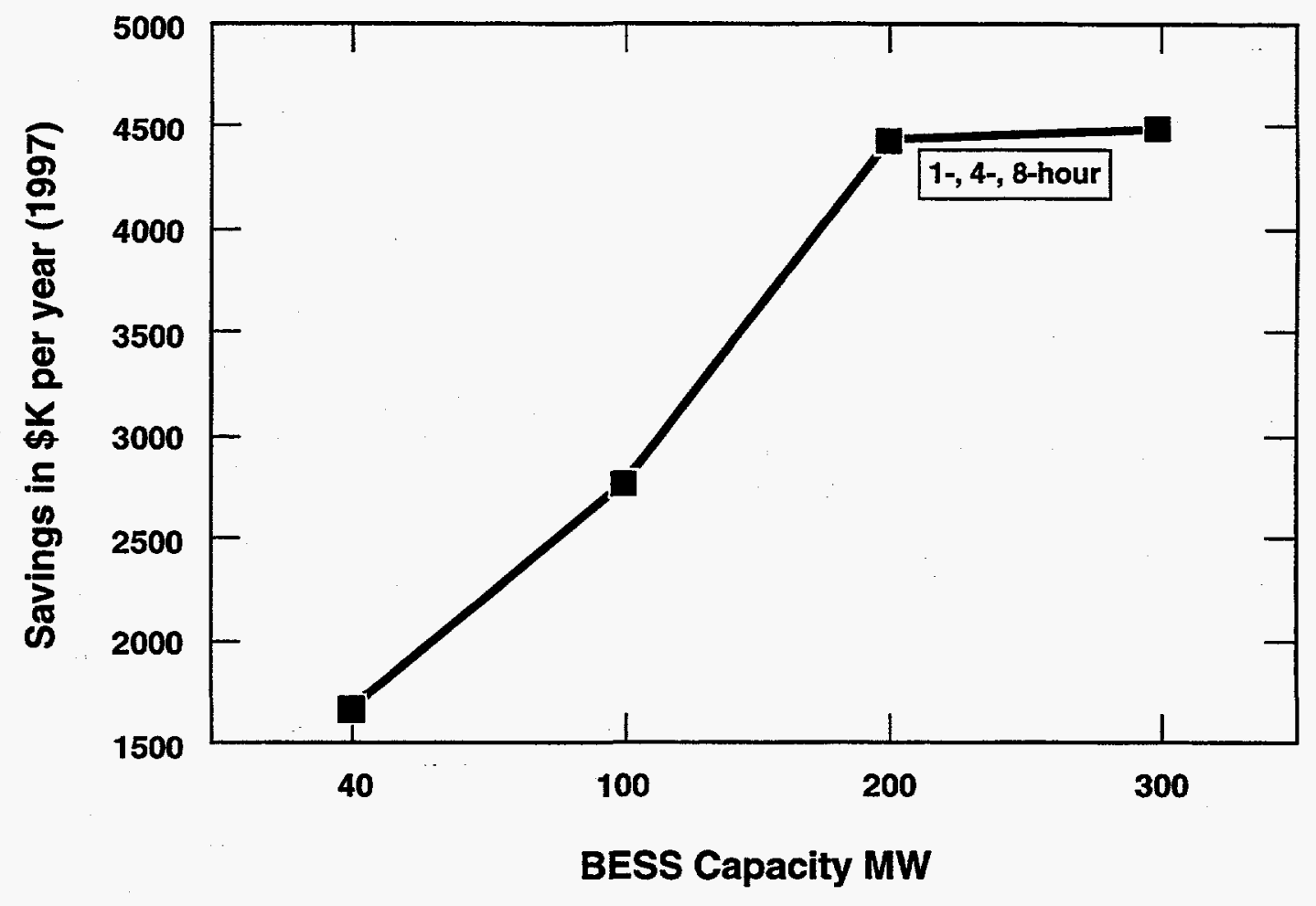

TRI-BATT-0001-0

Figure 4-1. BESS Used for Spinning Reserve Only by KCPL (1997) (Simulation Method: Monte Carlo, 12 iterations).

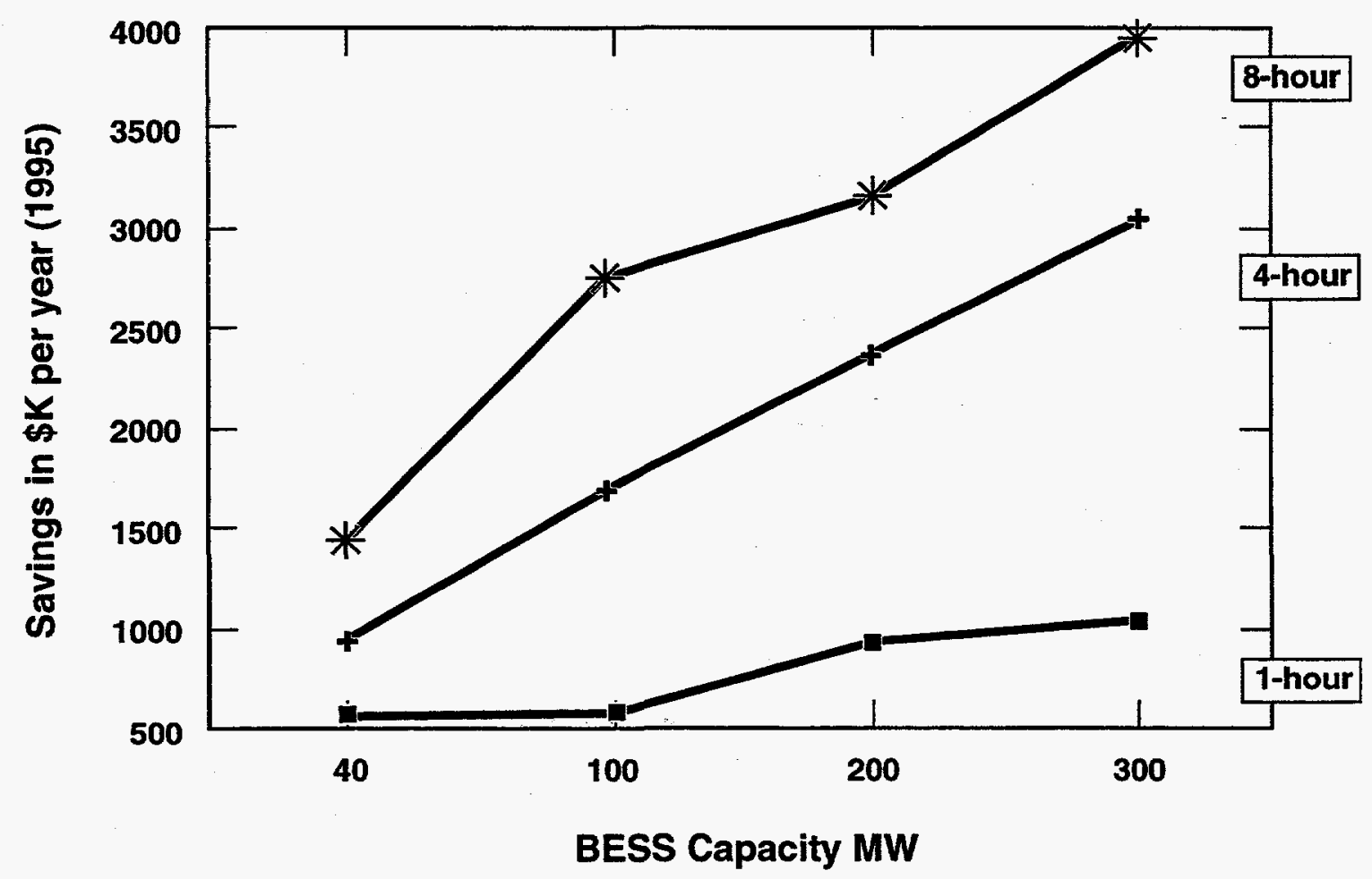

TRI-BATT-0002-0

Figure 4-2. BESS Used for Load Leveling Only by KCPL (1995) (Simulation Method: Monte Carlo, 12 iterations). 


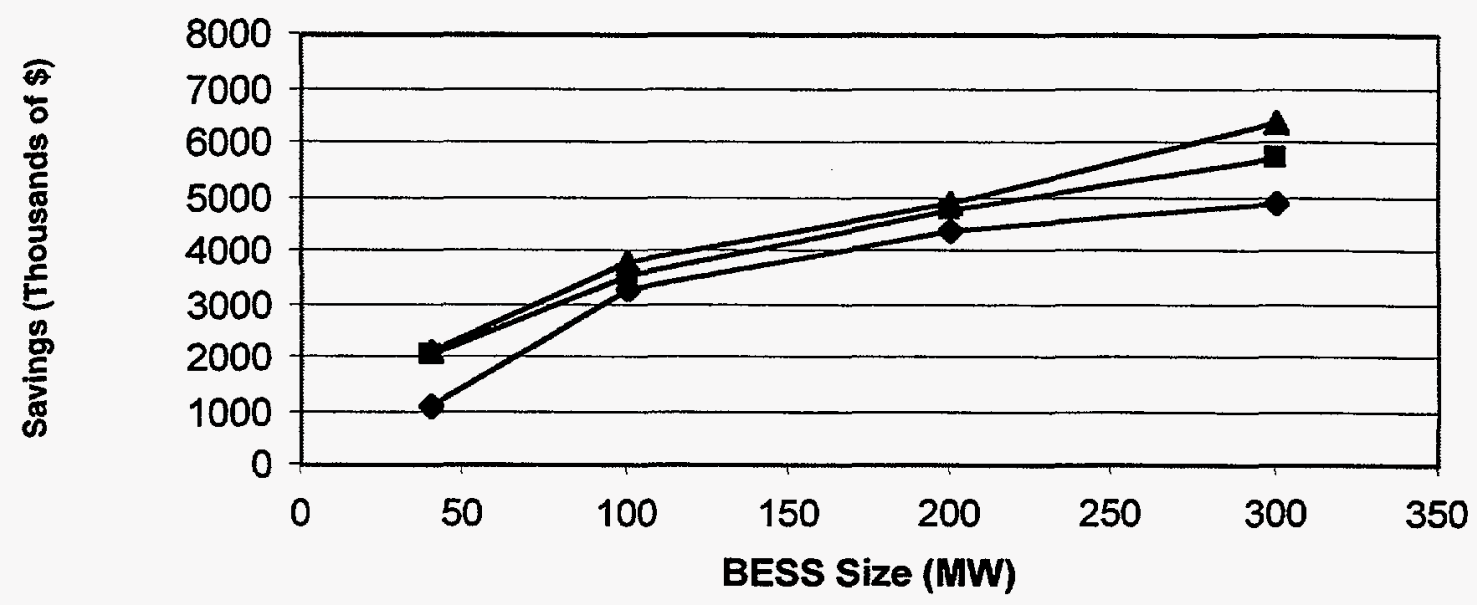

$\rightarrow-1$ Hour $\rightarrow-4$ Hour $\rightarrow-8$ Hour

TRI-BATT-0003-0

Figure 4-3. BESS Used for Load Leveling Including Spinning Reserve by KCPL (1996) (Simulation Method: Monte Carlo, 12 iterations).

The effect of the BESS O\&M costs on savings afforded by battery energy storage was also examined. The impact of both fixed and variable O\&M costs was minimal. Fixed O\&M costs averaged less than $0.13 \%$, while variable O\&M costs averaged less than $2.2 \%$ of the annual operating costs.

\section{Opportunities Analysis}

\section{ESA Activities}

During the first quarter of FY97, on November 12-13, 1996, the ESA met in Jacksonville, Florida, for its biannual meeting. This was the ESA's first official meeting after incorporating as a trade association. At the meeting, it broadened its charter to include non-battery forms of electrical energy storage. Over 70 representatives from the utility industry and from manufacturing and research organizations attended. Many of the presentations related to analysis and development projects sponsored or performed by the DOE ESS Program, which has had a sustaining role in the Utility Battery Group, the predecessor to the ESA, since its formation over 6 years ago. The meeting emphasized the completion of the $\mathrm{PQ} 2000$, a 2-MW/10-sec power quality system developed and tested by the ESS Program in collaboration with industry and now being commercially installed for utility and industrial applications. During the meeting, the ESA visited a container lithography plant where the first commercial $\mathrm{PQ} 2000$ had just been installed. At an evening meeting, a presentation was given by the ESS Program Manager on the new direction of the ESS Program. The ESA membership reacted positively to the ESS Program's projects and plans. An SNL staff member representing the ESS Program was reelected to the ESA board of directors. The board of directors took aggressive action by beginning to define projects aimed at helping to create storage products and at better defining user markets to meet ESA members' business needs.

The ESA and the ESS Program participated in the Renewable Energy Expo 1997 on April 17, 1997, on Capitol Hill. The exhibition and ice cream social was held in cooperation with the U.S. House Renewable Energy Caucus. ESA is part of a coalition of more than 40 sustainable energy trade organizations that are working to strengthen federal research and development support for sustainable technologies. The event featured exhibits from more than $\mathbf{5 0}$ companies and aims to educate Congress on the benefits of sustainable energy technologies. The ESA presented an exhibit and distributed literature to promote energy storage technologies and their use in sustainable energy systems. 
Also in FY97, ESA received a contract from the DOE/ESS Program to assist in developing communications products that included an energy storage brochure, an applications brochure, and an electronic presentation. An additional activity under this contract was the establishment of an IUG to undertake dialogue with DOE management. The DOE ESS Program manager, the SNL ESS Program manager, the ESA Executive Director, and several invited members representing users and customers of energy storage were in attendance at this first IUG meeting. The objective was to provide the DOE with feedback, direction, and suggestions with regard to potential users of energy storage. The IUG will be a standing group that assists the DOE in an advisory capacity.

In addition, the ESS Program, SEIA, DOE, and IIZRO are continuing to discuss activities to strengthen communication ties between the battery and solar industries.

During April 26-30, 1997, ESS program personnel participated in the SOLTECH meeting in Washington, D.C. The solar energy forum included combined annual solar events from the American Institute of Architects, the American Society of Mechanical Engineers, the American Solar Energy Society, the Interstate Renewable Energy Council, the Solar Industries Association, the Utility Photovoltaic Group, and the DOE. The ESA coordinated events with these organizations.

Three specific sessions were held in which energy storage was either discussed or highlighted. An ESS Program overview was presented at the PV Balance of Plant Committee Meeting and was also presented at the PV Executive Committee Meeting. All meetings were well attended, and storage issues consistently generated much interest and discussion. A key issue was a need for additional performance and life data for storage components and systems. Many new contacts were made with the PV industry, which will allow for improved interactions between the storage and renewables industries.

On April 29, 1997, SEIA held a joint session to discuss battery storage as a part of the SOLTECH ' 97 Conference. Approximately 25 representatives participated in discussions on the selection, design, performance, and life issues of battery energy storage in PV systems. The discussion centered around the following points:

- Lead-acid batteries are still the only option for PV systems.

- The PV market is growing rapidly; this is expanding the battery storage market.
- Uncertainty regarding battery selection, life, and performance is still the norm.

- PV suppliers are frustrated by a perceived lack of assistance and support by the battery industry.

The spring 1997 ESA meeting was held in Washington, D.C., on April 30-May 1. By following the SOLTECH meeting, it helped to enrich the collaboration between the solar and energy storage industries. The theme of the meeting was "Renewable Energy and Energy Storage: A Partnership That Makes \$ense." The spring ESA meeting was attended by over 50 members and invited guests, which included several members of the solar energy community. The featured sessions included grid-connected and non-grid-connected photovoltaic projects that have incorporated energy storage systems. Also, the energy storage technology committee, which is chaired by Southern California Edison, has been hard at work surveying UPS manufacturers. Survey data and product literature from more than 20 UPS suppliers were presented at this meeting.

\section{ILZRO RAPS Testing Activities}

On December 19, 1996, ESS Program staff met with staff from ILZRO to discuss activities of mutual interest for possible collaboration in FY97.

Collaboration on a RAPS storage seminar in Indonesia evolved from several initiatives. IIZRO completed a RAPS market study that identified Indonesia as a key emerging market that is representative of developing countries. As a result of discussions between ILZRO and SNL PV personnel, Indonesia was identified as a prime location for "mini grids," villages and small cottage industries using PV/diesel/storage systems. The Indonesian utility industry is interested in such systems.

IIZRO is also very interested in defining a joint project on VRLA reliability. Ongoing work performed under ALABC funding may be coordinated with the ESS Program under a collaborative effort. Charger specifications and designs were key areas for the study. ILZRO prepared a white paper with ideas for a collaborative effort and forwarded it to SNL for consideration.

On April 1, 1997, staff from the DOE ESS Program met with the president and staff of IIZZRO. The purpose of the meeting was to continue the dialogue necessary to define collaborative projects to be jointly funded and managed by the ESS Program and ILZRO. Both organizations are already co-funding research for an IEA Annex analyzing electrical energy storage systems applications and technologies. During these discussions, ILZRO agreed to contribute additional funds to 
the remainder of the Annex's activities. In addition, discussions focused on RAPS projects and on VRLA reliability improvement studies. It was agreed that standard RAPS duty cycles were needed so that laboratory testing could be used to characterize and improve integration of systems. There is also a need to address Third World national regulations requiring locally manufactured batteries to be used in RAPS even though the battery may be unsuitable for these applications. IIZRO strongly supported having a workshop during FY97 to bring key players together. A workshop was to be held in the first quarter of FY98 to address these issues.

\section{Executive Meetings}

In FY95, the ESS Program established an outreach team to assess industry needs and to assist the program in broadening its scope from BESS to a portfolio of energy storage technologies. The team, consisting of the DOE/Headquarters ESS Program Manager, the ESS Program Manager at SNL, and the ESS Program Manager at Energetics, Inc., met with executives from more than 15 organizations. The executives represented a cross section of independent power producers, investorowned utilities, electric cooperatives, and equipment manufacturers. The final report, titled Report on the Energy Storage Systems Program Executive Meetings Project, was published and distributed early in FY97.

The following objectives of the outreach effort were achieved: (1) the level of industrial interest in energy storage was determined; (2) DOE's plans for the ESS Program were shared; and (3) potential governmentindustry collaboration was explored. The meetings led to greater DOE awareness of the perceptions and needs of U.S. industry, promoted U.S. industry awareness of the ESS Program activities, and stimulated participation in the ESS Program by industrial organizations that were not previously involved. Subsequent analysis of the meeting minutes identified several themes:

- Energy storage market development will require committed and concerted efforts from both the U.S. government and industry;

- Utility restructuring and deregulation has and will continue to have significant impact on utilities' perceptions of and adoption of energy storage systems;

- Near- and long-term business opportunities that incorporate energy storage exist for companies-particularly in power quality; and
- The cost of energy storage systems must be lower for widespread adoption by industry to occur.

\section{PV Battery and Charge Controller Market and Applications Survey}

The purpose of this study was to determine the market size for PV systems that use battery storage to improve their efficiency and availability. The study was conducted using a survey designed and implemented under a contract with Arizona State University. The survey was sent to industry representatives who design and integrate stand-alone PV systems. The purpose of the survey was to document what types of batteries and how many of them are currently used in the stand-alone PV market. The survey also polled system integrators on their methods of specifying batteries and charge controllers for the systems they design. In FY97, Arizona State University prepared the final report.

\section{Status}

In early December 1996, a camera-ready original and electronic versions of the Photovoltaic Battery and Charge Controller Market and Applications Survey report were received by SNL; the document was assigned SAND report number 96-2900. Five hundred copies of SAND96-2600, Photovoltaic Battery and Charge Controller Market and Applications Survey, were printed and distributed in January 1997. Three hundred additional copies were distributed following the initial printing. Demand continued throughout the year.

In early May 1997, a presentation on the results of the PV Battery Charge Controller Market Applications Survey was made by SNL personnel at the ESA spring meeting held in Washington, D.C. Approximately 60 people attended the conference, with attendees demonstrating a high degree of interest in the presentation.

The survey included three separate segments tailored to the following groups: PV system integrators, PV charge controller manufacturers, and battery manufacturers.

The overall objective of the survey was to carry out the following:

- Quantify the market for batteries shipped with (or for) PV systems in 1995;

- Quantify the PV market segments by battery type and application;

- Characterize the operating environment for energy storage components in PV systems; and 
- Estimate the PV battery market for the year 2000 .

The following figures represent the results of the top-down analysis:

Worldwide sales of PV batteries $=2,961,000 \mathrm{kWh}$.

Worldwide wholesale value for PV batteries shipped in 1995 was $\$ 302 \mathrm{M}$.

Worldwide total installed capacity of PV batteries $=10,519,000 \mathrm{kWh}$.

U.S. sales of PV batteries in $1995=340,515 \mathrm{kWh}$.

U.S. sales of PV batteries in $1995=\$ 34.7 \mathrm{M}$.

The 21 system integrators (polled in the survey) supplied about $14 \%$ of the U.S. PV battery market (in terms of dollar sales). The approximations that went into these calculations limit accuracy to about $\pm 25 \%$.

The final report serves as an information exchange tool between the three elements of PV energy storage systems. Company names, names of company representatives, and phone/fax numbers provided in this report will allow direct communications between key participants in each of the three industries.

Survey respondents made several recommendations regarding matters that they considered important to ensuring the success of future energy storage/PV initiatives. Some recommendations cited an ongoing need for data acquisition and report dissemination; in general, it was recommended that information exchange efforts be continued but on a more regular basis. SNL's historical PV background, expertise, and role as repository of valuable $\mathrm{PV}$ information made it a logical choice as the point of contact for PV energy system information and to be given other, slightly broader responsibilities. These broader responsibilities would include (1) expanding the contact list developed in the survey; (2) expanding SNL's Internet web site to allow easy access to existing battery storage information/reports and to allow industry members to ask questions and contribute information; (3) distributing by e-mail a quarterly newsletter of summary information to the contact list; and (4) distributing an electronic annual report to industry contacts (by e-mail), with hard copies going to the DOE and to those individuals requesting them.

Responses to the final report have been very positive. For example, Stephen Vechy, Photovoltaic Sales and Marketing Manager for GNB (a respondent whose company has a substantial market share), said, "...the PV Survey we have been working with is considered a very valuable tool for us at GNB. I do not know of any other medium that can provide the level of detail on the PV battery market."

Interim dissemination of PV information will take place through presentations by the report authors at selected PV and battery conferences during FY97 and FY98. A contract for the interim activities was in place early in the third quarter of FY97. The final report is available from SNL upon request.

\section{Utility Restructuring Analyses}

\section{Monitoring Utility Restructuring}

In keeping with the ESS Program's objective of staying abreast of energy-related issues, an ESS Program representative from Sentech attended the Keystone Energy Board meeting in Keystone, Colorado, February 27-March 1, 1997. The main topics were utility restructuring and related issues. Several perspectives on restructuring were represented. Electric utilities represent one-sixth of the U.S. economy, and most of the conference attendees thought that restructuring was inevitable.

\section{Status}

Several perspectives on utility restructuring were presented at the conference. The position of the states was that

- structural changes in the industry should be encouraged when they result in improved economic efficiency and serve the broader public interest;

- network integrity and universal service should be maintained;

- customers should have an opportunity to make informed choices;

- customers should be protected from unfair, fraudulent and anticompetitive behavior;

- all classes of consumers should benefit;

- the quality of the environment should be maintained or improved;

- restructuring should be a public process with participation by all;

- and state commissions should determine retail electric policies, including restructuring policies. 
From an economic perspective, utilities were regulated because there was a natural monopoly in power generation. Since that no longer exists, a market should be allowed to operate. It was felt that repeal of the Public Utility Holding Company Act and Public Utility Regulatory Policies Act was necessary for restructuring to take place.

It was believed that congressional and legislative activity taking place indicated that a restructuring bill would not take as long to get through Congress as did the telecommunications deregulation bill (which took 10 years). The bills currently before Congress vary on the following issues: the date by which choice is guaranteed; the relative role of the states and federal government; the recoupment of stranded costs; and the role of renewables in a deregulated mix of power sources. The DOE is also working on a version of a restructuring bill, but it has not yet been made public.

The position of the utilities varied from utility to utility. Generally, utilities do not support competition; however, they are not opposing it and are preparing for it. The utilities believe the transition should be orderly, and they want an interstate system, not a patchwork quilt of regulations. Deregulated utilities in one state should be protected from becoming a dumping ground for excess power from utilities still covered under regulated prices in other states. Stranded costs is the issue that receives the most press, probably because $\$ 350 \mathrm{~B}$ in potential stranded utility assets exists. For some utilities, bankruptcy is a possibility.

Concerns exist that deregulation could lead to increased air emissions. Utilities constitute $3 \%$ of the gross domestic product and produce $50 \%$ of air emissions. Competition, it is suggested, will require equivalent air emission standards for all plants. Currently, variation in standards between regions and within regions can account for $75 \%$ of the competitive cost differential. Differences in allowed pollution levels creates a competitive advantage. Emission caps are required to meet long-term goals, and it is suggested that they be written into the restructuring bill. Others continue to argue that this is not necessary and that existing regulations are sufficient. These opinions tend to reflect the economic interests they represent.

The conclusion of the conference was that restructuring is inevitable, but many complex and critical issues need to be addressed before restructuring can efficiently and effectively proceed and deliver benefits to the public.

\section{Restructuring and the National Energy Outlook}

Energy issues in general and the impact of deregulation in particular were the focus of the NEMS/Annual Energy Outlook Conference, attended by Sentech and held in Crystal City, Virginia, on March 17, 1997. Forecast energy prices through 2015 are lower across the board than those given in the 1996 Annual Energy Outlook, as shown in Table 4-1.

It was suggested that there were several dilemmas regarding the OUT electricity future: Without storage, electricity cannot achieve a commodity price structure, which is the anticipated outcome of restructuring. Without storage, wind and solar energy systems remain niche technologies. But a $\mathrm{CO}_{2}$-stabilization policy will have to emphasize these non-fossil technologies as well as nuclear technologies. Industry credibility, system reliability, and current prices are risks and hinge on technology investment.

The price effects of the five recent industry deregulations (trucking, railroads, airlines, telecommunications, and natural gas) have been a $30-40 \%$ savings 5 to $10 \mathrm{yr}$ later. Gas pipeline operations and maintenance (O\&M) costs have fallen 50\% from 1991 to 1994 because of deregulation, while electricity O\&M costs have increased $8 \%$. However, some attendees believed that the reality of restructuring will be undelivered power, strategic behavior of power producers, and market power at the margin.

\section{Utility Restructuring Analyses at ORNL}

ESS Program staff visited ORNL on February 11, 1997 , to review the preliminary analysis that has begun on utility $T \& D$ in a deregulated market. ORNL has extensive experience in analyses of deregulated utilities, having published a series of reports on ancillary services and other emerging issues. One member of the ORNL team is currently involved with wind data analysis and is working with the DOE Headquarters Wind Program Manager and NREL. There is interest in studying spot market electricity prices and in reviewing how renewables and storage could interact.

Coordination issues were reviewed, and it was agreed that exchanging technical reports and maintaining open communication is essential to this process. ORNL is very interested in getting involved in other utility programs, such as the ESS Program. Negotiations continued in the third quarter of FY97.

The preprototype resonant snubber inverter was demonstrated and evaluated. This inverter is more efficient than conventional devices across a wide load 
Table 4-1. 1996 vs. 1997 Annual Energy Outlook Comparison

\begin{tabular}{lllc}
\hline & 1996 AEO & \multicolumn{1}{c}{ 1997 AEO (1995 \$) } & \% Change \\
\hline World Oil & $\$ 26$ & $\$ 21 /$ barrel & -19 \\
Natural Gas & $\$ 2.63$ & $\$ 2.13$ mcf at the wellhead & -19 \\
Coal & $\$ 17.75$ & $\$ 15.46$ at mine mouth & -13 \\
Electricity & $\$ 0.071$ & $\$ 0.063 / \mathrm{kWh}$ & -11
\end{tabular}

range, but it has not been sold to industry yet, and cost estimates are not available.

\section{Technology Assessments}

One of the goals of the ESS Program is to characterize and identify the challenges for advanced energy storage components (flywheels, SMES, etc.) to set the stage for component development projects in coming years. The DOE made a commitment to participate in the IEA Energy Conservation though Energy Storage (ECES) Annex IX, which includes performing a comprehensive state-of-the-art review of electrical energy storage technologies worldwide. The documentation of storage technologies being prepared under Annex IX is very useful and supports the technology assessments being performed by the ESS Program for flywheels and SMES. In pursuit of its goals in this area, ESS Program staff participated in many meetings throughout FY97 regarding flywheel technology initiatives.

\section{International Energy Agency Annex IX Project Activities}

The DOE OUT is a signatory to the Implementing Agreement for the IEA Annex IX program called Research and Development on ECES. In June 1996, the DOE OUT made a commitment to participate in the recently created Electrical Energy Storage Annex IX by pledging funding in support of its activities. The primary benefits of U.S. participation are increased awareness of analytical and technical developments in storage in the international arena, identification of projects of mutual interest, and the ability to assess the competitive position and market opportunities for energy storage systems in overseas markets. ILZRO is also interested in these objectives and has contributed funding for U.S. participation in Annex IX.
The DOE OUT and ILZRO have designated the ESS Program as their representative for Annex IX activities. This responsibility requires attending Participating Agent and Experts meetings in the U.S. and abroad, coordinating U.S. representation by experts for the various storage technologies, identifying projects of common interest to the participants, and supporting the implementation of these projects.

The objectives and expected outcomes for Annex IX were as follows:

- A critical examination of electrical energy storage technologies with respect to optimized electricity $T \& D$ networks.

- Development of quantitative cost/benefit and energy emissions models.

- Identification and resolution of potential barriers to implementation.

- Development of an international dialogue between utility companies and end users, system developers, and suppliers.

- Organization and presentation of major international conference(s) and workshop(s) to present the results of Annex IX.

\section{Status}

An SNL ESS Program staff member attended the IEA Annex IX Experts' Meeting on Utility Requirements, held in London in November 1996. This meeting was combined with a two-day Storage Technology Workshop sponsored by the London Underground. The attendees included a large contingent of staff from the city of London's Engineering, Construction, and Planning departments.

In England, meetings were also held with EA Technology, the IEA Annex IX Operating Agent, and with 
International Energy Systems (IES), a UK-based flywheel developer. The meeting with EA Technology focused on U.S. participation in Annex IX and reviewed the U.S. input to the utility requirements questionnaire. The meeting consisted of discussions about tasks planned under Annex IX, including the development of analytical software to evaluate the benefits of energy storage and assess the status of the various technologies. The meeting with IES provided an opportunity to discuss IES's flywheel technology and commercialization plans and the 5-kW flywheel energy storage (FES) system that IES had recently supplied to Bellcore for evaluation at its Chester Test Facility in New Jersey.

The London meeting was attended by representatives from the countries participating in Annex IX, including the U.S., Germany, the United Kingdom (UK), Sweden, and the Netherlands. Representatives from Italy and Japan attended as observers. Each participating representative at the Experts Meeting reviewed the status of the electricity generation and supply situation in his or her respective country and provided a perspective on where electricity storage fits into the picture. Representatives from Germany and Japan discussed plans for two BES projects related to renewables support and transit peak shaving.

The Annex IX Experts' Meeting on Flywheel Energy Storage was held November 18-19, 1996, in Orlando, Florida. John Price of the University of Texas at Austin attended this meeting as the designated expert for the U.S. His contribution to the proceedings was regarded as valuable by all the attendees because it represented an objective and nonvested perspective. His expertise includes various aspects of flywheel technology development and power conversion electronics.

The purpose of this meeting was to benchmark the current status of the technology and its economics as well as to identify research needs in relation to which the IEA could play an effective role. The agenda included both formal presentations and working group sessions so that a consensus could be reached on all the issues. The topics addressed at this meeting were expected to be relevant to other activities planned by Annex IX. Through discussions at this meeting, an important role emerged for the IEA: coordinating input from European participants addressing the development of safety guidelines to be advanced in the U.S. by Bellcore. Providing the opportunity for European countries to participate in the development of these safety guidelines ensures that the resulting guidelines will be internationally accepted. This facilitates the acceptance of U.S.-manufactured flywheel systems in the European market and vice versa.
The ECES 41st Executive Committee meeting was held in Istanbul December 4-5, 1996, and the representatives from the following countries attended: the U.S., Turkey, the UK, the Netherlands, Germany, Sweden, and Japan. This represented the first time that the electrical energy storage annex was introduced to this group. EA Technology outlined the objectives and expected outcomes of Annex IX and provided a review of the Experts Meetings that had been completed for batteries, fuel cells, SMES, flywheels, PCSs, and utility requirements.

ESS program staff also attended the Experts' Meeting on Power Conversion, in Heidelberg, Germany, on February 13, 1997. The meeting had 14 attendees, the majority of whom were experts in the field of power electronics. A total of seven formal presentations was made by speakers from five countries. The presentations covered existing and planned systems, ranging in power from $100 \mathrm{MVA}$ to $10 \mathrm{kVA}$. The experts discussion focused on the current state of the art, both in terms of components and systems. Applications and market potential were also discussed. A key point raised by the group was the issue of reliability. Power electronic devices are much more robust and are no longer the weak link in the chain.

In Chicago on March 4-5, 1997, the ESS Program staff was host to the Annex IX Experts' Meeting for Utilities (II) and Batteries (II). The two-day meeting included presentations by U.S. lead-acid and advanced battery manufacturers and U.S. utilities including Texas Utilities, Southern Company Services, and PG\&E. The U.S. battery presentations provided a thorough overview of the status of battery system development in the U.S., including the operation of the systems at Vernon and Metlakatla. The U.S. presentations were followed by similar presentations made by European utilities from the Netherlands, Germany, and the UK and by Ontario Hydro in Canada. The discussions at this meeting made it clear that the types of storage systems that have been developed through the ESS Program by companies such as AC Battery and GNB are the types that utilities will need in the near term. Some of the longer-term application requirements could be met by the advanced zincl bromine systems being developed by ZBB and Powercell.

The two days of presentations were followed by two days of site visits to battery and superconductivity system vendors. The sites visited included Superconductivity, Inc., AC Battery Corporation, Omnion Power Engineering, ZBB, and GNB. The European visitors were able to see the hardware that was described in the presentations of the previous two days. 
On March 20-21, 1997, Mr. Michael Gravely of Superconductivity, Inc. (now with American Superconductor Corp) participated in the Experts' Meeting on SMES Systems in Gelsenkirchen, Germany. This threeday meeting was held as part of an international SMES workshop organized by EUS, the German Annex IX Participating Agent. The first day followed a conference-style format, with a total of 12 presentations, and 40 delegates from the SMES scientific community, potential end users, and local and federal government agencies. The second day included a round-table discussion meeting, focusing on key issues related to SMES. The relatively high cost of SMES-based energy storage systems was recognized as the main barrier to future commercialization of the technology. Current research is looking at both low-temperature superconductors and high-temperature superconductors in both small-scale $(<100 \mathrm{~kJ})$ and large-scale $(>1 \mathrm{mWh})$ applications. A technical visit was made to the Leybold factory and offices in Cologne. Leybold is a leading manufacturer of cryogenic and vacuum systems used in SMES systems.

An ESS Program staff member attended the Modeling Requirements Experts' Meeting held in Chester, England, June 10-11, 1997. This was the first of two modeling meetings held in FY97 and was combined with the Participating Agents meeting to allow for the planning of the EESAT '98 (Electrical Energy Storage Applications \& Technology) Conference, scheduled for June 1998. The purpose of the modeling meeting was to discuss each participating country's needs and expectations for the storage benefits assessment computer models that were to be developed by EA Technology for Annex IX. In addition to the UK and the U.S., the countries attending this meeting included Canada, Germany, Netherlands, and Sweden. Each participant made a presentation outlining their modeling needs. The ESS representative proposed two separate computer models that have different complexity levels and yield correspondingly more or less detailed results. This concept of two levels of models was well received.

The Participating Agents meeting was focused on planning for EESAT '98. The purpose of EESAT ' 98 will be to provide a major forum on energy storage at which the technology and institutional issues that affect all energy storage applications worldwide could be reviewed. EESAT '98 will not only be a forum for papers and group discussions but will also provide a venue for the display of energy storage systems and subsystems hardware. The meeting included detailed discussions of the various sessions and section topics. EESAT '98 will be a major energy storage event in Europe with an anticipated attendance of 250-300.
On this trip, the ESS staff member also toured and met with Dutch and German Annex IX entities. KEMA, the participating agent for the Netherlands, is somewhat similar to EPRI organizationally but has evolved into more of a competitive commercial entity and provides engineering and consulting services to the Netherlands and Europe. The Netherlands has a deregulated utility structure with multiple distribution companies. KEMA is the lead in two flywheel projects, a $70-\mathrm{kW} / 1.5-\mathrm{kWh}$ system for a distribution project supported by four distribution companies, and a 1-MW/15-kWh system for a renewable power quality project, which they are conducting in collaboration with the European Commission.

In Germany, the ESS staff member was hosted by EUS and was asked to attend the German National Team Meeting. The EUS is a strong proponent of energy storage and is the focus for organizing the formation of a German utility battery group. The Germans were interested in the progress of battery storage systems in the U.S. from both conceptual and hardware development perspectives.

In the fourth quarter of FY97, ESS Program staff attended, via teleconference, the IEA's ECES Modeling Requirements Experts' Meeting, held in Arnhem, the Netherlands, on September 29, 1997. This meeting was the second of the two modeling meetings held in FY97. At this meeting, the various applications of storage systems were discussed in detail, with close attention being paid to the range of potential secondary applications vs. a corresponding range of primary applications. A short demonstration of the prototypical model functionality was provided.

With the completion of the two models, Phase I of Annex IX work program activities is essentially finished. The two models, a techno-economic, cost/benefit model and an energy/emissions model, are intended for use as first-level screening tools incorporating realistic default values, within the models, together with a complementary 'help' text, relating back to the applications domain. Both the Electrical Energy Storage Applications Model and the Electrical Energy Storage Emissions Model are spreadsheet-based, with a Visual BASIC front-end.

The applications model incorporates applications, technology and financial modules and allows assessments to be performed for various primary applications, with an associated range of secondary applications. The principal modeling output is the derivation of the cost/ benefit ratio vs. time, for any particular application. The emissions model emphasizes the complementarity between storage and the integration of renewables (and 
other nondispatchable power sources) and enables firstlevel assessments of storage/renewables integrations to be performed for various (user input) generating mixes. The principal modeling outputs relate to the annual emissions savings of $\mathrm{CO}_{2}$, $\mathrm{NOx}$, and $\mathrm{SOx}$.

Broad agreement was reached as to the principle of a follow-on, Annex IX Phase II work program at both modeling meetings and at the 42nd Executive Committee Meeting held in Sapporo, Japan, in June 1997. The detailed content of this Phase II work program was discussed and was to be presented at the 43rd Executive Committee Meeting during the first quarter of FY98 in Paris.

The Annex IX activities have succeeded in establishing broad dialogue among the U.S. storage community and its counterparts in Europe and Canada. The Annex IX activities have promoted the formal exchange of ideas on an international basis and exposed all sides to the developments that have taken place in recent years. U.S. utilities have a growing interest in overseas utility operations, and Annex IX is providing them an additional forum to learn about their European counterparts. Because of these factors, and anticipating the favorable outcome of future activities, most system vendors in the U.S. regard ESS Program participation in these activities as positive.

\section{PCS Assessment Project}

In the third quarter, the ESS Program began the process of evaluating state-of-the-art PCS technologies. The current plans include assessing the design architecture of and providing cost structures for the various types of PCSs required for storage utility applications. Also, the report generated from these evaluations will outline the state-of-the-art PCS when integrated with various storage technologies, e.g., batteries, flywheels, SMES, and supercapacitors. The resulting report will also identify standards relevant to PCS use within the utility industry. Ultimately, the outcome of the study will be the basis for recommendations for an R\&D plan on PCS component and subsystem development. PCS R\&D is scheduled to start February 1998.

The likely objective of possible future PCS development will be to advance a multi-technology, low-cost, and low-footprint PCS. At present, PCS cost is approximately $\$ 200-\$ 300 / \mathrm{kW}$ for utility-grid-connected systems and constitutes about $30 \%$ of the overall system costs. GNB and GE have made remarkable progress in improving the PCS design and functionality, as demonstrated by the Vernon facility PCS, but cost and footprint are still not optimized. As new storage technologies are integrated into the ESS program, it will be desirable to have a single PCS topology that can serve the needs of batteries, flywheels, and SMES, as well as renewable generation sources. The ultimate goal of this activity will be to develop a PCS that can serve all of these technologies, that has an installed cost of approximately $\$ 80 / \mathrm{kW}$ for utility-grid-connected systems, and that has a footprint one-third the size of existing PCS designs.

\section{Status}

The PCS study started in mid-April 1997. An internal agreement was placed on April 21, 1997, to conduct the study and produce a final report that:

- Characterizes the design architecture and cost of the types of PCSs (based on gate turn-off thyristors or integrated-gate bipolar transistors, four quadrant, self-commutated, line-commutated, etc.) needed for storage and renewable utility applications (1- to 10-MW range).

- Identifies state-of-the-art PCS electrical interfaces to batteries, flywheels, SMES, and supercapacitors.

- Identifies standards relevant to PCSs use in the utility industry.

- Synthesizes the results to develop recommendations for an R\&D plan for components and subsystems.

The ideal PCS would be able to interface any or all of the four major storage technologies (batteries, SMES, flywheels, and supercapacitors) with the utility grid (three-phase, grid-tied operation) or with renewable (non-grid-tied operation) power sources.

The ESS Program has identified seven target applications toward which future PCS development should be directed. These applications have the highest cost savings to the user and the greatest potential impact on industry and therefore are most likely to be commercialized in the near term. Four of the applications are gridtied: power quality, voltage regulation, customer demand peak reduction, and area/frequency regulation. The remaining three are non-grid-tied: residential/telecommunications, small and large villages, and small industrial. Each of these applications has different operating parameters and use different technologies as the primary source.

On September 12, 1997, an SNL staff member met with the Manager of Integrated Power Systems of Liebert Corporation in Irvine, California. The meeting focused on PCS development at Liebert. PCS design 
architecture and the costs of PCSs used with UPSs were discussed. Numerous opportunities exist for collaboration in technology development with Liebert.

\section{Performance and Economic Analysis of SMES, Flywheels, and CAES Systems Project}

The scope of the ESS Program includes a portfolio of energy storage technologies for electric utility applications. Table 4-2 provides a list of technologies and peripheral devices now included in the program scope.

The program approach has been to apply expertise gained from work with battery energy storage to the development of storage media, PCSs, peripheral devices, and advanced storage systems that depend on similar components. The ESS Program initiated this analysis project with Energetics, Inc., late in the second quarter of FY97 to identify the areas in which program expertise directly applies to this expanded range of technologies and where such program expertise must be developed.

The project developed a catalogue of private sector contacts and product literature for SMES, flywheels, and CAES; a bibliography of journal and trade publications related to SMES, flywheels, and CAES; an updated definition of application requirements and potential markets for specific applications; and a spreadsheet-based modeling tool that links the cost and performance of SMES and flywheels over time. The analysis includes the four major thrusts of the project, as outlined in the Table 4-3.

\section{Status}

In a review of the project at SNL during the fourth quarter of FY97, the consensus was that the project is making progress, while at the same time discovering much more complicated technology and economic issues than originally envisioned by SNL. The study will be completed in 1998 .

Because data collection to model generic SMES and flywheel systems would involve an extensive, timeconsuming process, Energetics was to develop spreadsheet tools that model specific SMES and flywheel system topologies for power quality applications and specific flywheel system topologies for peak shaving and renewable hybrid system support. The specificity of the modeling tools makes data collection and verification for the spreadsheets an achievable objective enabling baseline analysis. The SMES model development has advanced to a point where system costs and performance outputs approximate existing systems. The flywheel models are at a more rudimentary state of development.

Energetics also reported that the literature review for flywheels and SMES was complete and an industry survey tool was in final review. Interviews with industry experts began in early September. The first review of the technology primers for SMES, flywheels, cryogenics, and power electronics was completed, and a first draft of the CAES primer was finished. An initial review of the spreadsheet analysis tool was completed; data entry of literature-provided technology characteristics was underway, with additional development dependent on the results of the industry survey.

Energetics has contacted SMES and CAES system manufacturers and component manufacturers of power electronics, cryogenics, flywheel rotors, motor genera-

Table 4-2. Storage Media, Power Conversion Devices, Peripheral Devices, and Related Technologies

\begin{tabular}{llll}
\hline Storage Media & \multicolumn{1}{c}{$\begin{array}{c}\text { Power Conversion } \\
\text { Devices }\end{array}$} & \multicolumn{1}{c}{$\begin{array}{c}\text { Peripheral } \\
\text { Devices }\end{array}$} & \multicolumn{1}{c}{$\begin{array}{c}\text { Related } \\
\text { Technologies }\end{array}$} \\
\hline Batteries & Rectifiers & Utility Interfaces & Racks \& Housing \\
Flywheels & Inverters & Communications & Bearings \\
SMES & Motors/Generators & Monitors & Cryogenics \\
CAES & Frequency Converters & Controls & Pumps
\end{tabular}


Table 4-3. SMES, Flywheel, and CAES Project Thrusts, Activities, and Status at the End of FY97

\begin{tabular}{|c|c|c|}
\hline Thrust & Activities & Status \\
\hline \multirow[t]{2}{*}{ Collect Information } & $\begin{array}{l}\text { Conduct library \& Internet searches } \\
\text { and interviews } \\
\text { SMES, flywheel, and CAES }\end{array}$ & $\begin{array}{l}\text { SMES \& flywheel complete, CAES } \\
\text { under way. }\end{array}$ \\
\hline & $\begin{array}{l}\text { Survey stakeholders } \\
\text { Existing and projected status of tech- } \\
\text { nologies and markets, existing pro- } \\
\text { jected business trends and goals, } \\
\text { R\&D necessary to achieve projec- } \\
\text { tions }\end{array}$ & $\begin{array}{l}\text { Survey tools complete; contact list in } \\
\text { development; survey conducted } \\
\text { August to October } 1997 .\end{array}$ \\
\hline \multirow[t]{3}{*}{$\begin{array}{l}\text { Analyze } \\
\text { Information }\end{array}$} & $\begin{array}{l}\text { Develop a physical \& electronic } \\
\text { repository of information } \\
\text { Stakeholder contacts, technical } \\
\text { papers, manufacturers' literature }\end{array}$ & $\begin{array}{l}\text { Contact database in process; litera- } \\
\text { ture collections and electronic bibli- } \\
\text { ography for SMES \& flywheels } \\
\text { substantial; CAES collection is } \\
\text { nascent. }\end{array}$ \\
\hline & $\begin{array}{l}\text { Estimate technical \& economic } \\
\text { characteristics of storage systems } \\
\text { Present, in } 2005 \text { (near-term), in } 2010 \\
\text { (mid-term) }\end{array}$ & $\begin{array}{l}\text { Analysis of information from litera- } \\
\text { ture is under way. }\end{array}$ \\
\hline & $\begin{array}{l}\text { Conduct iterative spreadsheet } \\
\text { analysis } \\
\text { Refine estimates of technical and } \\
\text { economic characteristics, determine } \\
\text { benefit/cost for specific technology/ } \\
\text { application pairs }\end{array}$ & $\begin{array}{l}\text { First review of spreadsheet tool } \\
\text { complete; data entry of literature- } \\
\text { provided technology characteristics } \\
\text { is under way; additional develop- } \\
\text { ment depends on survey. }\end{array}$ \\
\hline \multirow[t]{2}{*}{ Identify Actions } & $\begin{array}{l}\text { Review analytic results to identify } \\
\text { critical issues } \\
\text { Most significant cost contributions, } \\
\text { crucial technical capabilities }\end{array}$ & $\begin{array}{l}\text { Activities will begin after analysis is } \\
\text { complete. }\end{array}$ \\
\hline & $\begin{array}{l}\text { Identify analysis and R\&D that } \\
\text { address critical issues }\end{array}$ & $\begin{array}{l}\text { Interim reports to SNL in February } \\
\text { and DOE/HQ in May; report to SNL } \\
\text { in August; regular updates in each } \\
\text { SNL quarterly report. }\end{array}$ \\
\hline \multirow[t]{2}{*}{ Report Results } & Provide interim reports & \\
\hline & $\begin{array}{l}\text { Draft and finalize overall project } \\
\text { report } \\
\text { Technology primers, approach, } \\
\text { results, recommendations }\end{array}$ & $\begin{array}{l}\text { First review of technology primers for } \\
\text { SMES, flywheels, cryogenics, and } \\
\text { power electronics complete; CAES } \\
\text { primer in first draft. }\end{array}$ \\
\hline
\end{tabular}


tors, and containment systems. Information gathering from these groups is expected to continue through the third quarter of FY98. Completion of the modeling tools and the final report draft is expected by about that time also.

In the fourth quarter of FY97, Energetics staff attended the PowerSystems ' 97 Conference, held September 9-10, 1997, to gather data and build contacts within the small group of manufacturers of these emerging technologies. During the two-day conference, ESS staff met several of the key players in both technologies: Beacon Power/SatCon, International Computer Power, Acumentrics (marketer of Trinity flywheels), Piller, Active Power, and Superconductivity, Inc. In addition to standard exhibit displays, the CleanSource ${ }^{\mathrm{TM}}$ Flywheel Energy Storage System by Active Power was demonstrated and was able to energize a light bank with stored energy. Contrary to what has been announced in the media, the CleanSource system is not an integrated system; it requires a stand-alone UPS system and does not include a power conversion subsystem. Acumentrics and Beacon Power had nonworking demos of their flywheels. Most companies expressed interest in cooperating with the ESS study on SMES and flywheels during the technology survey and information collection phases and are willing to release data, including costs and materials used. Energetics staff planned to follow up with the companies involved to maintain their interest in the SMES/flywheel study in particular and the ESS program in general.

\section{Advanced Technologies}

\section{Uninterruptible Power Supply Review}

The use of advanced storage systems in UPS devices is being explored with renewed interest by several companies.

On January 28, 1997, ESS Program staff visited SatCon Technology Corporation. The purpose of the meeting was to exchange information on the ESS Program and on the status of SatCon's flywheel technology for utility applications. In October 1996, SatCon announced its development of a flywheel-based UPS device for cable television and telecommunications applications. The flywheel is rated at $2 \mathrm{~kW}$ for one hour. It is intended to replace the battery pack in existing UPS devices and therefore does not include an inverter or other power electronics. The flywheel is expected to cost $\$ 2,000$ once it has been demonstrated and put into production. SatCon has prepared a compre- hensive business plan and has made flywheel-based UPS market projections exceeding $\$ 200 \mathrm{M} / \mathrm{yr}$ by 2001 .

On February 20, 1997, a representative from Exide Electronics visited SNL to discuss the ESS Program and Exide Electronics' UPS products. This representative had attended the ESA meeting held November 12-13, 1996, and started a dialogue at that time regarding the use of UPSs in energy storage applications. While Exide Electronics is interested in energy storage markets, it has recently scaled back its activities in this area due to a perceived lack of a large, immediate market. Exide Electronics believes that the UPS industry has existing products covering the range of 200-W to 1-MW applications. Exide is interested in developing a midvoltage-range (approximately 15-kV) substation-type energy storage product. A relevant role for the ESS Program would be to first define the specifications for such a device and then proceed with a cost-shared development activity.

Exide has made significant improvements in the last few years and now has software control over the UPS devices in all of its current products. To gain the maximum benefit from this capability, Exide Electronics expressed interest in getting help to define charge specifications for all the possible batteries that are used in its products. An insight gained from this meeting was that the PCS division of Exide Electronics and the battery suppliers communicate poorly; they were "just too different." This is a prevalent attitude in the industry and requires that a communications "bridge" be built. The ESS Program could play a major role in developing optimized charge specifications that could be cataloged in modern UPS products and called up when the battery is installed using software selection processes. Specifications regarding battery monitoring were also mentioned as something Exide Electronics would like from the ESS Program or another impartial organization.

Exide Electronics also expressed interest in flywheel- and SMES-based UPS systems. Exide Electronics' representative confirmed that Active Power Corp. had announced a flywheel UPS product and knew of another company that had connected a SMES to a UPS. The Exide Electronics representative is optimistic that hybrid systems, such as battery/SMES, may be viable in the future. The subject of renewables was also addressed at this meeting. While Exide Electronics has no experience in renewables, activities like the RGS project, an ESS initiative, would go forward and would possibly use commercial UPS hardware for the power electronics. 


\section{Flywheel Technology}

On October 4, 1996, staff from the ESS Program visited the Center For Electromechanics at the University of Texas at Austin, where research is conducted on flywheels. This research originated from $D o D$ Advanced Research Projects Agency (ARPA) contracts for railguns and the high-powered electrical systems associated with them. The flywheel work evolved from a need to eliminate bulky conventional generation and storage used to fire the railgun from mobile platforms. Compact flywheels were chosen as the preferred substitute.

The DoD programs are no longer supporting this work, and the present flywheel activity is supported primarily by sponsors interested in mobile applications who recognize that these systems could meet stationary application requirements as well. One of the main sponsors is the Federal Railroad Agency, which is developing flywheels to augment conventional power sources for locomotives. The flywheel will eliminate fluctuations in power along the rail route by tapping energy stored in the flywheels. The Federal Railroad Agency is aware of the potential for stationary applications and, as a result of the success with the current work, it is likely that it will extend its support to the development of flywheel systems to shave the peak at substations that supply rail systems, such as those of regional transit authorities. This application would be the same as that in the San Diego Gas \& Electric experiment to shave the peak of the regional transit railway using a battery system.

The capabilities observed at the University of Texas included not only the expertise for designing, building, and testing the flywheel but also expertise in power conversion and interconnection with the utility grid/network. Considerable interest was expressed by the university team in working with the ESS Program either in an advisory or a consultant capacity, or as a potential bidder.

The University of Texas team has followed the PQ2000 development initiative and recognizes that storage systems that target the power quality market have a strong future. It has developed its own preliminary design concept for a 3-MVA, 20-sec flywheel system that could conceivably be the next-generation successor to the battery-based PQ2000 system. If design goals are successfully achieved, such a flywheel-based system could offer a distinct footprint and cost advantage over current battery systems.

On November 15, 1996, an ESS staff member was invited to attend a meeting held by Bellcore at its Chester Test Facility in New Jersey. Bellcore provides test- ing and standards support to nine regional phone companies as well as other smaller phone service providers. Because of a perception of unsatisfactory battery performance at their outdoor and indoor switching sites, these phone service companies have decided to pursue the development of FES as a possible replacement for battery storage. The objective is to begin replacing existing batteries within the next 3 years.

The present battery energy storage capacity of all of Bellcore's switching sites is estimated to be $200 \mathrm{MWh}$, which includes small battery clusters of about $100 \mathrm{Wh}$ and larger battery banks of $100+\mathrm{kWh}$. Bellcore estimates that another $200+\mathrm{MWh}$ of storage capacity will be required within the next 3 years to support the high growth that this industry is experiencing and to support the greater power needs of new fiber-optic lines. With support from its subscribing companies, Bellcore initiated a proprietary test and demonstration effort, initially at the subsystem level, with a scaling up to full operating systems using flywheel systems from U.S. and UK suppliers. The demonstration during this meeting highlighted a 100-Wh/5-kW flywheel system. The analytical simulation and testing of flywheel failures were also reviewed.

Bellcore wants to start compiling guidelines so that flywheels can be tested safely in laboratory environments. Eventually, these guidelines will be extended to cover the safe deployment of these flywheel systems in the field. Development of such guidelines is seen as a key activity in the commercial development of flywheel systems. The Bellcore effort is very timely because it takes 4 to 6 years to develop standards that will be necessary as deployments of flywheel systems increase.

A flywheel currently being tested at Bellcore was supplied by IES. Also during this meeting, an ESS Program staff member had an opportunity to discuss IES's current flywheel technology and commercialization plans. IES is developing FES systems that are initially targeting a potentially large telecommunications market for ESS. A project currently in progress is the installation of a high-volume production capability for filament-wound flywheel rotors in a 104,000-sq-ft facility. The IES rotor is a cylinder that rotates on a vertical axis, unlike U.S. designs, which all consist of disks of varying thicknesses that rotate either horizontally or vertically. The IES configuration distributes the mass of the flywheel over a larger area, which reduces the hoop stress on the filament material. The large mass distributed in the tall cylindrical configuration also allows lower rotational speeds.

IES had supplied a 5-kW FES to Bellcore, and it is being evaluated as an advanced storage technology 
alternative to the BESS currently used by telecommunications companies. Although the system is operated at $5 \mathrm{~kW}$, it is designed to deliver $25 \mathrm{~kW}$. The full rating will be used after the completion of initial testing.

\section{Electricity Consumers Resource Council Meeting}

ESS Program staff met with a staff representative from Elcon (the Electricity Consumers Resource Council) in Washington, D.C. Elcon is an association of 28 large industrial consumers of electricity. Its member companies include Amoco, Bethlehem Steel, Chevron, Dow Chemical, DuPont, General Motors, Ford Motor, Procter and Gamble, and Intel. Elcon is strongly in favor of utility deregulation and retail competition and expects that unbundling will reduce electricity costs and improve power quality. There will be significant opportunities in the deregulated utility industry for use of storage in such applications as power quality and peak shaving, according to the Elcon representative. Deregulation could also impact interconnected operating services or ancillary services. Oil and chemical (paper, glass, etc.) companies may be most likely to investigate storage first because of strong economic and productivity motivations. Typical sizes for storage systems for these industrial applications are in the several megawatts of electrical capacity. In order to communicate ESS Program activities and issues, the Elcon representative will send a letter to all members describing the program and summarizing storage opportunities for industrial applications.

\section{Articles in the Electrical World Trade Journal}

The ESS Program has coauthored several articles about energy storage installations and electric utility industry developments in recent issues of McGrawHill's utility trade journal, Electrical World. In June 1997, the ESS Program coauthored an article with Energetics, Inc., and MP\&L titled "Battery Storage all but eliminates diesel generator." The article described the history, technology, and performance of the BESS that GE and GNB developed for Metlakatla, a remote island in southeast Alaska. The ESS Program used research conducted to support that article for another article coauthored with Energetics that was published in the August issue of the journal. This article describes the history and status of the electric utility industry in Alaska. The article incorporates information on how battery energy storage and SMES are emerging in renewable and hybrid systems in Alaskan utilities.

\section{Battery Energy Storage Market Feasibility Study}

The Battery Energy Storage Market Feasibility Study was published in July 1997. An expanded version of the report was published in September 1997. The study was conducted by Frost \& Sullivan and was designed specifically to quantify the expected energy storage markets for utility applications. This study was based on an SNL analysis performed earlier. The market study was performed to determine if enough potential markets exist to cause battery energy storage businesses to make the investment necessary to develop viable products. The report concluded that many of the groups surveyed, which included electricity providers, BESS vendors, regulators/consultants, and other technology advocates, viewed battery energy storage as an important enabling technology to facilitate the use of renewable energy, to address power quality improvement, and to resolve asset utilization issues.

\section{Premium Power Applications and Telecommunications}

The ESS Program manager and SNL staff made program-related presentations to the Lucent Technologies Premium Power Design Team. The Lucent team, which is meeting about every 3 months, is investigating technologies that provide high quality power at the point of use. Technologies receiving the most attention by the team include renewables (PV and wind) and storage (flywheels, batteries, and supercapacitors). This meeting was the third consecutive one attended by ESS staff and was held at Bell Laboratories in Murray Hill, New Jersey. The ESS presentations generated extensive questions concerning program technologies and emphasis. Numerous opportunities for collaboration in technology development exist for the ESS Program. At the request of Lucent and the ESS Program manager, SNL ESS staff will continue active participation in these meetings.

\section{NIST/ATP for Focused Program in Premium Power}

At a NIST planning workshop on August 12 and 13, 1997, ESS staff discussed a Focused Program proposal for the ATP. The topic of the workshop was "Premium Power," i.e., a low-disturbance, high-reliability power source. The need for premium power results from the changing infrastructure needs of U.S. industry, which has been estimated to suffer over $\$ 26 \mathrm{~B}$ in annual losses due to power interruption. But more importantly, pre- 
mium power is an enabling technology for portable electronics, broadband satellite communications, and a distributed power network. Lucent, one of the driving forces in the workshop, envisions a convergence of technologies in telephony, electronics/information systems, aerospace, and deregulated/distributed power, leading to a revolution in communication technology. Teledesic and the NEMI have a similar vision.
The Power technologies that would be developed if NIST chooses to select a focused program (allocating approximately $\$ 90 \mathrm{M}$ over five years and requiring an equal amount in industry matching funds) in premium power are advanced lithium rechargeable batteries, fuel cells, flywheels, and high-efficiency PV cells, including system integration issues. SNL had a strong presence at the workshop, which reffects its industrial ties through NEMI and its DOE programs such as energy storage systems and PV R\&D. 


\section{Appendix A: Presentations and Publications}

\section{Presentations}

A.A. Akhil, "Annex IX Experts' Meeting for Utilities (II) and Batteries (II) - Battery System Development in the U.S. including Systems at Metlakatla and Vernon," presented in Chicago, IL, March 4-5, 1997.

A.A. Akhil, D. Achenbach, G. Buckingham, G. Hunt, and N. Miller, "Electric Utility Battery Energy Storage, Opportunities in Alaska," seminar in Ketchikan, AK, August 4-6, 1997.

A.A. Akhil, P.C. Butler, "ESS Program Issues and Activities," presented to Southem California Edison at Sandia National Laboratories, Albuquerque, NM, August 25, 1997.

P.C. Butler, "Energy Storage and Photovoltaic Interfaces," presented at the Soltech '97 Conference, Washington, DC, April 26, 1997.

P.C. Butler, "Energy Storage System Integration," presented to the Presidential Committee of Advisors on Science and Technology, Washington, DC, May 20, 1997.

P.C. Butler, "ESS Program Overview," presented to Exide Electronics at Sandia National Laboratories, Albuquerque, NM, February 20, 1997.

P.C. Butler, "ESS Program Overview," presented to the International Lead Zinc Research Organization (ILZRO) and the Commonwealth Scientific and Industrial Research Organization (CSIRO), presented at Sandia National Laboratories, Albuquerque, NM, May 6, 1997.

P.C. Butler, "Market studies on battery storage for renewable energy technologies. Lab test results on lead-acid batteries for stationary applications," presented to the Lucent Technologies Premium Power Design Team, Murray Hill, NJ, July 10, 1997.

P.C. Butler, "Yuasa-Exide Battery Test Results," presented at Yuasa-Exide, Reading, PA, July 11, 1997.
P.C. Butler, C.P. Cameron, "New Developments in Energy Storage Systems," presented to the Lucent Technologies Premium Power Design Team, Dallas, TX, May 5, 1997.

P.C. Butler, G.P. Corey, "Photovoltaic Battery and Charge Controller Market and Applications Survey and ESS Program Overview," presented to the Industry Users Group at the Energy Storage Association (ESA) Meeting, Washington, DC, May 1-2, 1997.

P.C. Butler, G.P. Corey, N.H. Clark, and C.P. Cameron, "Renewable Generation and Storage," presented at the IEEE PV Specialists Meeting, Anaheim, CA, September 30, 1997.

P.C. Butler, G.P. Corey, R.G. Jungst, "ESS Program Overview," presented at Delphi Energy and Engine Management Systems, Indianapolis, IN, August 21, 1997.

P.C. Butler, G.P. Corey, R.G. Jungst, "VRLA Reliability Improvement," presented to Yuasa-Exide, Richmond, KY, September 26, 1997.

P.C. Butler, P. Taylor, "Battery Simulator Project Proposal," presented to the National Rural Electric Cooperative Association, Los Angeles, CA, June 12, 1997.

N.H. Clark, P.C. Butler, "Zinc/Bromine Project Activities," presented to representatives from Sumitomo Corporation at Sandia National Laboratories, Albuquerque, NM, September 19, 1997.

G.P. Corey, "Battery Energy Storage Fundamentals Workshop," presented at the National Renewable Energy Laboratory, Denver, CO, May 22, 1997.

G.P. Corey, "System Design and Maintenance Issues for Batteries in Renewable Energy Hybrid Systems," presented at the BATTCON97 National Battery Conference, Boca Raton, FL, April 21-22, 1997.

S. Kraft, "The Projected Penetration of Battery Systems in Regulated Utilities," S. Swaminathan, "Energy Storage Costs," A.A. Akhil, "IEA Energy Storage Technologies Network for Electric Optimization," 
G. Hunt, "Metlakatla Power and Light Project," G.P. Corey, "Update On The Transportable Battery Energy Storage System (TBESS) Development Program," C.E. Platt, "DOE Energy Storage Systems Program, New Directions," presented at the Energy Storage Association Meeting, Amelia Island, FL, November 11-13, 1996.

C.E. Platt, P.C. Butler, "Energy Storage Issues and Activities," presented to the Electricity Consumers Resource Council, Washington, DC, March 14, 1997.

C.E. Platt, P.C. Butler, P. Overholt, "ESS Program Overview," presented to Solarex, Frederick, MD, October 10, 1997.

\section{Publications}

A.A. Akhil and S. Kraft, July 1997, Battery Energy Storage Market Feasibility Study, SAND97-1275/1, and Battery Energy Storage Market Feasibility Study-Expanded Report, SAND97-1275/2. Sandia National Laboratories, Albuquerque, NM.
A.A. Akhil, R.K. Sen, and S. Swaminathan, February 1997, Cost Analysis of Energy Storage Systems for Electric Utility Applications, SAND97-0443. Sandia National Laboratories, Albuquerque, NM.

P.C. Butler, April 1997, Energy Storage Systems Program Report 1996, SAND97-1136. Sandia National Laboratories, Albuquerque, NM.

G.P. Corey and G.A. Buckingham, DOE's Battery Storage Program, in Power Quality Assurance Magazine, Vol. 8, No. 1, p. 16, January/February 1997.

M. Demarest, P. Taylor, D. Achenbach, and A. Akhil, Battery storage all but eliminates diesel generator, in Electrical World, June 1997.

A. Koenig, J. Rasmussen, April 1997, Sodium/Sulfur Battery Engineering for Stationary Energy Storage-Final Report, SAND96-1062. Sandia National Laboratories, Albuquerque, NM.

P. Taylor, M. Demarest, and P.C. Butler, T\&D in Alaska: Like an undeveloped nation, in Electrical World, August 1997. 


\section{Distribution}

ABB Power T\&D Co., Inc.

Attn: P. Danfors

16250 West Glendale Drive

New Berlin, WI 53151

American Electric Power Service Corp.

Attn: C. Shih

1 Riverside Plaza

Columbus, $\mathrm{OH} 43215$

Applied Power Corporation

Attn: Tim Ball

Solar Engineering

1210 Homann Drive, SE

Lacey, WA 98503

Ascension Technology

Attn: Edward Kern

Post Office Box 6314

Lincoln Center, MA 01773

Anchorage Municipal Light \& Power

Attn: Meera Kohler

1200 East $1^{\text {st }}$ Avenue

Anchorage, AK 99501

Bechtel Corporation

Attn: W. Stolte

P.O. Box 193965

San Francisco, CA 94119-3965

Berliner Kraft und Licht (BEWAG)

Attn: K. Kramer

Stauffenbergstrasse 26

1000 Berlin 30

GERMANY

Business Management Consulting

Attn: S. Jabbour

24704 Voorhees Drive

Los Altos Hills, CA 94022

C\&D Charter Power Systems, Inc. (2)

Attn: Dr. Sudhan S. Misra

Attn: Dr. L. Holden

Washington \& Cherry Sts.

Conshohocken, PA 19428
Argonne National Laboratories (2)

Attn: W. DeLuca

G. Henriksen

CTD, Building 205

9700 South Cass Avenue

Argonne, IL 60439

Arizona Public Service (2)

Attn: R. Hobbs

Herb Hayden

400 North Fifth Street

P.O. Box 53999, MS-8931

Phoenix, AZ 85072-3999

AVO International

Attn: Gary Markle

510 Township Line Rd.

Blue Bell, PA 19422

Babcock \& Wilcox

Attn: Glenn Campbell

P.O. Box 785

Lynchburg, VA 24505

California State Air Resources Board

Attn: J. Holmes

Research Division

P.O. Box 2815

Sacramento, CA 95812

Calpine Corp.

Attn: R. Boucher

50 W. San Fernando, Ste. 550

San Jose, CA 95113

Chugach Electric Association, Inc. (2)

Attn: T. Lovas

J. Cooley

P.O. Box 196300

Anchorage, AK 99519-6300

Consolidated Edison (2)

Attn: M. Lebow

N. Tai

4 Irving Place

New York, NY 10003

Corn Belt Electric Cooperative

Attn: R. Stack

P.O. Box 816

Bloomington, IL 61702 
Delphi Energy and Engine

Management Systems (3)

Attn: J. Michael Hinga

R. Galyen

R. Rider

P.O. Box 502650

Indianapolis, $\mathbb{N} 46250$

Alaska State Division Of Energy (3)

Attn: P. Frisbey

P. Crump

B. Tiedeman

333 West Fourth Ave, Suite 220

Anchorage, AK 99501-2341

EA Technology, Ltd.

Attn: J. Baker

Chester CH1 6ES

Capenhurst, England

UNITED KINGDOM

Eagle-Picher Industries

Attn: J. DeGruson

C \& Porter Street

Joplin, MO 64802

Electrosource

Attn: Michael Dodge

P.O. Box 7115

Loveland, CO 80537

Eltech Research Corporation

Attn: Dr. E. Rudd

625 East Street

Fairport Harbor, OH 44077

Energetics, Inc. (3)

Attn: H. Lowitt

P. Taylor

L. Charles

7164 Gateway Drive

Columbia, MD 21046

Energetics, Inc. (4)

Attn: M. Farber

R. Scheer

J. Schilling

P. DiPietro

501 School St. SW, Suite 500

Washington, DC 20024

Energy and Environmental Economics, Inc.

Attn: Greg J. Ball

353 Sacramento St., Suite 1540

San Francisco, CA 94111
International Energy Systems, Ltd.

Attn: G. Barker

Chester High Road

Nestor, South Wirral

L64 UE UK

UNITED KINGDOM

East Penn Manufacturing Co., Inc.

Attn: M. Stanton

Deka Road

Lyon Station, PA 19536

Electric Power Research Institute (3)

Attn: S. Chapel

S. Eckroad

R. Schainker

P. O. Box 10412

Palo Alto, CA 94303-0813

Electrochemical Engineering Consultants, Inc.

Attn: P. Symons

1295 Kelly Park Circle

Morgan Hill, CA 95037

Electrochemical Energy Storage Systems, Inc.

Attn: D. Feder

35 Ridgedale Avenue

Madison, NJ 07940

Energy Systems Consulting

Attn: A. Pivec

41 Springbrook Road

Livingston, NJ 07039

Firing Circuits, Inc.

Attn: J. Mills

P.O. Box 2007

Norwalk, CT 06852-2007

General Electric Company

Attn: N. Miller

Building 2, Room 605

1 River Road

Schenectady, NY 12345

General Electric Drive Systems

Attn: D. Daly

1501 Roanoke Blvd.

Salem, VA 24153 
GE Industrial \& Power Services

Attn: Bob Zrebiec

640 Freedom Business Center

King of Prussia, PA 19046

Giner, Inc.

Attn: A. LaConti

14 Spring Street

Waltham, MA 02254-9147

Golden Valley Electric Association, Inc.

Attn: S. Haagensen

Box 71249

758 Illinois Street

Fairbanks, AK 99701

GNB Technologies (4)

Industrial Battery Company

Attn: G. Hunt

J. Szymborski

R. Maresca

J. Boehm

Woodlake Corporate Park

829 Parkview Blvd.

Lombard, IL 60148-3249

Lawrence Berkeley Laboratory (3)

Attn: E. Cairns

K. Kinoshita

F. McLarnon

University of California

One Cyclotron Road

Berkeley, CA 94720

Longitude 122 West

Attn: S. Schoenung

1241 Hobart St.

Menlo Park, CA 94025

Lucent Technologies

Attn: C. Mak

3000 Skyline Drive

Mesquite, TX 75149

Lucent Technologies, Inc.

Attn: J. Morabito

Director, Global Research and Development

P.O. Box 636

600 Mountain Avenue

Murray Hill, NJ 07974-0636
GNB Technologies

World Headquarters

Attn: S. Deshpande'

375 Northridge Road

Atlanta, GA 30350

Hawaii Electric Light Co.

Attn: C. Nagata

P.O. Box 1027

Hilo, HI 96720

ILZRO (3)

Attn: J. Cole

P. Moseley

C. Parker

P.O. Box 12036

Research Triangle Park, NC 27709

Imperial Oil Resources, Ltd.

Attn: R. Myers

3535 Research Rd NW

Calgary, Alberta

CANADA T2L 2K8

Innovative Power Sources

Attn: Ken Belfer

1419 Via Jon Jose Road

Alamo, CA 94507

Metlakatla Power \& Light

Attn: H. Achenbach

P.O. Box 359

Metlakatla, AK 99926

Micron Corporation

Attn: D. Nowack

158 Orchard Lane

Winchester, TN 37398

ZBB Technologies, LTD.

Attn: Robert J. Parry

Managing Director

16 Emerald Tce.

West Perth

Western Australia 6005 
National Renewable Energy Laboratory (6)

Attn: L. Flowers

J. Green

S. Hock

R. DeBlasio

B. Stafford

H. Thomas

1617 Cole Blvd.

Golden, CO 80401-3393

New York Power Authority

Attn: B. Chezar

1633 Broadway

New York, NY 10019

NC Solar Center

Attn: Bill Brooks

Corner of Gorman and Western

Box 7401 NCSU

Raleigh, NC 27695-740

Northern States Power

Attn: D. Zurn

414 Nicollet Mall

Minneapolis, MN 55401

NPA Technology

Attn: Jack Brown

Suite 700, Two University Place

Durham, NC 27707

Oak Ridge National Laboratory (3)

Attn: B. Hawsey, Bldg. 3025, MS-6040

J. Stoval, Bldg. 3147 , MS-6070

J. VanCoevering, Bldg. 3147, MS-6070

B. Kirby, Bldg. 3147 , MS-6070

P.O. Box 2008

Oak Ridge, TN 37831

Public Service Company of New Mexico

Attn: J. Neal

Manager, Premium Power Services

Alvarado Square MS-BA52

Albuquerque, NM 87158

PEPCO

Attn: Brad Johnson

1900 Pennsylvania NW

Washington, DC 20068
Oglethorpe Power Company

Attn: C. Ward

2100 E. Exchange Place

P.O. Box 1349

Tucker, GA 30085-1349
Chief Technology Officer

Attn: Robert Wills

Advanced Energy Systems

Riverview Mill

Post Office Box 262

Wilton, $\mathrm{NH} 0308$

Omnion Power Engineering Corporation

Attn: H. Meyer

2010 Energy Drive

P.O. Box 879

East Troy, WI 53120

Orion Energy Corp.

Attn: Doug Danley

10087 Tyler Place \#5

ljamsville, MD 21754

Public Service Company of New Mexico

Attn: R. Flynn

Senior Vice President

Alvarado Square MS-2838

Albuquerque, NM 87158

International Business and Technology

Services Inc.

Attn: J. Neal

Administrator Research and Development 9220 Tayloes Neck Rd.

Nanjemoy, MD 20662

Gridwise Engineering Company

Attn: B. Norris

121 Starlight Place

Danville, CA 94526

Pacific Northwest Laboratory (2)

Attn: J. DeSteese, K5-02

D. Brown

Battelle Blvd.

Richland, WA 99352 
Power Technologies, Inc.

Attn: P. Prabhakara

1482 Erie Blvd.

P.O. Box 1058

Schenectady, NY 12301

Puerto Rico Electric Power Authority

Attn: W. Torres

G.P.O. Box 4267

San Juan, Puerto Rico 00936-426

Solar Electric Specialists Co.

Mr. Jim Trotter

232-Anacapa St.

Santa Barbara, CA 93101

ENERTEC

Attn: D. Butler

349 Coronation Drive

Auchenflower, Queensland, 4066

P.O. Box 1139 Milton BC Qld 4064

AUSTRALIA

Southern Company Services, Inc. (2)

Research and Environmental Affairs

$14 \mathrm{~N}-8195$

Attn: B. R. Rauhe, Jr.

K. Vakhshoorzadeh

600 North $18^{\text {th }}$ Street

P.O. Box 2625

Birmingham, Al 35202-2625

Trace Technologies (2)

Attn: Michael Behnke

W. Erdman

6952 Preston Avenue

Livermore, CA 94550

TRACE Engineering

Attn: B. Roppenecker

President

$5916195^{\text {th }}$ Northeast

Arlington, Washington 98223

RMS Company

Attn: K. Ferris

87 Martling Ave.

Pleasantville, NY 10570
Powercell Corporation (2)

Attn: Reznor I. Orr

Rick Winter

101 Main Street, Suite 9

Cambridge, MA 02142-1519

Raytheon Engineers and Constructors

Attn: A. Randall

700 South Ash St.

P.O. Box 5888

Denver, CO 80217

Siemens Solar

Attn: Clay Aldrich

4650 Adohn Lane

Post Office Box 6032

Camarillo, CA 93011

R\&D Associates

Attn: J. Thompson

2100 Washington Blvd.

Arlington, VA 22204-5706

California Energy Commission

Attn: Jon Edwards

1516 Ninth Street, MS-46

Sacramento, CA 95814

Sentech, Inc. (2)

Attn: R. Sen

K. Klunder

4733 Bethesda Avenue, Suite 608

Bethesda, MD 20814

Sentech, Inc.

Attn: Robert Reeves

9 Eaton Road

Troy, NY 12180

Santa Clara University

Attn: Charles Feinstein, Ph.D.

Department of Decision and Information

Sciences

Leavey School of Business and

Administration

Santa Clara, CA 95053 
SAFT Research \& Dev. Ctr.

Attn: Guy Chagnon

107 Beaver Court

Cockeysville, MD 21030

Salt River Project (2)

Attn: H. Lundstrom

G.E. "Ernie" Palomino, P.E.

MS PAB 357, Box 52025

Phoenix, AZ 85072-2025

Southern California Edison

Attn: R. N. Schweinberg

6070 N. Irwindale Ave., Suite I

Irwindale, CA 91702

Soft Switching Technologies

Attn: D. Divan

2224 Evergreen Rd., Ste. 6

Middleton, WI 53562

Solarex

Attn: G. Braun

630 Solarex Court

Frederick, MD 21701

The Solar Connection

Attn: Michael Orians

P.O. Box 1138

Morro Bay, CA 93443

Trojan Battery Company

Attn: Jim Drizos

12380-Clark Street

Santa Fe Springs, CA 90670

U.S. Department of Energy

Attn: C. Platt

EE-12 FORSTL

Washington, DC 20585

U.S. Department of Energy

Attn: K. Heitner

Office of Transportation Technologies

EE-32 FORSTL

Washington, DC 20585

U.S. Department of Energy

Attn: R. Brewer

EE-10 FORSTL

Washington, DC 20585
SEIA

Attn: S. Sklar

122 C Street NW

$4^{\text {th }}$ Floor

Washington, DC 20001-2104

SRI International

Attn: C. Seitz

333 Ravenswood Ave.

Menlo Park, CA 94025

Stored Energy Engineering (2)

Attn: George Zink

J.R. Bish

7601 E. $88^{\text {th }}$ Place

Indianapolis, IN 46256

Stuart Kuritzky

347 Madison Avenue

New York, NY 10017

Superconductivity, Inc. (2)

Attn: Jennifer Billman

Michael Gravely

P.O. Box 56074

Madison, WI 53705-4374

Switch Technologies

Attn: J. Hurwitch

4733 Bethesda Ave., Ste. 608

Bethesda, MD 20814

Trace

Attn: Michael R. Behnke

6952 Precision Avenue

Livermore, CA 94550

U.S. Department of Energy

Attn: P. Patil

Office of Transportation Technologies

EE-32 FORSTL

Washington, DC 20585

U.S. Department of Energy

Attn: T. Duong

EE-32 FORSTL

Washington, DC 20585

U.S. Department of Energy

Attn: J. Daley

EE-12 FORSTL

Washington, DC 20585 
U.S. Department of Energy

Attn: N. Rossmeissl

EE-13 FORSTL

Washington, DC 20585

U.S. Department of Energy

Attn: Jim Rannels

Photovoltaic Program

EE-11 FORSTL

1000 Independence Ave., S.W.

Washington, DC 20585-0121

U.S. Department of Energy

Attn: J. P. Archibald

EE-90 FORSTL

Washington, DC 20585

U.S. Department of Energy

Attn: M. B. Ginsberg

EE-90 FORSTL

Washington, DC 20585

U.S. Department of Energy

Attn: G. Buckingham

Albuquerque Operations Office

Technology Development Division

P.O. Box 5400

Albuquerque, NM 87185

TU Electric

R\&D Programs

Attn: James Fangue

P.O. Box 970

Fort Worth, TX 76101

University of Missouri - Rolla

Attn: M. Anderson

112 Electrical Engineering Building

Rolla, MO 65401-0249

U.S. Department of Energy

Attn: R. Eynon

Nuclear and Electrical Analysis Branch

EI-821 FORSTL

Washington, DC 20585

R. Weaver

777 Wildwood Lane

Palo Alto, CA 94303
U.S. Department of Energy

Attn: A. Jelacic

EE-12 FORSTL

Washington, DC 20585

U.S. Navy

Attn: Wayne Taylor

Code 83B000D

China Lake, CA 93555

U.S. Department of Energy

Attn: A. G. Crawley

EE-90 FORSTL

Washington, DC 20585

U.S. Department of Energy

Attn: P. N. Overholt

EE-11 FORSTL

Washington, DC 20585

U.S. Department of Energy

Attn: J. Cadogan

EE-11 FORSTL

Washington, DC 20585

U.S. Department of Commerce

Attn: Dr. Gerald P. Ceasar

Building 101, Rm 623

Gaithersburg, MD 20899

Virginia Power

Attn: Gary Verno

Innsbrook Technical Center

5000 Dominion Boulevard

Glen Ellen, VA 23233

Walt Disney World Design and Eng'g.

Attn: Randy Bevin

P.O. Box 10,000

Lake Buena Vista, FL 32830-1000

Yuasa, Inc. (3)

Attn: N. Magnani

F. Tarantino

G. Cook

P.O. Box 14145

2366 Bernville Road

Reading, PA 19612-4145 
U.S. Department of Energy

Attn: A. Hoffman

Office of Utility Technologies

EE-10 FORSTL

Washington, DC 20585

U.S. Department of Energy

Attn: R. Eaton

Golden Field Office

1617 Cole Blvd.

Building 17

Golden, CO 80401

Westinghouse

Attn: Tom Matty

P.O. Box 17230

Baltimore, MD 21023

Westinghouse STC

Attn: H. Saunders

1310 Beulah Road

Pittsburgh, PA 15235

W. R. Grace \& Company

Attn: S. Strzempko

62 Whittemore Avenue

Cambridge, MA 02140

Yuasa-Exide, Inc.

Attn: R. Kristiansen

35 Loch Lomond Lane

Middleton, NY 10941-1421

Crescent EMC

Attn: R. B. Sloan

Executive Vice President

P.O. Box 1831

Statesville, NC 28687

HL\&P Energy Services

Attn: George H. Nolin, CEM, P.E.

Product Manager Premium Power Services

P.O. Box 4300

Houston, TX 77210-4300

UFTO

Attn: Edward Beardsworth

951 Lincoln Ave.

Palo Alto, CA 94301-3041
The Technology Group, Inc.

Attn: Tom Anyos

63 Linden Ave.

Atherton, CA 94027-2161

ZBB Technologies, Inc.

Attn: P. Eidler

11607 West Dearborn

Wauwatosa, WI 53226-3961

ECG Consulting Group, Inc.

Attn: Daniel R. Bruck

Senior Associate

55-6 Woodlake Road

Albany, NY 12203

Westinghouse Electric Corporation

Attn: Gerald J. Keane

Manager, Venture Development

Energy Management Division

4400 Alafaya Trail

Orlando, FL 32826-2399

The Brattle Group

Attn: Thomas J. Jenkin

44 Brattle Street

Cambridge, MA 02138-3736

Exide Electronics

Attn: John Breckenridge

Director, Federal Systems Division

8609 Six Forks Road

Raleigh, NC 27615

Northern States Power Company

Attn: Gary G. Karn, P.E.

Consultant Electric Services

1518 Chestnut Avenue North

Minneapolis, MN 55403

Frost \& Sullivan (2)

Attn: Steven Kraft

Dave Coleman

2525 Charleston Road

Mountain View, CA 94043

C\&D Powercom

Attn: Larry S. Meisner

Manager Product Marketing

1400 Union Meeting Road

P.O. Box 3053

Blue Bell, PA 19422-0858 
Distributed Utility Associates

Attn: Joseph Iannucci

1062 Concannon Blvd.

Livermore, CA 94550

SAFT America, Inc. Attn: Ole Vigerstol National Sales Manager

711 Industrial Blvd.

Valdosta, GA 13601

American Superconductor Corporation Attn: S. Amanda Chiu, P.E.

Manager, Strategic Marketing

Two Technology Drive

Westborough, MA 01581

University of Texas at Austin

Attn: John H. Price

Research Associate

Center for Electromechanics

J. J. Pickel Research Campus

Mail Code R7000

Austin, TX 78712

U.S. Department of Energy

Attn: W. Butler

PA-3 FORSTL

Washington, DC 20585

U.S. Department of Energy

Attn: J. A. Mazer

EE-11 FORSTL

Washington, DC 20585

VEDCO Energy

Attn: Rick Ubaldi

12 Agatha Lane

Wayne, New Jersey 07470

Intercon Limited (2)

Attn: David Warar

6865 Lincoln Avenue

Lincolnwood, IL 60646

Utility PhotoVoltaic Group

Attn: Steve Hester

1800 M Street, N.W.

Washington, DC 20036-5802

U.S. Department of Energy

Attn: P. Maupin

ER-14

G-343/GTN

Germantown, MD 20874-1290
Tampa Electric Company

Attn: Terri Hensley, Engineer

P.O. Box 111

Tampa, FL 33601-0111

U.S. Department of Energy

Attn: R. J. King

EE-11 FORSTL

Washington, DC 20585

U.S. Department of Energy

Attn: A. O. Bulawka

EE-11 FORSTL

Washington, DC 20585

Southern California Edison

Attn: N. Pinsky

P.O. Box 800

2244 Walnut Grove Ave., Rm 418

Rosemead, CA 91770

U.S. Department of Energy

Attn: D. T. Ton

EE-11 FORSTL

Washington, DC 20585

U.S. Department of Energy

Attn: J. Galdo

EE-10 FORSTL

Washington, DC 20585

Queensland Department of Mines and Energy

Attn: N. Lindsay

Senior Project Officer

Energy Planning Division

GPO Box 194 Brisbane 4001, QId. Australia

Utility Power Group

Attn: Mike Stern

9410-G DeSoto Avenue

Chatsworth, CA 91311-4947

Amber Gray-Fenner

7204 Marigot Rd. NW

Albuquerque, NM 87120

ABB Power T\&D Company, Inc.

Attn: H. Weinerich

1460 Livingston Avenue

North Brunswick, New Jersey 
MS-0513, R. Eagan (1000)

MS-0953, W.E. Alzheimer (1500)

MS-0953, J.T. Cutchen (1501)

MS-0741, S. Varnado (6200)

MS-0212, A. Phillips, (10230)

MS-0340, J. Braithwaite (1832)

MS-0343, W. Cieslak (1832)

MS-0613, A. Akhil (1525)

MS-0613, D. Doughty (1521)

MS-0614, E. Binasiewicz (1522)

MS-0613, G. Corey (1525)

MS-0614, G.P. Rodriguez, (1523)

MS-0613, I. Francis (1525)

MS-0614, J.T. Crow (1523)

MS-0614, T. Unkelhaeuser (1523)

MS-0614, D. Mitchell (1522)

MS-0614, K. Grothaus (1523)

MS-0613, N. Clark (1525)

MS-0613 R. Jungst (1521)

MS-0704, P.C. Klimas (6201)

MS-0708, H. Dodd (6214)

MS-0752, M. Tatro (6219)

MS-0753, C. Cameron (6218)

MS-0753, R. Bonn (6218)

MS-0753, T. Hund (6218)

MS-0753, W. Bower (6218)

MS-1193, D. Rovang (9531)

MS-0614, A Jimenez (1523)

MS-0537, S. Atcitty (2314)

MS-0613, J.D. Guillen (1525)

MS-9403, Jim Wang (8713)

MS-0613, P. Butler (1525) (20)

MS-0619, Review \& Approval Desk For DOE/OSTI (12690) (2)

MS-0899, Technical Library (4916) (2)

MS-9018, Central Technical Files (8940-2) 